NBSIR 78-887

\title{
DEVELOPMENT AND EVALUATION OF AN LNG SAMPLING MEASUREMENT SYSTEM
}

W. R. Parrish

J. M. Arvidson

J. F. LaBrecque

Thermophysical Properties Divisiun National Engineering Laboratory

National Bureau of Standards

Boulder, Colorado 80303

July 1978

Prepared for:

LNG Sampling Measurement Supervisory Committee 



\section{DEVELOPMENT AND EVALUATION OF AN LNG SAMPLING MEASUREMENT SYSTEM}

W. R. Parrish

J. M. Arvidson

J. F. LaBrecque

Thermophysical Properties Division

National Engineering Laboratory

National Bureau of Standards

Boulder, Colorado 80303

July 1978

Prepared for:

LNG Sampling Measurement Supervisory Committee

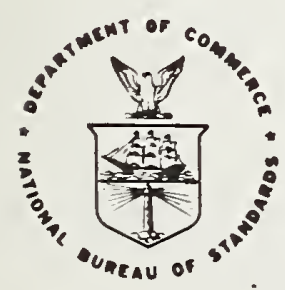

U.S. DEPARTMENT OF COMMERCE, Juanita M. Kreps, Secretary Sidney Harman, Under Secretary Jordan J. Baruch, Assistant Secretary for Science and Technology

NATIONAL BUREAU OF STANDARDS, Ernest Ambler, Director 
. 
1. 0 SUMMARY

2.0 INTRODUCTION

2.1. Scope of Project

2.1.1. Gas Analysis

2.1.2. LNG Sampling

2.2. Method of Evaluation

3.0 PREVIOUS WORK

3.1. Gas Analysis

3.2. LNG Sampling

4.0 GAS ANALYSIS

4.1. Comparison Between Gas Chromatograph and Mass Spectrometry

4.1.1. Gas Chromatograph System

4.1.2. Mass Spectrometer System

4.1.3. Evaluation of Results

4.2. Statistical Evaluation of GC Analyses

4.3. Evaluation of Gas Chromatograph Column Configuration and

Digital Integrators . . . . . . . . . . . . . . .

4.3.1. Selection of column configurations and column

Packings

4.3.2. Digital Integrator Evaluation

4.4. Determination of the Effect of Operating Variables on Gas

Chromatograph Analysis Accuracy and Precision . . . . . . . . 35

4.5. Sample Handling Procedures . . . . . . . . . . . . . . 38

4.5.1. Test Apparatus and Procedure . . . . . . . . . . 38

4.5.2. Evaluation of Results . . . . . . . . . . . . . 40

4.6. Conclusions and Recommendations . . . . . . . . . . . . . . . 40

4.6.1. Accuracy and Precision of Analysis by Gas

Chromatography . . . . . . . . . . . . . 40

4.6.2. Sample Handling . . . . . . . . . . . . . . . . . . 42

4.6.3. Recommended Criteria for Selecting a Gas Chromatograph-Integrator System . . . . . . . . . . . . 42

4.6.4. Recommendations for Future Work . . . . . . . . . 43

5.0 LNG SAMPLING ............................. . . . . . . . . . . . 43

5.1. Laboratory Tests . . . . . . . . . . . . . . . . . . . . 44 44

5.1.1. Laboratory Facility . . . . . . . . . . . . . 44

5.1.2. Experimental Procedure . . . . . . . . . . . . . 48

5.1.3. Experimental Results . . . . . . . . . . . . . . 51

5.2. Confirmation Tests................... . . . . . . . . 94

5.2.1. NBS LNG Flow Facility Test 1 . . . . . . . . . . . 94

5.2.2. Shipboard Tests . . . . . . . . . . . . . . . . 99

5.2.3. LNG Flow Facility Test 2... . . . . . . . . . . 106

5.3. Conclusions and Recommendations . . . . . . . . . . . . . . 125

5.3.1. Recommended LNG Sampling System Design and

Operating Criteria ............. . 128

5.3.2. Recommendations for Future Work . . . . . . . . . 128

6.0 REFERENCES ............................ . . . . . . . . 130

APPENDIX 7.1. Gas Analysis Data . . . . . . . . . . . . . . . . . 132

APPENDIX 7.2. Recommended Criteria for Selecting a Gas Chromatograph for Use in Analyzing Vaporized LNG Samples . . . 149

APPENDIX 7.3. Method for Computing the Uncertainty of a Gas

Analysis and a Method for Rejecting a Given Analysis . . 150

APPENDIX 7.4. Sampling Data... . . . . . . . . . . . . . 154

8.0 ACKNOWLEDGMENTS . . . . . . . . . . . . . . . . . . . . . 196 

W. R. Parrish, J. M. Arvidson and J. F. LaBrecque

This report describes the development and evaluation of procedures and components for sampling and analyzing LNG from flowing streams. Laboratory and field test results showed the total uncertainty in the computed heating value of samples taken with the recommended sampling system could be routinely within +0.3 percent; this included the +0.1 percent uncertainty in analysis by gas chromatography. Three sample probes and two vaporizer designs were considered. Of the ten operating variables considered, six were found to be important in sampling. Test results were used to establish recommended design and operating criteria.

Key words: Custody transfer; density; gas analysis; gas chromatography; heating value; hydrocarbon; liquefied natural gas; phase equilibrium; pipelines; sampling.

\subsection{SUMMARY}

Accurate determination of the total dollar value of LNG shipments requires knowing the cargo heating value; this is computed from the composition. At current LNG prices, a composition error of one percent in the heating value would cause an inequity of roughly $\$ 65,000$ for one $125,000 \mathrm{~m}^{3}$ LNG shipment. Accurate LNG composition determination requires:

a) a sample probe for drawing a sample representative of the fluid passing the sampling point,

b) a sample conditioner for completely vaporizing the sample,

c) a gas analyzer for accurately and precisely analyzing the sample composition, and

d) a correct set of operating parameters and procedures.

This report describes the results of a systematic study evaluating all of the above components. The work was confined to the problem of sampling from a flowing LNG stream.

Instead of directly measuring the heating value by gas calorimetry, the gas composition was analyzed so that both heating value and liquid density could be computed.

For analyzing vaporized LNG samples, gas chromatography was selected over mass spectrometry because it was found to be more precise and accurate. By using a gas chromatograph-programmable integrator system, the total uncertainty in the heating value (on a unit volume basis), as computed from the analyzed composition, routinely can be less than \pm 0.1 percent. This figure includes $a \pm 0.03$ percent uncertainty in the calibration gas composition; this uncertainty, which neglects the uncertainty of the individual components heating value, is based only on the uncertainty in the weighing process used to prepare the mixtures. The \pm 0.1 percent uncertainty also includes a random error of \pm 0.06 percent. The random error is three times the estimated standard deviation of \pm 0.02 percent. This value represents the maximum value obtained from over 100 measurements of three or more repetitive analyses employing a properly operating gas chromatograph-programmable integrator 
system. This report recommends procedures and equipment for analyzing vaporized LNG samples.

Based on the results of sampling tests at the NBS LNG Flow Facility, the total uncertainty of a single measurement in sampling and analyzing LNG mixtures can be less than \pm 0.3 percent in the computed heating value. This uncertainty includes the \pm 0.03 percent uncertainty in the calibration gas composition plus an uncertainty of \pm 0.27 percent for random error. The \pm 0.27 percent figure represents three times the upper limit of the standard deviation determined for the combined sampling plus analysis measurement process. The recommended sampling system consists of a side tap probe, a steam or electrically heated tube vaporizer, a gas mixing chamber and a sampling manifold. This report gives recommended sampling system design criteria. Also, it lists the recommended ranges of the operating variables found to affect sampling precision.

Data obtained during a shipboard test has limits of precision of $\pm 0.30 \%$. see section 5.2.2. These limits compare very favorably to the $\pm 0.27 \% \mathrm{ob}-$ tained on the flow facility.

\subsection{INTRODUCTION}

Composition plays an important role in determining the total dollar value of ING shipments. Sampling LNG presents special problems because of possible fractionation during the sampling process. Accurate and precise composition determination of LNG mixtures (and other cryogenic liquid mixtures) requires a Sampling-Measurement system (SMS) which contains:

a) a sampling probe which draws a sample without altering the composition,

b) a sample conditioner which completely vaporizes the sample, and

c) a gas analyzer which accurately and precisely analyzes the sample. Also, the SMS may include facilities for collecting representative samples of vaporized LNG for transport from the sampling point to the analytical laboratory. The proper operating parameters and procedures must be specified to minimize the total uncertainty in the measurement process.

\subsection{Scope of Project}

The project consisted of two primary tasks:

a) the evaluation of vaporized LNG analysis methods, and

b) the evaluation of LNG sampling techniques. This project carefully evaluated possible alternatives for each of the components of the SMS. Because of the time limitations only the most promising alternatives were considered in depth. The study covered only sampling from flowing LNG streams. Emphasis was on compositions typical of Algerian LNG (see table 2.1). 2.1.1. Gas Analysis

The initial phase of work evaluated the relative merits of analyzing vaporized LNG samples by gas chromatography (GC) and mass spectrometry (MS); accuracy, precision and simplicity were the primary factors considered. The 
Table 2.1. The anticipated composition range of Algerian LNG. The values in parentheses denote the ranges covered in this report.

\begin{tabular}{|l|l|}
\hline \multicolumn{1}{|c|}{ Component } & Composition Range, mol \\
Nitrogen & 0.60 to $1.40(0$ to 11$)$ \\
Methane & 84 to $92(65$ to 90$)$ \\
Ethane & 6 to $9.5(5$ to 18$)$ \\
Propane & 2.2 to $3.5(1.0$ to 5.4$)$ \\
iso Butane & 0.3 to $0.5(0$ to 0.8$)$ \\
normal Butane & 0.3 to $0.7(0.2$ to 4.8$)$ \\
Pentanes and heavier & 0 to $0.02(0$ to 0.3$)$ \\
\hline
\end{tabular}

second phase of work was a study of the effect of various parameters on the accuracy and precision of analysis by GC; the work included an evaluation of GC columns and GC data processors (i.e., integrators). Gas mixtures prepared by weight were used in all of these tests. Also, reliable procedures for obtaining a representative gas sample in a sample cylinder were identified.

2.1.2. LNG Sampling

The sampling portion of the project contained laboratory tests and field confirmation tests; these tests were performed at the NBS LNG Flow Facility and aboard the LNG tanker El Paso Consolidated.

The laboratory tests evaluated three probes -- a pitot tube, a side tap and a reference probe - and two continuous vaporizers - vaporizer A and a reference vaporizer. To distinguish effects due to the vaporizer from those of the probes, the probes were used with a reference vaporizer and vaporizer A with the reference probe. The laboratory evaluation provided a rapid way to determine the effect of a given operating variable while holding other variables constant. The variable's effect upon sampling accuracy was determined by using mixtures of known composition. In addition to the three probes and two vaporizers we considered the following operating variables:

a) flow rate of the liquid stream,

b) flow rate through the sampling device,

c) amount of subcooling (pressure differential between the sample point and the saturated liquid),

d) temperature of the LNG,

e) pressure drop upstream of the sample vaporizer,

f) time-averaging the sample,

g) vaporizer outlet temperature, and

h) composition, particularly the effect of pentane and higher hydrocarbons.

The field confirmation tests provided a scale-up test for the conclusions obtained from the laboratory tests. Two series of tests were made in 
the NBS flow facility. Here, operating conditions were closer to the conditions of actual LNG facilities in respect to size, pressures and flow rates. However, there was no way to directly determine the correct composition of the mixture in the flow facility. Also, operating conditions were not as constant and well defined as in the laboratory apparatus.

The shipboard tests provided an evaluation of a LNG sampling system under conditions comparable to those in LNG custody transfer operations. The primary variable evaluated in these tests was sampling rate. The actual LNG composition was unknown. However, comparisons were made between liquid samples taken from the inlet header to the ship's vaporizer and gas samples taken from the vaporizer outlet header. This provided a check on the liquid sampler performance.

\subsection{Method of Evaluation}

In LNG custody transfer, the composition is important because it is needed to compute the heating value and sometimes liquid density. Therefore, in this report we compared experimental results using compositions, computed heating values and computed liquid densities. Several sets [1,2] of ideal gas heating values are available. We chose the values proposed by the A.G.A. [1] (see table 2.2) because, with their method of correcting for gas nonidealities, computed heating values could be directly compared with the results of combustion calorimetry. For convenience, we omitted the non-ideality correction in most of the work. However, in the LNG flow facility tests, the nonideality correction was necessary to make direct comparison with calorimeter measurements. Methods for computing the liquid density are currently under study [3]. For the laboratory tests, we chose the semi-empirical method of Hiza [4] because of its relative simplicity; the extended corresponding states method [3] was used in the field tests.

Table 2.2. Pure component ideal gas heating values [1].

\begin{tabular}{|c|c|c|}
\hline Component & $\begin{array}{c}\text { Heating Value }{ }^{l} \\
\text { Btu/scf }\end{array}$ & $\mathrm{MJ} / \mathrm{m}^{3}$ \\
\hline $\mathrm{N}_{2}$ & 0 & 0 \\
\hline $\mathrm{CH}_{4}$ & 1012.1 & 37.701 \\
\hline $\mathrm{C}_{2} \mathrm{H}_{6}$ & 1773.0 & 66.045 \\
\hline $\mathrm{C}_{3} \mathrm{H}_{8}$ & 2523.3 & 93.994 \\
\hline$i_{4} \mathrm{H}_{10}$ & 3260.7 & 121.46 \\
\hline $\mathrm{nC}_{4} \mathrm{H}_{10}$ & 3269.8 & 121.80 \\
\hline$i_{5} \mathrm{H}_{12}$ & 4008.7 & 149.33 \\
\hline $\mathrm{nC}_{5} \mathrm{H}_{12}$ & 4018.9 & 149.71 \\
\hline $\mathrm{C}_{6}{ }^{\mathrm{H}} 14^{\prime}$, average & 4764.4 & 177.48 \\
\hline $\mathrm{C}_{7} \mathrm{H}_{16}$, average & 5509.7 & 205.34 \\
\hline
\end{tabular}

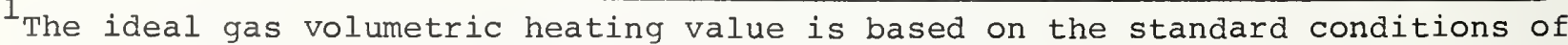
$60^{\circ} \mathrm{F}\left(15.6^{\circ} \mathrm{C}\right)$ and 30 inches of mercury $(0.1016 \mathrm{MPa})$. 
This report makes extensive use of statistical techniques in evaluating the experimental data. Table 2.3 lists the definitions of the statistical terms used.

Table 2.3. Definition of statistical terms used in this report.

Accuracy - the closeness to the true value.

Average value $(\bar{x})$ - the arithmetic average of replicate measurements. The average value represents the most likely value of the mean.

Bias (B) - a systematic offset between the mean and true value.

Estimated standard deviation (s) - an estimate, based on a finite number of replicate measurements, of the standard deviation of a measurement process.

Mean (X) - a value, usually unknown, about which the measured values of replicate measurements randomly scatter.

Measurement process - a series of steps used to assign a numerical value to a physical property.

Random error - an error related only to the random behavior within a measurement process, i.e., not a systematic offset.

Replicate measurements - two or more measurements made under conditions where all controllable variables are identical for all measurements.

Standard deviation $(\sigma)$ - a parameter often used as a measure of the scatter of random error in a measurement process.

Systematic error - an estimate of the upper limit of the unknown but fixed errors of a measurement process.

Total uncertainty - the estimated maximum error in a measurement process. In this report it is computed by summing the systematic error and the upper limit of the random error -- taken to be three times the estimated standard deviation.

Confidence interval - an interval, based on replicate measurements, for a parameter which will include the true value of the parameter a specified percentage of the time.

Precision - the closeness with which the results of replicate measurements agree -- usually quantified by the estimated standard deviation.

Determining the composition, like all measurement processes, involves experimental error. This error may be considered in terms of the accuracy of a process (bias) and its precision. Bias of a measurement process represents how closely the mean of the measured quantity conforms to the true value. Precision represents how closely the values obtained from a number of independent, repeated measurements agree, i.e., random error.

Replicate measurements yield estimates of both bias and precision. The difference between the average value, $\bar{x}$, of the measured values, $x_{i}$, and the true value is an estimate of the bias in the measurement process. Scatter about the average value is an estimate of the precision; normally the scatter is quantitated in terms of the estimated standard deviation, $s$. In this report we assume that the random errors follow the statistics of a normal distribution. The estimated standard deviation is given by 


$$
s=\sqrt{\sum_{i=1}^{n}\left(x_{i}-\bar{x}\right)^{2} /(n-1)}
$$

where $\mathrm{n}$ denotes the number of replicate measurements.

The values of $\bar{x}$ and $s$ will vary among different sets of the same measurement. However, they will vary about the true mean, $x$, and standard deviation $\sigma$. The values of $\mathrm{X}$ and $\sigma$ are considered known only after making a very large number of measurements. The values of $\mathrm{x}$ and $\sigma$ are estimated by using $\bar{x}, \mathrm{~s}$ and confidence intervals; for example, a 99 percent confidence interval for the mean value signifies that 99 percent of the time the interval will include the true value. In this case the interval is given by

$$
\bar{x}-t \cdot s / \sqrt{n}<x<\bar{x}+t \cdot s / \sqrt{n}
$$

where $t$ is the Student's statistic for a 99 percent confidence of $n$ repeated measurements.

For the standard deviation, the confidence interval is given by

$$
B_{L} \cdot S<\sigma<B_{U} \cdot S
$$

where $B_{L}$ and $B_{U}$ are values derived from the Chi squared statistic; they are functions of $\mathrm{s}, \mathrm{n}$ and the degree of confidence (e.g., 99 percent). The interval in equation (2.3) is unsymetrical about $\sigma$. In this report we present values of $n, \bar{x}$ and $s$ and, as a first approximation assume that $\bar{x}$ and $s$ are equal to $\mathrm{x}$ and $\sigma$.

We use the concept of total uncertainty in assuming a limit on the error in a measurement process. Total uncertainty reflects two errors -- systematic and random. The systematic error represents an estimate of the upper limit of the unknown, nonrandom errors of the measurement process. Its estimate is based on understanding the nonrandom errors of the components within the measurement process. The random error is estimated to be three times the estimated standard deviation - this roughly corresponds to a 99.7 percent confidence interval (it would equal a 99.7 percent confidence interval if the estimated standard deviation equaled the standard deviation).

One of the major goals of this project was to determine which operating variables affected the precision of composition measurement. To determine if a given variable changed the precision, measurements would be made at two (or more) values of the variable. How confidently we could detect the change in precision depended upon the number of samples taken under each set of conditions and upon the observed change in the estimated standard deviation. As shown in table 2.4, we have a 65 percent chance of detecting a difference in the precision when there is a factor of four difference between the observed standard deviation and when the measurement is repeated four times with each value of the operating variable; for a 62 percent chance of detecting a difference when there is a factor of two difference in the observed standard deviation it would take 10 measurements with each value of the operating variable. 
Table 2.4. Probability of detecting a difference in the standard deviation between two sets of conditions ( $A$ and $B$ ) when the measurements have a factor $\lambda$ difference in standard deviations and they are repeated $\mathrm{N}$ times under each set of conditions [5].

\begin{tabular}{|c|c|c|c|c|}
\hline \multirow[b]{3}{*}{$\mathrm{N}$} & \multicolumn{4}{|c|}{ Probability, percent } \\
\hline & \multicolumn{4}{|c|}{$\lambda\left(=\sigma_{B} / \sigma_{A}\right)$} \\
\hline & 1 & 2 & 3 & 4 \\
\hline $\begin{array}{r}4 \\
6 \\
8 \\
10\end{array}$ & $\begin{array}{l}5 \\
5 \\
5 \\
5\end{array}$ & $\begin{array}{l}25 \\
41 \\
52 \\
62\end{array}$ & $\begin{array}{l}49 \\
71 \\
87 \\
93\end{array}$ & $\begin{array}{l}65 \\
87 \\
95 \\
99\end{array}$ \\
\hline
\end{tabular}

\subsection{PREVIOUS WORK}

To our knowledge no systematic evaluation of LNG Sampling Measurement Systems (SMS) has been made. However, there are publications on gas analysis methods and on LNG sampling techniques.

\subsection{Gas Analysis}

We are unaware of any publications comparing gas chromatographic (GC) and mass spectrometric (MS) analyses of natural gas. However, ASTM standards exist for natural gas analysis by gas chromatography [6] and mass spectrometry [7]. Each standard gives the estimated reproducibility of analysis; values are given for the case of one laboratory and apparatus, and for the case of different laboratories. The ASTM standards indicate that the analyses should be considered suspect if differences between replicate analyses are greater than those given in table 3.1; also, the table gives the estimated error in heating values for these differences assuming the composition range given in table 2.1 .

There are several papers discussing different GC column configurations; these are discussed in section 4 .

\subsection{LNG Sampling}

Dalmaze [8] and Trigo [9] discussed two similar continuous SMS which are used in Europe. Figure 3.1 is a schematic of Dalmaze's system. Both use an upstream facing pitot tube located at the LNG pipe centerline as the probe. To prevent premature vaporization the probe line is cooled by an outer jacket through which LNG is circulated and returned to the main line. The sample then flows through a check valve to prevent backflashing and past an electrically heated vaporizer. Trigo's system replaces the check valve with a filter. The vaporized sample goes through a vessel to dampen pressure pulsations (if operating at less than $30 \mathrm{psig}(0.3 \mathrm{MPa})$ ), past a pressure controller, and to a chromatograph. Neither author describes the details of the gas analysis. Dalmaze's data showed a precision of \pm 0.6 percent in the computed heating value of liquid samples taken upstream of a LNG vaporizer; 


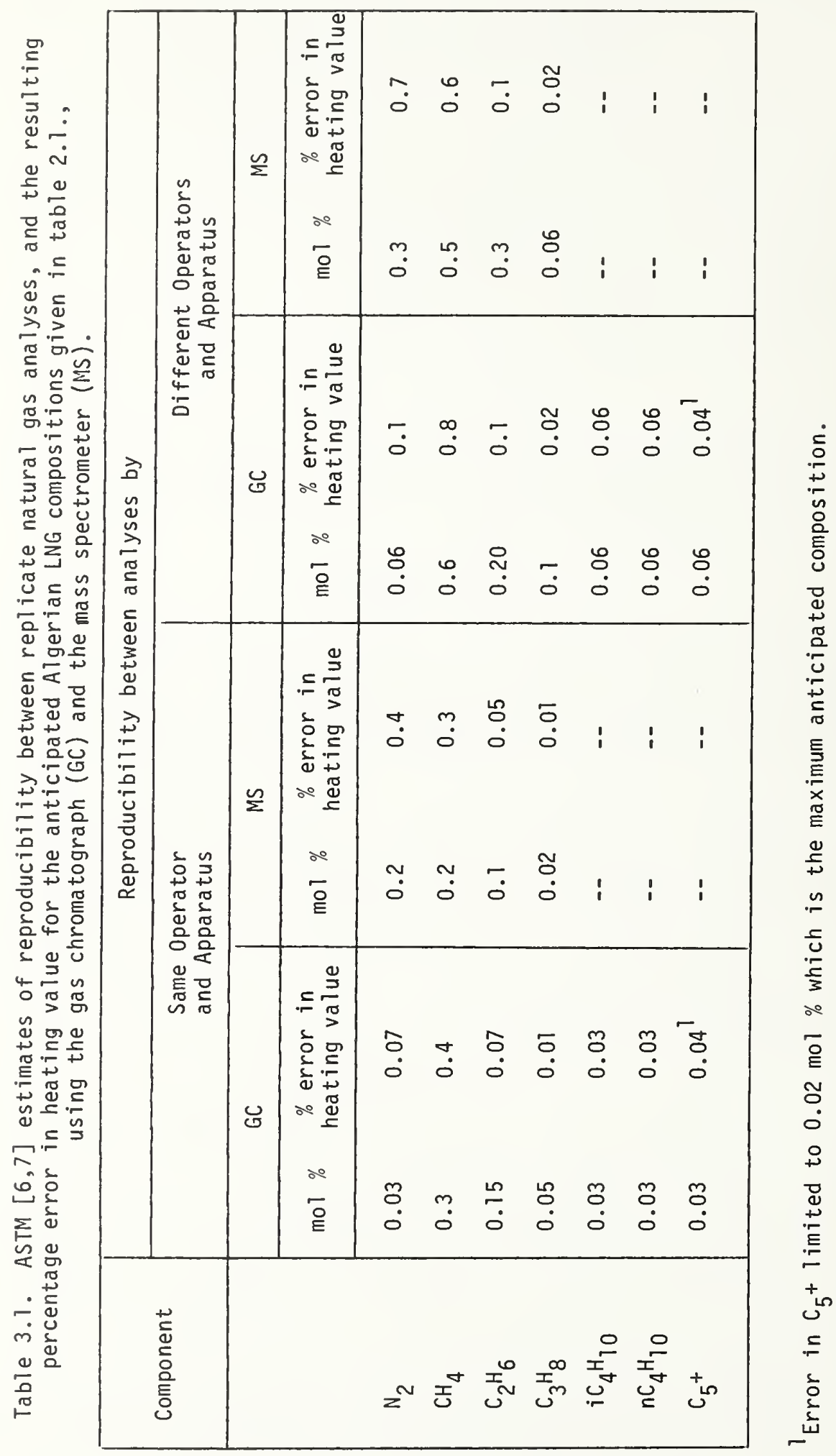




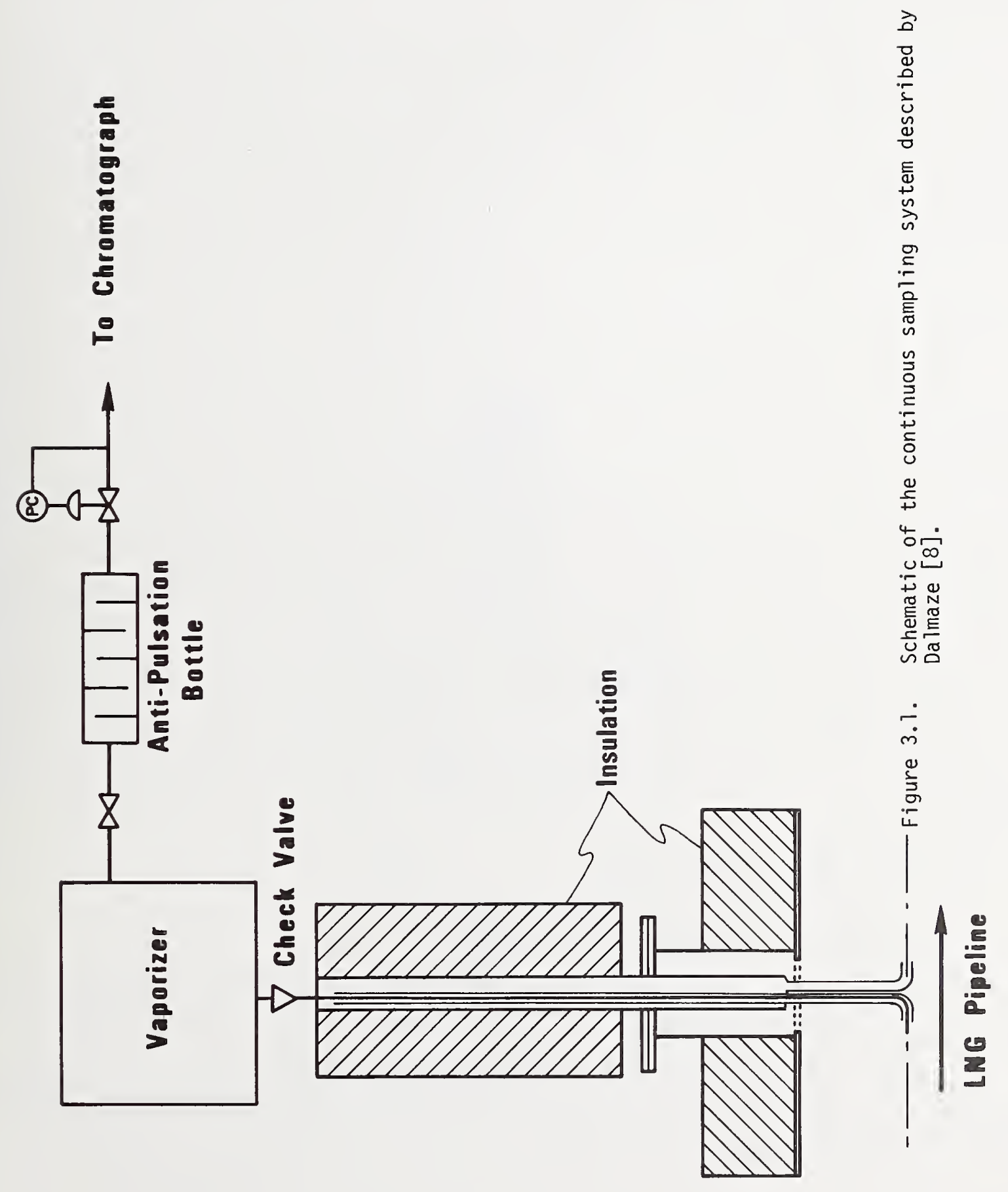


by sampling the totally vaporized LNG stream the precision was 0.4 percent. (The precision is defined here as three times the estimated standard deviation.) The difference in the average computed heating values between the two sampling methods is about 0.01 percent when 30 sets of samples were averaged over seven hours. Dalmaze reports that this difference is well within the error due to gas analysis alone.

There are at least two batch sampling devices which have been tried. One is the cryogenic sampler [10] shown in figure 3.2. LNG passes through a cooling passage which surrounds a cup contained in an evacuated outer container. Once the cup is at LNG temperature the sample valve is opened and the cup is filled with liquid. After the cup is full the sample valve is closed, the sample lines are disconnected and the sampler is allowed to warm to ambient temperature. The ratio of the cup volume to the total chamber volume is such that the final pressure will be approximately 500 psig (3.6 MPa) for LNG. A valve at the bottom of the sampler is used to draw a gas sample for analysis.

The other batch sampling device which collects the liquid is described by cook [1l] and is shown in figure 3.3. To take a sample, both valves are opened to allow LNG to flow through the sampler which is well insulated. Once the sampler is at LNG temperature, as evidenced by a continuous liquid flow from the device, both valves are closed. Then the device is removed from the sampling line and allowed to warm up. After the initial pressure rise, a pressure relief valve which is set above the cricondenbar (the maximum pressure at which a mixture may exist in two phases) of the mixture (> 2000 psi (13.8 MPa)) keeps the sample at a constant pressure and in one phase. Once the sampler is warm it can be connected directly to an analytical instrument.

Methods for collecting a gas sample from a pipeline have been discussed by Miller [12]; also, an ASTM standard exists for natural gas sampling from pipelines [13]. Miller concludes that all of the following filling methods give good results:

a) liquid displacement,

b) purge by fill and empty,

c) purge at a constant flow rate, and

d) fill of evacuated cylinder with no purge. Also, he briefly describes the two batch sampling devices used for collecting LNG as a liquid which were described above.

Finally, Chapman and Payne [14] give some general guidelines for sampling flowing streams. Although they do not describe cryogenic sampling systems, many of their guidelines still apply. 


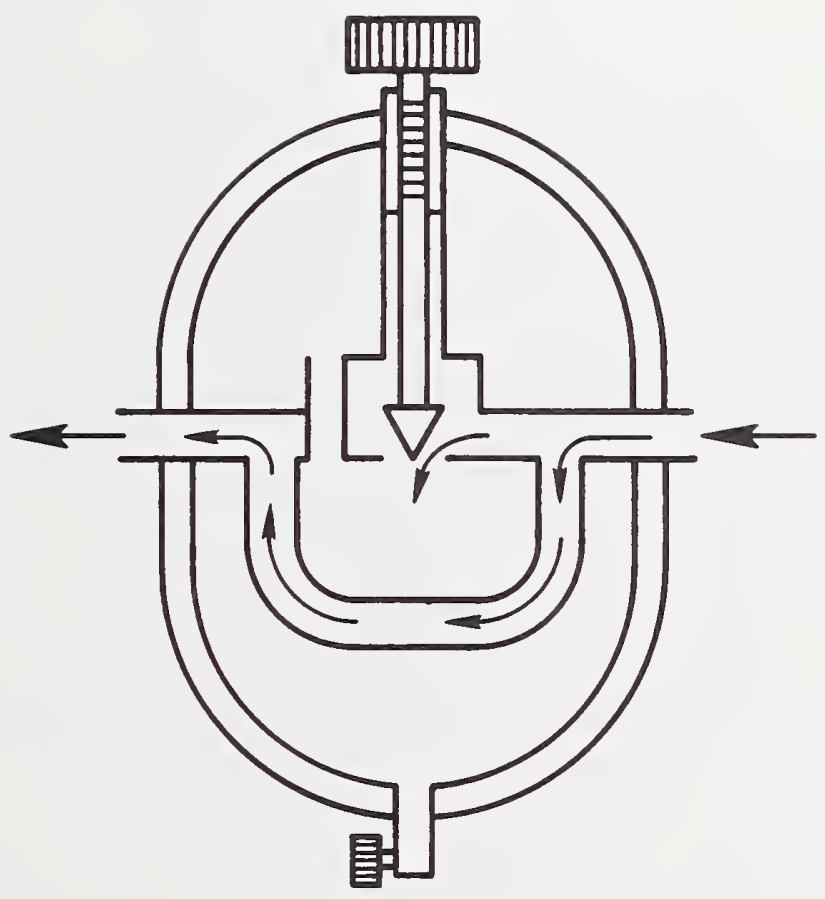

Figure 3.2. Schematic of cryogenic sampler [10]. 


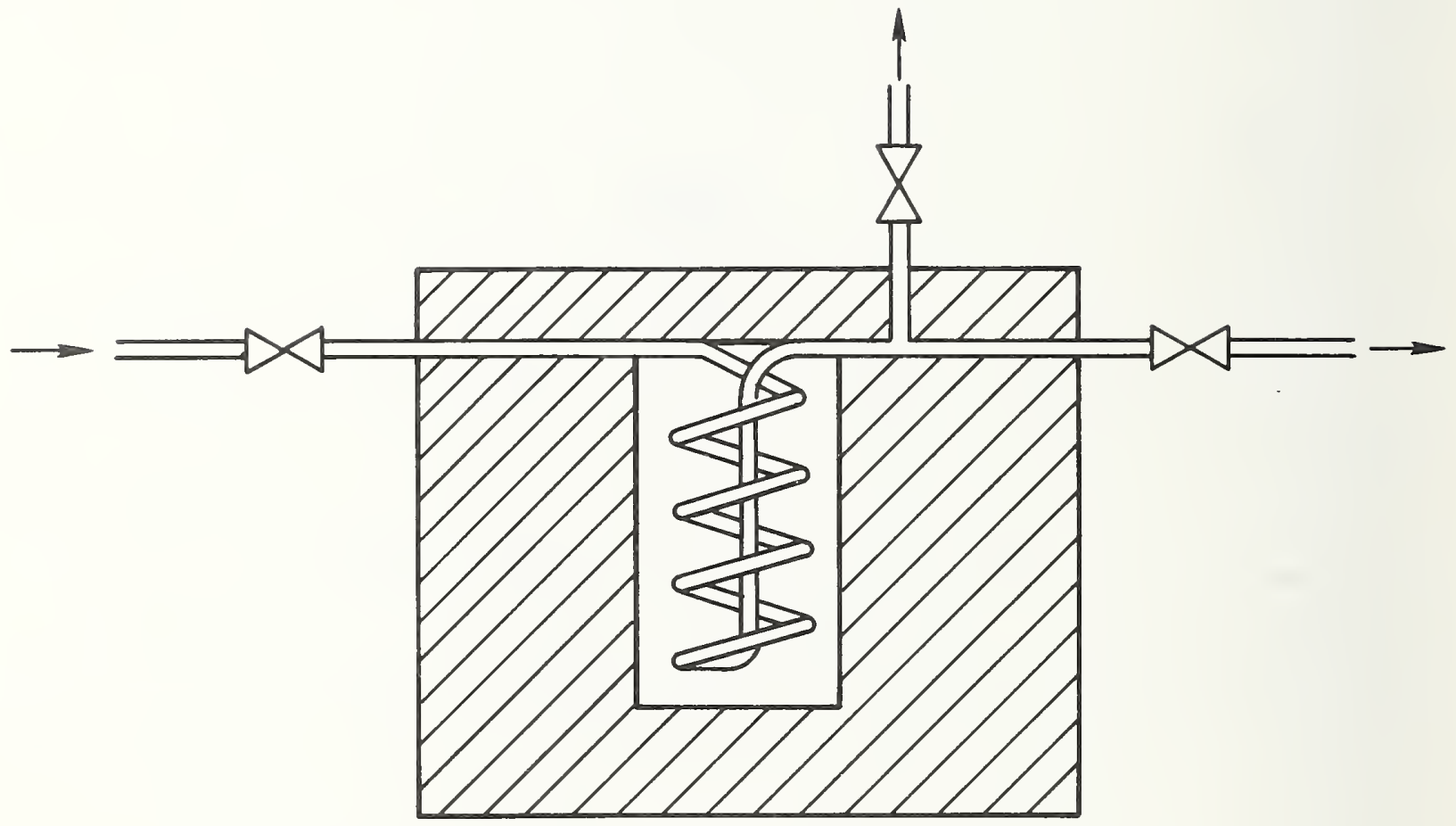

Figure 3.3. Schematic of LNG sampler described by Cook [11]. 


\subsection{GAS ANALYSIS}

Before any sampling data could be taken we had to determine the uncertainty involved in gas analysis. This evaluation and a comparison between gas chromatography (GC) and mass spectrometry (MS) were made early in the project. Later, we more carefully evaluated the effect of various operating variables, column configurations, and digital integrators on analysis precision and accuracy. Appendix 7.1 lists all of the data obtained for the gas analysis tests.

4.1. Comparison Between Gas Chromatography and Mass spectrometry

A comparison of precision and accuracy of GC and mass spectrometric analysis of LNG type mixtures was made by having a local MS laboratory analyze some prepared mixtures; these mixtures also were analyzed using a GC in our laboratory. The MS laboratory was capable of general quantitative analysis, including hydrocarbon analyses, on a routine basis.

4.1.1. Gas Chromatograph System

\subsubsection{Apparatus}

In this phase of the work we used a gas chromatograph containing two columns and a filament-type thermal conductivity detector, in conjunction with a programmable, digital integrator (integrator A). Traditionally, whenever feasible, peak heights were preferred over peak areas for computing compositions from GC analyses. The reasons for this were that peak heights were easier to measure and they were oftentimes more precise than the mechanical devices available for measuring peak areas. However, programmable integrators eliminate the drawbacks of using peak areas. Several sets of calibrations and analyses were made using both peak heights and peak areas. (Integrator A reports peak areas and/or peak heights.) These tests showed that the compositions based on peak heights had an estimated standard deviation which was four to five times greater than the estimated standard deviations for the the compositions computed from peak areas. Based on these results and the fact that the linear response between peak height and composition has a limited range, we used peak areas throughout this work.

Table 4.1 lists the GC operating conditions. Figure 4.1 is a schematic of the GC and ancillary equipment while figure 4.2 shows a chromatogram (on a logarithmic scale) for a gas mixture typical of Algerian LNG. The GC contained a sample valve which was used to inject the gas sample from either of two sample loops into the carrier gas stream. Helium carrier gas was maintained at a constant flow by using two stages of pressure regulation. The column bypass valve was used to bypass column 2 . In the bypass mode the carrier gas passed through a needle valve set to have the same pressure drop as column 2; this minimized the baseline upset during valve switching. 
Table 4.1. Gas chromatograph operating conditions.

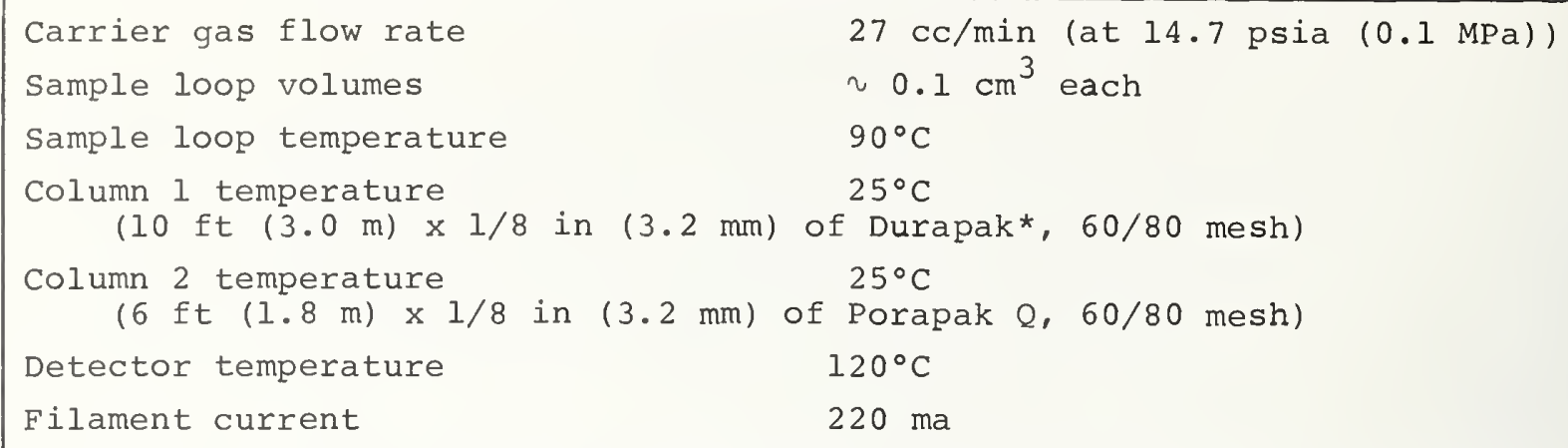

Certain commercial equipment, instruments, or materials are identified in this paper in order to adequately specify the experimental procedure. In no case does such identification imply recommendation or endorsement by the National Bureau of Standards, nor does it imply that the material or equipment identified is necessarily the best available for the purpose.

The integrator had a variety of operating parameters and timed events which could be used to maximize the precision of the data reduction of a chromatogram. The use of these parameters is illustrated in the next section.

4.1.1.2. Calibration procedure

All GC's require calibration with one or more mixtures of known composition; these mixtures should have a composition similar to that of the unknown mixtures. In this work we prepared all of the calibration mixtures by weight using high purity components; table 4.2 lists the component concentrations and their estimated uncertainties for all the prepared mixtures used here.

To make a calibration run, the sample loop first was purged by alternately evacuating and filling with the calibration gas. We found that one to three purges were adequate provided that the manifolding was arranged so that all of the gas passed through the sample loop during purging (see figure 4.1). However, it was imperative that all connections were leak-tight. After purging, the sample loop was filled to the desired pressure -- in our case 2 psig (0.11 $\mathrm{MPa}$ ) -- and the sample valve was switched, injecting the mixture into the carrier gas stream. During the first three minutes of the run column 2 remained in series; this allowed the nitrogen and methane to travel through both columns and the detector. (These columns did not resolve oxygen and nitrogen; therefore, any oxygen present was included in the nitrogen peak.) Once the methane was out of column 2, the column was bypassed, trapping the ethane. The integrator made a "forced baseline" just prior to the valve switch and ignored the tailing baseline after the switch. (The dotted lines under each peak in figure 4.2 represent the baseline as determined by the integrator.) The integrator then picked the bottom of the baseline drift as the baseline for the propane peak. Column 2 remained bypassed until the butanes passed through column 1. At 9 minutes column 2 was switched in again, allowing ethane to elute from the column. As before, the integrator 


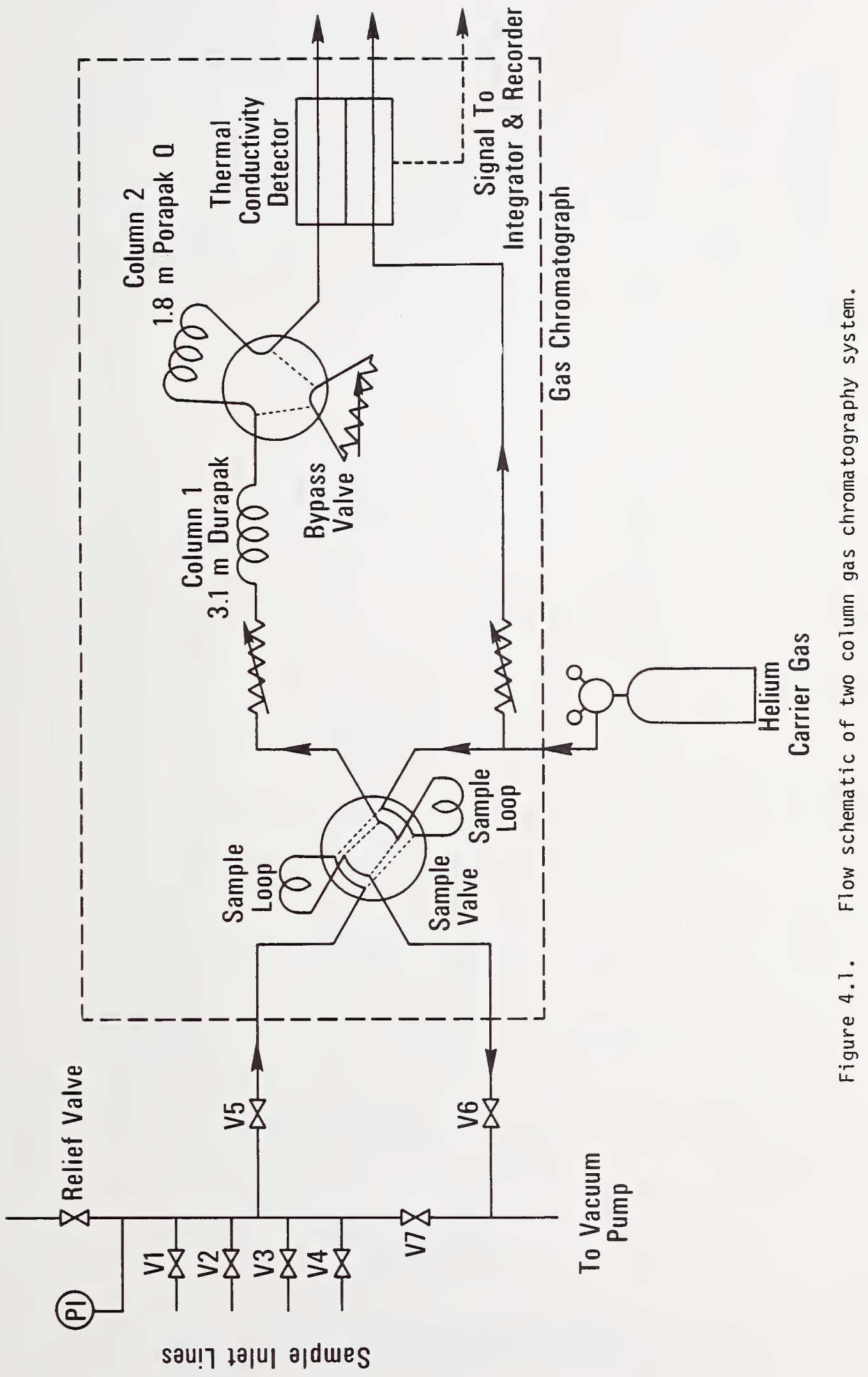




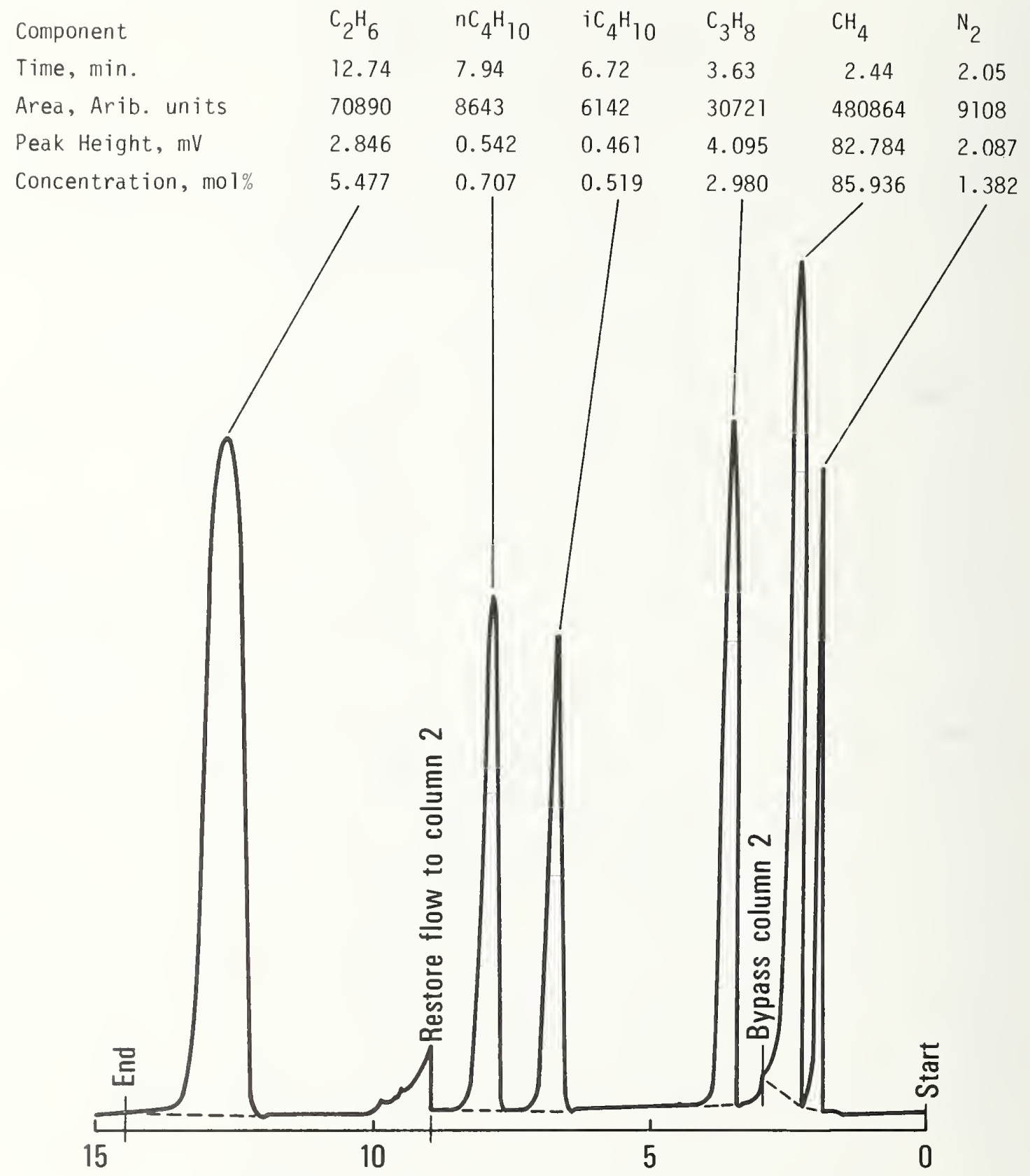

TIME, mIn

Figure 4.2. A chromatogram of a natural gas mixture. The peak heights are shown on a logarithmic scale. 


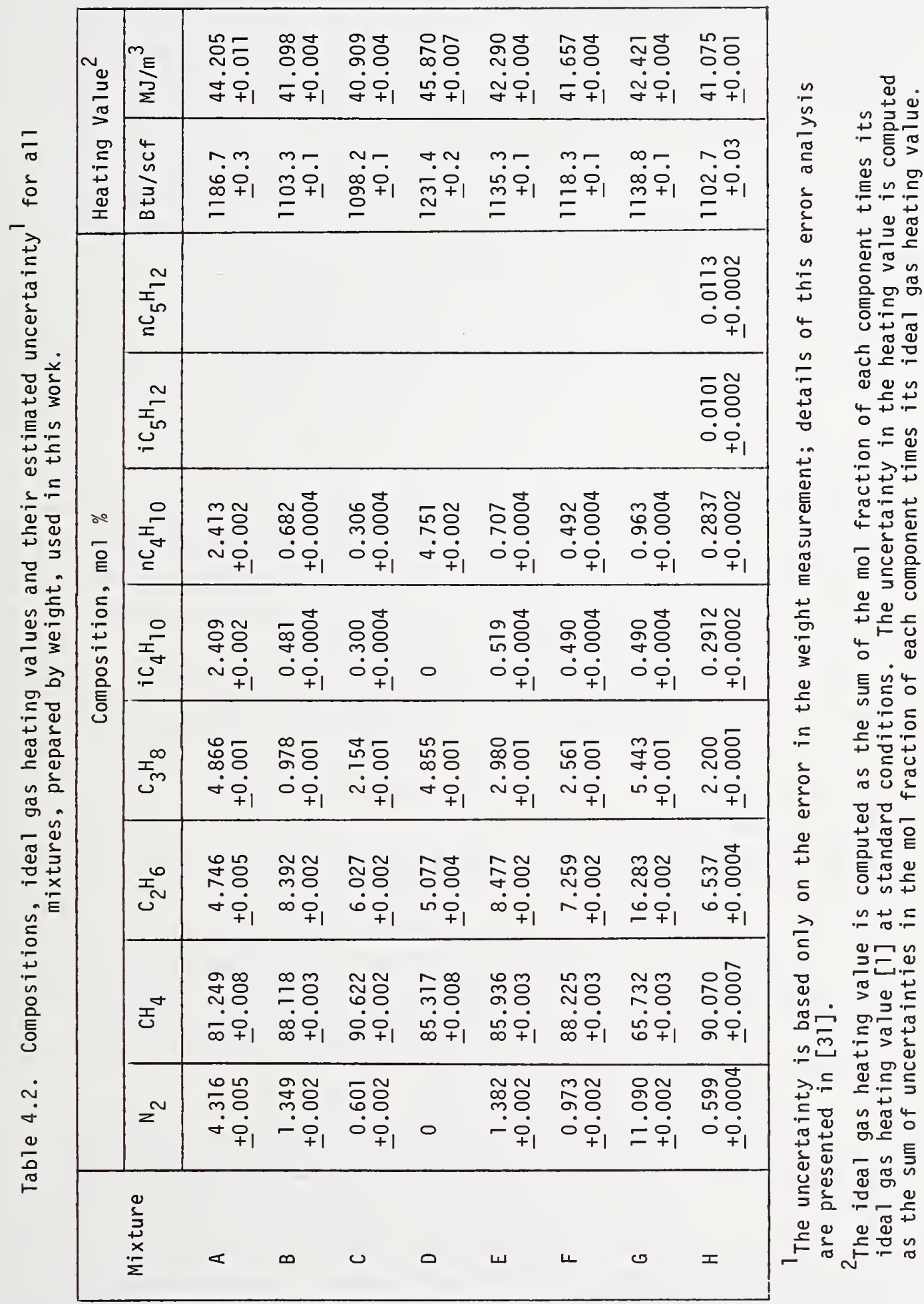


ignored the baseline upset due to valve switching. The tailing after switching valves was caused by a temporary decrease in carrier gas flow as pressure gradients in the line were being reestablished. The two peaks on the second tail were caused by minute air leakage during the valve switch. This leakage is caused by diffusion and can occur in pressurized helium and hydrogen systems.

The total analysis time was 14.5 minutes. If pentanes were present the same procedure was used but the analysis time increased to 24 minutes. The prepared mixtures in this study did not contain hexanes.

Using the areas under each peak and the known composition of the calibration gas, relative response factors were computed for each component. Normally, two or three calibration runs were made and the response factors averaged for each component. The GC was calibrated at the beginning of each operating day.

\subsubsection{Analysis procedure}

The procedure for an analysis of an unknown mixture was the same as a calibration run. However, in this case the relative response factors were used with the peak areas to determine the composition. In our work we normalized the results; this eliminated the need to know the exact amount of sample injected. However, we tried to keep the sample amount, i.e., sample pressure, constant to within $\pm 5 \%$ because variations in sample size may cause subtle effects which could diminish the analytical accuracy (see section $4.4)$.

4.1.2. Mass Spectrometer System

4.1.2.1. Apparatus

The mass spectrometer used for this work was a $180^{\circ}$ sector, high precision gas mass spectrometer [15]. It electronically scanned a mass range of two to 200 with the output recorded on a strip chart. By adjusting the sample pressure the pressure at the controlled leak could be set between 1 to 100 microns $(0.1$ to $13 \mathrm{~Pa})$. The controlled leak permitted a small amount of sample to continuously enter the ion chamber; the leak rate was proportional to the pressure upstream of the controlled leak.

\subsubsection{Calibration procedure}

Prior to running a calibration (or analysis), a background scan was made by closing the valve upstream of the controlled leak. Any peaks from the residual gas were noted. Next, high purity hydrocarbons (> 99.99 percent) were injected, one at a time, at pressures comparable to the expected partial pressures in the unknown mixture. The MS response was slightly non linear; however, this effect was negligible as long as the calibration pressure was within 3 to 4 microns $(0.4$ to $0.5 \mathrm{~Pa})$ of the components partial pressure in the unknown mixture. 
Hydrocarbons fracture inside the ion chamber. Each hydrocarbon has a characteristic cracking pattern and at least one mass peak which is unique to that hydrocarbon. The response factor was computed for each component by dividing the characteristic peak height (corrected for background) by the known calibration gas pressure. (Resolving the iso and normal butane required solving two simultaneous equations.)

\subsubsection{Analysis procedure}

After evacuating the line connecting the sample cylinder to the MS, the sample pressure was reduced to the desired level by a series of expansions into evacuated volumes. Then, the sample was opened to the controlled leak and a mass scan was made. Using response factors, peak heights (corrected for background) and sample pressure, the composition of each component was calculated.

\subsubsection{Evaluation of Results}

The MS laboratory received two sets of six samples. The first set contained duplicate samples of mixtures $A, B$ and D, while the second set contained duplicate samples of mixtures B, C and D; the samples were labeled with the approximate composition of the sample. The MS lab reported two analyses on each sample. Table 4.3 gives the results of the MS and GC analyses. The raw data are listed in Appendix 7.1. Since this was not a statistically balanced test, only a comparison of the bias (i.e., accuracy) and precision could be made; there was no way to determine what factors affected the accuracy and precision. However, it was found that the second set of MS analyses showed a significant improvement in the standard deviation, whereas, there was little change in the bias. In all cases both biases and standard deviations for the GC analyses were much smaller than those of the MS analyses.

The manager of the analytical laboratory where the MS analyses were made feels that the MS is an important qualatative and quantative tool [15]. However, for routine gas analyses, where all of the components are known, he believes that a properly designed and operated GC-digital integrator system will be more precise than the MS. (His laboratory contains several types of both MS and GC instruments.)

The precision of the MS analysis results obtained in our study is poorer than would be expected based on the ASTM standard [7] (see table 3.1). One possible reason is that the reference mixture used in the ASTM standard to determine analytical precision did not include butanes; butanes and heavier hydrocarbons made the data reduction of the mass spectrum much more difficult. Also, the concentration levels of components other than methane were lower in the ASTM mixture than in our study.

In addition to our comparison we received a tabulation of roughly 30 sets of analyses of natural gas mixtures containing 95 mol percent or more 


\begin{tabular}{|c|c|c|c|c|c|c|c|c|c|c|}
\hline \multirow{7}{*}{ 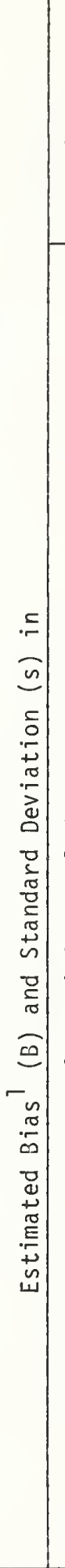 } & 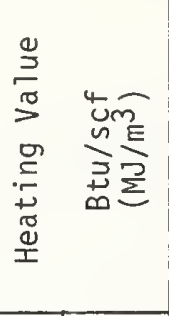 & $\infty$ & 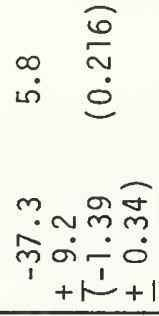 & 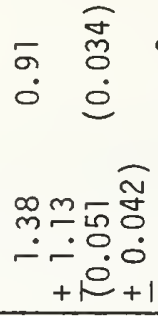 & $\begin{array}{l}\text { vo } \\
\text { rí }\end{array}$ & 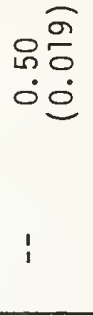 & 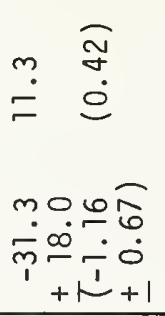 & 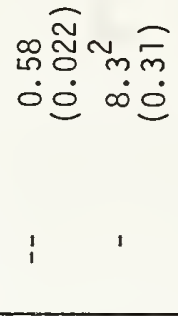 & 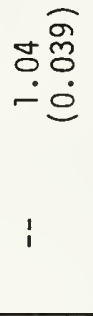 & 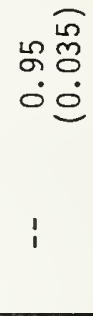 \\
\hline & $\begin{array}{l}\stackrel{0}{I^{2}} \\
U^{\sigma}\end{array}$ & $\infty$ & $\begin{array}{l}\tilde{J} \\
0 \\
0 \\
+m \\
80 \\
00 \\
+1 \\
+1\end{array}$ & $\begin{array}{l}0 \\
\stackrel{0}{0} \\
\dot{0}\end{array}$ & $\begin{array}{l}2 \\
0 \\
0 \\
0\end{array}$ & $\begin{array}{l}\text { டீ } \\
8 \\
0\end{array}$ & $\begin{array}{l}\tilde{0} \\
0 \\
0 \\
0 \% \\
50 \\
00 \\
00 \\
10 \\
+1 \\
\end{array}$ & $\begin{array}{ll}\widetilde{N} & \stackrel{N}{\mathscr{O}} \\
\stackrel{0}{0} & \dot{0} \\
\dot{0} & 0\end{array}$ & $\begin{array}{l}\stackrel{\infty}{\%} \\
\dot{0}\end{array}$ & $\begin{array}{l}\infty \\
0 \\
0 \\
0\end{array}$ \\
\hline & $\begin{array}{l}\stackrel{\circ}{I^{\prime}} \\
\underbrace{}_{-}\end{array}$ & in & $\bar{ָ}$ & $\begin{array}{l}\text { ㅇ. } \\
\text {. } \\
\dot{0}\end{array}$ & 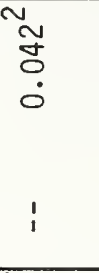 & $\begin{array}{l}\stackrel{2}{\circ} \\
8 \\
0\end{array}$ & $\begin{array}{l}\infty \\
0 \\
0 \\
0 \\
0 \\
\tilde{m} \\
\dot{0} 0 \\
+1 \\
+1 \\
\end{array}$ & 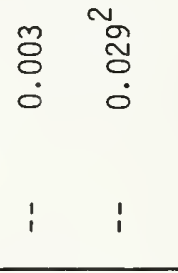 & i & $\begin{array}{l}\stackrel{1}{0} \\
0 \\
0 \\
1\end{array}$ \\
\hline & $\begin{array}{l}\infty \\
\bar{\circ}\end{array}$ & $\infty$ & $\begin{array}{l}\tilde{\sigma} \\
0\end{array}$ & $\begin{array}{l}\bar{̃} \\
\dot{0}\end{array}$ & $\begin{array}{l}\text { No } \\
\text { Oे } \\
0 \\
\dot{0}\end{array}$ & $\begin{array}{l}\text { 영 } \\
\dot{0}\end{array}$ & $\begin{array}{l}g \\
\dot{0} \\
0 \\
+\infty \\
0 \stackrel{0}{0} \\
i 0 \\
+1 .\end{array}$ & \begin{tabular}{cc}
$\frac{m}{0}$ & \multirow{0}{*}{} \\
$\dot{0}$ & $\dot{0}$ \\
1 & 1
\end{tabular} & $\begin{array}{l}\text { ㅇ } \\
0 \\
0\end{array}$ & సิ \\
\hline & 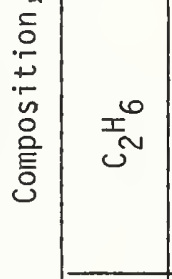 & 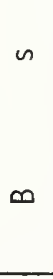 & 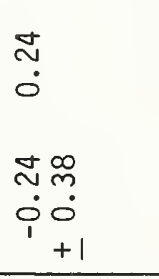 & $\begin{array}{l}\bar{\sigma} \\
\dot{0}\end{array}$ & $\stackrel{\sim}{\sim}$ & $\begin{array}{l}0 \\
0 \\
0 \\
0\end{array}$ & $\stackrel{\stackrel{0}{\circ}}{\circ}$ & 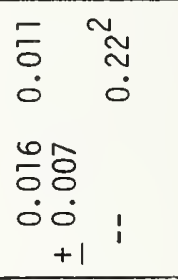 & $\begin{array}{l}\tilde{0} \\
0 \\
0\end{array}$ & $\begin{array}{l}\text { ले } \\
\text { Oे } \\
\dot{0} \\
1\end{array}$ \\
\hline & 工̃ $^{\sigma}$ & n & $\begin{array}{l}0 \\
\dot{0} \\
\dot{\sigma}= \\
\dot{0}= \\
+1 \\
\end{array}$ & $\begin{array}{l}\grave{\vdots} \\
\dot{0}\end{array}$ & $\stackrel{\sim}{\tilde{N}}$ & $\begin{array}{l}\dot{J} \\
\dot{0} \\
\dot{0}\end{array}$ & 哭 & 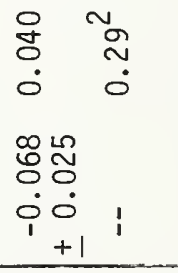 & 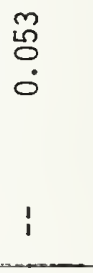 & $\begin{array}{l}\overline{8} \\
0 \\
\vdots\end{array}$ \\
\hline & $z^{N}$ & $n$ & 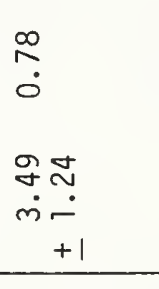 & ণ্ & $\stackrel{N}{N}$ & $\begin{array}{l}\stackrel{\text { L }}{0} \\
\dot{0}\end{array}$ & $\stackrel{5}{\circ}$ & 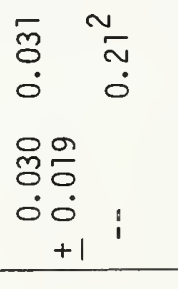 & $\begin{array}{l}\overline{8} \\
\dot{0} \\
8 \overline{0} \\
80 \\
0 \\
0 \\
+1\end{array}$ & $\begin{array}{l}\infty \\
8 \\
0 \\
0\end{array}$ \\
\hline \multicolumn{2}{|c|}{ 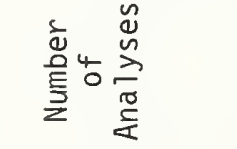 } & & $\theta$ & 0 & $\infty$ & $\Xi$ & $\sigma$ & $m$ & $\infty$ & $m$ \\
\hline \multicolumn{2}{|c|}{ 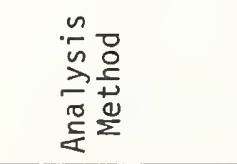 } & & $\sum$ & Uु & $\sum$ & பூ & $\sum$ & பு & પ્ & ర્ \\
\hline \multicolumn{2}{|r|}{ 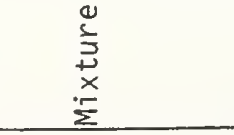 } & & 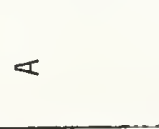 & & $\infty$ & & 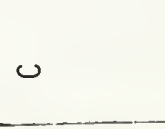 & 0 & & W \\
\hline
\end{tabular}

$\frac{5}{\frac{\pi}{1}}$

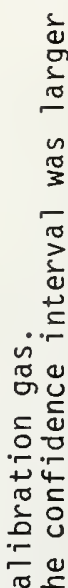

덩

ن

혼

ज

워

บ!

ก

둘

$\times \frac{2}{n}$ i

$\equiv \pi$

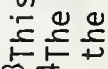

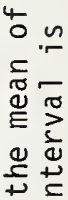

बิำ

崩

足

Uै $\dot{0}$

드른

눙

4

0

ฮ 웡

404

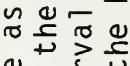

य

凹

무 $\tilde{a}$

드응

4 穴

ज荙

$\therefore$ 동

궁

을

$\propto \mathscr{\nu}$

点这导点 
methane. Samples of each gas mixture were analyzed by MS in two different industrial laboratories and by GC. Also, the heating value of the mixture was measured by using combustion calorimetry. Table 4.4 lists the average error and its estimated standard deviation between the computed heating values, based on gas analysis, and the measured values. Clearly, the GC analysis is much better than one MS laboratory and has a better estimated standard deviation than the second MS laboratory.

Table 4.4. The average error and its estimated standard deviation between

the heating values computed from analyses by gas chromatography (GC), two different mass spectrometers (MS) and the heating value as measured by combustion calorimetry for natural gas mixtures containing 95 mol o or more methane [16].

\begin{tabular}{|c|c|c|}
\hline $\begin{array}{c}\text { Analytical } \\
\text { Method }\end{array}$ & $\begin{array}{c}\text { Average Error } \\
\text { Btu/scf } \\
\left(\mathrm{MJ} / \mathrm{m}^{3}\right)\end{array}$ & $\begin{array}{c}\text { Standard Deviation } \\
\text { Btu/scf } \\
\left(\mathrm{MJ} / \mathrm{m}^{3}\right)\end{array}$ \\
\hline GC & $\begin{array}{c}1.27 \\
(0.0473)\end{array}$ & 0.55 \\
MS I & 5.05 & 3.63 \\
MS II & $(0.1881)$ & $(0.1352)$ \\
& 1.17 & 1.46 \\
$(0.0436)$ & $(0.0544)$ \\
\hline
\end{tabular}

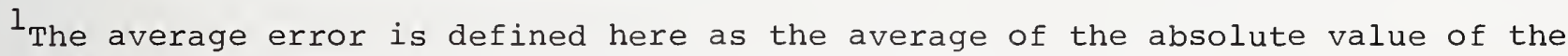
difference between the computed and measured heating values.

\subsection{Statistical Evaluation of GC Analyses}

Based on the above results the GC was selected to be used in this project. Therefore, a statistically defined test was required to determine the analytical precision and accuracy of the GC; also, the effect of various operating parameters needed to be defined. In this test we looked for operator, composition, and day-to-day effects. We used two operators, four mixtures (mixtures C, E, F and G, table 4.2) and ran the tests for four days. Figure 4.3 shows the computed ideal gas heating values for mixture $\mathrm{E}$ (the calibration gas) as a function of chronological order and operator; the $\sigma$ error bar represents one estimated standard deviation $(0.20$ percent) in the heating value. Although there was no operator dependence, there was a day to day shift in the average value; this probably was due to calibration shifts. Also, there were apparent changes in the scatter from day to day which could not be explained; however, excluding the outlier on the last day, the total scatter was $0.09 \%$.

The outlying point on the fourth day illustrates an instrument malfunction discovered in this test. Roughly $20 \%$ of the analyses contained one component, usually nitrogen, methane or ethane, whose composition was more than four estimated standard deviations from the average value. During this period, the integrator started malfunctioning and had to be returned to the factory. After receiving the repaired instrument another test was performed, 
$\varepsilon^{W / \Gamma W} ' \exists \cap 7 \forall \Lambda$ 9NIL $\forall \exists H$ У

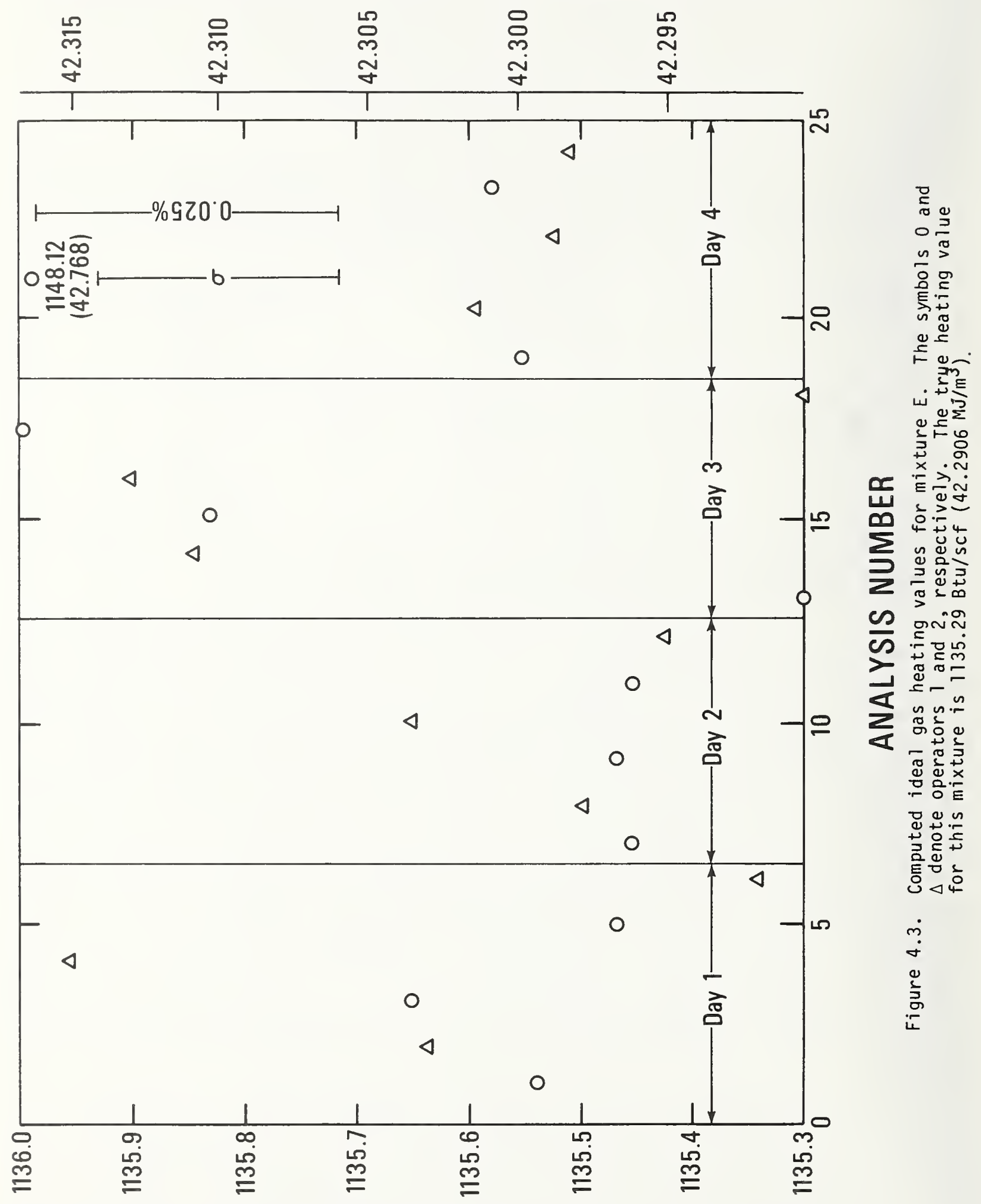

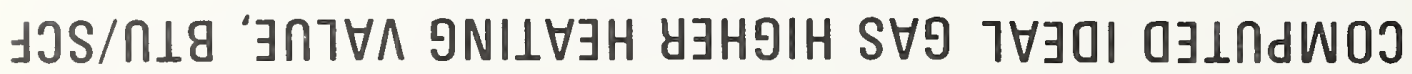


this time using only one operator and one gas mixture. Figure 4.4 shows the computed heating values for the 44 analyses which were taken over a two day period. This time the total spread of computed heating values was $0.07 \%$ and the largest deviation in heating values was 2.8 estimated standard deviation; $75 \%$ of the analyses were within one estimated standard deviation of the average. This indicated that the malfunctioning integrator had caused the outliers.

Table 4.5 lists the biases and estimated standard deviations obtained from the results of the above two tests; values differing from the average measured value by more than four estimated standard deviations were omitted in the computations. Comparing the biases of mixture $G$ with those of the other mixtures points out the necessity of using a calibration gas which is similar to that of the unknown mixture. Also, the estimated standard deviations were generally larger for mixture G; this indicates that the operating variables would require some modification when analyzing mixtures containing large amounts of nitrogen and/or ethane.

Figure 4.3 and 4.4 illustrate how an insufficient number of calibration runs can introduce biases into the computed heating values. Since the calibration gas was the analyzed gas in these figures, the biases had to be caused by the calibration. In the first test all results were based on a single calibration run at the beginning of the day while two calibrations were made at the beginning of each day in the second test. We recomputed the biases for the second test by using the first three runs of each day for calibration; the bias dropped from 0.009 to 0.005 percent. Thus, it appears that at least three good (i.e., not a set that includes an outlier) calibration runs should be used to minimize baises introduced by calibration. This assumes that the other parameters in the GC system remain constant. Since this may not always be the case, calibrations should be made several times during the day as an additional check.

4.3. Evaluation of Gas Chromatograph Column Configuration and Digital Integrators The previous section determined the precision and accuracy of one gas chromatograph (GC)-integrator system. Additional tests employing different column configurations and integrators were needed to determine the factors limiting the precision of GC analyses. This section describes tests using two different three column configurations and two different GC's, and tests directly comparing two different integrators. Table 4.6 summarizes the chromatograph-integrator combinations used in all of the analysis tests. 


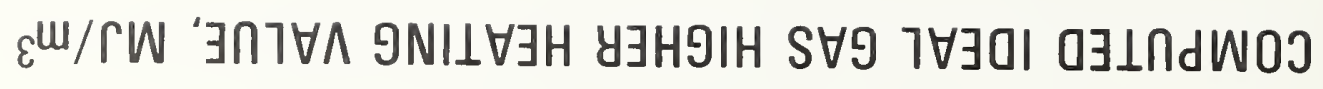

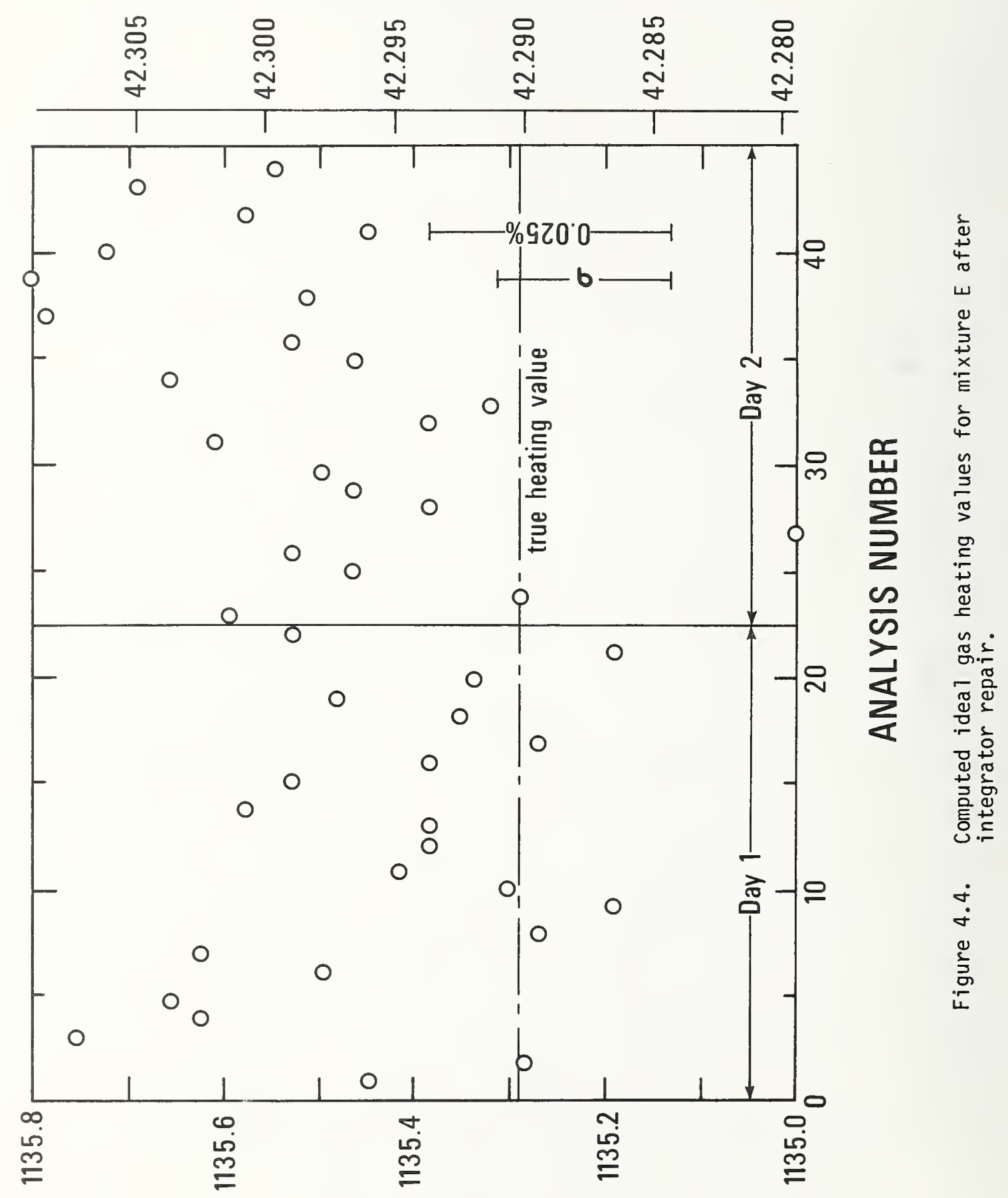

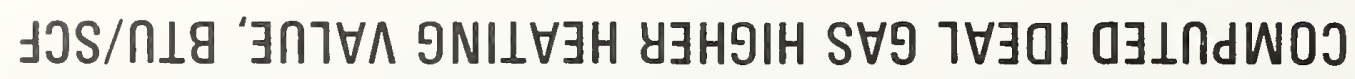




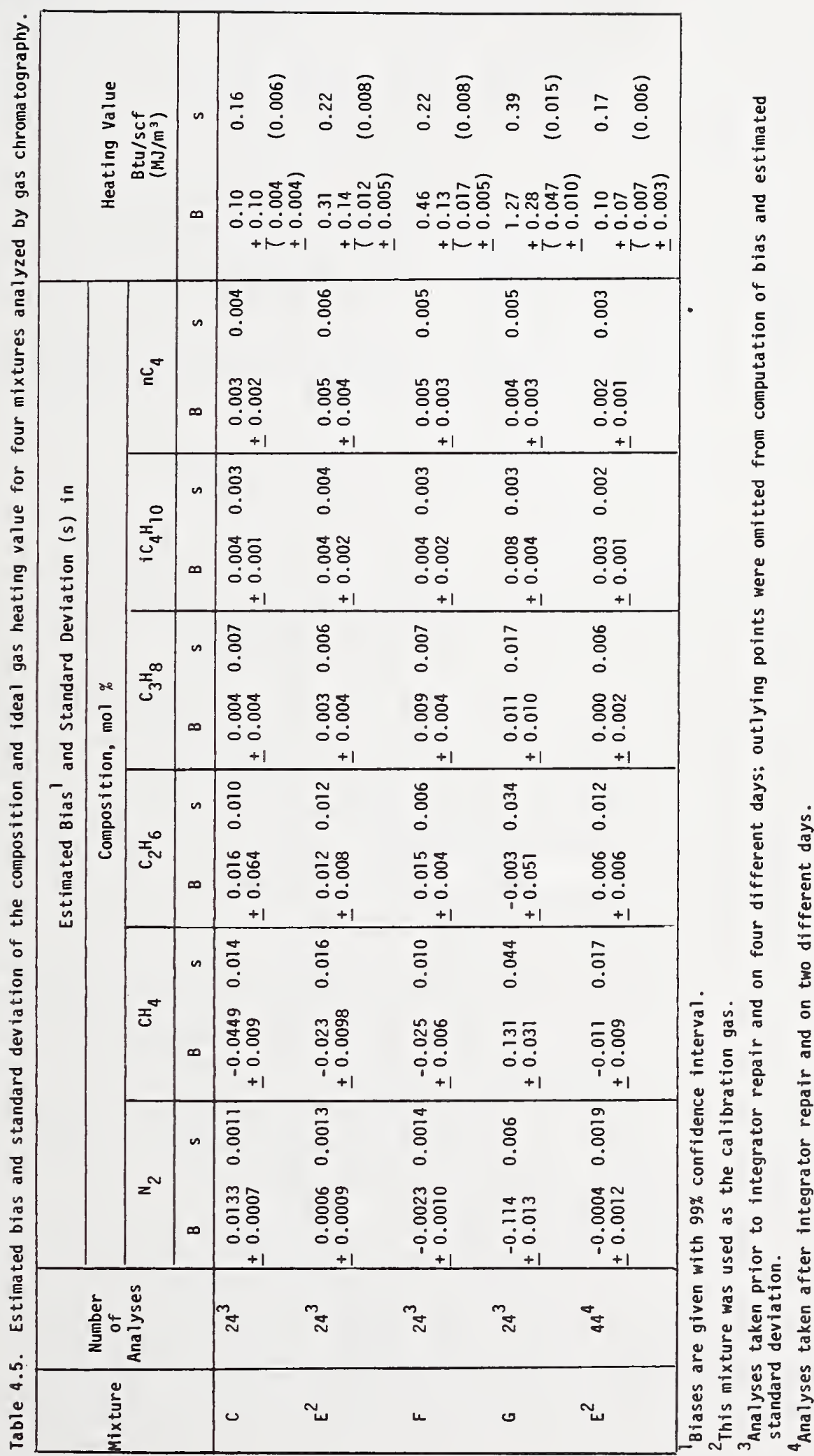


Table 4.6. Summary of gas chromatograph-integrator systems used in analysis tests.

\begin{tabular}{|l|c|c|c|} 
& \multirow{2}{*}{$\begin{array}{c}\text { Two Column } \\
\text { Configuration }\end{array}$} & \multicolumn{2}{c|}{ Three Column Confirugration } \\
\cline { 3 - 4 } & I & Configuration A & Configuration B \\
\hline Chromatograph & Hot-wire & Thermistor & I \\
Automatic Valve & No & Yes & Not-wire \\
Integrator & A & A \& B & A \\
\hline
\end{tabular}

4.3.1. Selection of Column Configurations and Column Packings

obtaining the most accurate and precise analysis of vaporized LNG samples requires:

a) resolving oxygen, nitrogen and methane through pentane and column back flushing (i.e., carrier gas flow reversal) to obtain a composite $\mathrm{C}_{6}{ }^{+}$ peak,

b) analyzing for all components in a single sample injection,

c) completing the analysis within approximately 30 minutes,

d) operating the column ovens in an isothermal mode,

f) minimizing the effect of baseline upset by valve switches, and

g) computing the composition by using peak areas.

The primary purpose in resolving the nitrogen and oxygen peaks is to detect contaminated samples since the most likely contaminant is air. Also, it is a good way to detect leaks in the GC plumbing. The need for good resolution between the hydrocarbons is obvious. The anticipated concentration of hexane and heavier components is small ( 0.01 mol percent); therefore, combining the $\mathrm{C}_{6}+$ fraction into one peak by backflushing causes an insignificant error in the computed heating value.

The GPA [17] and ASTM [6] analysis procedures suggest using two sample injections -- one injection into a column to resolve air and methane through pentane followed by a backflush for the $\mathrm{C}_{6}+$ peak; a second injection into a different column to resolve nitrogen, oxygen and methane (the column then is backflushed to remove the remaining hydrocarbons). However, the two analyses must be combined. This is done through sample size or methane peak area. Both methods diminish analytical precision.

The primary reason for minimizing the analysis time is that the peak height to peak width ratio decreases with increasing residence time. Maximum accuracy and precision in peak area measurement decreases as the ratio decreases. It was found that, for the column configurations and operating parameters considered here, the analysis times fell in two ranges -- one was 40 minutes or greater and the other was 24 to 30 minutes. Configurations 
having long analysis times elute the $\mathrm{C}_{6}+$ peak last; the other configurations elute methane last.

Temperature programming is an attractive way of reducing analysis time and sharpening peaks of the heavier components. However, whenever feasible, isothermal column oven operation is normally preferred over temperature programming when using thermal conductivity detectors. This is because flow variations caused by changing column temperature produce baseline drift when using these detectors. Temperature programming becomes attractive if the baseline drift can be compensated for reliably by the integrator or if flame ionization detectors are used. These detectors are insensitive to flow variations but also do not detect nitrogen, oxygen and carbon dioxide.

Multicolumn configurations require valve switching with its associated carrier gas flow upsets; these, in turn, produce baseline upsets. The time duration of baseline upsets are minimized by:

a) adjusting flow restrictors in column bypass lines so that the steady-state carrier gas flow rate remains constant after switching the column in or out, and

b) using carrier gas inlet pressure instead of mass flow to control the flow rate $[18]$.

To minimize peak integration problems, each valve switch should occur far enough away from the nearest peaks to allow baseline establishment between the peaks and the valve switch.

Traditionally, peak height measurement was preferred over peak area measurement for computing composition from chromatograms. Peak height was used because it was easy, quick and usually more precise than peak area. However, the peak height response is linear over a narrow concentration range, using a $0.5 \mathrm{~cm}^{3}$ sample loop volume, peak height response is linear at concentrations below roughly $10 \mathrm{~mol}$ percent (peak area response is close to 1 inear over the entire composition range). Also, peak heights cannot be used with composite backflush peaks. The currently available programmable integrators eliminate the drawbacks to using peak areas. Also, since both methane and $\mathrm{C}_{6}{ }^{+}$peaks must be measured, peak area measurement was selected.

Compromises are necessary to meet the requirements listed above. It is possible to make the complete analysis on one column [19], but it requires temperature programming between $-70^{\circ} \mathrm{C}$ and $145^{\circ} \mathrm{C}$ and the $\mathrm{C}_{6}+$ backflush peak retention time is about 22 minutes; the $\mathrm{C}_{6}+$ peak width is roughly 3 minutes which, in combination with the baseline drift caused by temperature programming, can cause errors in the peak area measurement. If the separation of oxygen and nitrogen is not required, the analysis can be made by temperature programming between 35 and $145^{\circ} \mathrm{C}$. In this case the analysis time is roughly 15 minutes. Based on the data for five replicate natural gas analyses [19], the estimated standard deviation in the computed heating value for this method is 0.04 percent. 
The most commonly used column packing for isothermally resolving nitrogen and oxygen is molecular sieve 5A [18]. It makes a good separation between nitrogen and methane, but cannot be used with the higher hydrocarbons. This means that at least two columns in series are needed -- one to separate oxygen, nitrogen and methane (molecular sieve) and one to resolve the higher hydrocarbons (we used DC $200 / 500$ on Chromasorb PAW). Using this configuration without temperature programming, the retention time for the pentanes is roughly 20 minutes. After eluting the pentanes, the DC 200/500 column is backflushed with the $\mathrm{C}_{6}+$ peak eluting in another 20 minutes; this peak becomes so broad that at the $0.01 \mathrm{~mol}$ percent level it would not be detected using a TC detector and a $0.5 \mathrm{~cm}^{3}$ sample loop.

When operating the columns isothermally the preferred way to shorten the pentane and $\mathrm{C}_{6}+$ retention times is to use two columns to resolve the $\mathrm{C}_{2}+$ hydrocarbons. By selecting the proper column packings, lengths, and temperatures, and by using column bypassing, the components can be eluted in almost any sequence desired. In this work we considered two three-column configurations -- one which eluted the pentanes and $\mathrm{C}_{6}+$ peaks midway through the analysis (configuration $A$ ) and one which eluted them at the beginning of the analysis (configuration $B$ ).

\subsubsection{Column configuration A}

Figure 4.5 shows a schematic of this three column arrangement and figure 4.6 is a chromatogram of a sample taken during a flow facility sampling test; table 4.7 lists the operating parameters for this configuration. The vaporized LNG samples were analyzed using the following automatic valve switching sequence:

Step 1. Switch valve V1 for sample injection -- all columns are in series.

Step 2. Switch valve V2 to bypass columns 2 and 3 after oxygen, nitrogen and methane have entered these columns; ethane through pentanes are eluted in this step. (Restrictor A is adjusted so that its pressure drop is comparable to the pressure drop of columns 2 and 3; this minimizes baseline upset after valve switchings.)

Step 3. Switch valve Vl to original position to start backflush. Step 4. Switch valve V2 to put columns 2 and 3 back in series with column 1 .

Step 5. Switch valve V3 to bypass column 3 which now contains oxygen, nitrogen and methane; ethane (and carbon dioxide, if present) are eluted in this step. (Restrictor $\mathrm{B}$ is set to provide the same pressure drop as column 3.)

Step 6. Switch valve V2 to bypass column 2 ; the $\mathrm{C}_{6}{ }^{+}$peak elutes in this step. 


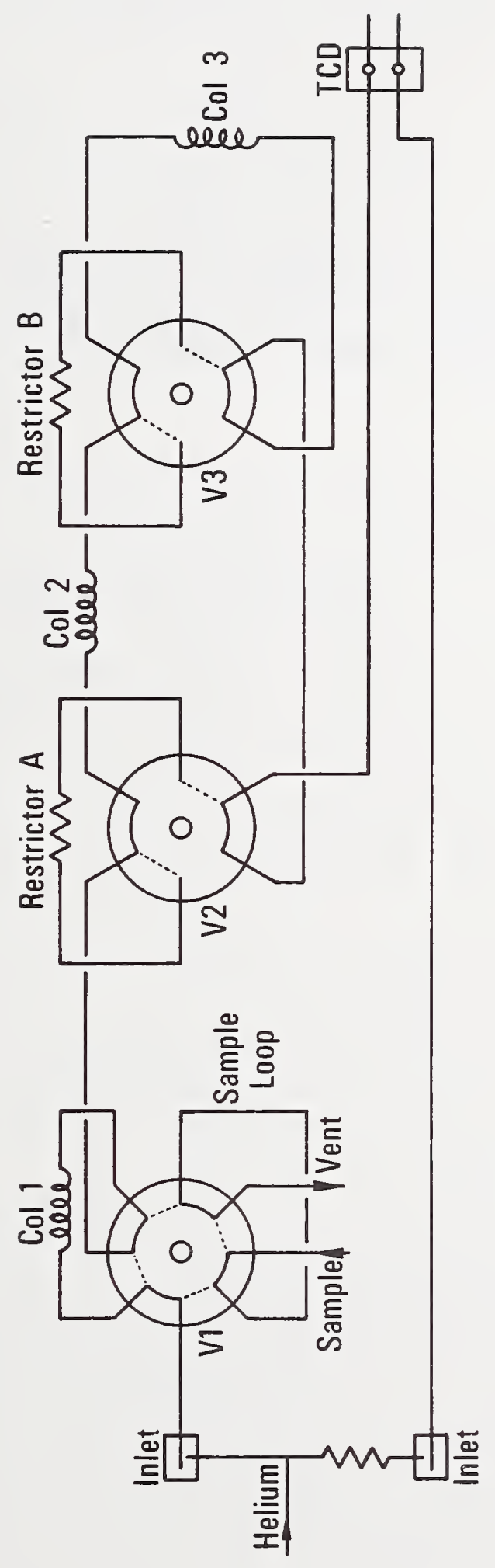

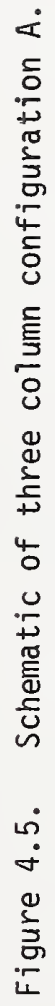




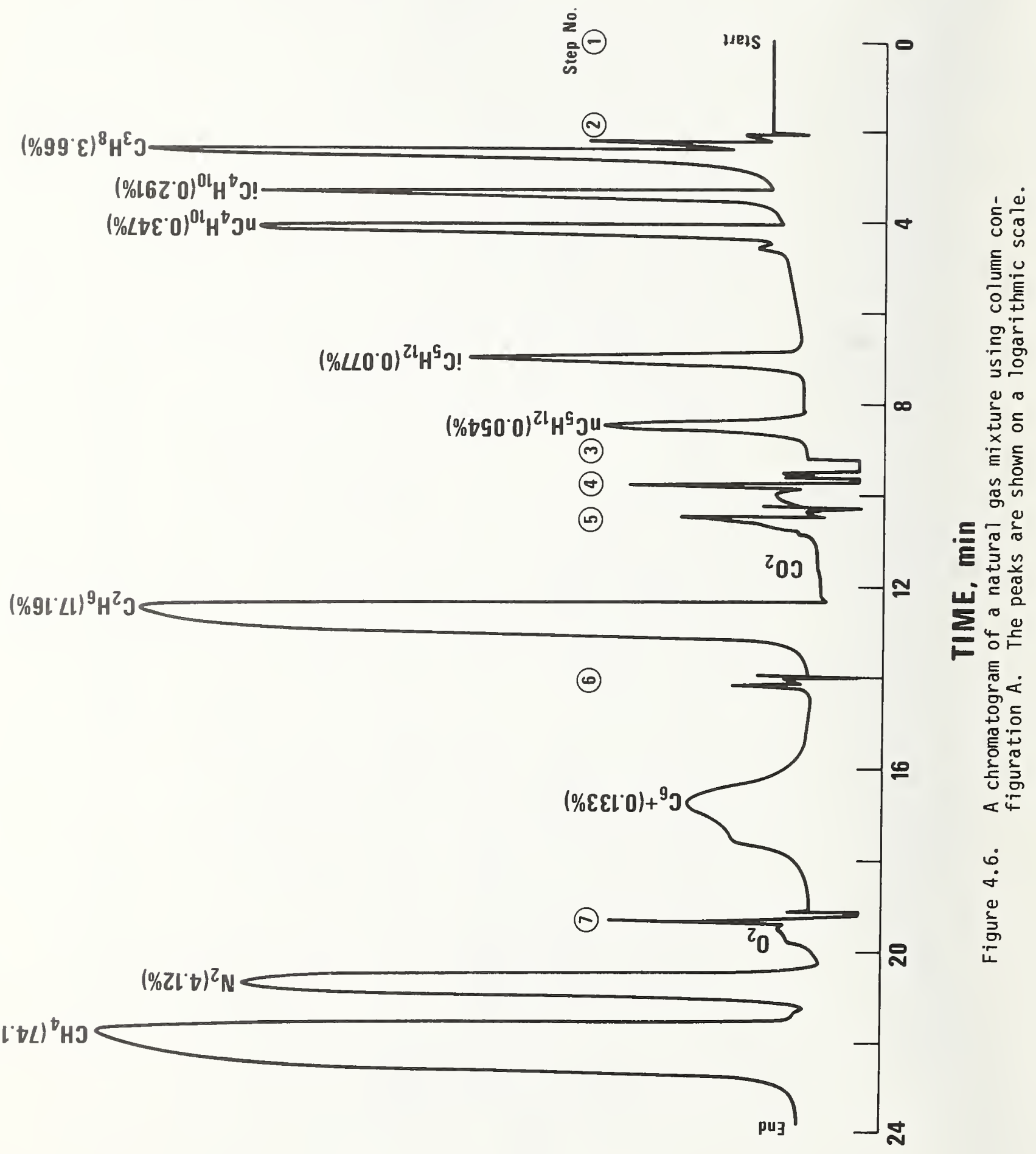


Step 7. Switch valves V2 and V3 to put column 2 and 3 in series; oxygen, nitrogen and methane elute in this step.

Table 4.7. Operating conditions for Column Configuration A.

Carrier gas flow rate

Sample loop volume

Column 1 temperature

(10 ft. $(3 \mathrm{~m}) \times 1 / 8$ in. $(3.2 \mathrm{~mm})$ of

15\% Squalane on Chromosorb PAW, 60/80 mesh)

Column 2 temperature

( $5 \mathrm{ft} .(1.5 \mathrm{~m}) \times 1 / 8$ in. $(3.2 \mathrm{~mm})$ of

Porapak $\mathrm{N}, 60 / 80$ mesh)

Column 3 temperature

$5 \mathrm{ft.}(1.5 \mathrm{~m}) \times 1 / 8 \mathrm{in.}(3.2 \mathrm{~mm})$ of

Molecular sieve 5A, 60/80 mesh)

Detector temperature

Detector current

(Thermistor detector)

$$
\begin{aligned}
& 27.5 \mathrm{scm}^{3} / \mathrm{min} \\
& 0.5 \mathrm{~cm}^{3} \\
& 66^{\circ} \mathrm{C}
\end{aligned}
$$

$66^{\circ} \mathrm{C}$

$66^{\circ} \mathrm{C}$

$66^{\circ} \mathrm{C}$

Table 4.8 lists the results of a series of analyses made using this configuration and prepared mixture $H$ (see table 4.2). A comparison of these results with results given in table 4.4 shows that the precision of the two different column configurations was somparable. No biases were found in this test since the same mixture was used for both calibration and analysis; three calibrations were made prior to running the replicate samples. It is encouraging that configuration $A$, with eight valve switches, had about the same precision as the much simpler two column system which had only three valve switches.

Unfortunately, the backflush peak in configuration $A$ was so broad that one of the two integrators (integrator $A$ ) had difficulties in accurately measuring the $\mathrm{C}_{6}+$ peak area at the $0.10 \mathrm{~mol}$ percent level (see sections 5.2.3.1). Although integrator $B$ reliably integrated the $\mathrm{C}_{6}{ }^{+}$peak, the broad backflush peak affected the reliability of integrating the following two peaks. It is extremely unlikely that the integrators would reliably detect a $\mathrm{C}_{6}{ }^{+}$peak at the $0.01 \mathrm{~mol}$ percent level. (Missing a $\mathrm{C}_{6}+$ concentration of $0.01 \mathrm{~mol}$ percent produces a 0.04 percent error in the computed heating value.)

The only way to obtain a relatively precise $\mathrm{C}_{6}+$ analysis is to reduce the retention time; this can be done by choosing a different three-column configuration.

\subsubsection{Column configuration B}

If precise determination of pentanes and $\mathrm{C}_{6}+$ concentrations in the 0.01 mol percent range is required, these components must be eluted at the beginning of the analysis. This is done by using the columns listed in table 4.9 and the flow scheme shown in figure 4.5. Configuration $B$ uses the following valve sequence: 


\begin{tabular}{|c|c|c|c|c|}
\hline \multirow{9}{*}{ 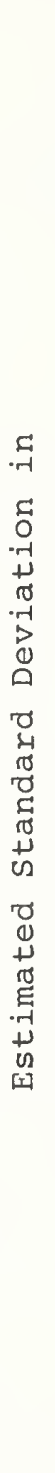 } & \multicolumn{2}{|c|}{ 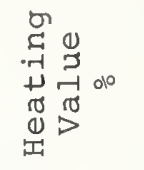 } & $\begin{array}{ll}\overrightarrow{+} & \overrightarrow{+} \\
0 & 0 \\
0 & 0 \\
0 & 0\end{array}$ & $\begin{array}{l}\mathscr{0} \\
\dot{0}\end{array}$ \\
\hline & \multirow{8}{*}{ 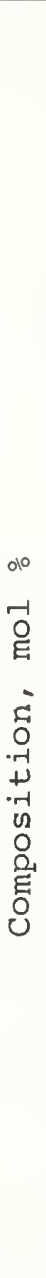 } & 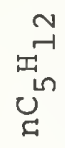 & $\begin{array}{ll}0 & \\
\circ & N \\
\circ & 0 \\
0 & 0 \\
0 & 0\end{array}$ & $\begin{array}{l}\infty \\
\circ \\
\circ \\
0 \\
\dot{0}\end{array}$ \\
\hline & & 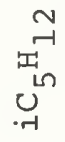 & $\begin{array}{ll}\infty & 0 \\
\circ & N \\
0 & 0 \\
0 & 0 \\
0 & 0\end{array}$ & $\begin{array}{l}\text { m } \\
\circ \\
\circ \\
\circ \\
\dot{0}\end{array}$ \\
\hline & & 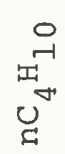 & 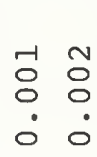 & $\begin{array}{l}\infty \\
\circ \\
\circ \\
\circ \\
\dot{0}\end{array}$ \\
\hline & & 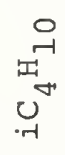 & $\begin{array}{ll}0 & \\
\circ & -1 \\
\circ & 0 \\
\circ & 0 \\
0 & 0\end{array}$ & $\begin{array}{l}5 \\
\circ \\
\circ \\
\circ \\
\dot{0}\end{array}$ \\
\hline & & $u^{\infty}$ & $\begin{array}{ll}1 & m \\
\circ & 0 \\
0 & 0 \\
0 & 0\end{array}$ & $\begin{array}{l}\text { 웅 } \\
\circ \\
0\end{array}$ \\
\hline & & $\tilde{u}^{6}$ & $\begin{array}{ll}m & \infty \\
0 & 0 \\
0 & 0 \\
0 & 0\end{array}$ & $\begin{array}{l}r \\
-1 \\
0 \\
0\end{array}$ \\
\hline & & $\underbrace{\sigma}$ & $\begin{array}{ll}0 & 0 \\
0 & -1 \\
0 & 0 \\
0 & 0\end{array}$ & $\begin{array}{l}\stackrel{0}{N} \\
\circ \\
0\end{array}$ \\
\hline & & $z^{2}$ & $\begin{array}{ll}1 & 0 \\
0 & 0 \\
0 & 0 \\
0 & 0\end{array}$ & $\begin{array}{l}1 \\
\circ \\
\circ \\
0\end{array}$ \\
\hline \multicolumn{3}{|c|}{ 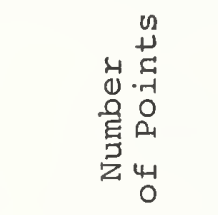 } & $\underset{r}{N} \stackrel{-}{N}$ & $r$ \\
\hline \multicolumn{3}{|c|}{ 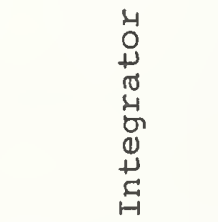 } & $\varangle \Phi$ & $\varangle$ \\
\hline \multicolumn{3}{|c|}{ 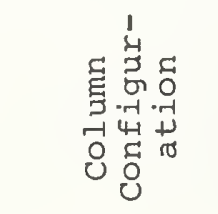 } & $\varangle$ & $\varphi$ \\
\hline
\end{tabular}


Step 1. Switch valve Vl for sample injection -- all columns are in series.

Step 2. Switch valve V2 to bypass columns 2 and 3 after all components except $\mathrm{C}_{5}+$ have entered these columns; the iso and normal pentane elute in this step.

Step 3. Switch valve V1 back to original position to backflush the $\mathrm{C}_{6}+$ component.

Step 4. Switch valve V2 to put columns 2 and 3 into series again.

Step 5. Switch valve V3 to isolate oxygen, nitrogen and methane in column 3. Ethane through the butanes are eluted in this step.

Step 6. Switch valve V3 to elute oxygen, nitrogen and methane.

Table 4.9. Operating conditions for Column Configuration B.

\begin{tabular}{|c|c|}
\hline $\begin{array}{l}\text { Carrier gas flow rate } \\
\text { Sample loop volume }\end{array}$ & $\begin{array}{c}28 \mathrm{scm}^{3} / \mathrm{min} \\
0.5 \mathrm{~cm}^{3}\end{array}$ \\
\hline $\begin{array}{l}\text { Column } 1 \text { temperature } \\
(6 \mathrm{ft} .(1.8 \mathrm{~m}) \mathrm{x} 1 / 8 \mathrm{in} .(3.2 \mathrm{~mm}) \text { of } \\
\text { DC } 200 / 500 \text { on Chromasorb PAW, } 60 / 80 \mathrm{mesh})\end{array}$ & 62 to $68^{\circ} \mathrm{C}$ \\
\hline $\begin{array}{l}\text { Column } 2 \text { temperature } \\
(25 \mathrm{ft} .(7.6 \mathrm{~m}) \mathrm{x} 1 / 8 \mathrm{in.}(3.2 \mathrm{~mm}) \text { of } \\
\text { DC } 200 / 500 \text { on Chromasorb PAW, } 60 / 80 \text { mesh })\end{array}$ & $60^{\circ} \mathrm{C}$ \\
\hline $\begin{array}{l}\text { Column } 3 \text { temperature } \\
(6 \mathrm{ft} .(1 / 8 \mathrm{~m}) \times 1 / 8 \text { in. }(3.2 \mathrm{~mm}) \text { of } \\
\text { Molecular sieve, 5A, 60/80 mesh) }\end{array}$ & $65^{\circ} \mathrm{C}$ \\
\hline Detector temperature & $120^{\circ} \mathrm{C}$ \\
\hline Detector current & $220 \mathrm{ma}$ \\
\hline
\end{tabular}

Table 4.8 gives the results of a feasibility test for column configuration $\mathrm{B}$; figure 4.7 is a chromatogram of a mixture containing a $\mathrm{C}_{6}+$ fraction. The numbers indicate that this configuration produces more scatter than configuration A. However, these results are inconclusive because during these tests:

a) there were temperature fluctuations in the column 1 oven (this oven was a valve oven and was not designed for precise temperature contol);

b) there were small air leaks which caused baseline shifts during the $\mathrm{n}$-pentane and ethane peaks, (the shifts were found by running an analysis of the carrier gas) and

c) there were indications that column 3 had been contaminated and needed to be regenerated; this caused extreme tailing of the methane peak.

Either of the latter two problems could produce the observed scatter in the computed heating value. Additional tests should be made to determine the precision of this configuration under better operating conditions. 


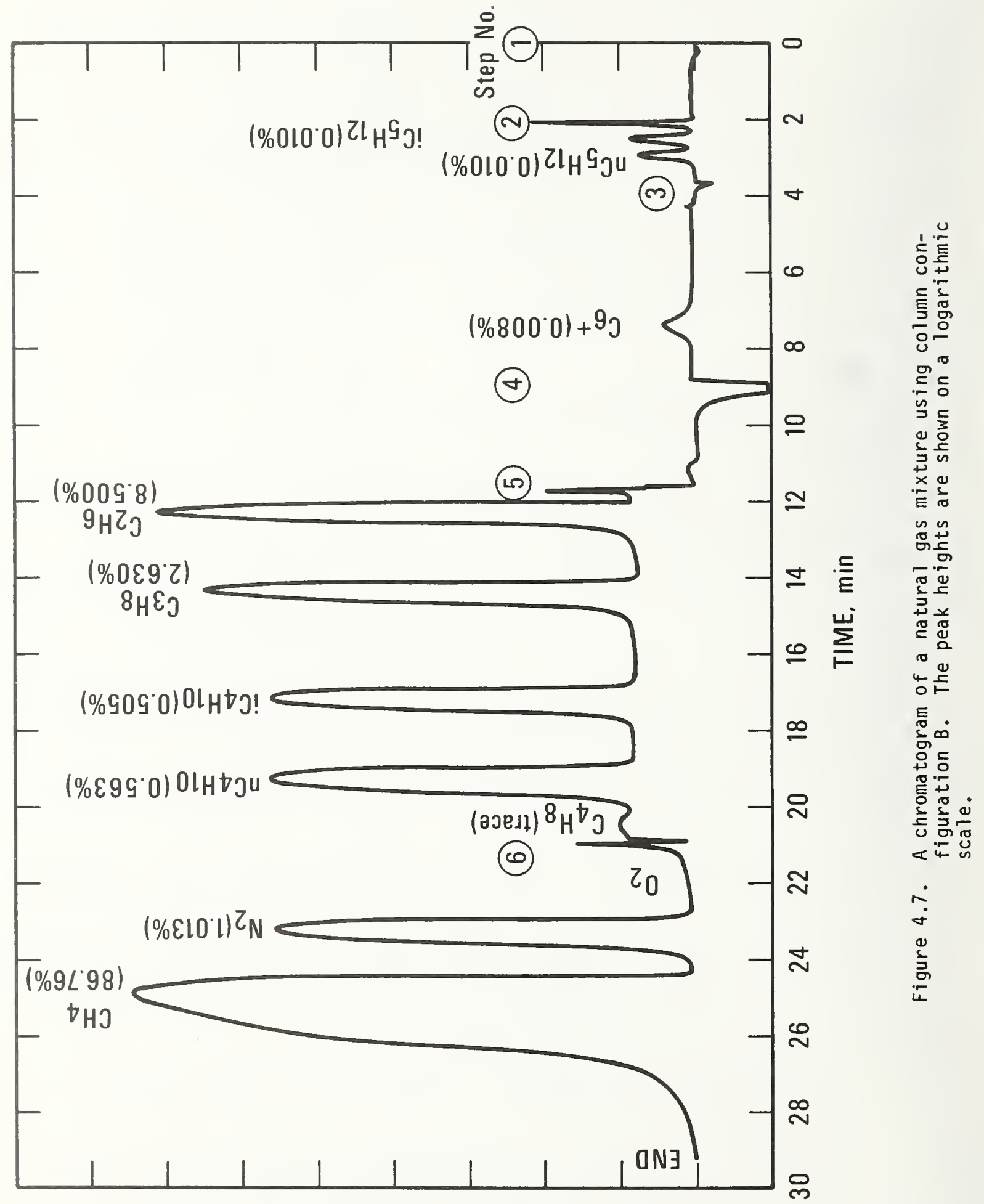


Comparison of pentane peak heights showed that the peak heights using configuration $B$ were twice that of configuration A. A sample containing $C_{6}{ }^{+}$ was analyzed using configuration $B$; the $C_{6}{ }^{+}$peak eluted as a single sharp peak instead of the broad double peak produced by configuration $A$.

\subsubsection{Digital Integrator Evaluation}

The purpose of this work was to directly compare the accuracy and precision of two different programmable digital integrators. All digital GC integrators use voltage to frequency converters and counters to convert the detector output voltage into peak areas. The primary difference in integrators is in how they treat the converted signal. Both integrators used in this evaluation employed sophisticated software programs; these programs identified peaks, baseline segments and small peaks riding on the tail of larger peaks. Also, they compensated for transient baselines when computing peak areas. Both integrators were programable so that automatic adjustments, which were unique to the particular analysis, could be made during the analysis. The primary differences between the two integrators were that the software programs used different peak detection algorithms and that integrator B had considerably more programming capabilities; however, this versatility was unnecessary for analyzing vaporized LNG samples.

Table 4.8 shows the results of a direct comparison between the two integrators. For these tests, both integrators were connected directly to the GC detector output. Although integrator B has significantly greater scatter for some of the components, the precision in the heating value. for both instruments was comparable.

During the last two days of a four day test period both integrators produced one or more extraneous results. The outliers appeared to occur randomly among the integrators which excluded the GC as the cause. We suspect that the outliers were caused by power fluctuations since the integrators were on different circuits; the GC detector power supply was connected to a constant voltage transformer. Shortly after these tests there were several power fluctuations severe enough to shut down the integrators.

4.4. Determination of the Effect of Operating Variables on Gas Chromatograph Analysis Accuracy and Precision

Variation in any of the operating parameters listed in table 4.7 could affect analysis precision and accuracy. However, variables such as column temperature will be electronically controlled. Therefore, they will be constant unless the set point is changed. The variables most subject to change are sample amount (i.e., sample pressure since a fixed volume sample loop is used) and carrier gas flow rate because it must be set manually. 
Table 4.10 lists the results of two tests using column configuration A and both integrators. In one test we injected samples at pressures of 13.7, 21.1 and 8.6 psia $(94,145$ and $59 \mathrm{kPa})$; the calibration sample pressure was 13.7 psia $(94 \mathrm{kPa})$. The table shows that the precision was insensitive to sample pressure. However, there was an apparent linear relationship between bias and sample pressure. This test indicates that maintaining the sample pressure within \pm 10 percent of that used for calibration will keep the bias to less than 0.025 percent in the computed heating value.

The observed bias was caused by the method the integrators used to determine the peak area. Unless the peak was very large and sharp, part of the peak area was lost during the baseline determination. The absolute amount of area lost remained nearly constant as the peak area changed, provided that the peak width at the half-height did not change. Therefore, the relative amount of area lost decreased with increasing peak size. Since the methane peak was so large there was a negligible amount of area lost during baseline determination. However, this was not the case for all other components except the pentanes. (The pentane peak areas were so small that the effect was within the data scatter.) This explains why the apparent methane content decreased and the ethane through butane contents increased with increasing sample injection pressure.

In the second test the carrier gas flow was varied by \pm 7 percent. Integrator A results were insensitive to the flow variation, whereas, integrator $\mathrm{B}$ showed a bias in the computed heating value. This bias was caused by the method used to establish baseline between the nitrogen and methane peaks. During these tests integrator B was programmed to force a baseline at a specified time. The time was set at the bottom of the valley between the two peaks (see figure 4.6) when the carrier gas flow rate was $26.5 \mathrm{scm} / \mathrm{min}^{3}$ Increasing the carrier gas flow rate made the valley bottom occur before the forced baseline. Therefore, the forced baseline caused the integrator to ignore part of the methane peak; this lowered the apparent methane content and raised the apparent composition of the other components. This problem can be eliminated by having the integrator automatically select the valley bottom as the baseline when two peaks are not completely resolved.

Based on these tests it appears that the precision and accuracy of the computed heating values are uneffected by changes of \pm 7 percent in the carrier gas flow rate. This conclusion strictly applies only to configuration $\mathrm{A}$. However, it should apply to other column configurations which have comparable time spacings between valve switches and peak elutions. 


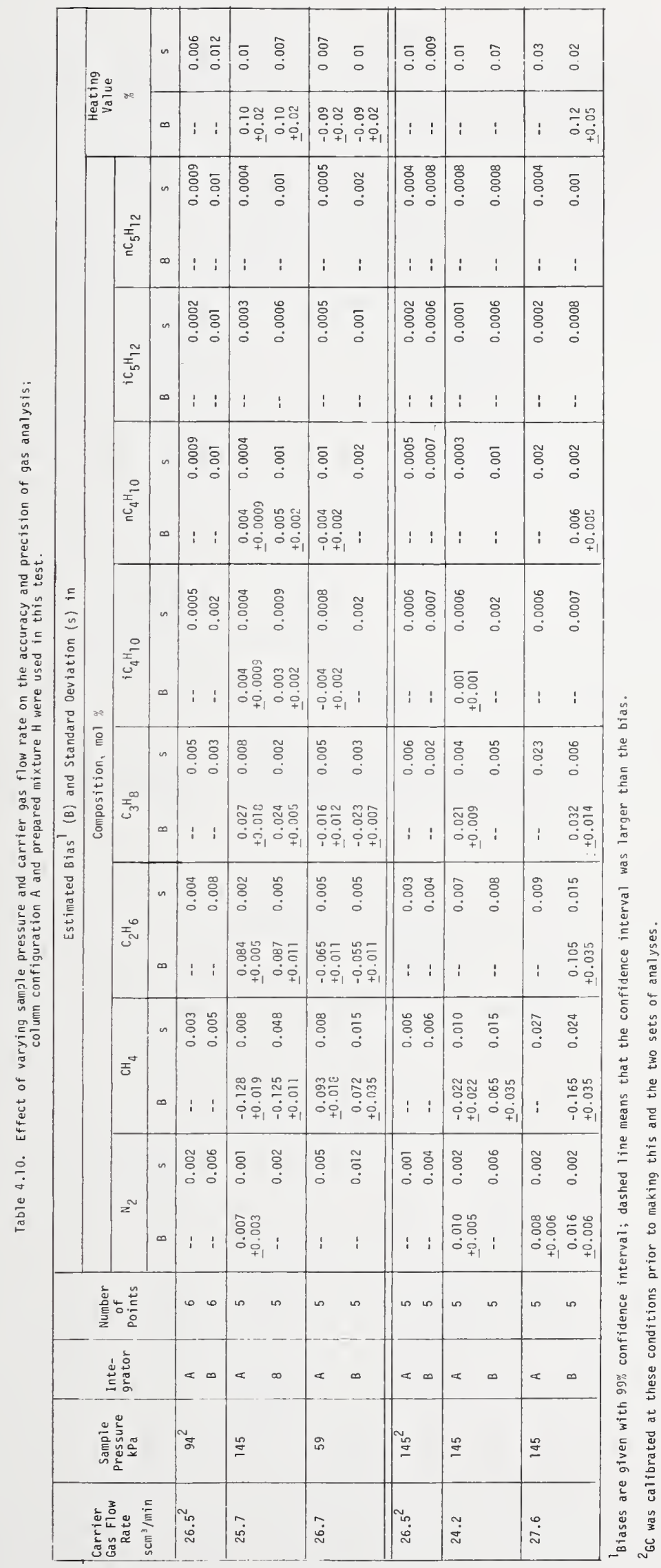




\subsection{Sample Handling Procedures}

Typically, the LNG sampling procedure will include the filling of gas sample containers. Therefore, we need to know which filling procedures are the most reliable and if there are any effects of storage which could change the sample composition over a period of time. Considering the filling procedures described by Miller [12] (see discussion in section 3.2) and our own past experiences, we feel that the fill and purge technique along with purging at a constant flow rate are the simplest and most reliable; however, when using the latter technique, some method of flow measurement is desirable.

In using the purge and fill technique we must know how many purges are adequate to remove the original gas. Miller [12] states that 3 to 8 are sufficient; the ASTM standard [13] recommends 10 at one point and 3 to 8 in another. The number depends upon the line pressure because the important factor is the number of sample container volumes of gas, at ambient pressure (assuming ideal gas behavior), which pass through the sample container. Assuming complete mixing, 10 volumes of gas should be adequate. However, we felt that a test was necessary to determine:

a) the number of purges required, both in filling the sample cylinder and in purging the lines to the GC, and

b) the effect of sample "aging" which could change the apparent composition.

\subsubsection{Test Apparatus and Procedure}

Figure 4.8 shows a schematic of the apparatus for evaluating sample handling techniques. In the first test we determined the number of purges necessary to reduce the air concentration to below the detectable limit on the GC. We used $150 \mathrm{~cm}^{3}$ stainless steel sample cylinders with valves at each end; the valves contained teflon packing and Kel-F stem tips. The valves were fitted with a gland and nut for making an o-ring coupling to the sample line. The sample cylinders were not pretreated in any way. However, they were pressure checked to $1500 \mathrm{psi}$ (10 MPa) and vacuum checked with a helium leak detector. In this test, we attached a sample cylinder to valve V5. Initially, several analyses were made directly from the prepared mixture cylinder. In addition to noting the nitrogen content of the mixture, we also recorded the ratio of the methane to nitrogen peak areas. (This is a sensitive method for detecting air leaks.) To make sure that air was in the sample cylinder initially, we evacuated the manifolding between valves V2 and V3, with V5 and V6 open, but V7 closed; after closing V5, V7 was opened to let air in. Next the manifolding was pressurized to 30 psig 10.3 $\mathrm{MPa}$ ) with the mixture by opening valves $\mathrm{Vl}$ and $\mathrm{V} 2$. To purge and fill the sample cylinder we would alternately open valve V5 with V7 closed, then close V5 and open V7; V7 was left open just long enough to bleed the pressure 


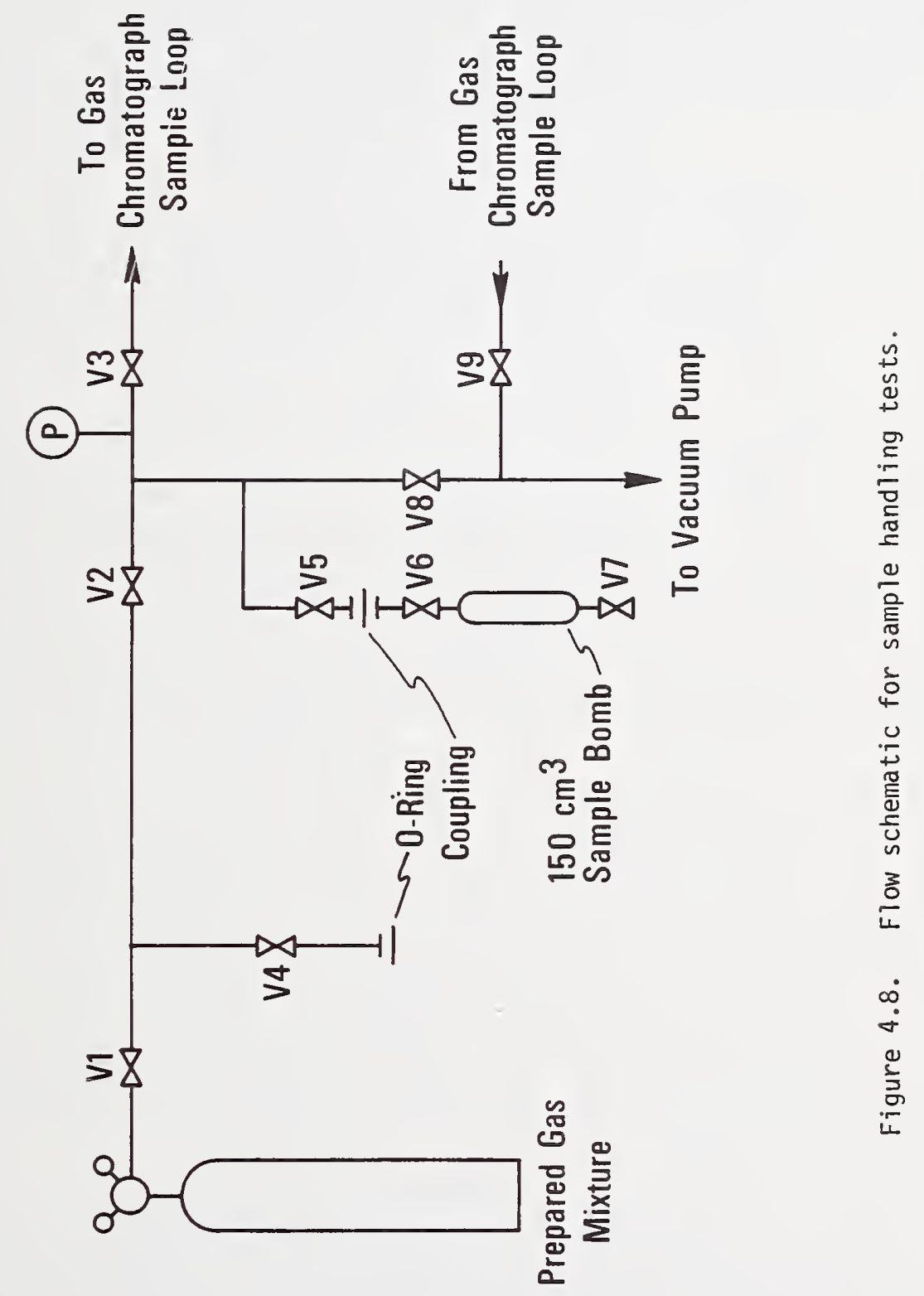


to near ambient. After the desired number of purges, valve 22 was shut and the manifolding evacuated through V8. During this evacuation, valve V5 was open but V6 closed. Next we cracked open valve V6 to fill the manifold to 2 psig (0.1l MPa). After filling the manifold, valve V5 was closed and V6 opened. Opening valves V3 and V9 evacuated the manifold and GC sample loop. After V9 was closed we cracked open valve V5 to fill the line with sample gas and the analysis started. Originally the GC sample loop was purged several times, but tests showed that one 20 to 30 second evacuation and fill was sufficient. However, if there was sufficient pressure in the sample cylinder, we repeated the evacuation and fill at least once.

\subsubsection{Evaluation of Results}

Analyses were taken on samples from cylinders purged and filled 4, 6, 10 and 14 times. Only the last one indicated that all of the air was removed. This is equivalent to 42 sample container volumes of gas at ambient conditions, four times more than would be expected if there was complete mixing •

In the second test we looked at sample aging to see if processes such as adsorption on sample cylinder walls would alter sample composition. Again we used sample cylinders initially containing air and used 14 purge and fills with a sample pressure of 30 psig $(0.3 \mathrm{MPa})$. However, this time the sample containers were filled at the o-ring coupling adjacent to valve V4; for analysis we attached the sample cylinders to valve V5 and followed the line and GC sample loop purging procedure outlined above. To ensure that the change in composition, if any, was not due to biases in the GC analysis, the prepared mixture from the cylinder was analyzed before and after each sample cylinder analysis. Analyses were made at 1/2, 4, 24, 48 hours and 50 days after filling; in all cases the samples were within one estimated standard deviation of the original mixture for all components.

Additional tests (see section 5.2.1.1) showed that continuous purging also was a satisfactory sample collecting technique. However, the sample container was purged the equivalent of 14 or more purge and fills. The gas throughput was estimated by monitoring the pressure, flow rate (5 to 11 standard liters per minute) and time.

\subsection{Conclusions and Recommendations}

\subsubsection{Accuracy and Precision of Analysis by Gas Chromatography}

Based on the results of comparative tests it was found that a gas chromatograph-digital integrator system was more accurate and precise than mass spectrometry. Additional tests showed that the gas chromatograph produced a bias (i.e., the total uncertainty consists of only analytical precision) of 0.02 percent, or less, in the computed heat value provided that: 
a) the response factors for computing the composition are the average of three or more calibrations,

b) the gas chromatograph and digital integrator operating parameters remain constant during calibration and analysis runs, and

c) the calibration and unknown mixture compositions are comparable. Test results showed that gas mixtures within the anticipated LNG composition range given in table 2.1 can be analyzed by gas chromatography using only one calibration gas (which is within the same range) without producing biased results.

The total uncertainty in computing the heating value routinely can be less than \pm 0.1 percent. This assumes:

a) taking three or more replicate analyses and averaging the computed heating value,

b) making three or more calibration runs prior to the analyses and averaging the resulting response factors for each component,

c) using a calibration gas which has a total uncertainty in the composition which, neglecting the specific heating value of each component, corresponds to an accuracy of \pm 0.03 percent in the computed heating value (if the calibration gas is prepared by a commercial vendor, an independent verification of the composition should be made),

d) using a gas chromatograph-integrator system with a known precision of 0.06 percent, or better (based on three standard deviations), in the computed heating value, and

e) following the sample injection procedures described previously (sections 4.1.1.2 and 4.1.1.3) for gas analysis.

Appendix 7.3 outlines how to compute the total uncertainty and how the number of calibration and analysis runs affect the uncertainty; also, it provides a method for rejecting a given analysis.

If precise analysis of $\mathrm{C}_{5}+$ is unnecessary, column configuration $\mathrm{A}$ should be used for analyzing vaporized LNG samples. If the pentanes and $\mathrm{C}_{6}{ }^{+}$ peak areas need to be precisely known, column configuration B is recommended; however, further tests are needed to insure that the configuration will be as precise as configuration A. Also, other column configurations need to be evaluated.

To maintain the maximum accuracy and precision, the sample amount and carrier gas flow rate should be kept constant to within \pm 7 percent. It is recommended that a high quality rotameter be used to monitor the flow rate; the rotameter can be calibrated with a simple soap bubble flowmeter.

Direct comparison of two different integrators showed that the two instruments had comparable precision. Based on all of the tests (see section 4.3.1.1 and 4.3.2), we conclude that, at present, the digital integrator is less precise than the gas chromatograph employing a thermal conductivity detector. Therefore, the most precise analysis will be one in which the integrator "sees" the sharpest 
peaks and the least baseline fluctuations before and after peaks. To maximize the piecision, a programmable integrator should be used.

\subsubsection{Sample Handling}

Tests showed that both the purge and fill technique and the continuous purge technique were accurate methods for collecting vaporized LNG samples. However, both techniques require some care to insure that the cylinder has been purged properly.

Commercially available stainless steel sample cylinders are recommended for collecting gas samples. No special preparation of the cylinders is required prior to their use. Tests showed that stainless steel cylinders do not alter the hydrocarbon content over a six week period. (However, stainless steel is not inert to sulphur compounds.)

4.6.3. Recommended Criteria for Selecting a Gas Chromatograph-Integrator System

Based on our experience we recommend that the following features be included in any gas chromatograph-integrator system dedicated to routine analysis of vaporized LNG samples:

a) Automatic valve switching - this is required to insure that the right valve is switched at the right time.

b) Thermal conductivity detector -- this is the only detector that is sensitive to all the components in natural gas and is linear in response over the anticipated concentration ranges (i.e., the output signal is directly proportional to the concentration). Hot wire filaments are preferrea over thermistors because they provide superior stability, longer operating life and fewer anomalies of operation [20]. The instrument should contain a thermal protect device to minimize the risk of oxidizing the filaments. To maximize sensitivity the detector cell volume should be as small as possible.

c) Isolated power supply -- this is necessary to prevent electrical noise generated by oven temperature controllers from entering the detector circuitry. The detector power input should be connected to a constant voltage transformer to minimize effects of line power fluctuations.

d) Carrier gas flow control by inlet pressure -- this is preferrable to mass flow control when the analysis involves valve switching [18]. A two-stage pressure regulator should be used to keep the inlet pressure constant.

e) Readily accessible valve and column connections -- this is needed to make routine maintenance and leak checking easy.

f) Programmable digital integrator -- this is necessary to maximize the analytical precision. A memory protect feature should be used 
to prevent losing programs during momentary power failures. A constant voltage transformer should be connected to the integrator to minimize noise due to line power fluctuations.

4.6.4. Recommendations for Future Work

If $\mathrm{C}_{5}+$ hydrocarbons must be analyzed precisely, additional testing of column configuration $B$ is needed to determine the analytical precision of the method. Other column packings should be considered for column 1 of this configuration.

A survey of the open literature shows that there is no widely accepted method for analyzing vaporized LNG samples. An extensive study should be made to determine the best gas chromatographic technique for analyzing LNG type mixtures. The study should include selecting the best column packings, column configurations and detectors. Capillary columns should be considered because these columns produce extremely sharp peaks which are ideal for use with digital integrators. Once the gas chromatograph system has been selected, extensive tests should be made to establish representative values for the precision and accuracy of the technique.

\subsection{LNG SAMPLING}

The sampling tests included both laboratory and field tests. The laboratory tests provided close control of all operating variables whereas the field tests permitted evaluation of a full scale sampling system.

The chronological order of the tests and the variables considered for their effect on sampling accuracy and precision were:

a) laboratory tests (Probe Evaluation) - sampling rate, LNG flow rate, temperature, pressure, degree of subcooling and three probes;

b) laboratory tests (Vaporizer Evaluation) - sampling rate, temperature, degree of subcooling, LNG flow rate and two vaporizer designs,

c) field tests (LNG Flow Facility Test 1) - three probes and three vaporizers,

d) laboratory tests (General Tests) - accumulator residence time, vaporizer outlet temperature, pressure drop upstream of vaporizer, heat leak to sample probe and presence of heavy components $\left(C_{5}+\right)$ in the LNG,

e) field tests (Shipboard Tests) - sampling rate and comparison between liquid and vapor sampling,

f) field tests (LNG Flow Facility Test 2) - sampling rate, heat leak, start-up transients and three variations of a vaporizer design.

This section discusses all the laboratory tests before describing the field tests. 


\subsection{Laboratory Tests}

\subsubsection{Laboratory Facility}

This section discusses all aspects of the laboratory facility with the exception of the gas analysis equipment; this is discussed in section 4.1.1. 5.1.1.1. Laboratory Scale Apparatus

Figure 5.1 shows a schematic of the laboratory scale apparatus used in this work. The cryogenic portion of the apparatus was contained in an evacuated double walled dewar which was 33 inches $(840 \mathrm{~mm})$ deep and had a. 10-3/4 inch $(270 \mathrm{~mm})$ inside diameter. The LNG vessel, which was $8-1 / 2$ inch $(215 \mathrm{~mm})$ long with an outer diameter of 8 inches $(203 \mathrm{~mm})$, had an inner volume of roughly 6 liters; the wall was copper and the two end plates were brass. A centrifugal pump circulated LNG through a turbine flowmeter, with a range of 0.25 to $2.5 \mathrm{gpm}(0.016$ to $0.16 \mathrm{~L} / \mathrm{s})$, and through the test section between valves $\mathrm{T} 1$ and $\mathrm{T} 2$. All of the lines in this loop were $1 / 2$ inch (12.7 $\mathrm{mm})$ O.D. copper tubing except for a 3 inch (76 mm) long section containing 1 inch (25 mm) O.D. copper tubing just downstream of valve Tl. This short section acted as a mixing chamber to reduce flow turbulence caused by the valve. The test section was a 6-3/4 inch (171 mm) long straight section. It contained two probes -- an upstream facing pitot tube and a side tap. Both probes were mounted vertically and were made of $1 / 16$ inch ( $1.59 \mathrm{~mm}$ ) O.D. by 0.023 inch $(0.58 \mathrm{~mm})$ I.D. stainless steel tubing. There was roughly 6 inches $(150 \mathrm{~mm}$ ) of line between the probes and valves T4 and T5.

Besides the pitot tube and side tap, a "reference" probe was located in the straight-run leg of a tee positioned just upstream of valve Tl. Since the flow into the tee was downward, the reference probe was in essence located on the bottom of the line. There were 8 inches $(200 \mathrm{~mm})$ of 0.023 inch $(0.58 \mathrm{~mm})$ I.D. stainless steel tubing between this probe and valve T3.

Valves $\mathrm{Tl}$ through $\mathrm{T} 6$ were bellows valves which were located inside the insulating vacuum space at LNG temperature. They were actuated by stem extensions protruding through the top plate of the apparatus. Valves T3 through $\mathrm{T} 6$ were mounted on a brass plate which was soldered to the top of the mixing chamber.

After a probe was selected by opening either valve T3, T4, or T5, the sample passed through $1 / 16$ inch $(1.59 \mathrm{~mm})$ O.D. by 0.023 inch $(0.58 \mathrm{~mm})$ I.D. stainless steel tubing to one of three vaporizers. If the sample went to the reference vaporizer it first passed through valve T6 and 8 inches $(203$ $\mathrm{mm}$ ) of tubing; valve $\mathrm{T} 6$ was a needle valve used to provide additional pressure drop to prevent sample backflash, i.e., flow reversal due to vaporization. The reference vaporizer consisted of a 5 inch (127 mm) long section of $1 / 16$ inch $(1.58 \mathrm{~mm})$ O.D. by 0.051 inch $(1.28 \mathrm{~mm})$ I.D. stainless steel tubing and a 12 inch $(304 \mathrm{~mm})$ long section of $1 / 8$ inch $(3.18 \mathrm{~mm})$ O.D. by 0.101 inch $(2.56 \mathrm{~mm})$ I.D. stainless steel tubing. The sample was vaporized 


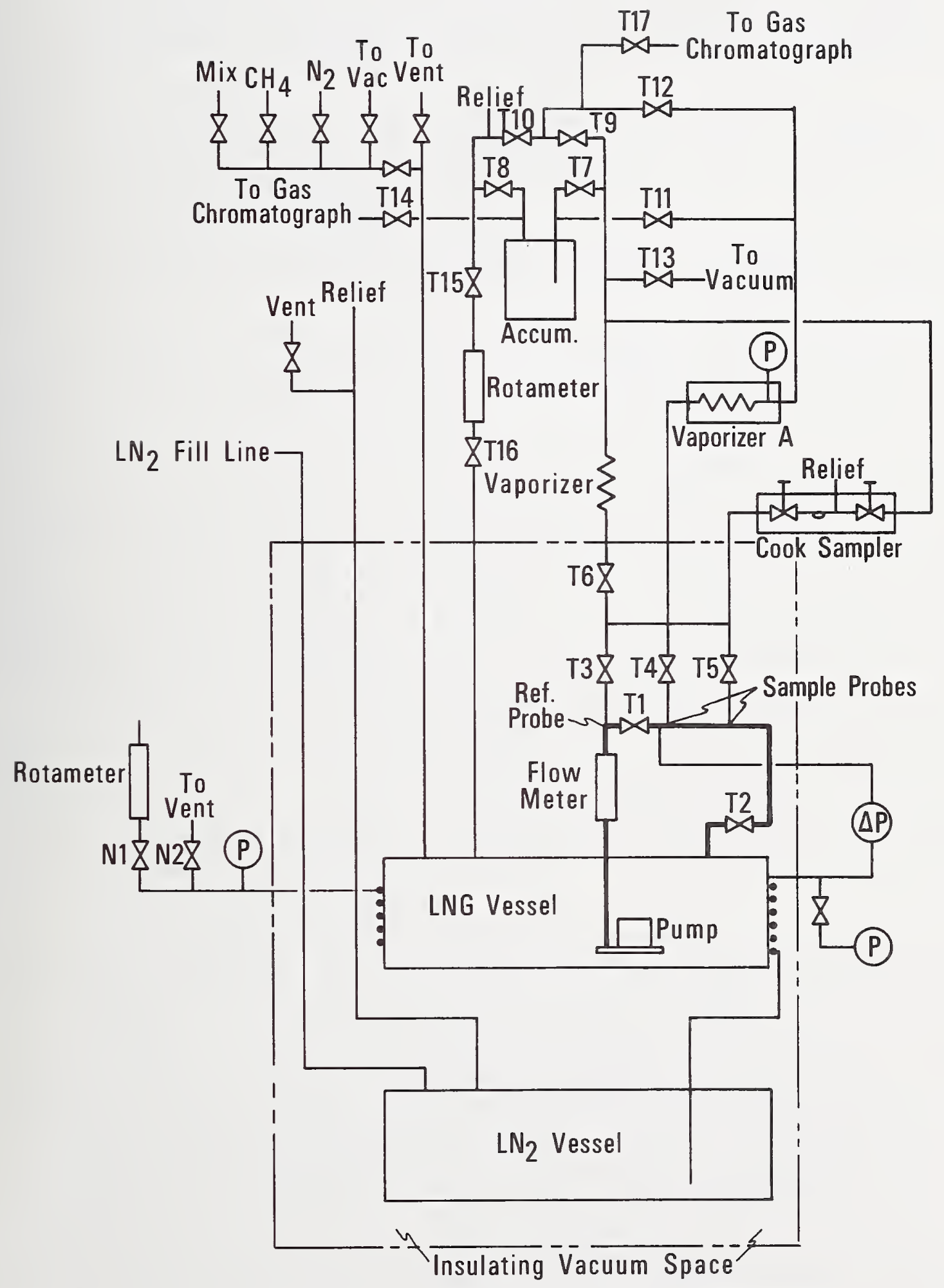

Figure 5.1. Schematic of 1aboratory scale apparatus. 
by passing a low voltage, high amperage DC current through the two sections of tubing. To prevent shorts, the two ends of the vaporizer were epoxied into micarta couplings. The reference vaporizer was located less than $1 / 2$ inch $(13 \mathrm{~mm})$ from where the sample line left the vacuum insulated space. After the sample left the vaporizer it went to a manifold containing a 2 liter accumulator, through a 0 to 11.4 liter per minute (lpm) rotameter and back to the LNG vessel. The lines between the vaporizer and rotameter were $1 / 4$ inch $(6.35 \mathrm{~mm}) \mathrm{O} . \mathrm{D}$. by 0.190 inch $(4.83 \mathrm{~mm}) \mathrm{I} . \mathrm{D}$. copper tubing; the copper tubing downstream of the rotameter was $3 / 8$ inch (9.53) 0.D. by 0.343 inch $(8.71 \mathrm{~mm})$ I.D. The accumulator could be isolated by closing valves T7 and T8; to maintain the sample flow, valves $\mathrm{T} 9$ and $\mathrm{TlO}$ (a regulating valve) were opened when the accumulator was isolated. Samples could be taken from the accumulator through valve T14 and from the bypass line through valve T17.

The second vaporizer, vaporizer A, contained an electrically heated vaporizing element, an adjustable back pressure regulator and a 0 to 30 psig (0.1 to $0.3 \mathrm{MPa}$ ) pressure gauge in a single unit. The heating element was a I-l/4 inch $(31.8 \mathrm{~mm})$ wide by 28 inch $(71.1 \mathrm{~cm})$ long section of $100 \mathrm{mesh}, 316$ stainless steel screen wrapped around a $1 / 2$ inch $(12.7 \mathrm{~mm})$ O.D. stainless steel tube. The diameter of the tube plus screen was 0.71 inches (18 $\mathrm{mm}$ ). The vaporizer was designed to have the sample flow through the screen perpendicular to the axis of the tube. Also, the vaporizer contained a bypass valve and a pressure relief valve to protect the pressure gauge; both of these valves were capped in this study. Approximately 15 inches (381 mm) of stainless steel tubing connected the probes to vaporizer A. To prevent premature vaporization the line was vacuum jacketed to within 1 inch (25 mm) of the vaporizer inlet. When using this vaporizer, valves Tll and Tl2 replaced the function of valves $\mathrm{T} 7$ and $\mathrm{T} 9$.

The third vaporizer was a cook sampler. Whereas the reference vaporizer and vaporizer A were for continuous sampling, the cook sampler was designed for the batch sampling. Since the LNG sample was used to cool the sampler, the lines were piped to return the vapor to the LNG vessel; otherwise, the mixture would be depleted too quickly. The line from the probes to the sampler was roughly 15 inches $(381 \mathrm{~mm})$ long and vacuum jacketed.

Liquid nitrogen $\left(\mathrm{LN}_{2}\right)$ was used as the refrigerant in this study. The $\mathrm{LN}_{2}$ vessel was $9-7 / 8$ inches $(251 \mathrm{~mm})$ in diameter and 10-3/4 inches (273 mm) long and could contain about 10 liters of liquid. The LNG vessel was cooled by liquid flowing from the $\mathrm{LN}_{2}$ vessel and through a coil wrapped and soldered on the LNG vessel. Cold nitrogen vapor leaving the coil went to another coil soldered on a $1 / 8$ inch (3.2 mm) thick copper plate located roughly 2 inches $(50 \mathrm{~mm}$ ) below the top plate. All lines into the vacuum space were in thermal contact with this plate to reduce heat leakage. After 
leaving the copper plate the nitrogen went to valve $\mathrm{Nl}$ and to a 0-44 liter per minute full scale rotameter and/or to bypass valve N2. When the apparatus was temporarily shutdown, e.g., overnight, nitrogen gas vented through another line which contained a relief valve set at 8 psig $(0.16 \mathrm{MPa})$.

During these periods the $\mathrm{LN}_{2}$ vessel needed to be filled every 24 to 28 hours. The LNG vessel cooled at a rate of 1 to $2 \mathrm{~K}$ per day during idle periods.

To minimize radiation heat leak in the vacuum space, the apparatus was surrounded by a copper radiation shield. This shield was fastened to the $\mathrm{LN}_{2}$ vessel and extended up to the copper plate.

\subsubsection{Instrumentation}

The temperature was measured using a platinum resistance thermometer (PRT) calibrated on the IPTS-68 temperature scale. The PRT was encased in a copper sheath pressurized with helium gas and positioned near the bottom of the LNG vessel. To measure the resistance we used a one ma constant current source with a potentiometer and a nanovolt null detector. The thermometer current was monitored by measuring the voltage drop across a 100 ohm standard resistor. Initially, we had the output from the null detector go to a power regulator; this regulator powered either a 120 or a 230 ohm heater wrapped on the LNG vessel. Although the temperature control was good $( \pm$ $0.01 \mathrm{~K})$, crosstalk developed between the power regulator and the null detector. This control method was dropped and thereafter the temperature was controlled by manually adjusting the $\mathrm{LN}_{2}$ flow rate; using this method we could control the temperature to $\pm 0.03 \mathrm{~K}$ or better.

The saturation pressure of the LNG was measured with a 0 to 100 psia $(0$ to $6.9 \mathrm{MPa}$ ) quartz bourdon tube pressure gauge; this gauge was calibrated against an air dead weight gauge. The difference between the LNG pressure in the test section and in the LNG vessel was measured with a 0-300 inches of water ( 0 to $0.075 \mathrm{MPa}$ ) differential pressure gauge; this gauge was not calibrated during this project.

\subsubsection{Safety features}

Since the project involved flammable fluids all vents on the LNG system were tied to the room vent system. In addition, all vacuum pump outlets were connected to the same vent system. A relief valve, set at $120 \mathrm{psig}$ $(0.93 \mathrm{MPa})$, was located on the sample return line; this relief valve lead to the vent system. Finally, the insulating vacuum system had a relief valve connected to the vent and a pressure switch-solenoid valve combination. If the vacuum pressure increased to 100 microns (13 Pa), or, if there was a power failure the solenoid closed, isolating the vacuum space from the vacuum pump. 


\subsubsection{Recirculation pump motor}

In the early stages of the project we had problems with motors to drive the recirculation pump. The same pump had been operated in liquid helium using a small three phase induction motor [21]. However, this motor had too much slippage when used with LNG (the density of LNG is four times greater than that of liquid helium). Two small motors in tandem still did not provide sufficient torque. Next we went to a 1/7 HP (106 watt) DC brush motor. The motor had sufficient torque but operated only 100 hours before the brushes failed. We replaced the brushes and used the same motor for another 90 hours. We then purchased and installed a larger three phase induction motor ( $1 / 2 \mathrm{hp}$ (373 watt) at $10,000 \mathrm{rpm}$ ); it worked satisfactorily for the remainder of the project.

5.1.2. Experimental Procedure

5.1.2.1. Cooldown and Filling Procedure

After checking for leaks the insulating vacuum space was evacuated for 15 or more hours. By this time, the pressure was down to $10^{-4} \mathrm{~mm} \mathrm{Hg}(0.1$ Pa) or less. The complete LNG system was evacuated and back filled several times with high purity nitrogen which passed through a molecular sieve purifier. The cooldown was started by filling the $\mathrm{LN}_{2}$ vessel with liquid nitrogen. With bypass valve N2 (see figure 5.1) wide open it took about 2 hours to bring the apparatus to $110 \mathrm{~K}$.

Once at LNG temperature, all instruments and the pump were tested and the system was checked for cold leaks. If all was well the prepared mixture was condensed into the LNG vessel. Using a pressure of 40 to $50 \mathrm{psi}(0.27$ to $0.34 \mathrm{MPa}$ ) above the mixture's saturation pressure it took about one hour to fill the LNG vessel; when the LNG vessel was full there was a sudden rise in the pressure of the LNG system. At this point the startup was complete.

\subsubsection{Preparation of Known Mixture}

Because the accuracy of Sampling-Measurement Systems needed to be known, prepared mixtures of known composition were required in the laboratory scale apparatus. Of the several preparation methods considered, it was decided that the fastest and most accurate method was to fill a large $\left(1.75 \mathrm{ft}^{3}(49.6 \mathrm{~L})\right)$ gas cylinder with pure fluids and analyze the resulting mixture. (Size and weight limitations of the mass balance made preparation by weight unfeasible.) Partial pressures were used as a guide for estimating how much of each component should be added. Prior to filling, the cylinder was evacuated while being warmed with a heat lamp for at least 48 hours. The cylinder was filled to $1100 \mathrm{psi}(7.59 \mathrm{MPa})$, which was well below the dew point pressure of the mixtures used here, and warmed with heat lamps for at least 6 hours. To enhance mixing, the cylinder was alternately heated in vertical and horizontal positions; when in the horizontal position a heat lamp was placed at each end of the cylinder. Next, a sample of the 
mixture was analyzed on the GC; the cylinder then was heated for several more hours before making another analysis. If the analyses did not agree, the procedure was repeated until they did. (It never took more than 48 hours to obtain complete mixing.) Next, a series of at least 6 analyses were made on the mixture and the results averaged to determine the composition as accurately as possible.

After filling the LNG vessel the cylinder pressure was 100 to 150 psig ( 0.79 to $1.14 \mathrm{MPa})$. The mixture remaining in the cylinders was analyzed again to see if the composition had changed. Also, this gas mixture was analyzed several times during each operating day so that day to day shifts in the analysis could be detected. Table 5.1 gives the final sets of analyses for the prepared mixtures.

\subsubsection{Operating procedure}

The daily startup consisted of bringing the system to the desired operating condition and calibrating the gas chromatograph. The reference vaporizor and vaporizer A required 15 to 30 minutes, depending upon the sample flow rate, to establish steady-state conditions. The flow through the vaporizer had to be stable to obtain temperature control because the sample stream constituted 25 to 50 percent of the heat load on the system. (The only other major heat input was from the pump motor.)

After establishing the desired operating conditions the accumulator was isolated by closing valve $\mathrm{T} 8$ and valve $\mathrm{T} 7$ or Tll (see figure 5.1), depending upon the vaporizer used. (Operating the Cook sampler is discussed below.) To ensure a representative sample of the mixture leaving the vaporizer, the sample passed through the accumulator for at least 10 minutes under steadystate conditions. Immediately after isolating the accumulator either valve T9 or Tl2 was opened (valve Tlo remained open) to avoid upsetting the system. At this time the operating variables could be changed so that the system would be stable when the next sample was ready to be taken. Under normal operation the power input to the reference vaporizer was set so that the tubing just downstream was warm to the touch; vaporizer A contained a thermostated heater set at $125^{\circ} \mathrm{F}\left(40^{\circ} \mathrm{C}\right)$.

To analyze the trapped sample in the accumulator the line between valve T14 and the GC was evacuated by opening valves V1, V5 and V6 (see figure 4.1) After closing valve V6, the line then was pressurized to about 2 psig (0.11 MPa) by opening valve Tl4. This purge and evacuate procedure was repeated three times; next valve Tl 4 was left open and VI closed. Then the analysis procedure described in section 4.1 .1 .3 was followed.

To draw a sample from the accumulator bypass line, valves V2 and V7 were opened to evacuate the line connecting V2 and Tl6. After closing V7, valve Tl7 was opened to pressurize the line to about 2 psig ( $0.11 \mathrm{MPa}$ ). After repeating the purge procedure three times, valve V2 was closed and T17 


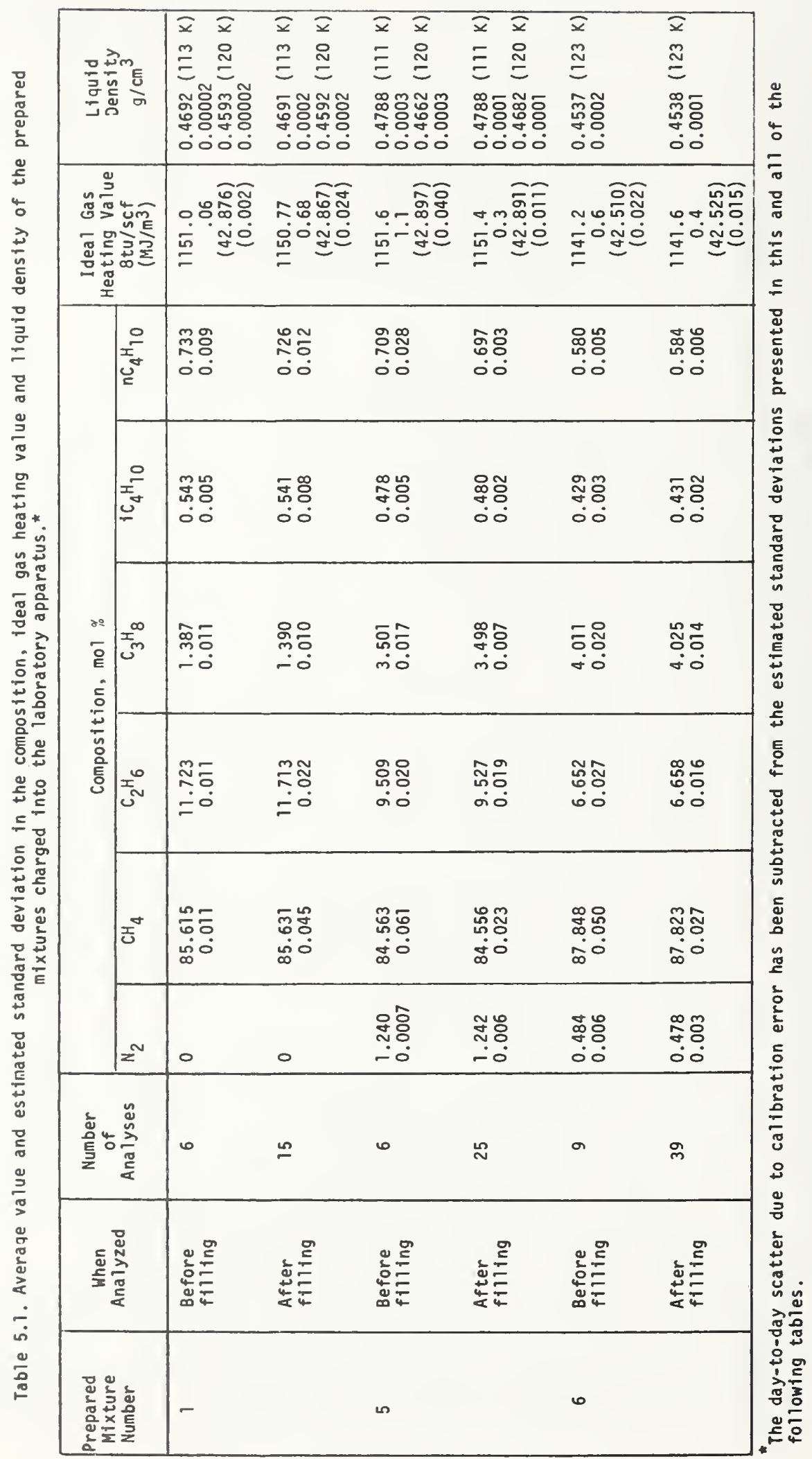


left open. Next, the analysis procedure was followed. The sample flow in the bypass line was uninterrupted during the purging procedure.

Initially, at least two analyses were made on each sample. Since each analysis took 14.5 minutes, this limited us to analyzing a maximum of two samples per hour. Once the integrator was repaired, only one analysis was made on each sample unless the results were more than three estimated standard deviations, for gas analysis alone, from the expected values. In this case, another analysis was made; in all cases, duplicate analyses were within one estimated standard deviation of the first analysis for all components. The prepared mixture from the cylinder was analyzed several times a day. Most often these were made during a temperature change and/or a $\mathrm{LN}_{2}$ vessel filling -- each of which took about 30 minutes. The prepared mixture also was analyzed at the end of the day after shutting down the apparatus.

Sample flow to the cook sampler was obtained by closing valves T6, Tll, and $\mathrm{T} 12$ and by opening valves $\mathrm{T} 7$ and $\mathrm{T} 8$ and the valves on the cook sampler (see figure 5.1). Once the sampler contained only liquid the valves on the sampler were closed and it was allowed to warm up. Next the accumulator was evacuated by closing valve T8 and opening valve Tl3 for several minutes. After closing valve Tl3, the downstream valve on the Cook sampler was opened. Then the accumulator was isolated by closing valve $\mathrm{T} 7$ and the mixture analyzed following the procedures described above.

\subsubsection{Control of operating variables}

The operating variables initially considered in this study were temperature, Reynold's number in the test section (Re), difference between the pressure at the sampling point and saturation pressure $(\Delta p)$ and sampling rate $(Q)$. The temperature was maintained by balancing the refrigerant flow against the heat input. Usually temperature control was held by having only valve Nl open (see figure 5.1); however, when operating at high sample flow rates, bypass valve $\mathrm{N} 2$ had to be opened as much as $1 / 4$ turn. Both Re, i.e., flow rate in the test section, and $\Delta p$ were set by adjusting pump speed and valve $\mathrm{T} 2$. (In all tests reported here valve $\mathrm{Tl}$ remained wide open.) Valve T15 controlled the sampling rate.

5.1.3. Experimental Results

The laboratory tests were divided into three phases:

a) Probe Evaluation

b) Vaporizer Evaluation

c) General Tests.

The first two phases were conducted prior to the first flow facility tests. The last series of tests were made to explain the unexpectedly poor results obtained at the flow facility. The second flow facility tests and the shipboard tests followed the general laboratory tests. 


\subsubsection{Probe evaluation}

The purpose of this phase of work was to:

a) determine which, if any, operating variables affected the reliability of the three probes,

b) determine which of the test probes was the most reliable,

c) show that the reference probe produced samples of the same composition as the test probes, and

d) establish the precision and accuracy of the reference probe.

The reason for using a reference probe was to determine the mixture composition. This probe design is unfeasible for most industrial applications. However, to prove the probe's reliability required tests using mixtures of known composition. In the probe evaluation three different compositions were used and two of these were mixtures of known composition.

In addition to the composition, the following operating variables were considered:

a) three sample flow rates (Q),

b) four Reynold's numbers (Re) in the test section,

c) two operating pressures, i.e., temperatures, and

d) five differential pressures $(\Delta \mathrm{p})$ i.e., the difference between the pressure at the sampling point and the saturation pressure of the mixture.

Table 5.2 lists the values of the variables according to run number and table 5.3 gives the estimated standard deviations in composition, ideal gas heating value and liquid density for each probe in each test. Except where noted in the text, average values of composition, ideal gas heating value, and liquid density for these tests are indistinguishable statistically from the corresponding values given in table 5.1. (Appendix 7.4 lists the raw data for all sampling tests.) Except for Test 2, the estimated standard deviation in heating value and density for the sampling data is presented as a percentage of the average values obtained from analyses of the prepared mixture in the gas cylinder. In Test 2 the percentage is based on the average of all of the probe analyses.

\section{Test 1}

The purpose of this test was to establish the feasible operating range of the variables and to identify operating variables which affect the reliability of the probes. Prepared mixture 1 was used in this test. Figure 5.2 shows the deviation in the computed ideal gas heating values as a function of probe and run number. The deviation is the difference between the heating value obtained via the probe sample and the heating value given in table 5.1 for mixture 1 , all divided by the tabular value. Replicate points for a given run number represent the results of replicate gas analyses. We found that the occasional large scatter between replicate analyses was 


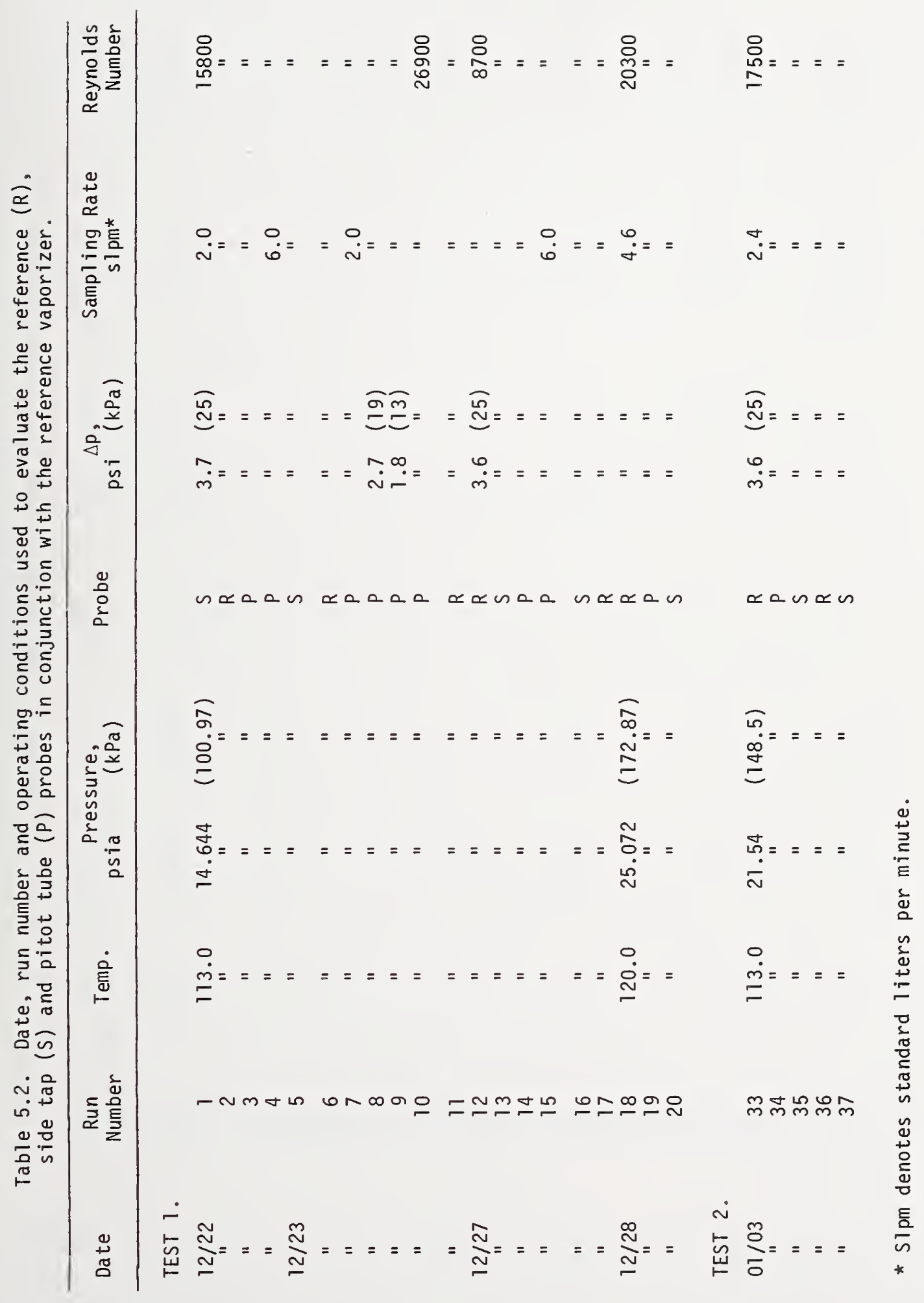




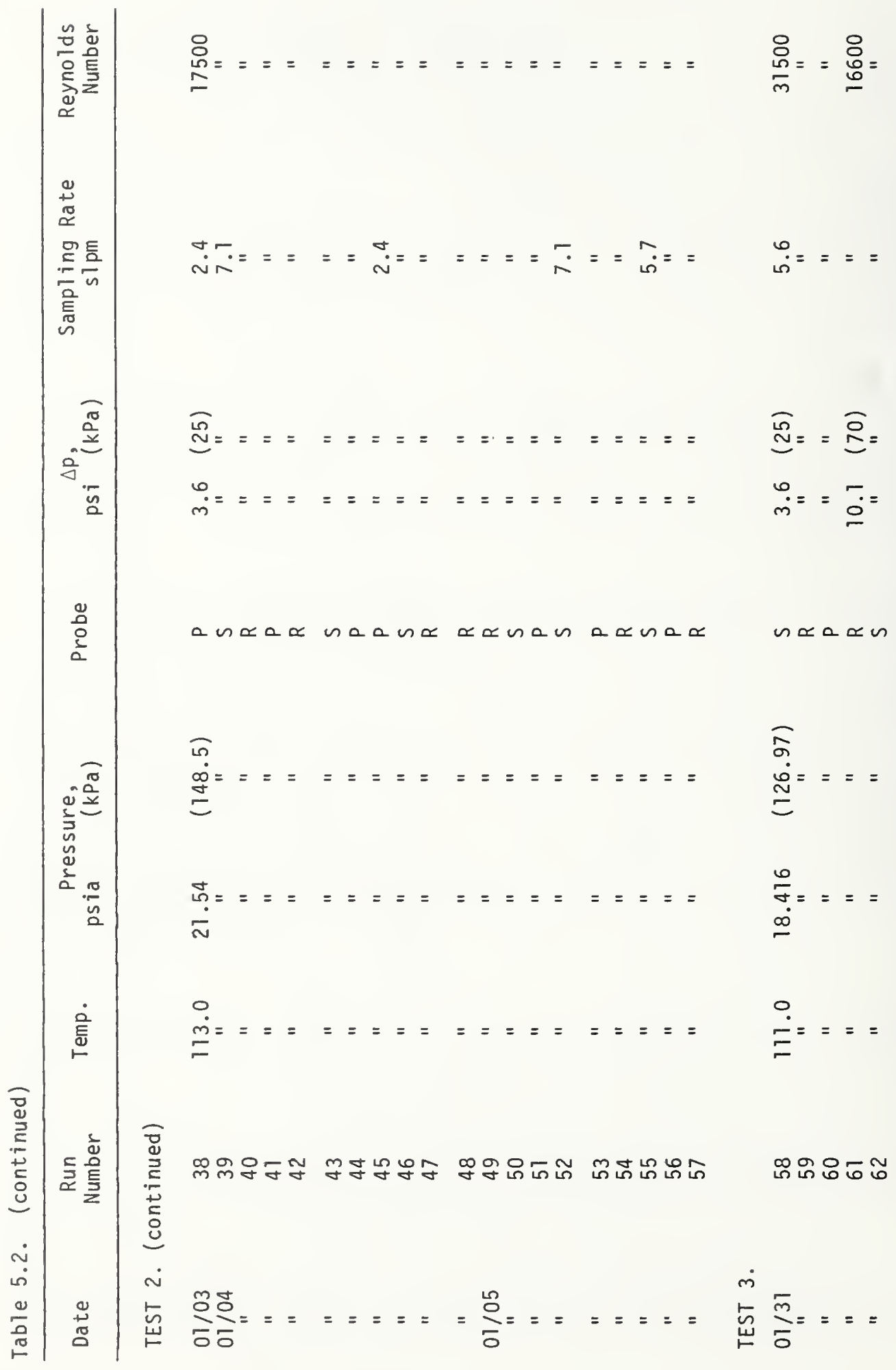




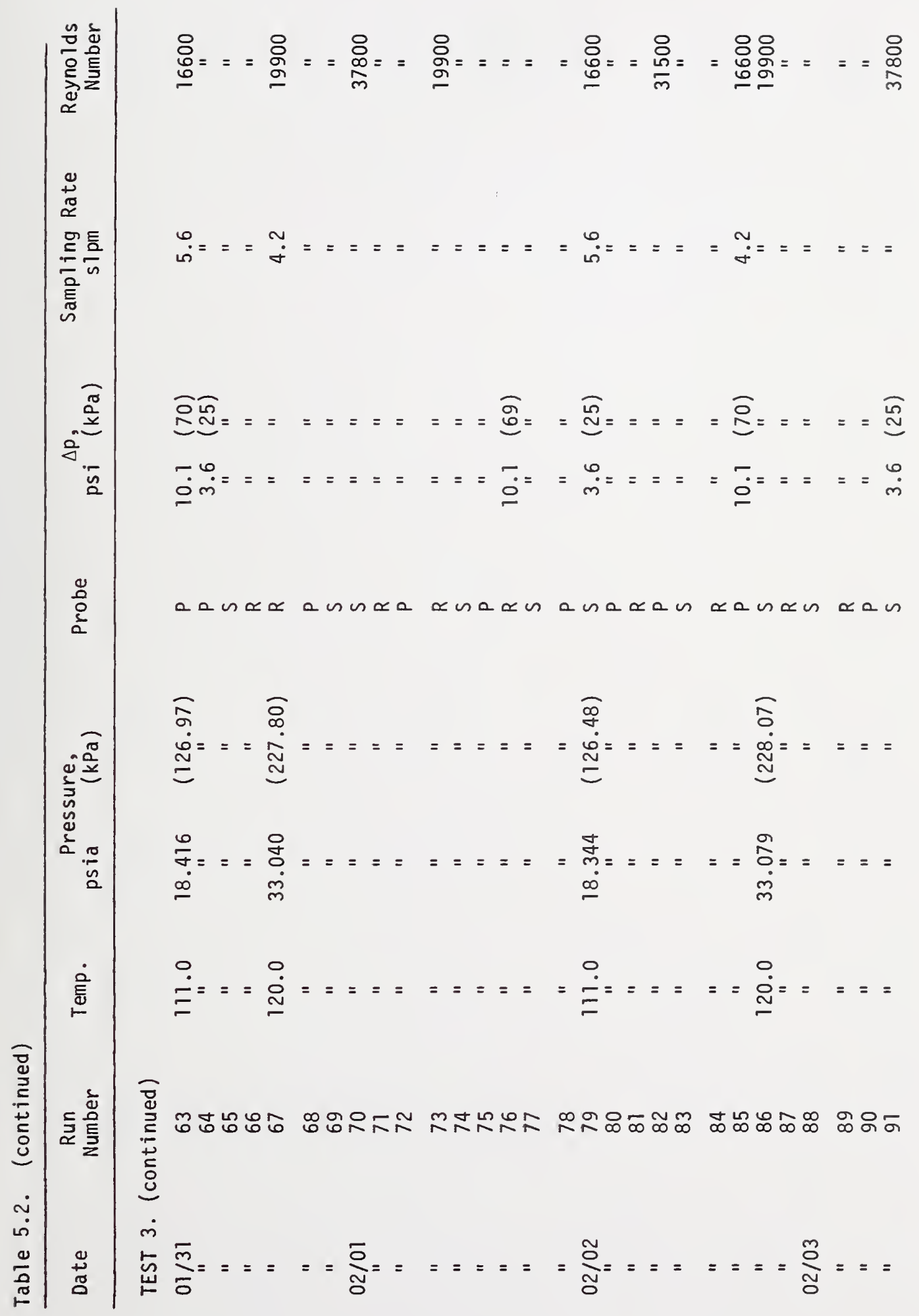




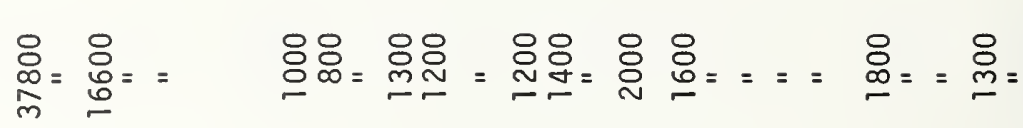

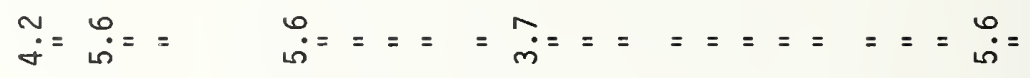

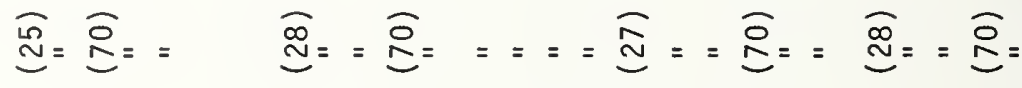

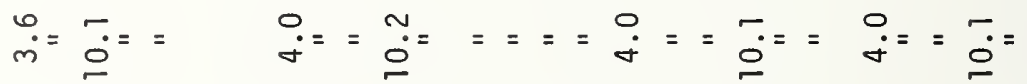

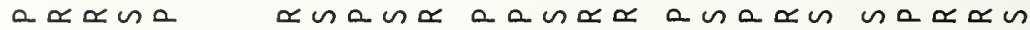

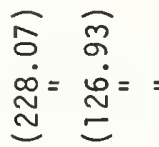

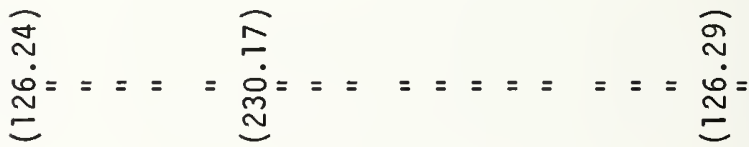

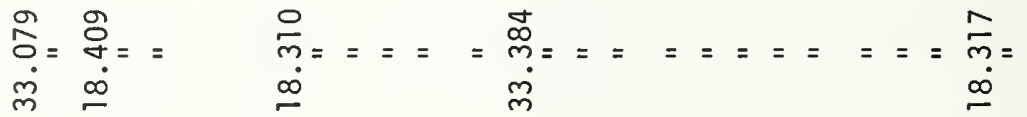

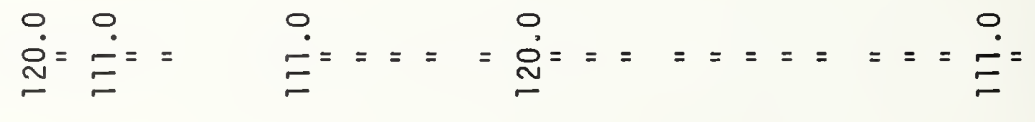

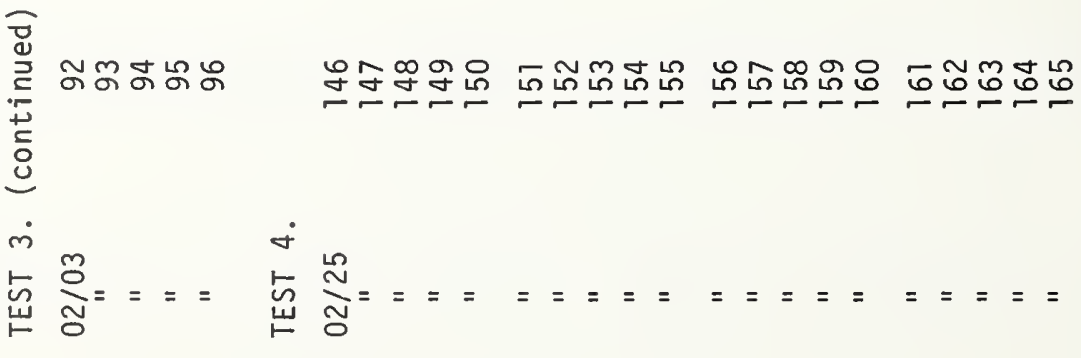




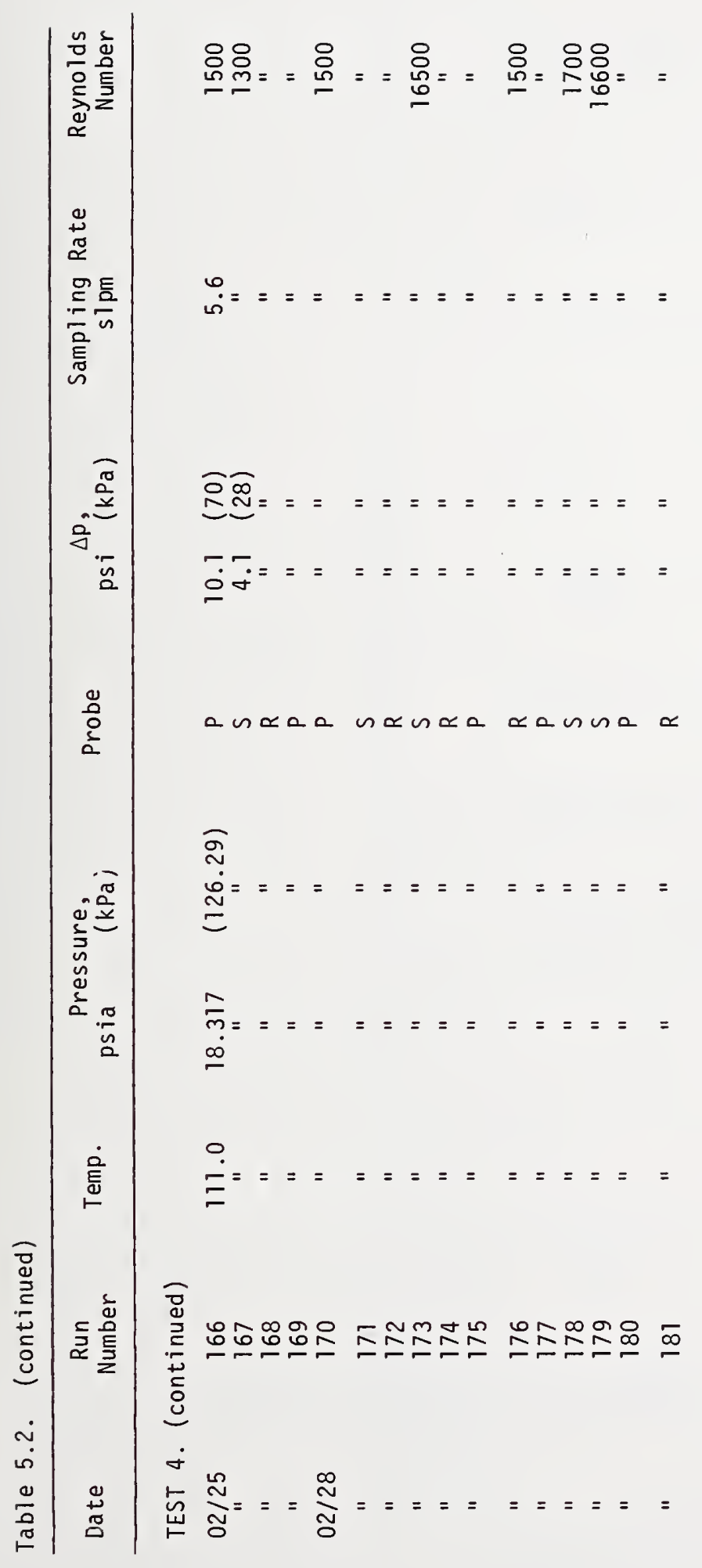




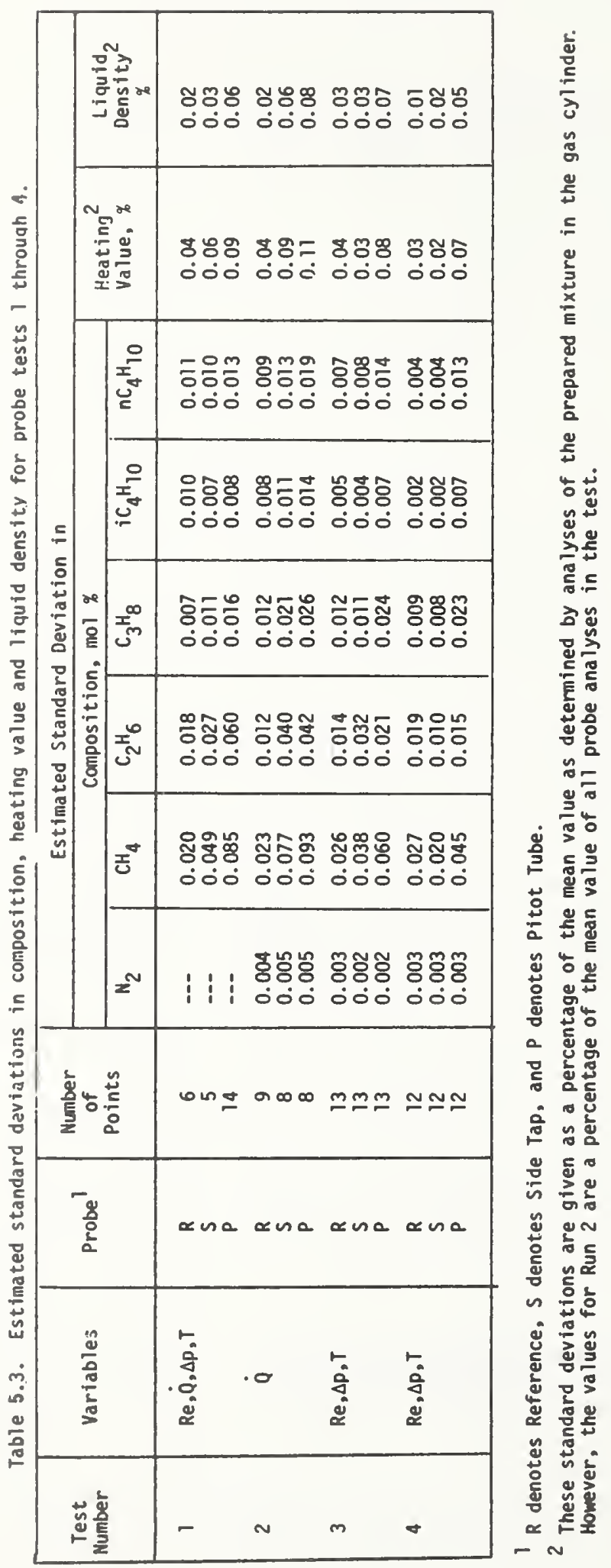




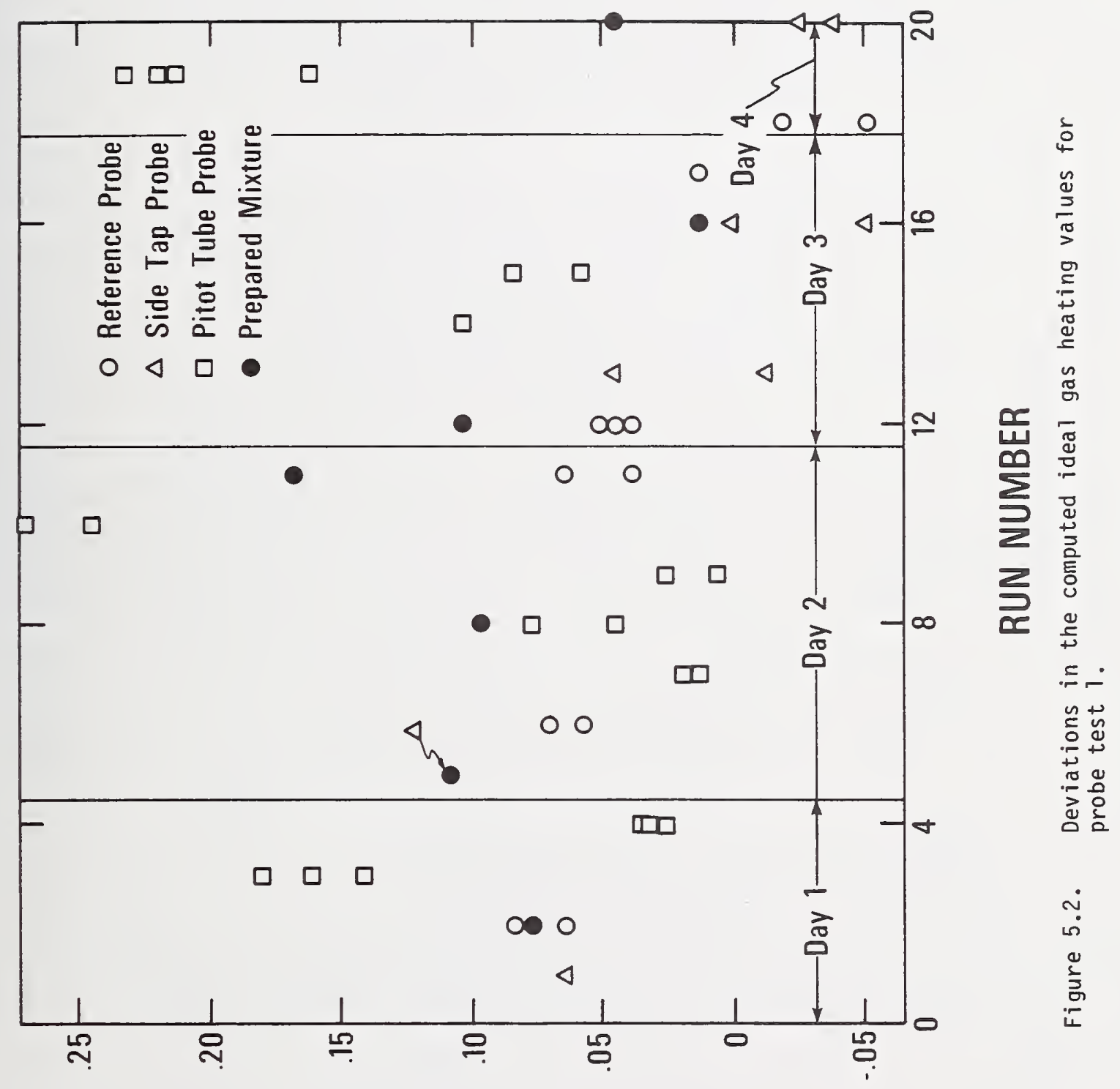

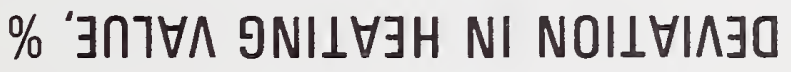


caused by a GC integrator malfunction (see section 4.2). Although this scatter confuses the results somewhat, figure 5.2 (and table 5.2) shows that the pitot tube tends to be more erratic. The results showed that it is possible to obtain representative samples at a $\Delta \mathrm{p}$ as low as 1.8 psi 10.012 $\mathrm{MPa})$; the pressure drop in the sampling system prevented us from trying a lower $\Delta \mathrm{p}$.

A statistical analysis of the results from the reference probe and the prepared mixture indicate that the reference probe collected a representative sample. The figure indicates that most of the computed heating values were slightly higher than the prepared mixture; this bias apparently was caused by not making three independent GC calibrations each day. Figure 5.2 shows that all three probes sampled the same liquid.

\section{Test 2}

The first test was not a statistically designed experiment; therefore, the effect of each operating variable could not be quantitatively determined. Nitrogen was added to the mixture to bring the nitrogen content to roughly $1.34 \mathrm{~mol}$ \% for Test 2. (Two intermediate concentrations of 0.55 and $4.34 \mathrm{~mol}$ \% nitrogen content were made before reaching the $1.34 \mathrm{~mol} \%$ level; the data taken with these mixtures are given in Appendix 7.4 but not discussed here.) In this test the sampling rate was varied between 2.4 and 7.2 slpm (standard liters per minute, at $70^{\circ} \mathrm{F}\left(21^{\circ} \mathrm{C}\right.$ ) and $14.7 \mathrm{psia}(0.101 \mathrm{MPa})$ ). Figures 5.3 and 5.4 show the scatter, on a percentage basis about the mean, in the computed heating value and density as a function of run number and probe. There seems to be a day-to-day effect in the scatter with the first and last days being the worst and best, respectively. The only plausible explanation for this behavior is that the contents may not have been well mixed on the first day (this same trend seems apparent in figure 5.2).

In these tests the prepared mixture was condensed into the LNG vessel from the top. This unfortunately minimized the mixing during the filling process. The same procedure was followed when adding nitrogen. In each case the sampling tests began immediately after filling and the only mixing occurred during the recirculation of the LNG.

Table 5.4 lists the estimated standard deviations of the composition, heating value and liquid density as a function of probe and sampling rate. The test results show that the sampling rate has a strong effect on sampling precision.

Test 3

In this test we varied the temperature, flow rate and pressure difference but kept the sampling rate constant at 4.2 or 5.6 slpm. Prepared 


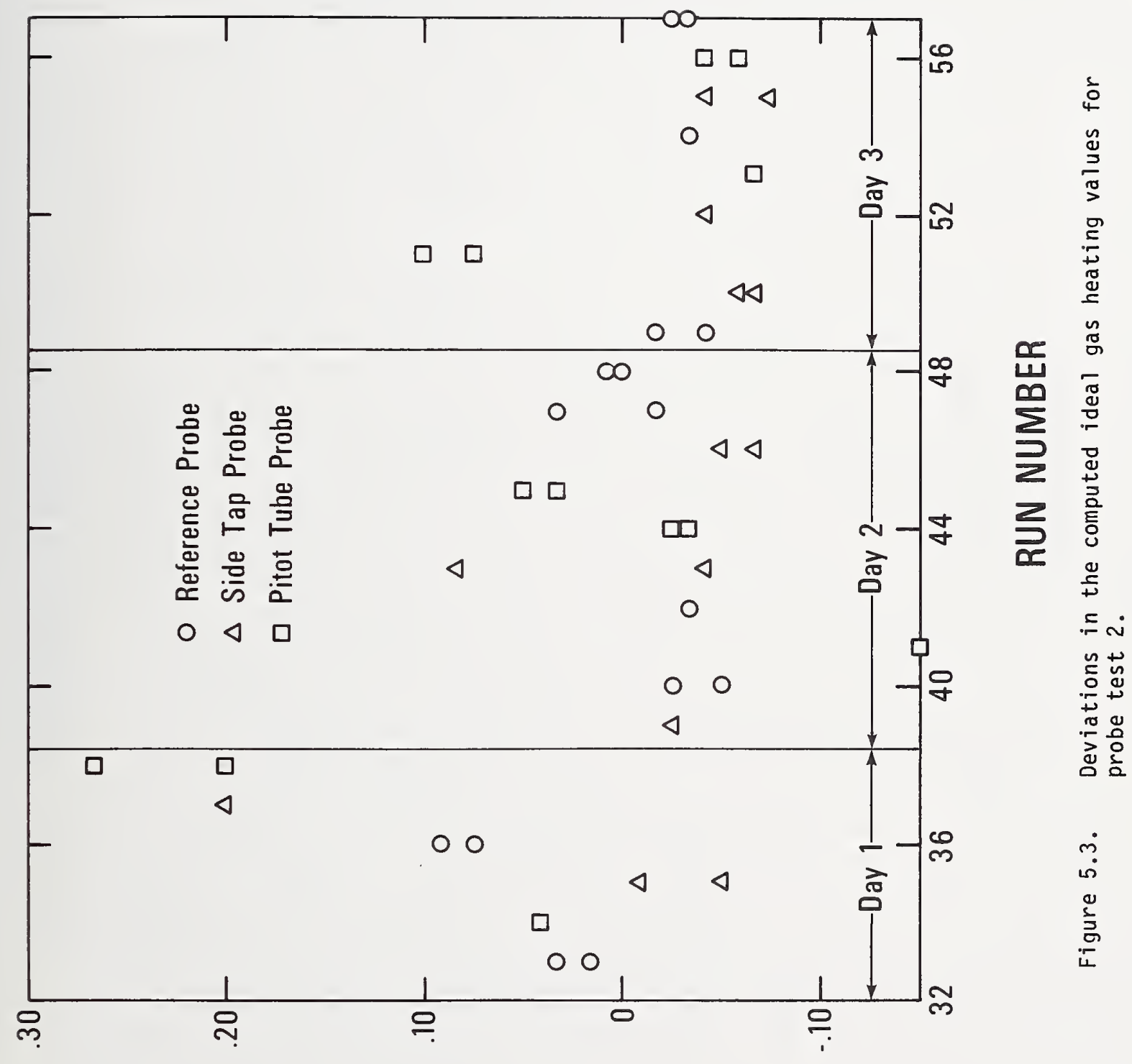

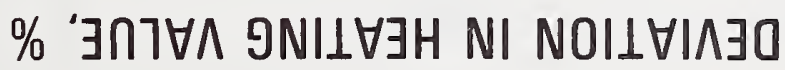




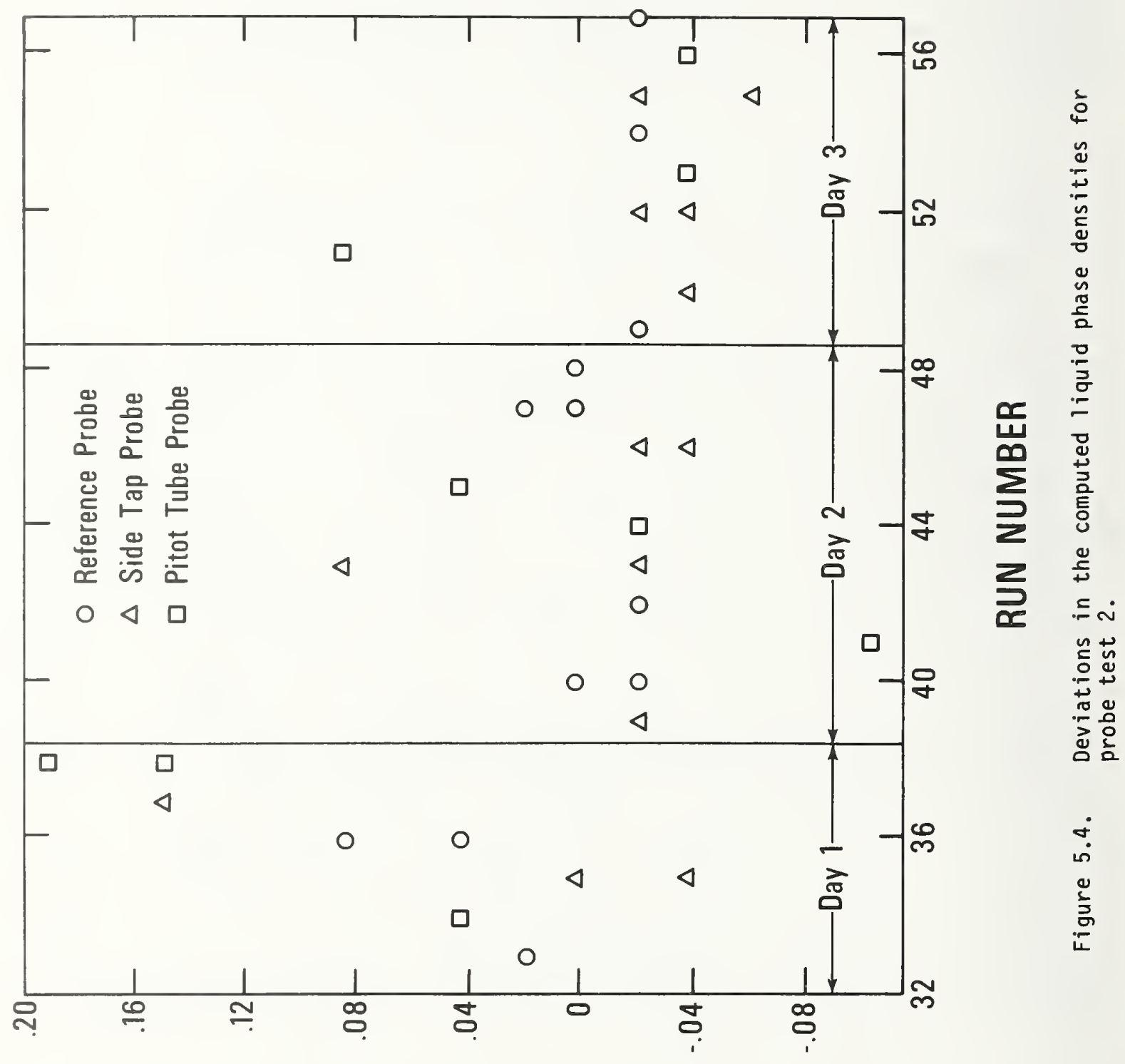

\% 'IISNJO NI NOII $\forall I \Lambda \exists O$ 


\begin{tabular}{|c|c|c|c|c|}
\hline \multirow{8}{*}{ 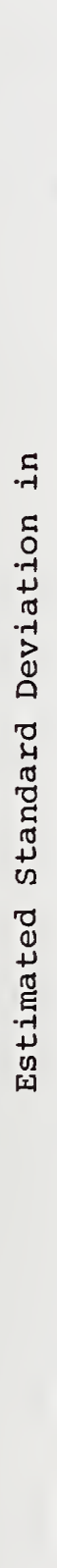 } & \multirow{2}{*}{\multicolumn{2}{|c|}{ 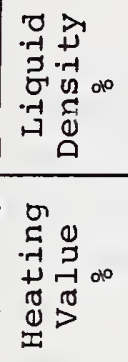 }} & $\begin{array}{l}m \infty \\
00 \\
0 \\
0\end{array}$ & $\begin{array}{l}\circ N=1 \\
\circ 00 \\
00\end{array}$ \\
\hline & & & 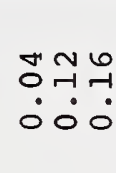 & 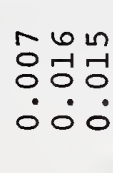 \\
\hline & \multirow{6}{*}{$\begin{array}{c}010 \\
-1 \\
0 \\
0 \\
E \\
\vdots \\
-0 \\
-1 \\
-1 \\
0 \\
0 \\
0 \\
0 \\
0 \\
0\end{array}$} & 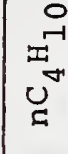 & $\begin{array}{l}0 \text { 에 } \\
\text {-1 } \\
0 \\
0 \\
0 \\
0\end{array}$ & $\begin{array}{l}\text { m소 } \\
000 \\
0 \\
0 \\
0\end{array}$ \\
\hline & & $\underbrace{0}_{-\rightarrow-1}$ & 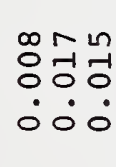 & 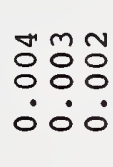 \\
\hline & & $u^{\infty}$ & 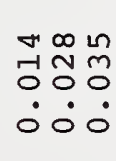 & $\begin{array}{l}10 \% \\
\circ \circ 0 \\
\circ \\
\circ \\
0\end{array}$ \\
\hline & & $v^{0}$ & 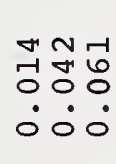 & 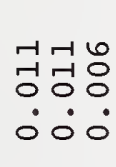 \\
\hline & & 焉 & 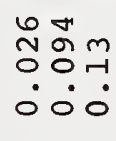 & 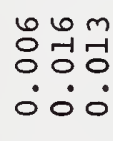 \\
\hline & & $z^{N}$ & $\begin{array}{l}m-10 \\
\text { ᄋ̊ㅇㅇ } \\
\circ \circ 0 \\
\circ 0\end{array}$ & 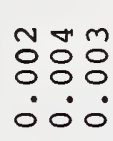 \\
\hline \multicolumn{3}{|c|}{ 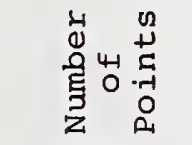 } & しூ & $\nabla \nabla \nabla$ \\
\hline \multicolumn{3}{|c|}{$\begin{array}{l}0 \\
0 \\
0 \\
0 \\
0.1 \\
.1\end{array}$} & $\alpha \cos \theta$ & 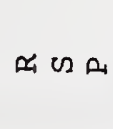 \\
\hline \multicolumn{3}{|c|}{ 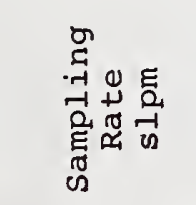 } & $\dot{\sim}$ & $\stackrel{r}{r}$ \\
\hline
\end{tabular}


mixture 4 was used in this test. Recirculation pump characteristics permitted operation at both low and high flow rates (Reynolds numbers of 17,000 to 31,500$)$ at a low $\Delta \mathrm{p}(3.6 \mathrm{psi}(25 \mathrm{kPa}))$, but only the low flow rate at the high $\Delta \mathrm{p}(10.1 \mathrm{psi}(70 \mathrm{kPa}))$. Shortly after starting this test the turbine meter stopped working. However, we had already noted the pump speed required for the desired flow rates at each $\Delta \mathrm{p}$ when operating at $111 \mathrm{~K}$ and used these to set the flow rate. We assumed that the same $\Delta \mathrm{p}$ and pump speed were required to obtain the desired flow rates at $120 \mathrm{~K}$. This was verified later when the turbine meter began working again.

Figure 5.5 shows the deviation in the ideal gas heating value for this test. Neither the figure nor a statistical analysis of the data (see table 5.3) show an effect due to $R e, \Delta p$ or $T$. Again, the pitot tube had the most scatter. The nitrogen content in the liquid was 0.024 mol\% lower than in the prepared mixture 2; calculation showed that this could have been caused by nitrogen going into the vapor phase during condensation into the apparatus.

Test 4

The purpose of this short test was to ascertain the effect of laminar flow on sampling precision. The difference in operating variables between this test and test 3 was that the Reynold's number was 1500 or 17,000 instead of 17,000 or 31,500 . In this test the low flow rate was maintained the first day while $\Delta \mathrm{p}$ and temperature were varied; the second day the flow rate and $\Delta \mathrm{p}$ were varied while the temperature was held constant at $111 \mathrm{~K}$. Figure 5.6 shows the deviation in ideal gas heating value. During the first part of the second day the power supply for the pump frequently tripped the circuit breaker. Each shutdown caused the vaporizer to warm up. We believe that the increased scatter during the first part of day 2 was caused by the reference vaporizer not being at steady state conditions when the gas sample was trapped in the accumulator. Once the power supply problem was fixed (prior to run number 177) the scatter became comparable to that of the previous day.

The results indicate that the probes work equally well in laminar and turbulent flow. The statistical analysis shows that the nitrogen content decreased by 0.006 mol\% when going from 111 to $120 \mathrm{~K}$. This effect had not been detected in any other test, nor for any other component. However, by the time of this test roughly 100 samples had been withdrawn from the apparatus, thus increasing the vapor space in the LNG vessel. Calculations showed that this apparent temperature effect could have been caused by the increased amount of nitrogen in the vapor phase at $120 \mathrm{~K}$.

5.1.3.2. Vaporizer evaluation

The probe tests showed that the reference probe to be the most reliable of the three probes tested. Therefore, the reference probe was used in the evaluation of vaporizer $A$ and the cook sampler. Since the cook sampler is 


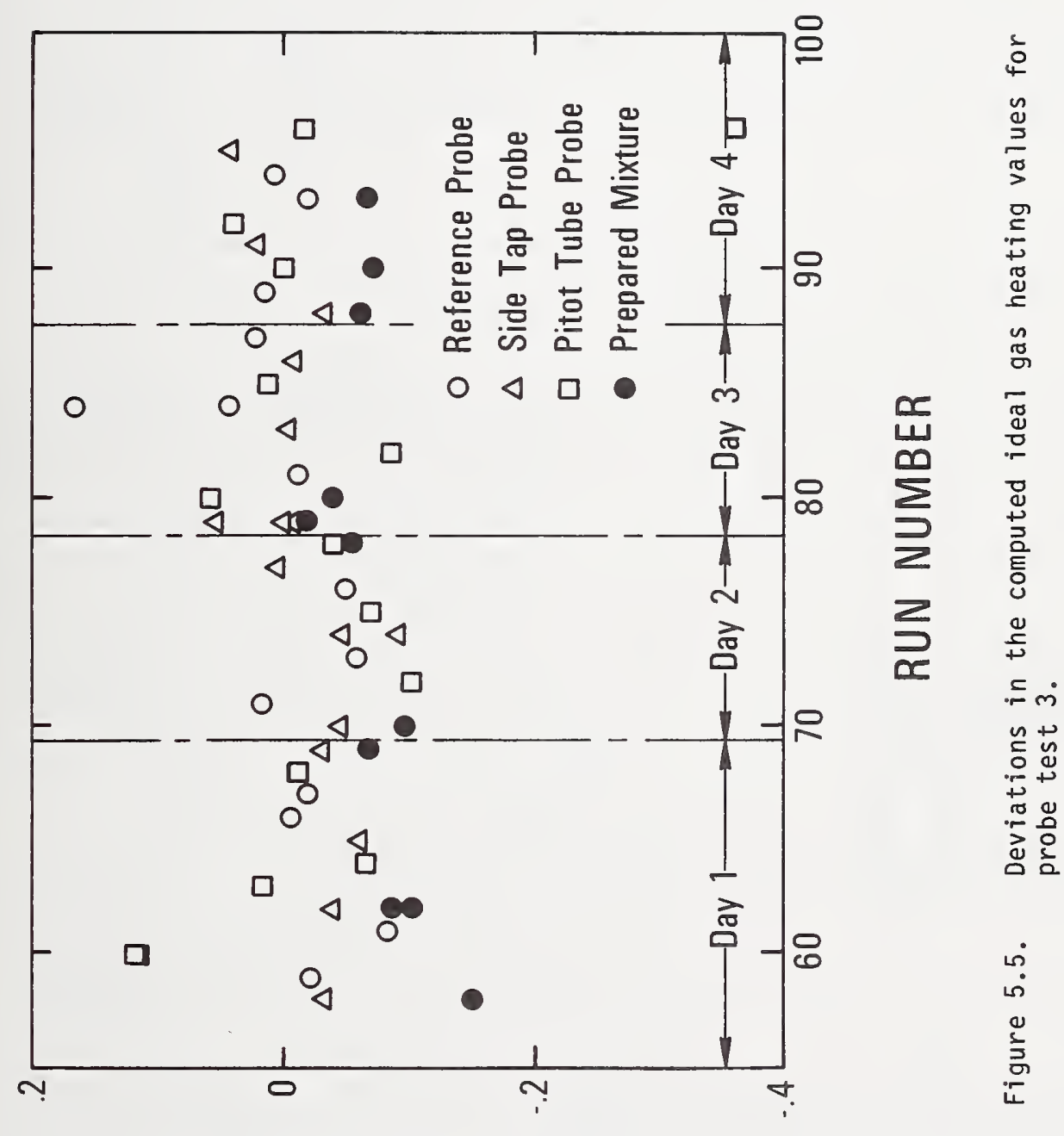

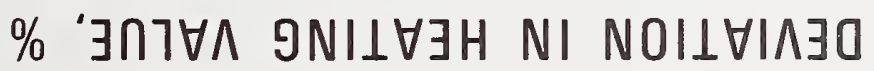




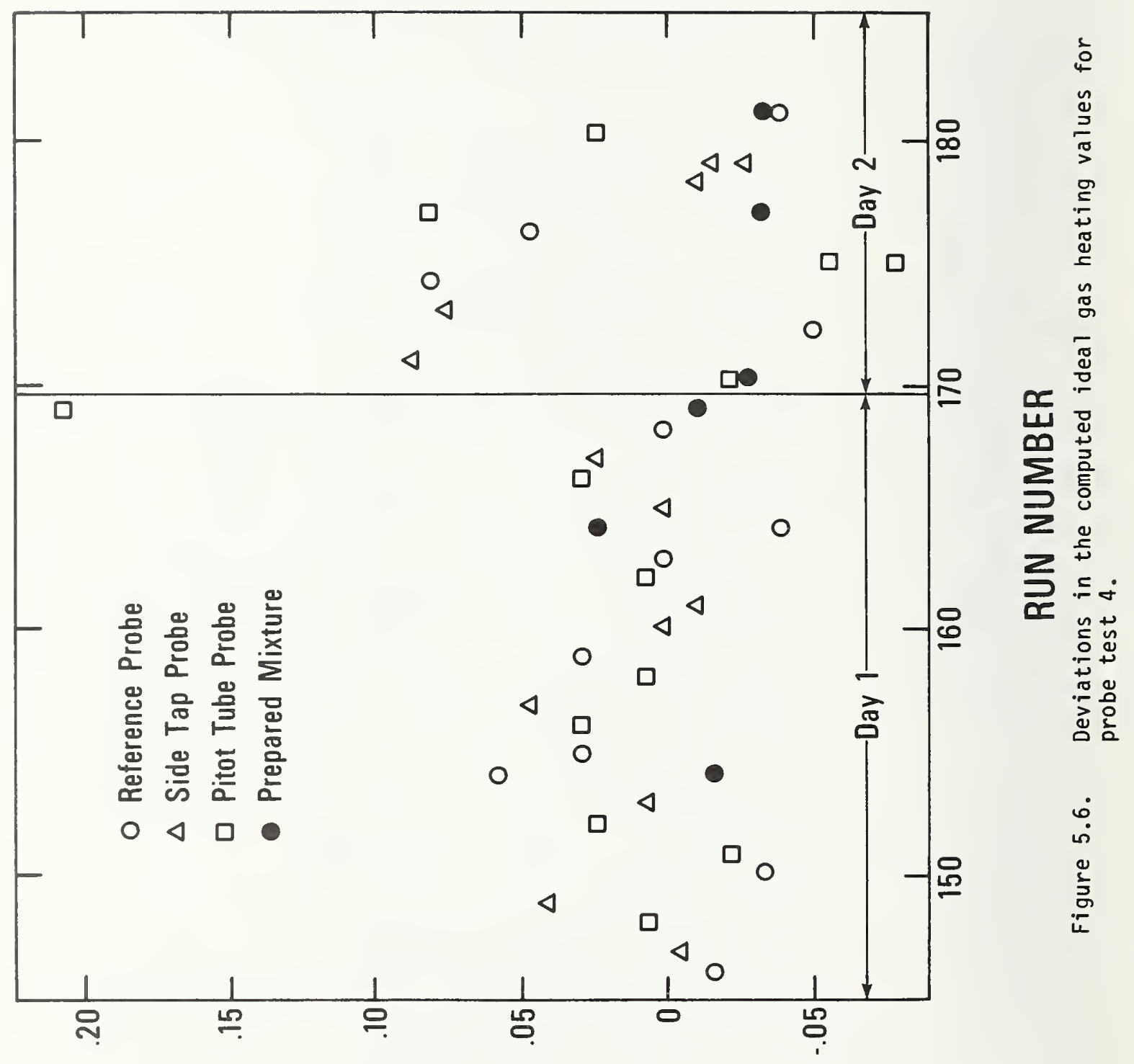

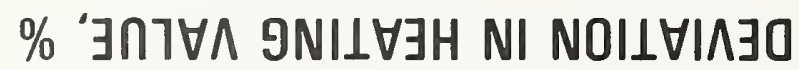


is designed for batch sampling, it is not a continuous vaporizer like the reference vaporizer and vaporizer A. Preliminary testing of the Cook sampler showed that it would not work well on the laboratory apparatus. Cook [22] indicated that it is designed for use with high sampling rates so that the total sampling time would be less than 30 seconds. In our tests the sampling rate was so low that it took at least 30 minutes to cool the sampler down. By this time the sampler valves were very cold and leaked when closed. Because of this problem and because the primary interest was in continuous sampling systems the cook sampler was not tested further on the laboratory apparatus. However, vaporizer A was found to work at low sampling rates; it was evaluated in the same manner as the probes. Prepared mixture 4 was used in both tests. Table 5.5 lists the values of the operating variable and 5.6 lists the estimated standard deviation in composition, ideal gas heating value and liquid density.

\section{Test 1}

The purpose of this test was to evaluate vaporizer $A$ at two sampling rates (2.0 and $5.6 \mathrm{slpm})$, temperatures ( 111 and $120 \mathrm{~K})$, pressure differences (3.6 to $10.1 \mathrm{psi}(25$ to $70 \mathrm{kPa})$ ) and flow rates ( $\operatorname{Re}$ of 18,000 to 35,000 ); these conditions are comparable to those used for the probe evaluations. Figure 5.7 shows the deviation in heating values for this test. The estimated standard deviation in the heating value for this vaporizer was about 20 times greater than that observed for the reference vaporizer during the probe tests. However, the precision of the reference system was poorer in this test than in any other test. This increased scatter was due to either incomplete accumulator purging and/or to taking a sample too quickly after starting the reference vaporizer. Three points on the third day showed that the reference system precision was a factor of three worse than usual.

During these runs the accumulator residence time was 40 to 120 seconds; the samples were analyzed after 10 minutes of purging the accumulator. The fourth reference sample was taken after the accumulator was purged for 20 minutes this sample was representative of the prepared mixture.

Once it was obvious that vaporizer A was not performing well, we made several minor changes to try to reduce the scatter. Originally the sampling rate was set by using valve T15 (see figure 5.1); starting with run 137, the sample rate was set by adjusting the pressure regulator on the vaporizer. This did not improve the results. During most of this test the throttling valve (valve T6, figure 5.1) for the reference vaporizer was roughly $1 / 4$ open. We made two reference vaporizer runs (runs 108 and 109) with the valve wide open, thinking that the valve might be preventing backflashing (this was the purpose of the valve). With the valve wide open, the pressure drop in the lines between the probe and the two vaporizers was comparable. 


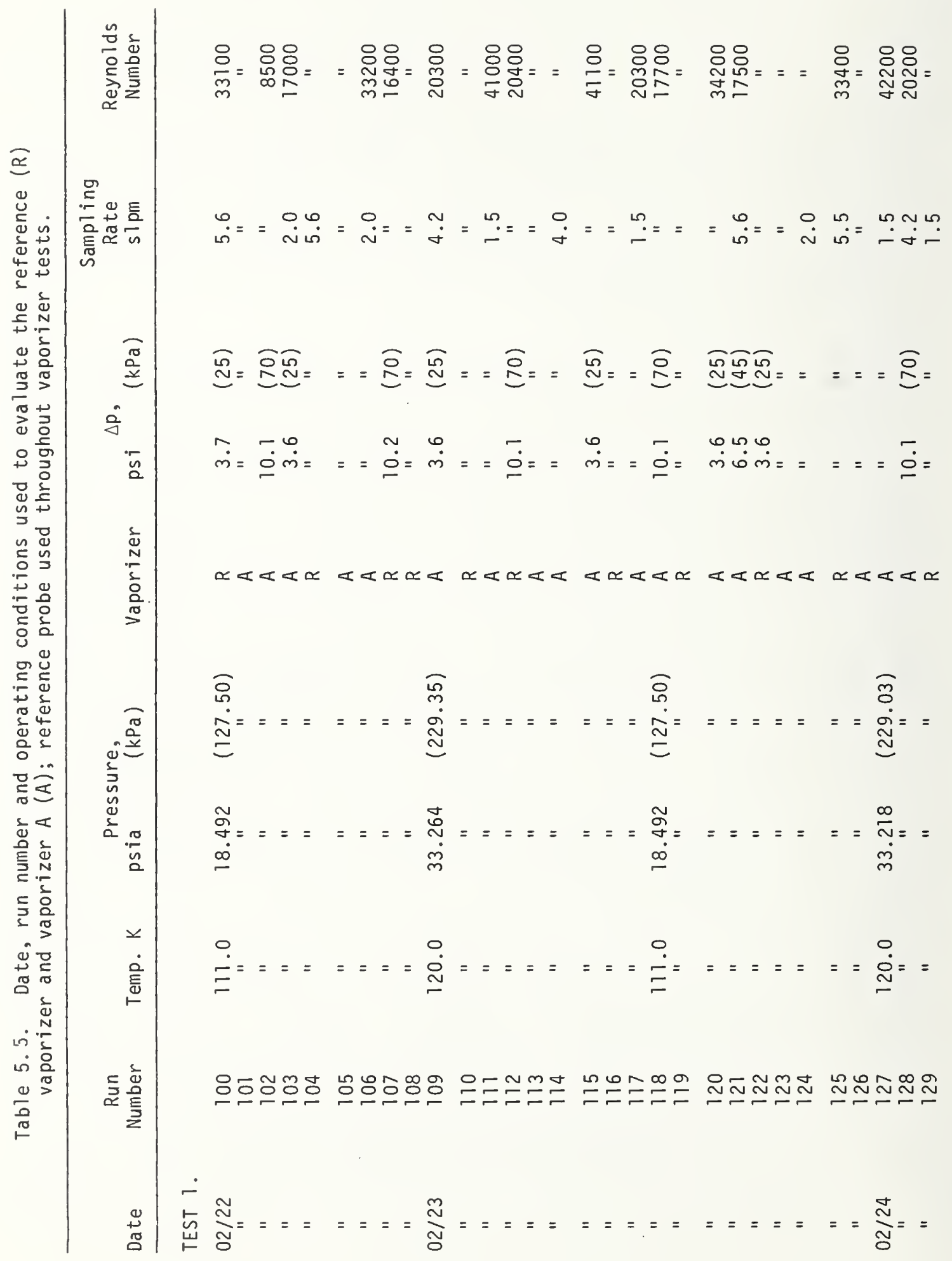




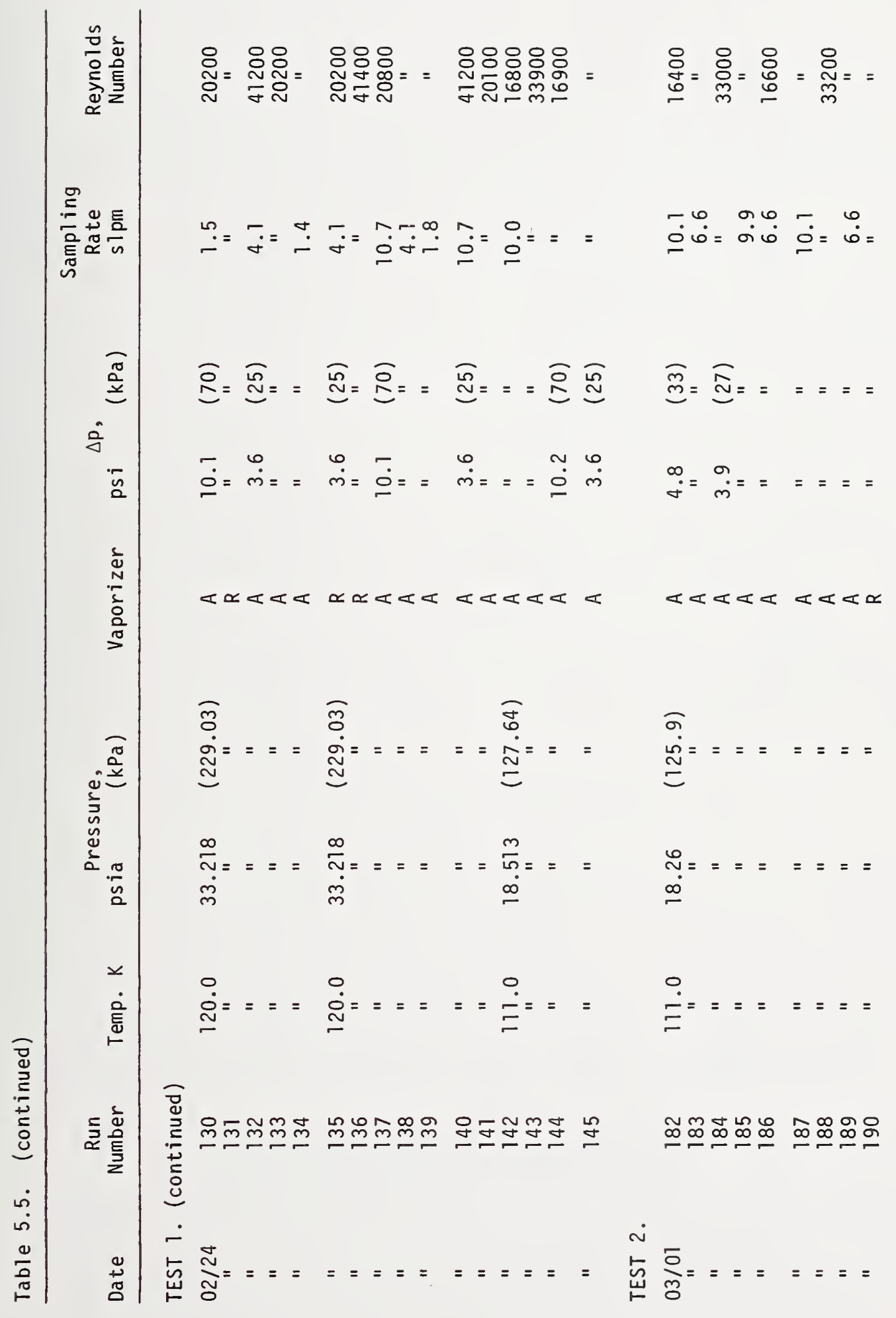




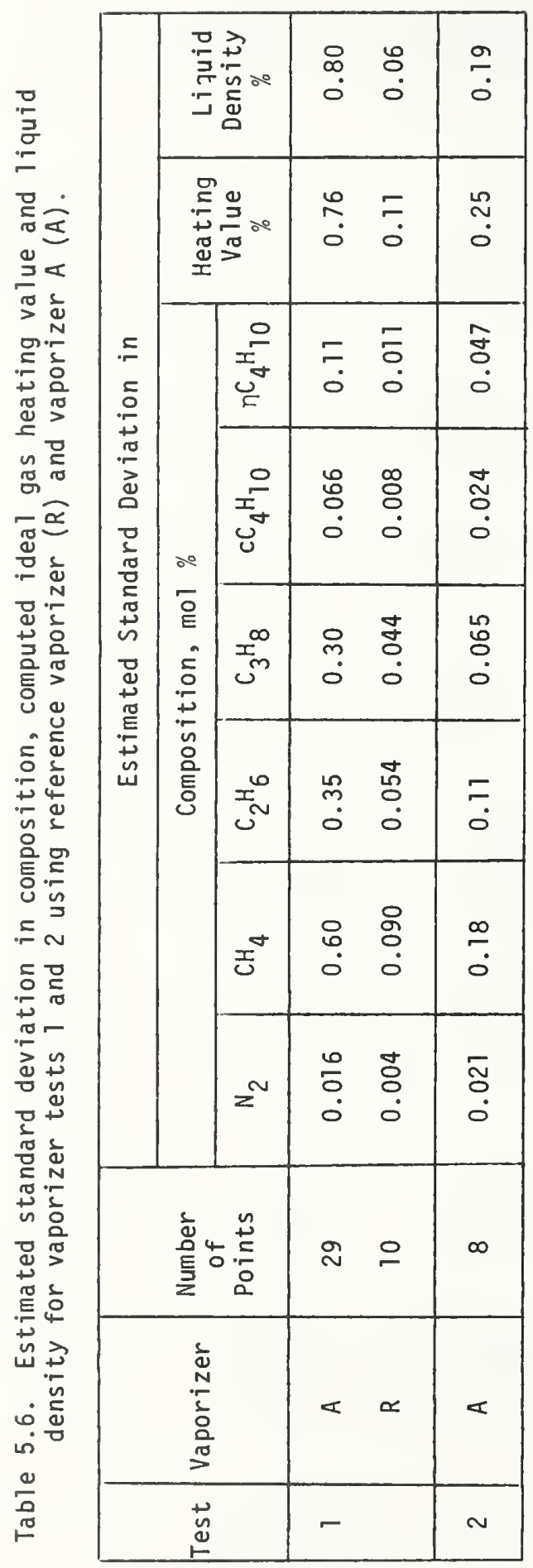




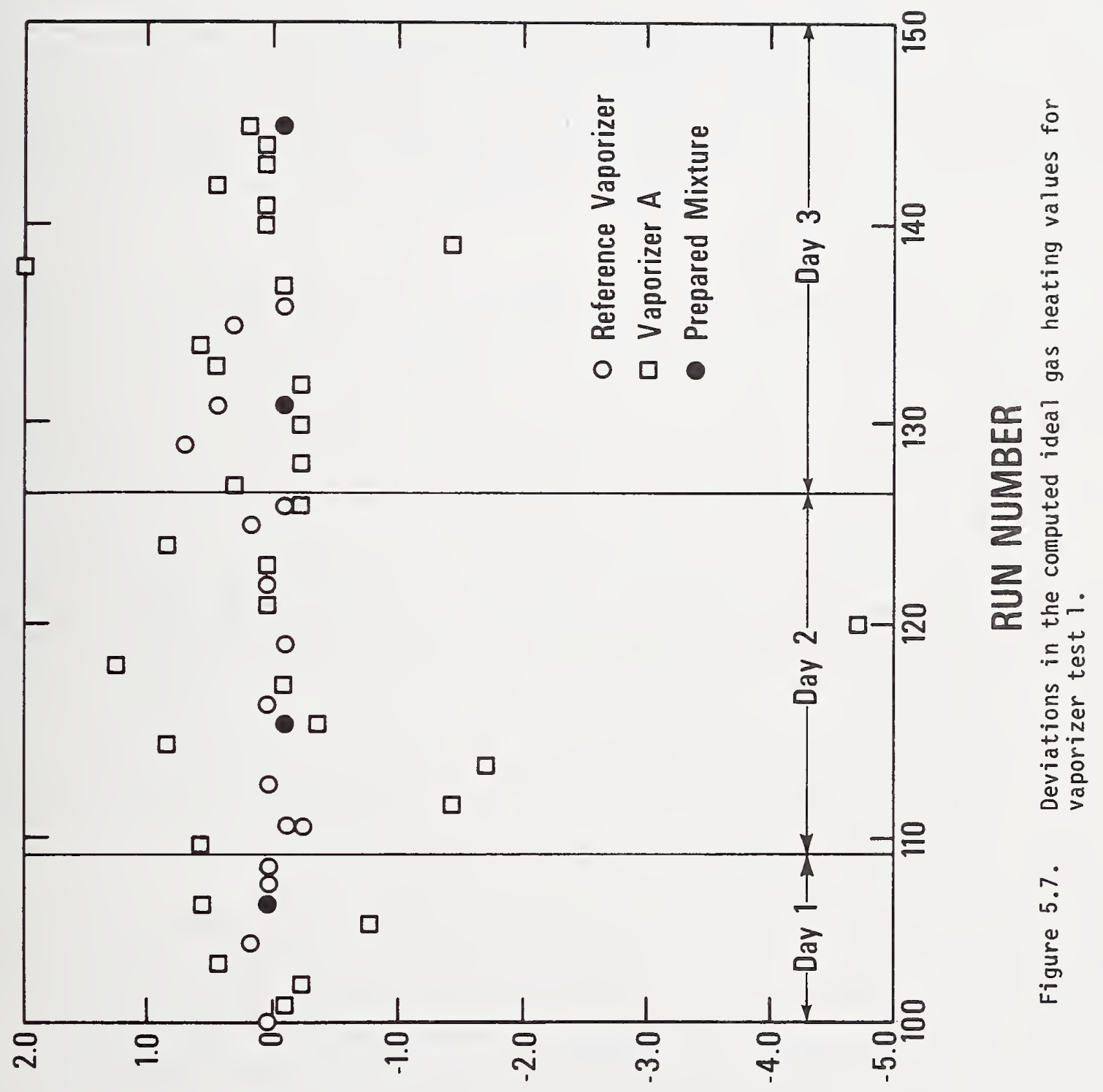

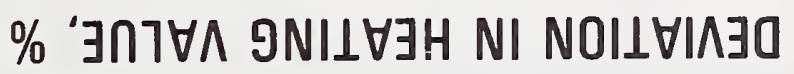


Having the valve wide open did not diminish the performance of the reference probe. Near the end of the test the sampling rate was increased to $16 \mathrm{slpm}$ (runs 137, 140 and 14l) or $10 \mathrm{slpm}$ (the last five runs). Since the higher sampling rate seemed to improve the vaporizer performance, another test was planned to determine the effect of high sampling rate.

\section{Test 2}

In this test we operated at $111 \mathrm{~K}$ and a $\Delta \mathrm{p}$ of roughly $3.8 \mathrm{psi}$ (27 $\mathrm{kPa}$ ) and varied the Reynold's number between 16,000 and 33,000 and sampling rate between 6.7 and $19 \mathrm{slpm}$. Figure 5.8 shows the deviation in the heating values for this test. The estimated standard deviation in heating value for vaporizer $A$ in this test was 0.25 percent as compared to 0.76 percent for the first test but still high compared to the typical 0.05 percent obtained for the reference vaporizer. We do not know why runs 188 and 189 are so different from the rest of the data.

\subsubsection{General tests}

To explain the poor results obtained in the first flow facility test (see section 5.2.1.1) it was necessary to conduct additional laboratory measurements. These tests considered whether sampling precision could be affected by:

a) eliminating the sample accumulator,

b) increasing or decreasing the vaporizer outlet temperature,

c) heat leak to the sample probe,

d) minimizing the pressure drop upstream of the vaporizer,

e) decreasing the sample residence time in the accumulator, and

f) having relatively high concentrations of heavy hydrocarbons $\left(C_{5}\right.$ 's through $\mathrm{C}_{8}$ 's) in the LNG.

The following operating variables were held constant during each test:

a) temperature and pressure,

b) sampling rate, $\dot{Q}$ (except when varying accumulator residence time),

c) Reynold's number (Re) in the test section, and

d) differential pressure, $\Delta \mathrm{p}$.

Table 5.7 gives the values of the operating variables for these tests. These variables values were in the range known to give good results in the previous laboratory tests. Prepared mixture 6 (see table 5.1) was used in tests 1 through 5; LNG, which was prepared by condensing natural gas containing $\mathrm{C}_{6}+$ was used in the last test. The reference vaporizer was used in all of the tests.

Test 1

The purpose of this test was to determine the sampling precision when drawing samples from the accumulator bypass line while having the accumulator bypassed. In all previous laboratory tests (but not the first flow facility test) samples had been taken only from the accumulator. Table 5.8 and 


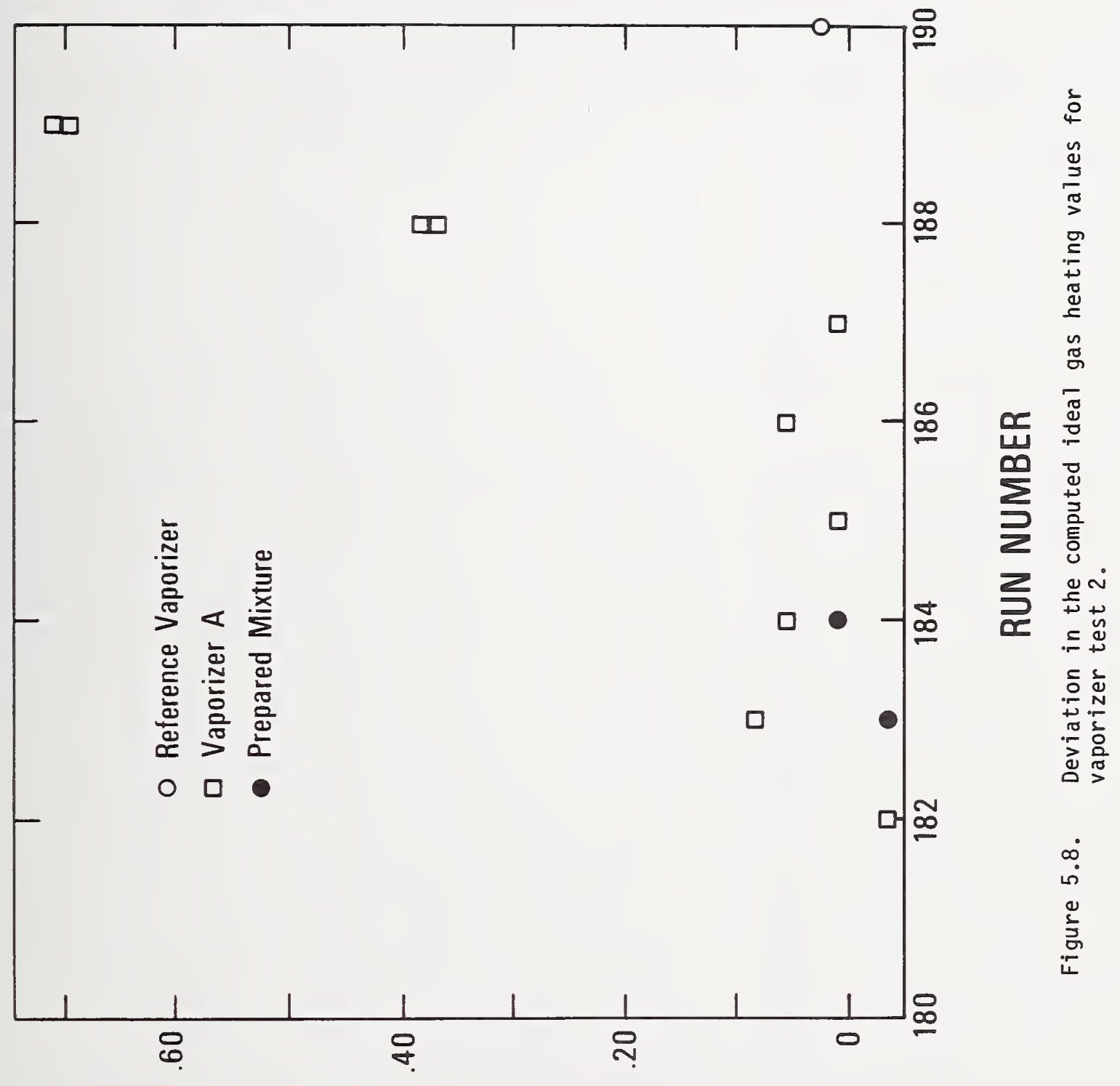

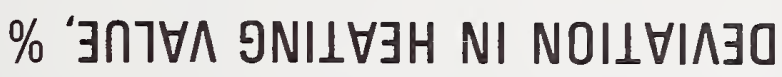


Table 5.7. Date, run number and operating conditions for general tests; reference vaporizer used throughout these tests; $R, S$, and $P$ refer to reference, side tap and pitot tube probes, respectively.

Test 1. Temperature $=123.0 \mathrm{~K}$, Pressure $=36.0$ psia $(248 \mathrm{kPa})$, Sampling Rate $=$ $5.0 \mathrm{~s} 1 \mathrm{pm}$, Reynolds Number $=22,800, \Delta P=5.0 \mathrm{psi}(35 \mathrm{kPa})$.

Date

Run Number

\begin{tabular}{|c|c|}
\hline $\begin{array}{l}4 / 14 \\
11 \\
11 \\
11\end{array}$ & $\begin{array}{l}191 \\
192 \\
193 \\
194 \\
195\end{array}$ \\
\hline $\begin{array}{l}\text { " } \\
" \\
"\end{array}$ & $\begin{array}{l}196 \\
197 \\
198 \\
199 \\
200\end{array}$ \\
\hline $\begin{array}{l}4 / 15 \\
11 \\
11 \\
" 1\end{array}$ & $\begin{array}{l}201 \\
202 \\
203 \\
204 \\
205\end{array}$ \\
\hline $\begin{array}{l}11 \\
" \\
" \\
4 / 18\end{array}$ & $\begin{array}{l}206 \\
207 \\
208 \\
209 \\
210\end{array}$ \\
\hline $\begin{array}{l}11 \\
4 / 19 \\
11\end{array}$ & $\begin{array}{l}211 \\
212 \\
213 \\
214 \\
215\end{array}$ \\
\hline $\begin{array}{l}11 \\
" \\
" 1 \\
"\end{array}$ & $\begin{array}{l}216 \\
217 \\
218 \\
219 \\
220\end{array}$ \\
\hline $\begin{array}{l}11 \\
11 \\
11\end{array}$ & $\begin{array}{l}221 \\
222 \\
223 \\
224 \\
225\end{array}$ \\
\hline $\begin{array}{l}\text { " } \\
4 / 20 \\
" 1 \\
"\end{array}$ & $\begin{array}{l}226 \\
227 \\
228 \\
229 \\
230\end{array}$ \\
\hline
\end{tabular}

Probe

Accumulator Bypassed

$\begin{array}{ll}R & \text { No } \\ " 1 & \text { Yes } \\ \text { " } & \text { Yes } \\ " & \text { No } \\ " & \text { Yes } \\ " & \text { Yes } \\ \text { P } & \text { No } \\ " & \text { No } \\ " & \text { Yes } \\ & \text { Yes }\end{array}$

"

$\mathrm{R}$

No

No

Yes

No

Yes

No

Yes

No

Yes

Yes

Yes

No

No

Yes

Yes

No

Yes

No

No

Yes

Yes

No

Yes

No

No

Yes

Yes

No

Yes

No 
Table 5.7. (Continued)

Test 1. (Continued

\begin{tabular}{|c|c|c|c|}
\hline Date & Run Number & Probe & Accumulator Bypassed \\
\hline $\begin{array}{c}4 / 20 \\
" 1 \\
" 1 \\
"\end{array}$ & $\begin{array}{l}231 \\
232 \\
233 \\
234 \\
235\end{array}$ & $\begin{array}{l}R \\
" 1 \\
P \\
" 1 \\
S\end{array}$ & $\begin{array}{l}\text { Yes } \\
\text { No } \\
\text { Yes } \\
\text { No } \\
\text { Yes }\end{array}$ \\
\hline $\begin{array}{l}" 1 \\
"\end{array}$ & $\begin{array}{l}236 \\
237 \\
238\end{array}$ & " & $\begin{array}{l}\text { No } \\
\text { Yes } \\
\text { Yes }\end{array}$ \\
\hline
\end{tabular}

Test 2. Temperature $=123.0 \mathrm{~K}$, Pressure $=36.0$ psia $(238 \mathrm{kPa})$, Sampling Rate $=$ $5.0 \mathrm{slpm}$, Reynolds Number $=22,800, \Delta P=5.0 \mathrm{spi}(36 \mathrm{kPa})$, Probe $=$ side tap.

\begin{tabular}{|c|c|c|c|}
\hline Date & Run Number & Vaporizer Power, Watts & Accumulator Bypassed \\
\hline $\begin{array}{l}4 / 21 \\
" 1 \\
" 1 \\
"\end{array}$ & $\begin{array}{l}239 \\
240 \\
241 \\
242 \\
243\end{array}$ & $\begin{array}{l}0.0 \\
1 " \\
11 \\
11 \\
1 "\end{array}$ & $\begin{array}{l}\text { Yes } \\
\text { No } \\
\text { Yes } \\
\text { No } \\
\text { Yes }\end{array}$ \\
\hline $\begin{array}{l}\text { " } \\
" 1 \\
" 1\end{array}$ & $\begin{array}{l}244 \\
245 \\
246 \\
247 \\
248\end{array}$ & $\begin{array}{c}\text { " } \\
99.6 \\
98.6 \\
97.5 \\
98.7\end{array}$ & $\begin{array}{l}\text { No } \\
\text { No } \\
\text { Yes } \\
\text { No } \\
\text { Yes }\end{array}$ \\
\hline $\begin{array}{l}1 " \\
4 / 22 \\
" 1 "\end{array}$ & $\begin{array}{l}249 \\
250 \\
251 \\
252 \\
253\end{array}$ & $\begin{array}{l}11 \\
" \\
0.0 \\
" 1\end{array}$ & $\begin{array}{l}\text { Yes } \\
\text { No } \\
\text { No } \\
\text { Yes } \\
\text { No }\end{array}$ \\
\hline $\begin{array}{l}\text { " } \\
\text { " } \\
\text { " }\end{array}$ & $\begin{array}{l}254 \\
255 \\
256 \\
257 \\
258\end{array}$ & $\begin{array}{c}" \\
" 1 \\
" \\
98.6 \\
97.5\end{array}$ & $\begin{array}{l}\text { Yes } \\
\text { No } \\
\text { Yes } \\
\text { No } \\
\text { Yes }\end{array}$ \\
\hline $\begin{array}{l}" \\
" \\
" \\
4 / 25\end{array}$ & $\begin{array}{l}259 \\
260 \\
261 \\
262 \\
263\end{array}$ & $\begin{array}{l}97.0 \\
" \\
96.5 \\
" 1 \\
63.2\end{array}$ & $\begin{array}{l}\text { No } \\
\text { Yes } \\
\text { No } \\
\text { Yes } \\
\text { No }\end{array}$ \\
\hline$"$ & 264 & 62.0 & No \\
\hline
\end{tabular}


Table 5.7. (Continued)

Test 3. Temperature $=123.0 \mathrm{~K}$, Pressure $=35.5$ psia $(245 \mathrm{kPa})$, Sampling Rate $=$ $5.0 \mathrm{~s} 1 \mathrm{pm}$, Reynolds Number $=22,900, \Delta \mathrm{p}=5.0 \mathrm{psi}(35 \mathrm{kPa})$.

\begin{tabular}{|c|c|c|c|}
\hline Date & Run Number & Probe & $\begin{array}{r}\text { Probe Heater } \\
\text { Watts }\end{array}$ \\
\hline $\begin{array}{l}4 / 25 \\
" 1 \\
" 1 \\
4 / 26\end{array}$ & $\begin{array}{l}265 \\
266 \\
267 \\
268 \\
269\end{array}$ & $\begin{array}{l}S \\
11 \\
11 \\
1 " \\
P\end{array}$ & $\begin{array}{l}0.1 \\
0.4 \\
1.7 \\
6.7 \\
0.0\end{array}$ \\
\hline $\begin{array}{l}" \\
" \\
" \\
"\end{array}$ & $\begin{array}{l}270 \\
271 \\
272 \\
273 \\
274\end{array}$ & $\begin{array}{l}\text { " } \\
" 1 \\
" 1\end{array}$ & $\begin{array}{l}0.1 \\
0.4 \\
1.0 \\
1.7 \\
3.8\end{array}$ \\
\hline $\begin{array}{l}\text { " } \\
4 / 29 \\
" 1 \\
" 1\end{array}$ & $\begin{array}{l}275 \\
299 \\
300 \\
301 \\
302\end{array}$ & $\begin{array}{l}\text { " } \\
" 1 \\
" 1\end{array}$ & $\begin{array}{l}6.7 \\
0.0 \\
1.7 \\
6.7 \\
1.7\end{array}$ \\
\hline $\begin{array}{l}\text { " } \\
" \\
" \\
"\end{array}$ & $\begin{array}{l}303 \\
304 \\
305 \\
306 \\
307\end{array}$ & $\begin{array}{l}\text { " } \\
" 1 \\
" 1 \\
"\end{array}$ & $\begin{array}{l}6.7 \\
0.0 \\
6.7 \\
1.7 \\
0.0\end{array}$ \\
\hline $\begin{array}{l}\text { " } \\
" 1\end{array}$ & $\begin{array}{l}308 \\
309 \\
310\end{array}$ & $\begin{array}{l}" \\
"\end{array}$ & $\begin{array}{l}1.7 \\
0.0 \\
6.7\end{array}$ \\
\hline
\end{tabular}

Test 4. Temperature $=123.0 \mathrm{~K}$, Pressure -35.3 psia $(243 \mathrm{kPa})$, Sampling Rate $=$ $5.0 \mathrm{~s} 1 \mathrm{pm}$, Reynolds Number $23,500, \Delta \mathrm{p}=5.0 \mathrm{psi}(35 \mathrm{kPa})$, Probe $=$ side tap.

\begin{tabular}{ccc} 
Date & Run Number & Needle Valve, Throttled \\
\hline $4 / 26$ & 276 & Yes \\
$" 1$ & 277 & Yes \\
$" 1$ & 278 & No \\
$"$ & 279 & Yes \\
$4 / 27$ & 280 & No \\
$" 1 "$ & 281 & Yes \\
$"$ & 282 & No \\
$" 1$ & 283 & Yes \\
$"$ & 284 & No \\
$"$ & 285 & Yes \\
$"$ & 286 & No \\
$"$ & 287 & Yes \\
$"$ & 288 & No \\
& 298 & Yes
\end{tabular}


Table 5.7. (Continued)

Test 4. (Continued)

\begin{tabular}{ccc} 
Date & Run Number & Needle Valve, Throttled \\
\hline $4 / 27$ & 291 & No \\
$" 1$ & 292 & Yes \\
$5 / 02$ & 311 & No \\
$" 1 "$ & 312 & No \\
$" 1$ & 313 & No \\
$" 1 "$ & 314 & No \\
$" 115$ & No \\
$" 1$ & 316 & No \\
$"$ & 317 & Yes \\
$"$ & 318 & Yes \\
$"$ & 319 & Yes \\
& 320 & Yes \\
& 321 & Yes
\end{tabular}

Test 5. Temperature $=112.0 \mathrm{~K}$, Pressure $=16.8 \mathrm{psi}(116 \mathrm{kPa}), \Delta \mathrm{p}=8 \mathrm{psi}$, Reynolds Number $=9,100(56 \mathrm{kPa})$, Probe $=$ side tap.

\begin{tabular}{cccc} 
Date & Run Number & $\begin{array}{c}\text { Sampling Rate } \\
\text { slpm }\end{array}$ & $\begin{array}{c}\text { Accumulator } \\
\text { Residence Time, s }\end{array}$ \\
\hline $4 / 28$ & 293 & 12.2 & 10.5 \\
$"$ & 294 & 8.6 & 15.0 \\
$"$ & 295 & 5.9 & 21.8 \\
$"$ & 296 & 12.2 & 10.5 \\
$"$ & 297 & 8.6 & 15.0 \\
$"$ & 298 & 12.2 & 10.5
\end{tabular}

Test 6. Sampling Rate $=5 \mathrm{slpm}, \Delta \mathrm{p}=5.0 \mathrm{psi}(35 \mathrm{kPa})$, Reynolds Number $=22,000$.

\begin{tabular}{|c|c|c|c|c|c|}
\hline Date & Run Number & Temperature & $\begin{array}{l}\text { Pres } \\
\text { psia }\end{array}$ & $\begin{array}{l}\text { ure } \\
\mathrm{kPa}\end{array}$ & Probe \\
\hline $5 / 11$ & 322 & 123.5 & 32.2 & 222 & $\mathrm{~S}_{\text {" }}$ \\
\hline$"$ & $\begin{array}{l}323 \\
324\end{array}$ & $"$ & $"$ & $"$ & $"$ \\
\hline$"$ & $\begin{array}{l}3<4 \\
325\end{array}$ & $"$ & $"$ & $"$ & $"$ \\
\hline$"$ & 326 & $"$ & $"$ & $"$ & $"$ \\
\hline$"$ & 327 & $"$ & $"$ & $"$ & $"$ \\
\hline $5 / 12$ & 328 & 121.5 & 32.1 & 221 & $"$ \\
\hline "11 & 329 & "1 & $"$ & " & $"$ \\
\hline$"$ & 330 & $"$ & " & $"$ & $"$ \\
\hline$"$ & 331 & $"$ & $"$ & $"$ & $"$ \\
\hline
\end{tabular}


Table 5.7. (Continued)

Test 6. (Continued)

\begin{tabular}{|c|c|c|c|c|c|}
\hline Date & Run Number & $\underset{\mathrm{K}}{\text { Temperature }}$ & $\begin{array}{l}\text { Pres } \\
\text { psia }\end{array}$ & $\begin{array}{l}\text { ure } \\
\mathrm{kPa}\end{array}$ & Probe \\
\hline $5 / 12$ & $\begin{array}{l}332 \\
333\end{array}$ & 121.5 & 32.1 & 221 & $\begin{array}{l}S \\
" 1\end{array}$ \\
\hline$"$ & 334 & $"$ & $"$ & $"$ & $"$ \\
\hline $5 / 16$ & $\begin{array}{l}335 \\
336\end{array}$ & 120.0 & 40.1 & 276 & " \\
\hline$"$ & 337 & $"$ & $"$ & $"$ & $P$ \\
\hline$"$ & 338 & $"$ & $"$ & $"$ & $"$ \\
\hline$"$ & 339 & $"$ & $"$ & $"$ & $"$ \\
\hline$"$ & 340 & $"$ & $"$ & $"$ & $"$ \\
\hline$"$ & 341 & $"$ & $"$ & $"$ & 1 \\
\hline
\end{tabular}




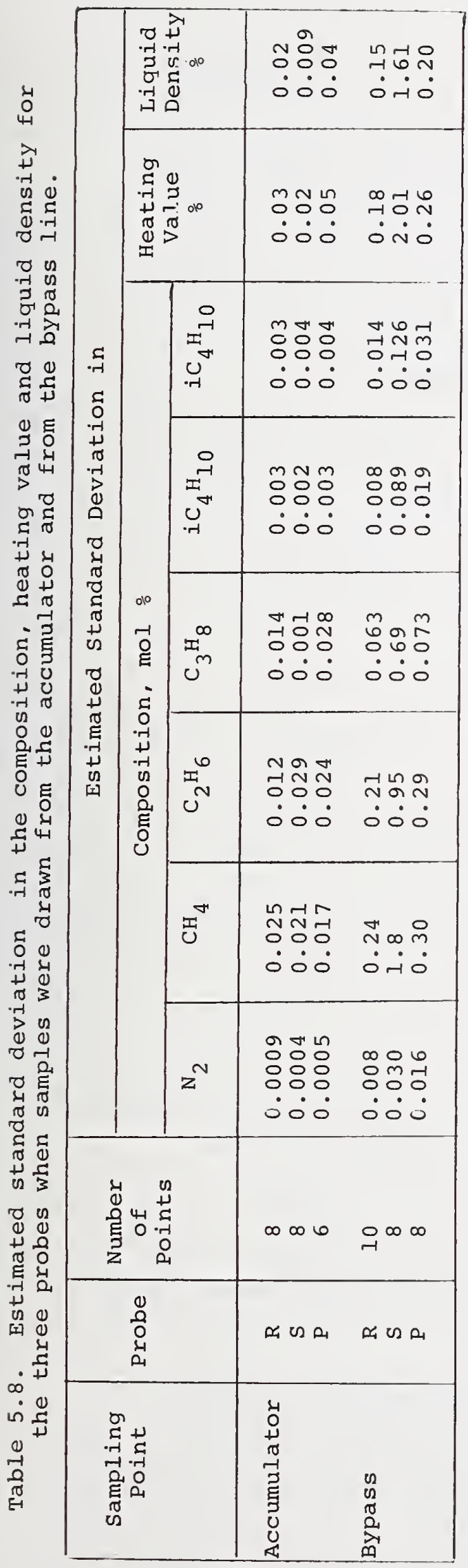


figure 5.9 show that the scatter increased markedly when the accumulator was not used. This indicates that the vaporization process generates inhomogeneities in the sample which can be eliminated by time averaging the sample in an accumulator. The accumulator was used in all remaining tests.

In addition to taking discrete samples we continuously fed a small gas sample stream ( $10 \mathrm{cc} / \mathrm{min}$ ) to an ultrasonic detector. It was hoped that by continuously monitoring overall composition fluctuations (there was no easy way to selectively monitor one component) a periodic behavior could be found. Samples from the bypass line, accumulator, prepared mixture cylinder and from a pure methane cylinder were analyzed continuously. Only the pure methane sample showed no composition fluctuations. The other samples showed random fluctuations with the bypass sample having the largest scatter. The fluctuations in the prepared mixture and accumulator samples were comparable in magnitude. This indicates that even gas mixtures withdrawn from cylinders will contain some composition variations. Unfortunately, it was not possible to quantify the fluctuations in terms of mol percent.

Test 2

The dew point temperature of the LNG mixtures in the first flow facility test was well below ambient temperature; however, it was thought that a possible problem could have been the use of a long vaporizer warmed only by cold water. To simulate this condition in the laboratory we varied the power to the vaporizer; this, in effect, changed the vaporizer length. Three different power levels, 0, 62 and 98 watts, were used. With no input power, the vaporizer plus approximately 5 feet $(1.5 \mathrm{~m})$ of the $1 / 4$ inch $0 . D$. $(6.4 \mathrm{~mm})$ copper tubing downstream of the vaporizer became coated with frost. At 62 watts the vaporizer outlet temperature was warm to the touch; this was the temperature that was used in all other laboratory tests. At 100 watts, the tubing just downstream of the vaporizer was too hot to touch for more than a second. At all three power levels the accumulator remained at ambient temperature. Only the side tap probe was used in this test and the values for the 62 watt case were taken from the previous test.

Table 5.9 shows that only the 0 power case affected the sampling precision. These results tend to indicate that it is better to vaporize the sample quickly. It was thought that the higher heat input might offset the effect of bypassing the accumulator. However, table 5.9 and figure 5.10 show that the increased heat input did not improve the sampling precision when the accumulator was bypassed.

Test 3

In the first flow facility test the lines from the probes to the vaporizers were uninsulated. Therefore, it was thought that heat leak could cause the observed sampling problems. To test the effect of heat leak we 


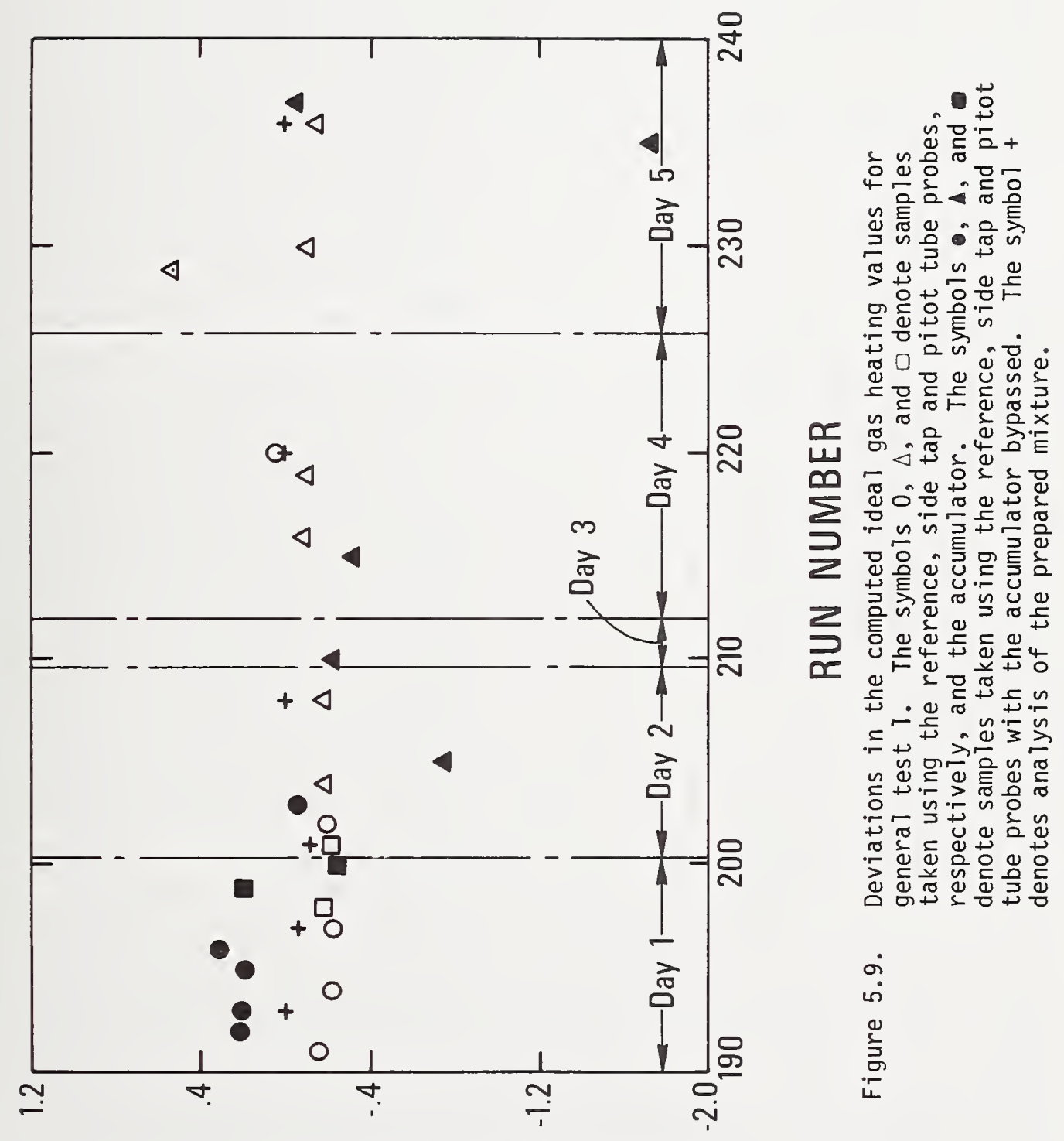

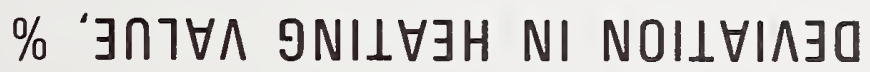




\begin{tabular}{|c|c|c|c|c|c|}
\hline \multicolumn{2}{|c|}{ 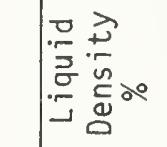 } & $\stackrel{0}{\stackrel{0}{0}}$ & $\begin{array}{l}\tilde{O} \\
\dot{0}\end{array}$ & $\begin{array}{l}\tilde{O} \\
\dot{0}\end{array}$ & $\begin{array}{l}\vec{J} \\
\stackrel{0}{0}\end{array}$ \\
\hline \multicolumn{2}{|c|}{ 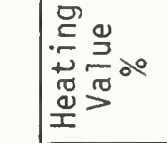 } & $\begin{array}{r}\overparen{Z} \\
0\end{array}$ & $\begin{array}{l}\tilde{0} \\
\dot{0}\end{array}$ & $\begin{array}{l}\tilde{O} \\
\dot{0}\end{array}$ & 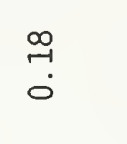 \\
\hline \multirow{6}{*}{ 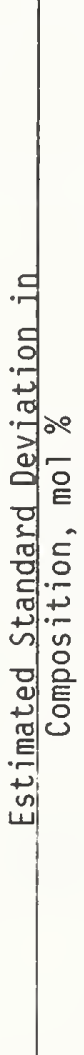 } & 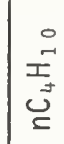 & $\begin{array}{l}0 \\
\stackrel{0}{0} \\
0 \\
0\end{array}$ & $\begin{array}{l}\dot{0} \\
0 \\
0\end{array}$ & $\begin{array}{l}\text { m} \\
\dot{0}\end{array}$ & $\begin{array}{l}\infty \\
0 \\
0\end{array}$ \\
\hline & 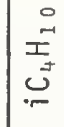 & $\begin{array}{l}0 \\
\text { o. } \\
\dot{0}\end{array}$ & $\begin{array}{l}\text { ठे } \\
\dot{0}\end{array}$ & $\begin{array}{l}m \\
\dot{8} \\
\dot{0}\end{array}$ & $\begin{array}{l}\mathscr{8} \\
\dot{0} \\
\dot{0}\end{array}$ \\
\hline & $\stackrel{I}{\infty}^{\infty}$ & $\begin{array}{l}\text { 怘 } \\
0 \\
0\end{array}$ & $\begin{array}{l}\text { 忽 } \\
0 \\
0\end{array}$ & $\begin{array}{l}\infty \\
0 \\
0\end{array}$ & $\begin{array}{l}\infty \\
\stackrel{0}{0} \\
\dot{0}\end{array}$ \\
\hline & $\frac{0}{\mathcal{N}^{N}}$ & 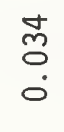 & $\begin{array}{l}m \\
\stackrel{m}{0} \\
0 \\
0\end{array}$ & $\begin{array}{l}\stackrel{2}{\tilde{O}} \\
\dot{0} \\
\dot{0}\end{array}$ & $\stackrel{\widetilde{7}}{\stackrel{0}{0}}$ \\
\hline & İ & $\stackrel{\text { هু }}{\circ}$ & $\begin{array}{l}\infty \\
\stackrel{\infty}{0} \\
0\end{array}$ & $\begin{array}{l}\text { ㅇ } \\
0 \\
0\end{array}$ & $\stackrel{\infty}{\stackrel{0}{0}}$ \\
\hline & $z^{N}$ & $\begin{array}{l}\stackrel{\infty}{0} \\
\stackrel{0}{0} \\
\dot{0}\end{array}$ & $\begin{array}{l}\overrightarrow{8} \\
\dot{0} \\
0\end{array}$ & $\begin{array}{l}\tilde{8} \\
\dot{0}\end{array}$ & $\begin{array}{l}\text { \& } \\
\dot{0}\end{array}$ \\
\hline \multicolumn{2}{|c|}{ 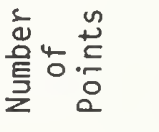 } & $\omega$ & $\approx$ & & 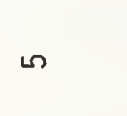 \\
\hline \multicolumn{2}{|l|}{ 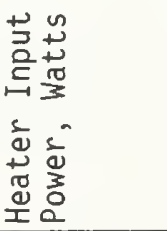 } & 0 & రి & 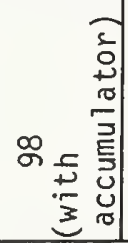 & 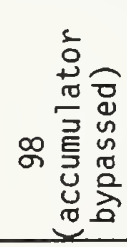 \\
\hline
\end{tabular}




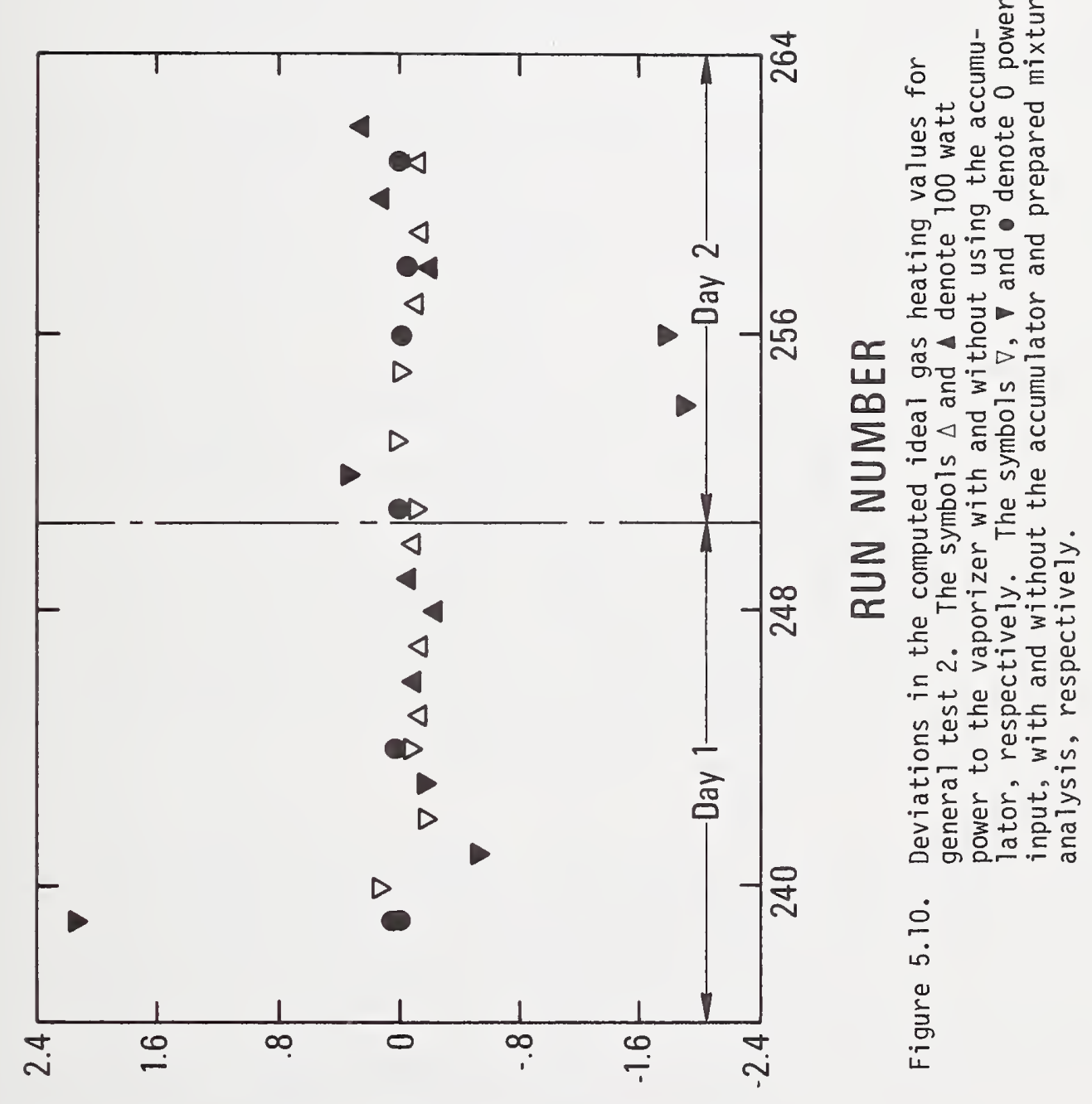

\% ’ $\exists \cap 7 \forall \Lambda$ פNIL $\forall \exists H$ NI NOIL $\forall I \Lambda \exists O$ 
attached $42 \mathrm{ohm}$ heaters to the pitot and side tap probe. Since the probe line was $1 / 16$ inch ( $1.6 \mathrm{~mm}$ ) O.D. tubing it was impractical to wrap heater wire directly on the tubing. The heater wire was wrapped on a copper cylinder which was soft soldered to the probe lines approximately 1.5 inches (38 $\mathrm{mm}$ ) from where they entered the test section. The heaters covered approximately 0.5 inches $(13 \mathrm{~mm}$ ) of the $1 / 16$ inch $(1 / 6 \mathrm{~mm})$ stainless steel tube giving a heat transfer area of $0.10 \mathrm{in}^{2}\left(63 \mathrm{~mm}^{2}\right)$.

In the first part of the test we heated the side tap and took samples at input powers of $0.10,0.42,0,1.7$ and 6.7 watts -- this corresponds to $0.2,0.7,0,3$ and 11 percent of the power (62 watts) to the vaporizer. As figure 5.11 shows there was no apparent effect on sampling. At 6.7 watts the heater shorted out. The test was repeated for the pitot tube. Although, statistically, there was no apparent change in the precision, increasing the heat seemed to decrease the methane and nitrogen content (runs 269 through 275 in figure 5.12). Therefore, it was decided to repeat the test with the heat input randomized instead of systematically increasing the input power. Table 5.10 lists the estimated standard deviations. This test showed that the apparent trend noted before for nitrogen was coincidence and that there was no detectable effect on the sampling precision.

During the last run of this test, this heater shorted out too. When the apparatus was disassembled we found that both heaters were unsoldered from the tubing. Soft solder ( $50 \% \mathrm{Sn}, 50 \% \mathrm{~Pb})$ melts at $490 \mathrm{~K}$ [23] and the thermal conductivity for 304 stainless steel is roughly 0.12 watts/cm-K [24]. Using these values, the heater length and tube dimension, and 6.7 watts input power, thermal conductivity calculations show that the temperature of the inside tube wall could have been as high as $480 \mathrm{~K}$. Therefore, there had to be film boiling inside the probe line. The effect of heat leak was studied in the second flow facility test.

Test 4

During previous tests the needle valve upstream of the reference vaporizer was used to provide some pressure drop in the liquid phase which would reduce the possibility of backflashing. In the vaporizer evaluation (see section 5.1.3.2) we opened the needle valve and found no apparent change in the sampling precision. If the needle valve could be omitted it would eliminate an operating variable in the LNG sampling system. Therefore, we wanted to confirm the previous results in this test using the side tap instead of the reference probe.

When wide open there was an estimated $0.03 \mathrm{psi}(0.2 \mathrm{kPa})$ across the needle valve (valve T6, figure 5.1); in this case regulating valve Tl5 was used to control the sample flow rate. The maximum pressure drop ( 1.5 psi (10.3 kPa)) across the needle valve was obtained by using it to control the sampling rate; in this case all valves downstream of the needle valve were wide open. (We estimated the pressure drop in the vaporizer and the line to 


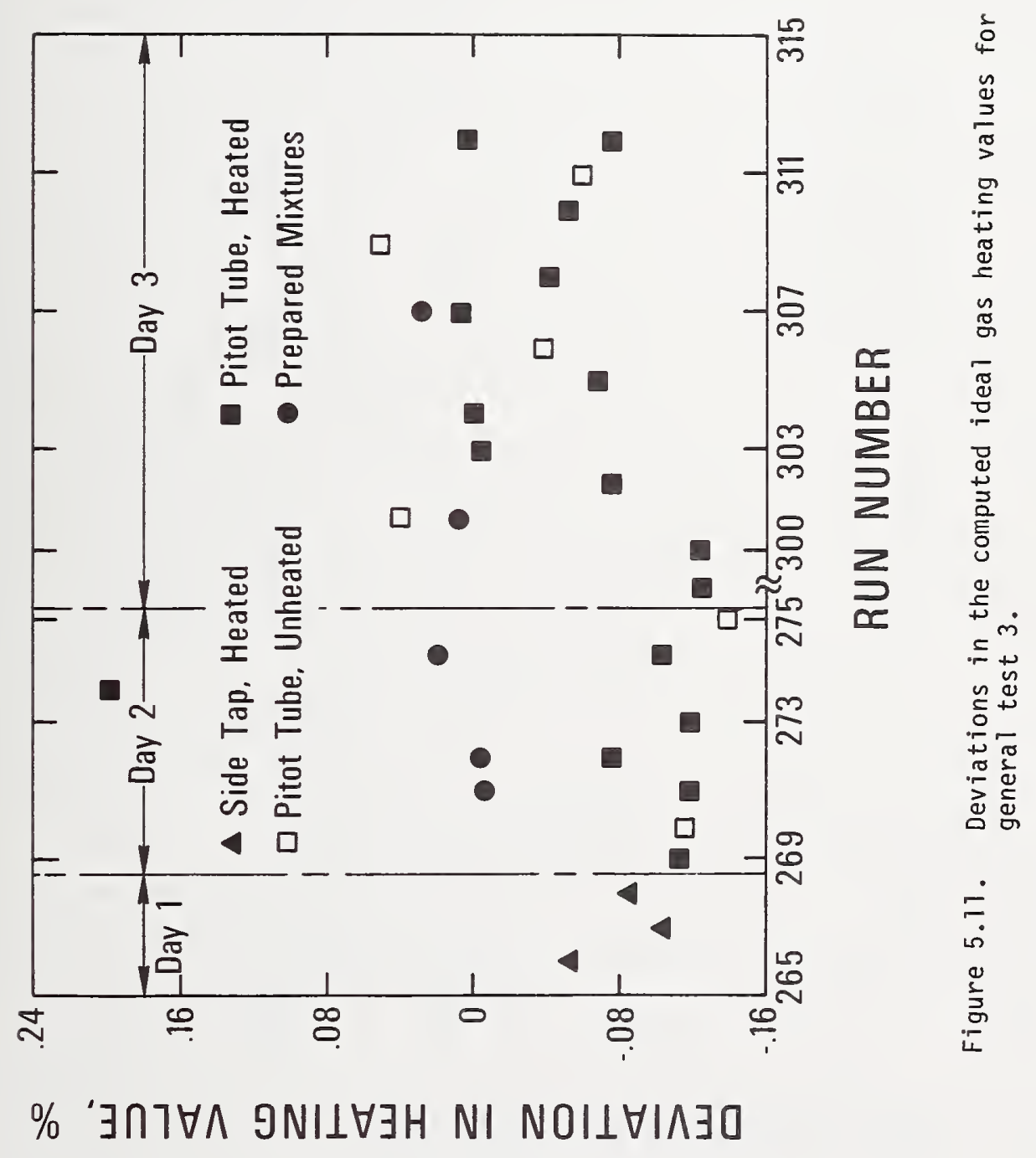




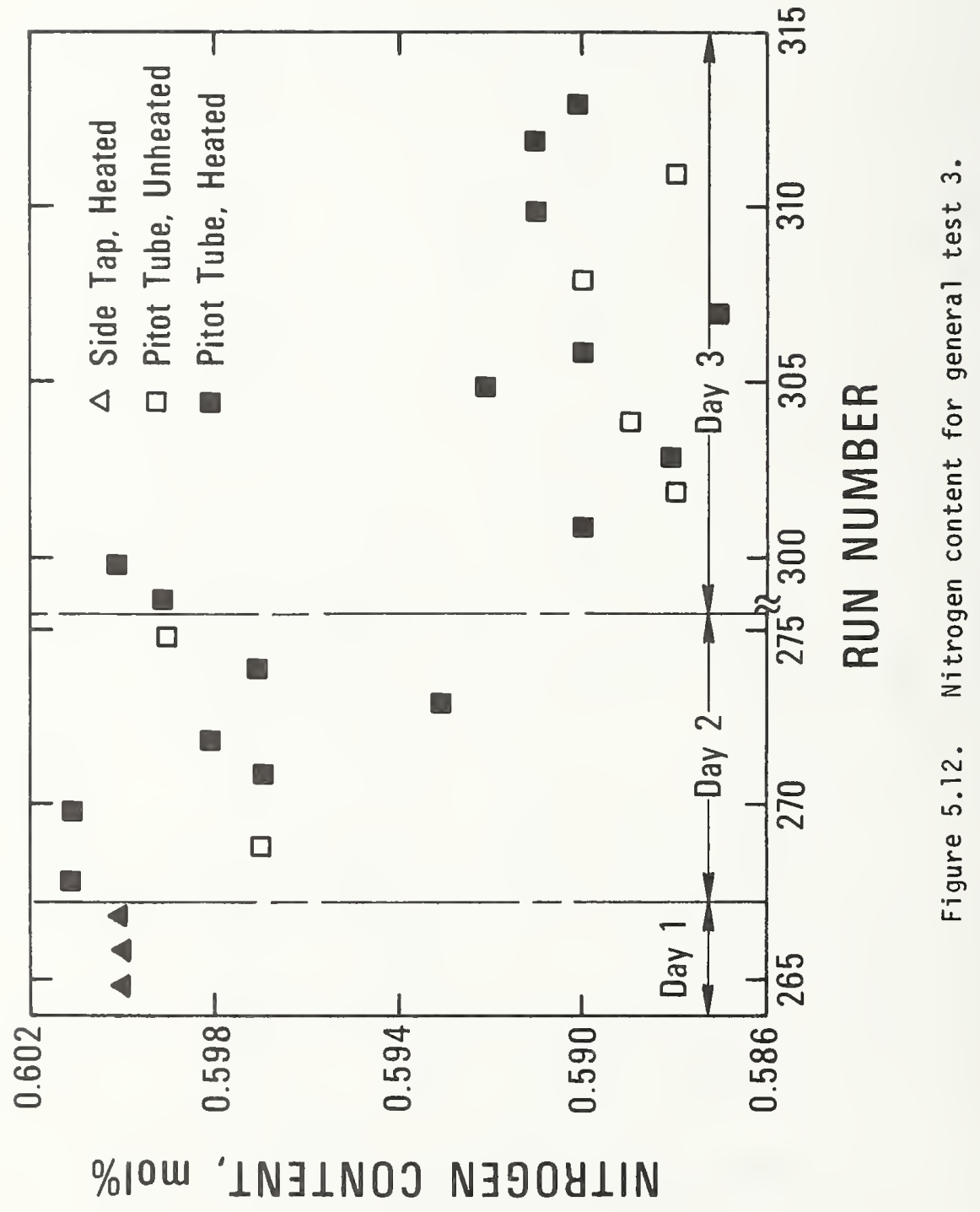




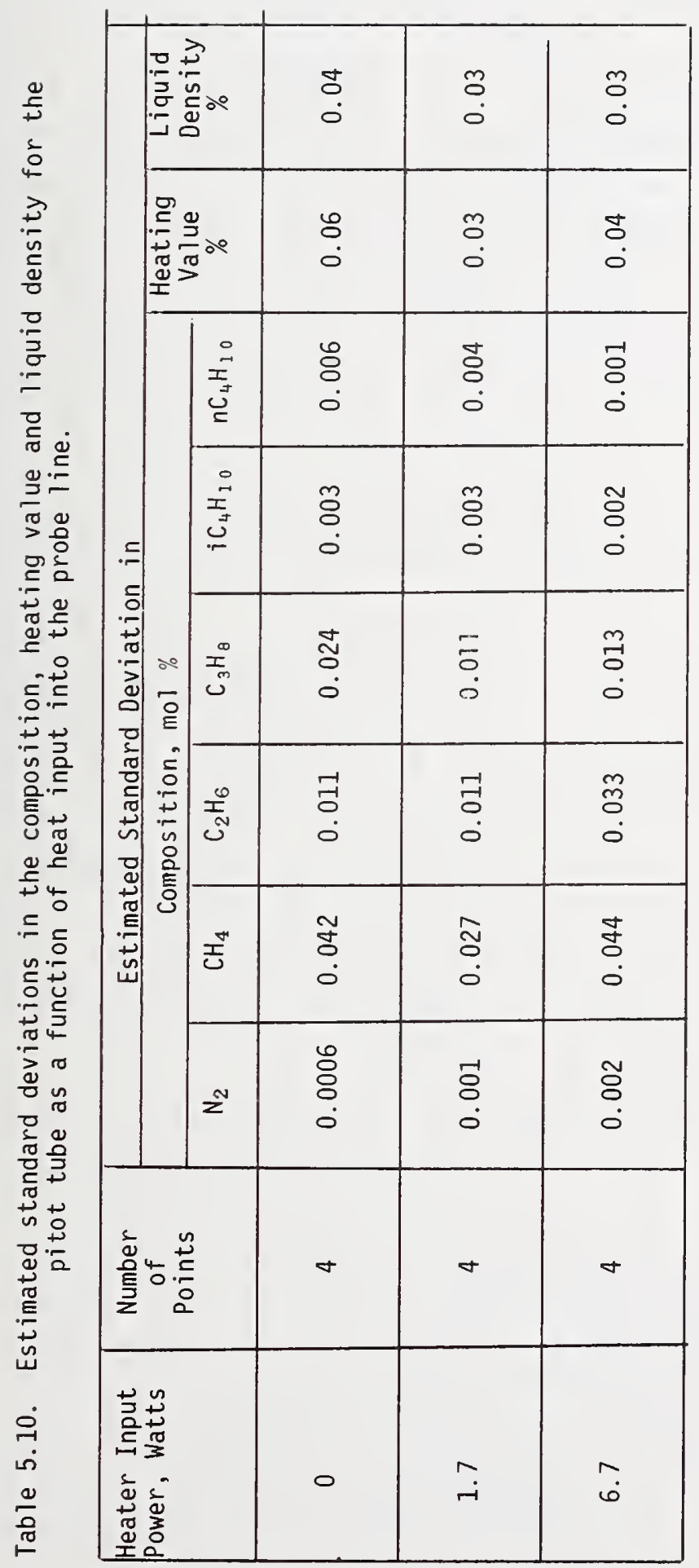


the vaporizer to be $1.0 \mathrm{psi}(6.9 \mathrm{kPa})$ and $1.8 \mathrm{psi}(12.4 \mathrm{kPa})$, respectively.) When controlling the sampling rate with the needle valve, the sampling rate had fluctuations of $\sim \pm 50$ percent of the average reading.

Table 5.11 and figure 5.13 show that the amount of pressure drop across the needle had no apparent effect on the sampling precision. However, there may have been sufficient resistance in the line to the vaporizer to prevent backflashing. This test was repeated in the second flow facility test.

Test 5

The first test in this phase of work clearly indicated that an accumulator was needed. However, the minimum acceptable residence time in the accumulator was not determined. In this short test we varied the residence time between 10 and 22 seconds. Residence times for past tests were in the range of 15 to 30 seconds. The 10 second residence time corresponded to a full scale reading on the rotameter used to measure the sampling rate. Figure 5.14 shows the heating values for this short test. Although the first point (293) appears too high it still is well within the error limits of gas analysis alone. There were too few data points to do a statistical analysis on each residence time. However, an analysis of the whole group indicated that the estimated standard deviation in computed heating values was comparable to the best values obtained in other laboratory tests ( $\sim 0.02$ percent).

Test 6

In all of the previous laboratory tests, prepared mixtures containing nitrogen and methane through butane were used. The LNG for the first flow facility test was prepared by condensing natural gas obtained from the local gas utility. The liquid contained roughly 0.2 mol percent hexanes and higher hydrocarbons. It was thought that the presence of heavy components may have caused some of the sampling problems experienced in the first flow facility test. Therefore, additional natural gas from the local utility was condensed and transferred into the laboratory apparatus. While holding all operating variables constant, a series of runs was made to determine the effect of heavy components on the sampling precision.

Table 5.12 lists the average values and estimated standard deviations for this test; figure 5.15 shows the deviation in the heating value. (The deviation is defined here as the difference between the measurement and average value divided by the average value for the given mixture.) Runs were made with different nitrogen levels. All of these analyses were made using column configuration A (see section 4.3.1.1). The estimated standard deviations for the first two days were comparable to previous laboratory tests. (The $0.005 \mathrm{~mol}$ percent value for the estimated standard deviation of nitrogen was typical for the gas chromatograph used on this test.) However, the imprecision was much greater in the heating value on the last day. This 


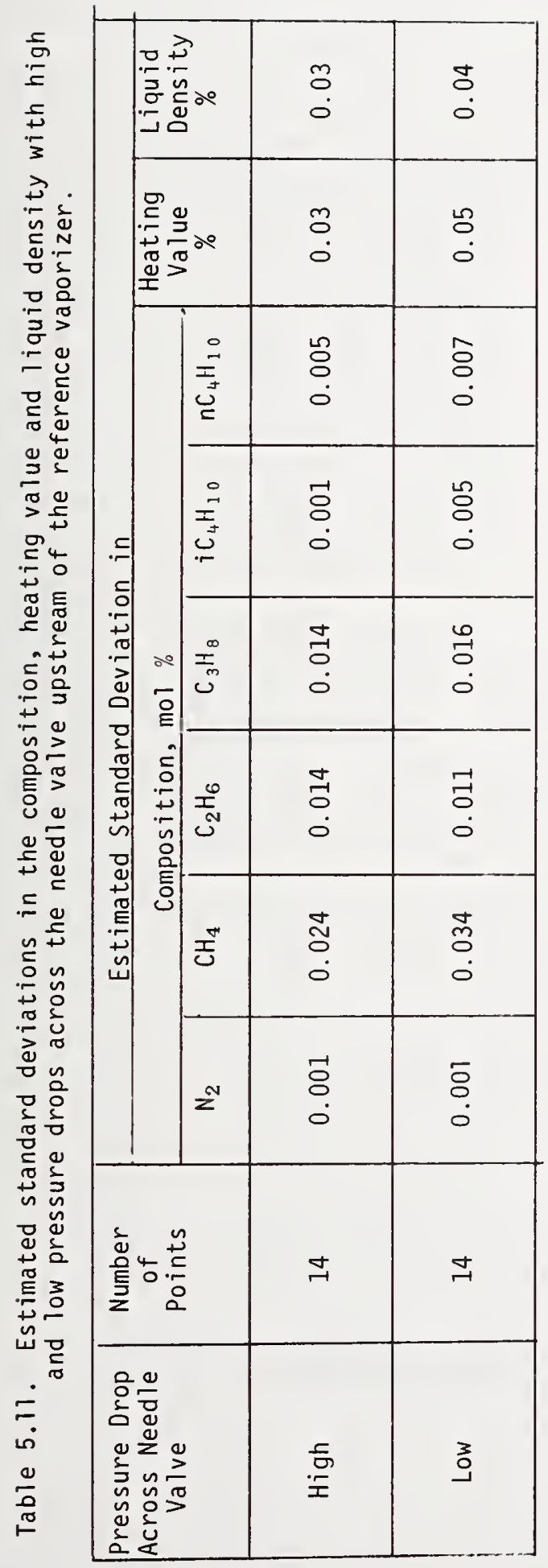




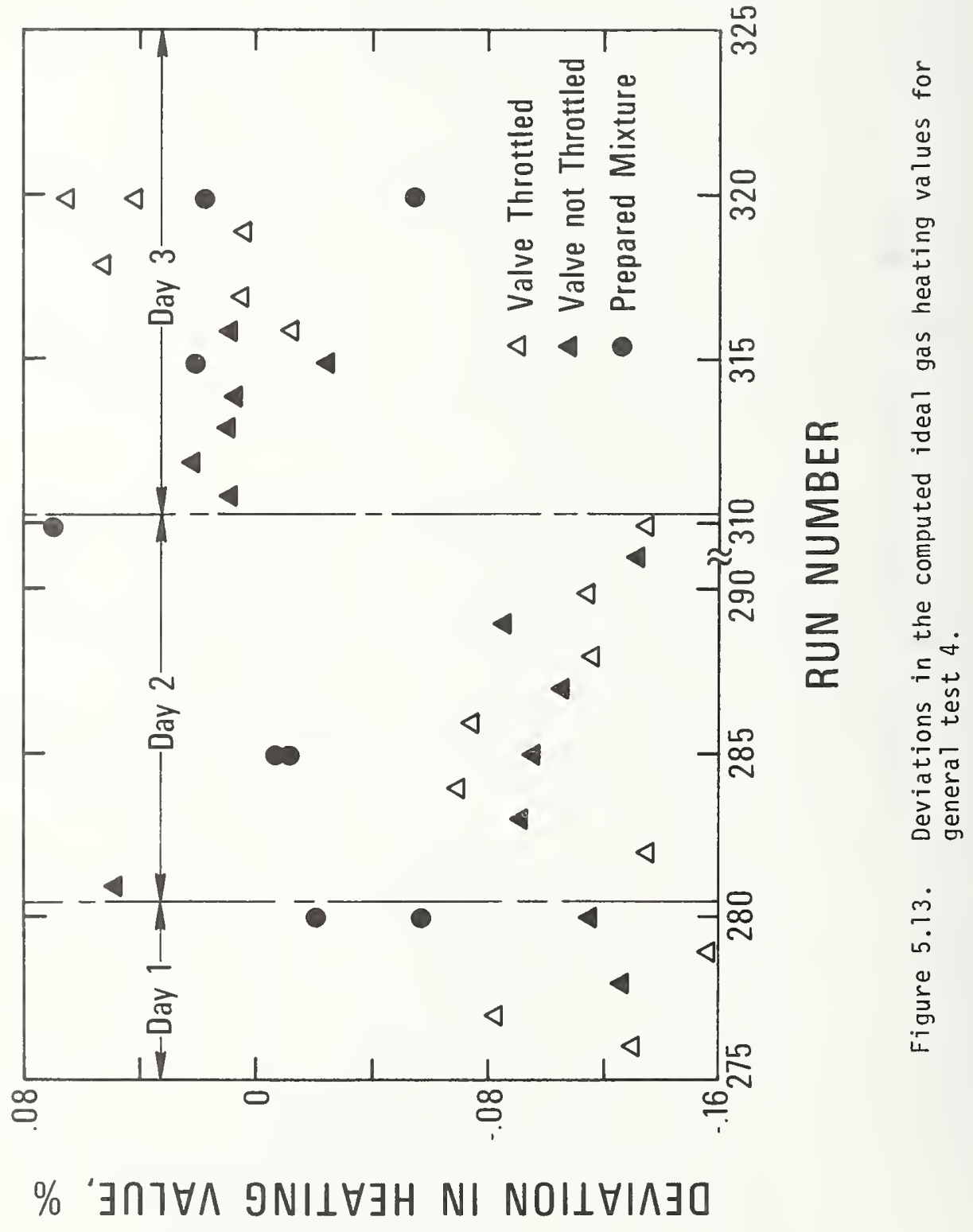




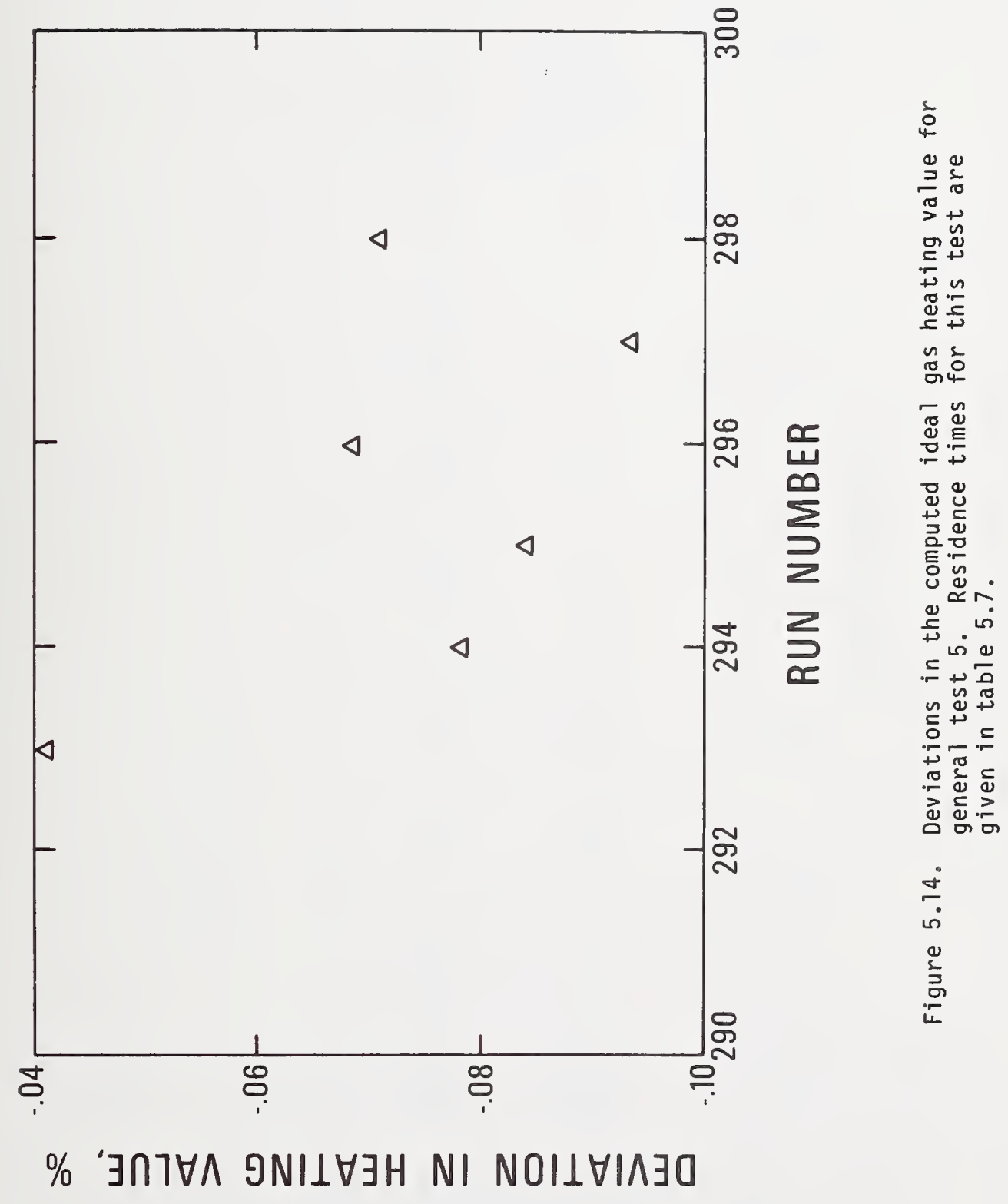




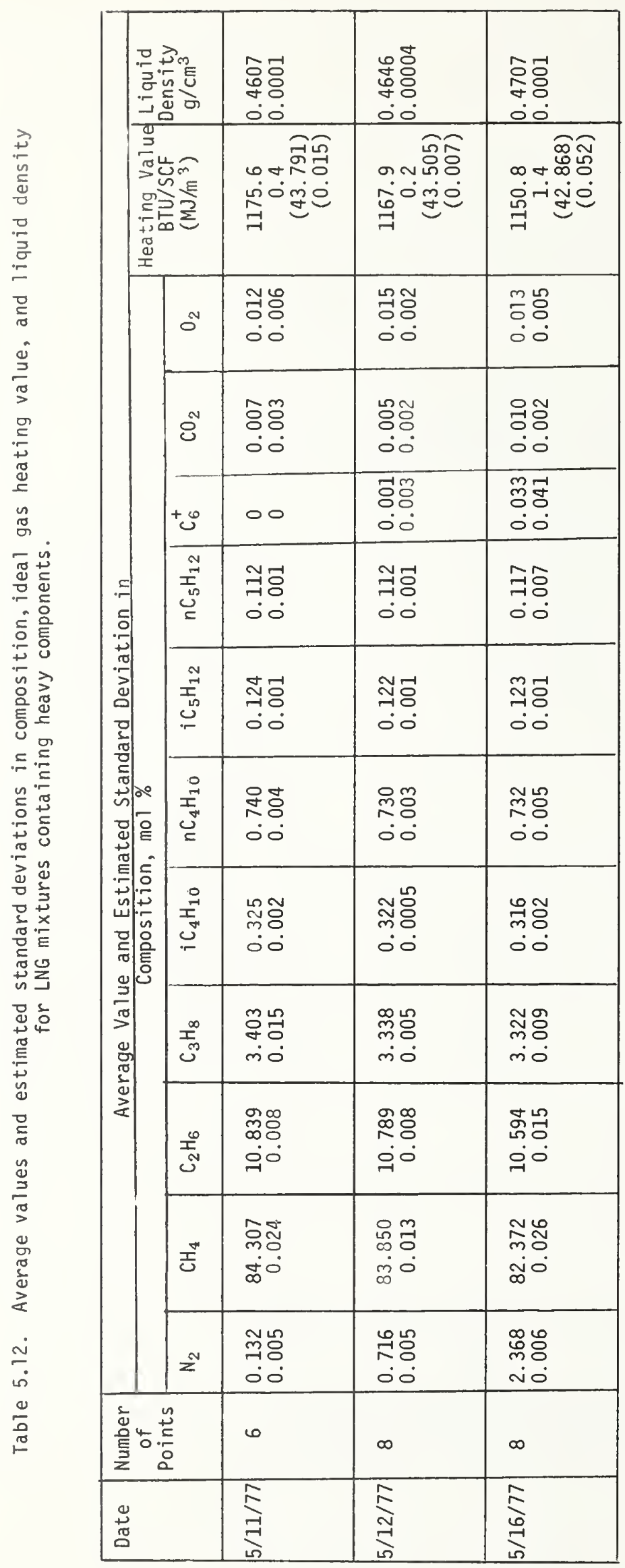




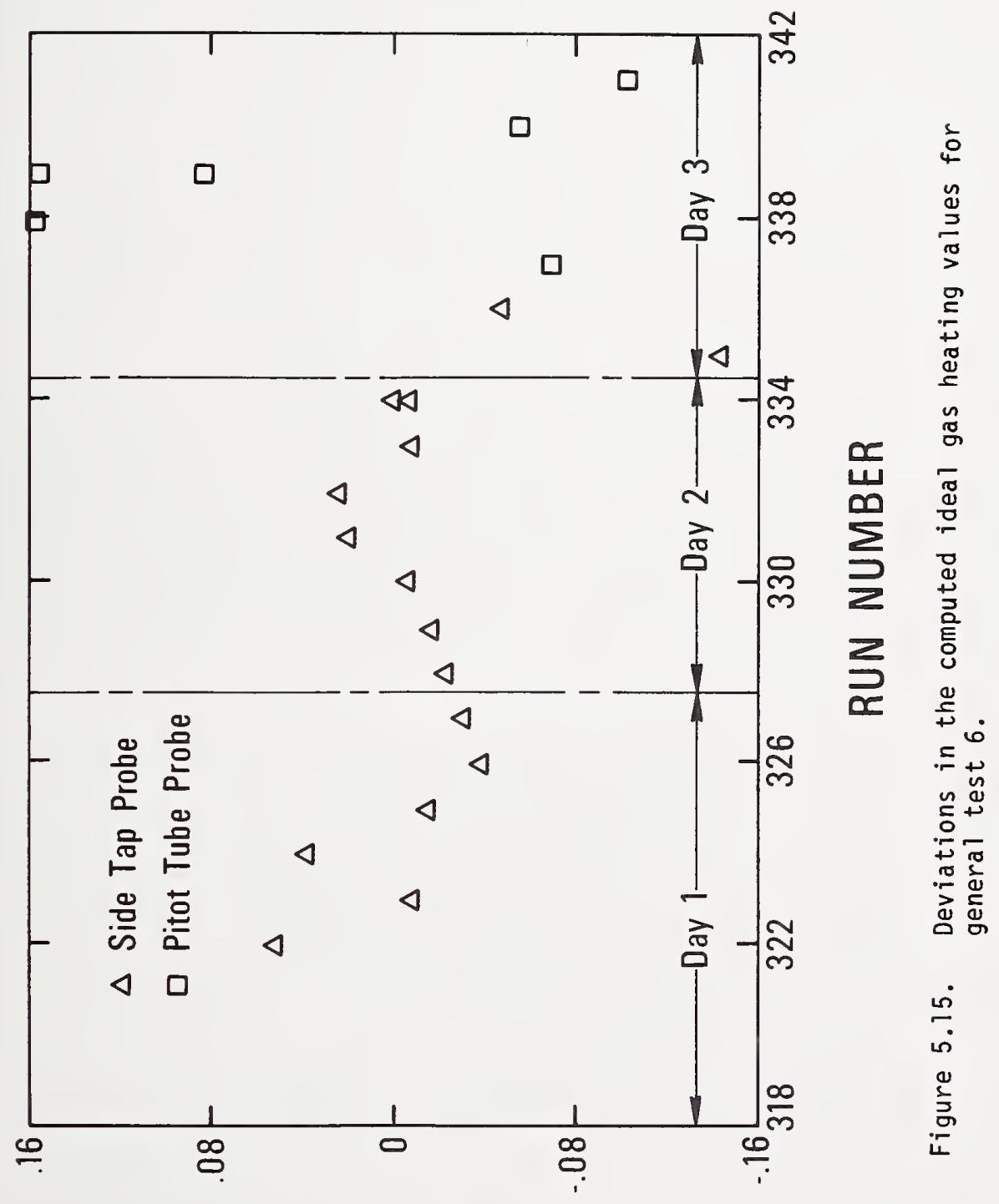

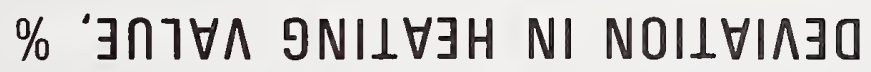


was due to an increase in the scatter of the normal pentane and the $\mathrm{C}_{6}{ }^{+}$ component peaks. An estimated standard deviation of 0.04 mol percent in the $\mathrm{C}_{6}+$ peak corresponds to nearly $2 \mathrm{Btu} / \mathrm{scf}\left(0.08 \mathrm{MJ} / \mathrm{m}^{3}\right)$ or 0.17 percent in the ideal gas heating value. The problem was not in sampling but in the inability of the digital integrator to correctly determine the area of the peak. (This problem is discussed in section 4.3.1.1).

At the time of these tests we did not have a calibration gas containing pentanes; therefore, response factors for the pentanes and $\mathrm{C}_{6}+$ (assuming the peak contained equal parts of $n$-hexane and $n$-heptane) were estimated by taking the ratio of the response factor for the given component to that of n-butane [25] and multiplying that by the response factor for n-butane as determined from calibration. The same approach was used for the oxygen and carbon dioxide peaks except that nitrogen, instead of $n$-butane, was used in the ratio.

Based on the results of this test, the presence of heavy components does not affect the sampling precision but they can affect the analytical precision. This test pointed out the analytical problem of correctly integrating the $\mathrm{C}_{6}{ }^{+}$ backflush peak.

\subsection{Confirmation Tests}

It was important that the conclusions obtained from the small scale laboratory tests be confirmed in a facility comparable to the proposed industrial installation. Three confirmation tests were made -- two at the NBS LNG Flow Facility and one aboard the LNG tanker El Paso consolidated. The shipboard test was made after completing the laboratory tests and between the two flow facility tests.

\subsubsection{NBS LNG Flow Facility Test 1}

The LNG flow facility [26] is an outdoor pilot plant which has been used primarily for LNG flowmeter measurements. Figure 5.16 shows a schematic of the facility and table 5.13 lists the pertinent operating data. For the sampling tests a $3 \mathrm{ft}(0.9 \mathrm{~m})$ long test section was inserted roughly $10 \mathrm{ft}(3 \mathrm{~m})$ downstream of the recirculation pump. All lines in the flow loop were 2.5 in $(72 \mathrm{~mm})$ diameter stainless steel pipe and all lines except the test section were vacuum jacketed.

Table 5.13. LNG flow facility operating characteristics

\begin{tabular}{|l|l|}
\hline Temperature Range & $95-140 \mathrm{~K}$ \\
Temperature Stability & $\pm 1 \mathrm{~K}$ or better \\
$\begin{array}{l}\text { Pressure Range } \\
\text { Pump Discharge Pressure } \\
\quad \text { (above weigh tank pressure) }\end{array}$ & $19-110$ psia $(0.13-0.76 \mathrm{MPa})$ \\
LNG Flow Rate & $2.7-30$ psid $(19-207 \mathrm{kPa})$ \\
Reynold's Number & $20-200 \mathrm{gpm}(76-760 \mathrm{Lpm})$ \\
\hline
\end{tabular}




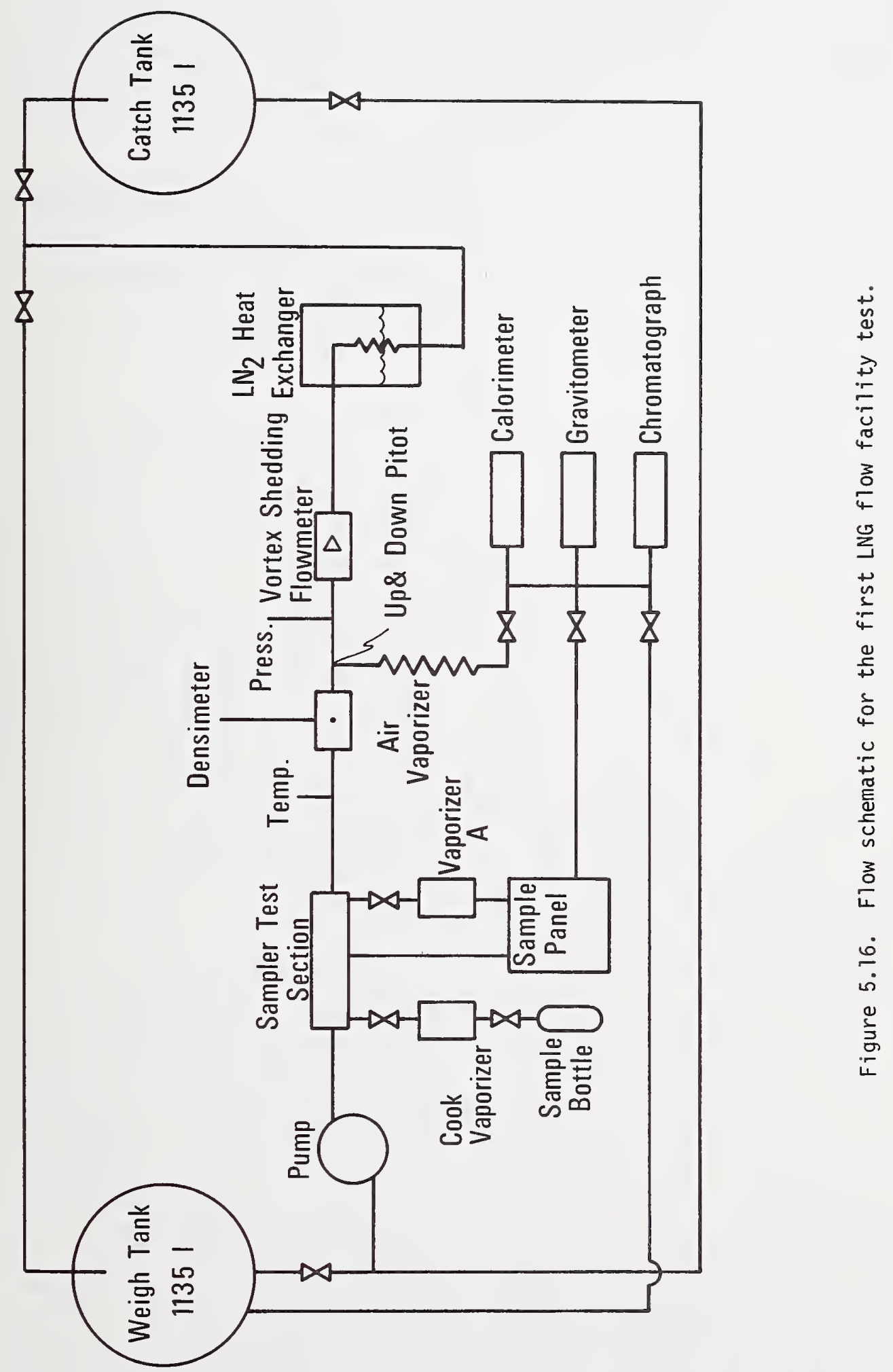


Vaporized samples from the test section were collected in $150 \mathrm{~cm}^{3}$ sample cylinders for analysis in the laboratory GC. For these tests we used column configuration $A$ (see section 4.3.1.1). The vaporized samples also could be sent to a gas gravitometer and combustion calorimeter. These units were located approximately $50 \mathrm{ft}(15 \mathrm{~m})$ away in a constant temperature room. The residence time of gas in the line between the sample panel and calorimeter was 1.6 minutes. Additional gas samples could be taken just upstream of the calorimeter and gravitometer.

It was possible to send gas samples directly to a process gas chromatograph. But since it measured only the concentration of nitrogen, methane, ethane, carbon dioxide and propane it was not used in these tests. Also, there was a pitot tube (up and downstream facing pitot)-air vaporizer sampling system [27] downstream of the sampling test section. It was used only in the first test.

During the initial startup the flow loop was purged with dry nitrogen and then cooled down with liquid nitrogen which was recirculated through the flow loop. After cooldown, LNG was transferred into the weigh tank. For the sampling tests the LNG was pumped from the bottom of the weigh tank and returned to the top of the weigh tank. The temperature was controlled by adjusting the liquid level in the liquid nitrogen heat exchanger.

The "true" composition of the LNG in the flow facility could not be measured. This limited the tests to comparing only the precision of the various sampling systems. However, the composition could be held constant throughout an operating day. System venting during shutdown caused day to day shifts in the composition. LNG for this test was made by condensing the natural gas supplied by the local gas utility. The gas was dried with a desiccant and the carbon dioxide was removed by filtering the liquid [27].

In Test 1 we wanted tu compare three probes -- a side tap, a side tap with a capillary opening and an upstream facing pitot tube; two vaporizers -- a water heated coil and vaporizer A; and the Cook sampler. Figure 5.17 shows a schematic of the sampling system (a sample accumulator was not. usea). All three probes were mounted horizontally in the test section and were 6 in $(152 \mathrm{~mm})$ apart. The test section was enclosed in a 5 in (127 mm) section of copper tubing. The annular space was evacuated to provide insulation. (However, during the tests it became obvious that the vacuum was very poor because a heavy layer of frost formed on the outer tube.) All three probes were made of $1 / 8$ in $(3.2 \mathrm{~mm})$ O.D. by 0.101 in $(2.56 \mathrm{~mm})$ I.D. stainless steel tubing. The probe lines were vacuum jacketed 6-1/2 in (165 $\mathrm{mm})$ beyond the 5 in $(127 \mathrm{~mm})$ tube. The pitot tube had a $90^{\circ}$ bend with the intake on the flow section center line. 


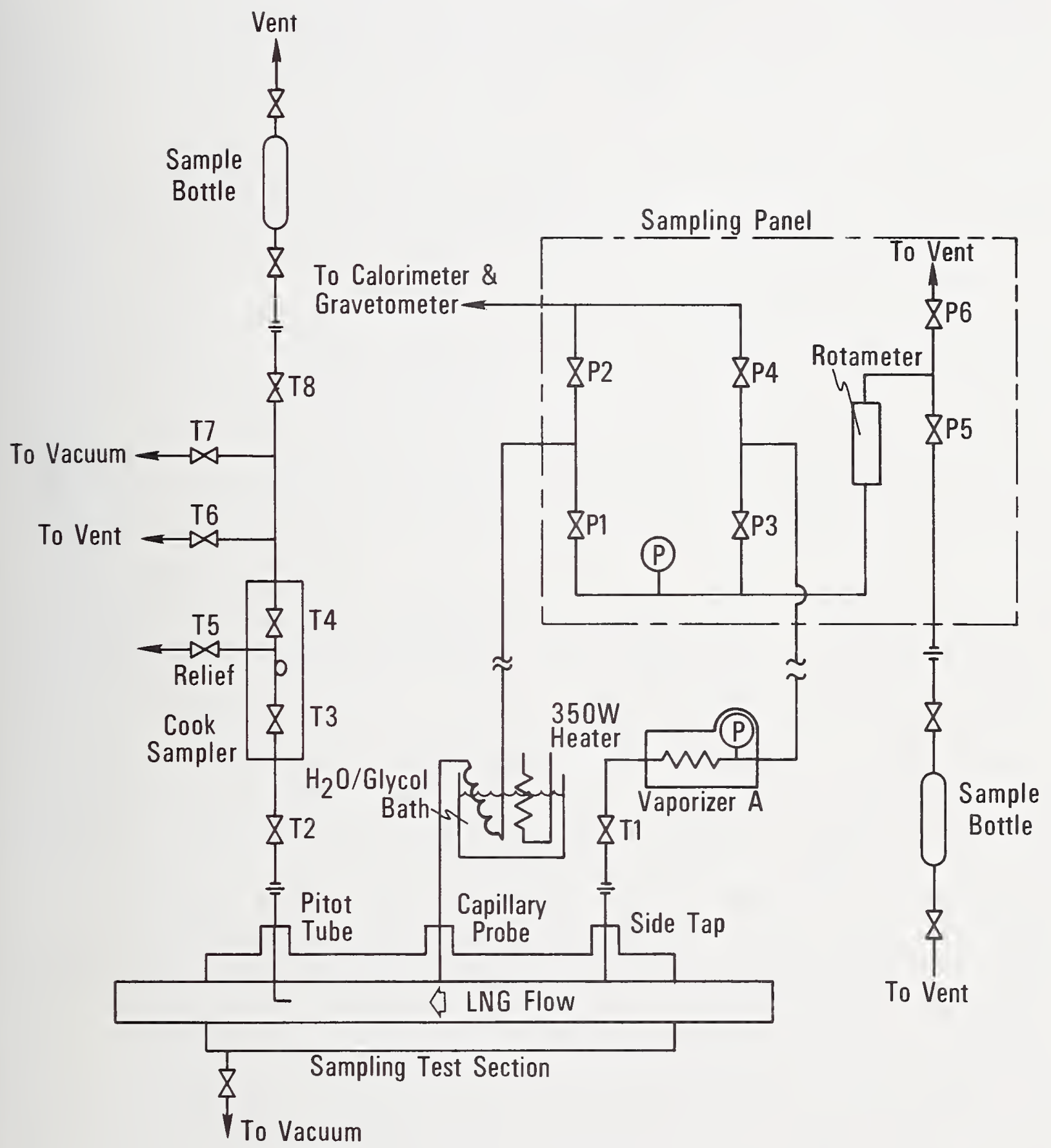

Figure 5.17. Schematic of sampling system used in flow facility test 1. 
It was thought that if part of the pressure drop between the probe and vaporizer could be taken in the liquid phase there would be no danger of backflash; hence, it would not matter how the sample was vaporized downstream. Therefore, a capillary probe was built which contained a $1 / 4$ in $(6.4 \mathrm{~mm})$ long section of 0.007 in $(0.18 \mathrm{~mm})$ I.D. tubing. This was soldered into the $1 / 8 "(3.2 \mathrm{~mm})$ O.D. tubing. The capillary section produced roughly $5-1 / 2 \mathrm{psi}(38 \mathrm{kPa})$ pressure drop for a liquid flow corresponding to 8 slpm of gas flow.

The water heated vaporizer consisted of $10 \mathrm{ft}(3 \mathrm{~m})$ of $1 / 4$ in $(6.35 \mathrm{~mm})$ O.D. $x 0.190$ in (4.83) I.D. copper tubing immersed in a water-glycol bath which was at $\sim 30^{\circ} \mathrm{F}\left(-1^{\circ} \mathrm{C}\right)$. During operation the coil would have a ice layer which extended about $3 \mathrm{ft}(0.9 \mathrm{~m})$ along the tubing in the bath.

5.2.1.1. Test results

The results of this test were extremely poor; the best agreement between two samples was $0.04 \%$ in the heating value. However, this was fortuitous because the typical scatter was on the order of one percent. The scatter was unaffected by the probe and vaporizer used. It was found that the heating values of the samples taken five minutes apart from the same sampling system varied by 0.7 percent; samples taken simultaneously from the same stream at the panel and at the gravitometer inlet differed by 1.5 percent. However, during all of these tests the calorimeter and gravitometer remained steady. (The gas specific gravity is much less sensitive to composition than the heating value, e.g., in the composition range studied a 1.5 percent change in the heating value corresponds to only 0.4 percent change in the specific gravity.)

Initially, it was thought that the scatter could be caused by the different methods of filling the sample cylinder. Samples taken at the panel were purged and filled 14 times; the sample cylinders at the gravitometer/calorimeter inlet were filled by continuous purge through. To test the effect of sample cylinder filling procedure on precision, one of the calibration gases was connected to the sample panel. Using comparable sample flows and pressures to those used in the other tests, samples were taken at both the panel and the gravitometer/calorimeter inlet. The resulting sample compositions were within the error of the gas analysis alone; therefore, the sample cylinder filling procedure was not a problem.

The possibility that the scatter was caused by either liquid composition fluctuations or by the presence of vapor in the test section was considered. The stability of the densimeter in the LNG flow facility indicated that there were no composition fluctuations. The possibility of two phase flow was eliminated because the vortex shedding flowmeter would have behaved erratically in two phase flow. At this point it was decided to make additional laboratory tests (see section 5.1.3.3) to determine the cause of the poor sampling precision. 
Even with the erratic sampling precision, the following qualitative results were obtained:

1. It was not possible to obtain reliable samples from the cook sampler as tested; this sampler should have been insensitive to the problems experienced with the continuous samplers. However, it is possible that valve T2 (figure 5.17) was leaking during the warm up period or that the reduction in sample pressure when filling the sample cylinder caused partial condensation. (The ambient air during these tests was 30 to $40^{\circ} \mathrm{F}\left(-1.1\right.$ to $\left.4.4^{\circ} \mathrm{C}\right)$ ). 2. Based on the band width of the gravitometer trace, the up and down pitot-air vaporizer and the capillary probe-water vaporizer systems produced more precise samples than did the side tap-vaporizer A system. The gravitometer band width for the capillary probe-water vaporizer samples and gravitometer calibration gas (air) were comparable. Also, it was found that the heating values for the side tap-vaporizer A samples were 0.5 to 1 percent higher than those from the other two systems; the heating value difference between these two systems was less than 0.2 percent.

3. The capillary probe is not a feasible probe in industrial applications where entrained solids could cause plugging. In the flow facility there were small amounts of solid carbon dioxide which plugged the capillary line.

\subsubsection{Shipboard Tests}

Using the information obtained in the laboratory and first flow facility tests, a full scale sampling system was designed for tests aboard the LNG tanker El Paso Consolidated. Sampling tests were made at Canvey Island, England during the ship's cargo system trials. Two sampling systems were installed -- a liquid sampling system was installed on the 3 inch (76 mm) diameter header to the ship's ING vaporizer; a gas sampling system was placed on the 16 inch $(406 \mathrm{~mm}$ ) diameter vaporizer outlet header. Sampling the gas phase provided a check on the liquid sampling system.

Figure 5.18 shows a schematic of the liquid sampling system and table 5.14 lists the component dimensions. The system had a $1 / 4$ inch, schedule 80 pipe (13.7 mm O.D. $\times 7.67 \mathrm{~mm}$ I.C.) side tap probe mounted horizontally on the header. All valves, fittings and tubing upstream of the sample panel were stainless steel; tubing in the panel was copper and the other components were brass. Except for the filter connections and union just upstream of the vaporizer, all connections upstream of the vaporizer were socket welds. The line between the header and vaporizer was wrapped with a one inch (25 mm) layer of fiberglass pipe insulation and sealed with duct tape. Valves $T 1$ and $T 2$ were bellows valves with the valve components welded together. (We have had success using these valves in cryogenic applications.) Valve T2 was a metering valve; it and the back pressure regulator were used to control the sampling rate. 


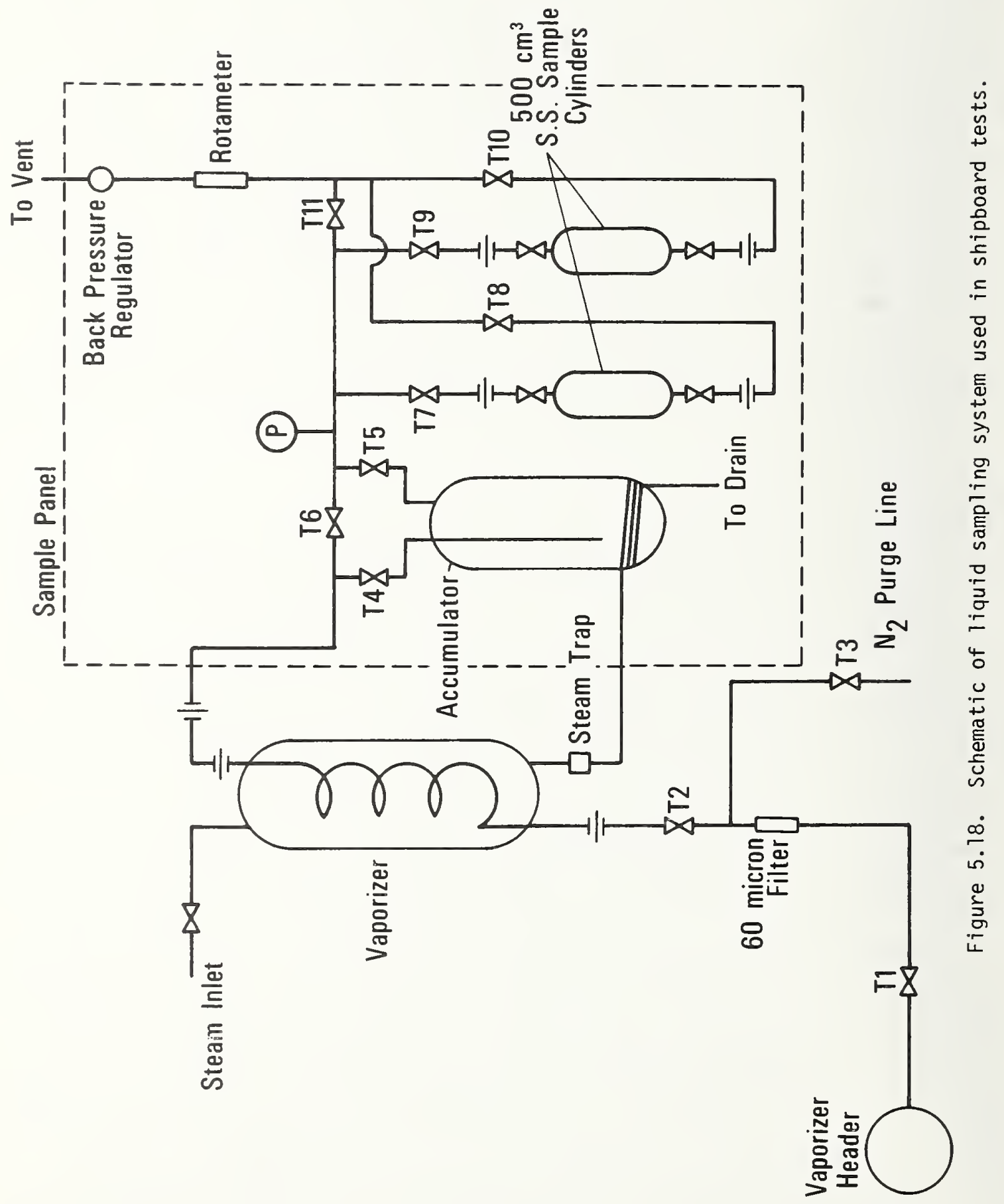


Table 5.14. Dimensions of LNG Sampling System used on Shipboard Tests

\begin{tabular}{|c|c|c|c|}
\hline Component & $\begin{array}{l}\text { Length } \\
\text { inches }(\mathrm{mm})\end{array}$ & $\begin{array}{l}\text { Outer Diameter } \\
\text { inches (mm) }\end{array}$ & $\begin{array}{l}\text { Inner Diameter } \\
\text { inches (mm) }\end{array}$ \\
\hline Vaporizer Header & -- & $\begin{array}{l}3.5 \text { ( } 88.9) \\
(3 \text { in pipe) }\end{array}$ & \\
\hline $\begin{array}{l}\text { Side tap and line } \\
\text { between header and } \\
\text { Valve Tl }\end{array}$ & $4 \frac{1}{2}(114)$ & $\begin{array}{l}0.540(13.7) \\
\left(\frac{1}{4} \text { in Sch } 80\right. \\
\text { pipe) }\end{array}$ & $0.302(7.67)$ \\
\hline $\begin{array}{l}\text { Line between Valve } \\
\mathrm{T} 1 \text { and filter (con- } \\
\text { tained a long radius } \\
90^{\circ} \text { bend) }\end{array}$ & $11(279)$ & $0.25(6.4)$ & $0.180(4.57)$ \\
\hline $\begin{array}{l}\text { Line between filter } \\
\text { and Valve } T 2\end{array}$ & $\sim 3(76)$ & $0.25(6.4)$ & $0.180(4.57)$ \\
\hline $\begin{array}{l}\text { Line between Valve } \\
\text { T2 and union at } \\
\text { vaporizer }\end{array}$ & $18(460)$ & $0.125(3.18)$ & $0.101(2.56)$ \\
\hline $\begin{array}{l}\text { Vaporizer tubing } \\
\text { (formed into a } 4 \\
\text { in (102 mm) diam- } \\
\text { eter hel } i x \text { ) }\end{array}$ & $45(1140)$ & $0.188(4.76)$ & $0.164(4.15)$ \\
\hline $\begin{array}{l}\text { Vaporizer Casing } \\
\text { (with welded cap } \\
\text { ends) }\end{array}$ & $20(508)$ & $6.00(150)$ & $5.94(151)$ \\
\hline $\begin{array}{l}\text { Line from Vaporizer } \\
\text { to union (contained } \\
\text { a long radius } 90^{\circ} \\
\text { bend) }\end{array}$ & 11 (279) & $0.25(6.4)$ & $0.180(4.57)$ \\
\hline Line to Valve $\mathrm{T} 3$ & $14(356)$ & $0.25(6.4)$ & $0.180(4.57)$ \\
\hline $\begin{array}{l}\text { Accumulator } \\
\text { (with welded cap } \\
\text { ends) }\end{array}$ & $24(610)$ & $6.00(152)$ & $5.94(151)$ \\
\hline
\end{tabular}


The nitrogen purge connection (which was insulated up to valve T3) was used for displacing air from the sampling system; it was located downstream of the 60 micron filter so that nitrogen could be used to back purge the filter, if necessary. However, the filter never clogged during these tests. Because of film boiling, a precise ( \pm 20 percent) design of the sample vaporizer would have been extremely tedious. Therefore, the design was based on the warming of methane gas from 115 to $310 \mathrm{~K}$. A flow rate of 65 slpm was used. We assumed that the steam side temperature was constant at $340^{\circ} \mathrm{F}\left(171^{\circ} \mathrm{C}\right)$ this corresponds to the temperature of $205 \mathrm{psia}$ ( $1.41 \mathrm{MPa}$ ) steam isentalpically expanded to $60 \mathrm{psia}(0.4 \mathrm{MPa})$. The heat transfer resistances on the steam side and in the tube wall were negligible compared to the gas phase resistance; properties of methane $[28,29]$ at $150 \mathrm{~K}$ were used in the calculations. The final vaporizer tube length was twice the length computed using the above assumptions.

The steam inlet line, vaporizer and condensate line were insulated; this was done primarily for personnel safety. Condensate from the vaporizer was used to warm the bottom of the accumulator to provide additional mixing.

The accumulator was sized to provide a 30 second residence time for a sample rate of $65 \mathrm{slpm}$ and sample pressure of $50 \mathrm{psig}(0.45 \mathrm{MPa})$. The length to diameter ratio was 2.5 and the volume was 11 liters.

The sample panel layout was designed so that the sample flow could be maintained with or without sample cylinders in the system. The back pressure regulator was extremely useful for making minor changes in the sampling rate and setting the sample cylinder pressure.

The gas sampling system consisted of a $1 / 4$ inch, schedule 80 pipe (13.7 $\mathrm{mm}$ O.D. $\mathrm{x} 7.67 \mathrm{~mm}$ I.D.) side tap mounted vertically on the top of the outlet header, a block valve and $1 / 4$ inch $(6.35 \mathrm{~mm})$ O.D. by 0.190 inch $(4.83 \mathrm{~mm})$ I.D. copper tubing going to the sample panel. This panel had the same layout as the liquid sample panel but included a needle valve upstream of the accumulator for flow control. This system was designed for a vaporizer outlet pressure comparable to the inlet pressure (65 psig (0.055 MPa)). However, the outlet pressure was only 1.5 to 2 psig ( 0.112 to $0.115 \mathrm{MPa})$; this reduced the sampling rate to approximately 1 slpm from the anticipated 10 or more slpm.

Gas analyses were made using a gas chromatograph containing a $30 \mathrm{ft}$ $(9.1 \mathrm{~m})$ long column of DC $200 / 500$ on Chromasorb P and a $5 \mathrm{ft}$ (1.5 m) molecular sieve 5A (MS) column. The column valve configuration permitted backflushing the DC 200/500 column and bypassing the MS column. Nitrogen and methane were resolved on the MS column. Ethane through the butanes were separated on the DC $200 / 500$ column; the column was backflushed to obtain a $\mathrm{C}_{5}+$ peak. Digital integrator $\mathrm{A}$ was used to measure peak areas. The precision of the analytical system was found to be 0.06 percent in the computed heating value. 


\subsubsection{Test Results}

The primary purpose of this test was to examine the precision of the LNG sampling system. The LNG was totally vaporized downstream of the sampling probe and the analysis of this gas was to serve as the basis on which to evaluate the liquid sample analysis. However, the analyses of the vaporized gas produced erratic results that are felt to be more a function of the low pressure of the gas than composition change in the pipeline. Of the six sets of sampling data taken, only the second set contained sufficient samples taken under constant vaporizer conditions to directly compare the gas and liquid sample compositions. See figure 5.19. Since composition variations were probably less of a factor than the gas analyses, separate means and standard deviations were computed for the liquid samples and for the gas samples for each of the six data sets. See table 5.15. The heating values are computed using the A.G.A. method [1] and assumes equal parts of iso and normal pentane; the liquid phase densities were computed from the extended corresponding states model [3] (Appendix 7.5 lists the compositions and operating parameters for all of the tests).

During the first data set the vaporizer inlet pressure varied erratically (30-56 psig). Therefore, these samples were taken only to gain experience in operating the sampling system. For data set 6, the chromatograph-integrator system was behaving erratically with respect to the butane peaks. For these reasons, the results for these two data sets, as given in table 5.15, do not represent a properly operating system under stable operating conditions and were not included in subsequent data analysis.

Although the conditions under which liquid samples were taken for data sets $2,3,4$, and 5 are considered acceptable for sampling purposes, some points were deleted from the data analyses. It was found that the LNG sampling system worked well at sampling rates of $12.5 \mathrm{slpm}$ or greater; however, two samples, run No. 19 at $3.4 \mathrm{slpm}$ and run No. 57 at $6.2 \mathrm{slpm}$, yielded poor results and wer omitted from the analyses. Also during these tests the accumulator residence time of the "good" liquid samples ranged between 28 and 76 seconds, and on this basis run No. 25 was also omitted. Run No. 31 was omitted from the data analyse because it did not go through the accumulator and run No. 35 was omitted as the evidence indicated that it was an outlier. For data set 4, run No. 51 was analy three times; the first analysis, being completely wrong, was omitted.

An estimate of standard deviation was calculated based on data sets 2,3 , 4 , and 5. For the liquid samples the value obtained was 0.72 Btu/scf with 17 degrees of freedom. An upper $99 \%$ confidence bound for the standard deviation based on this estimate is $1.18 \mathrm{Btu} / \mathrm{scf}$, or $0.1 \%$ based on a heating value of $1200 \mathrm{Btu} / \mathrm{scf}$. 


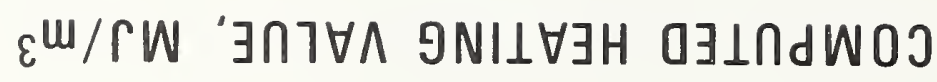

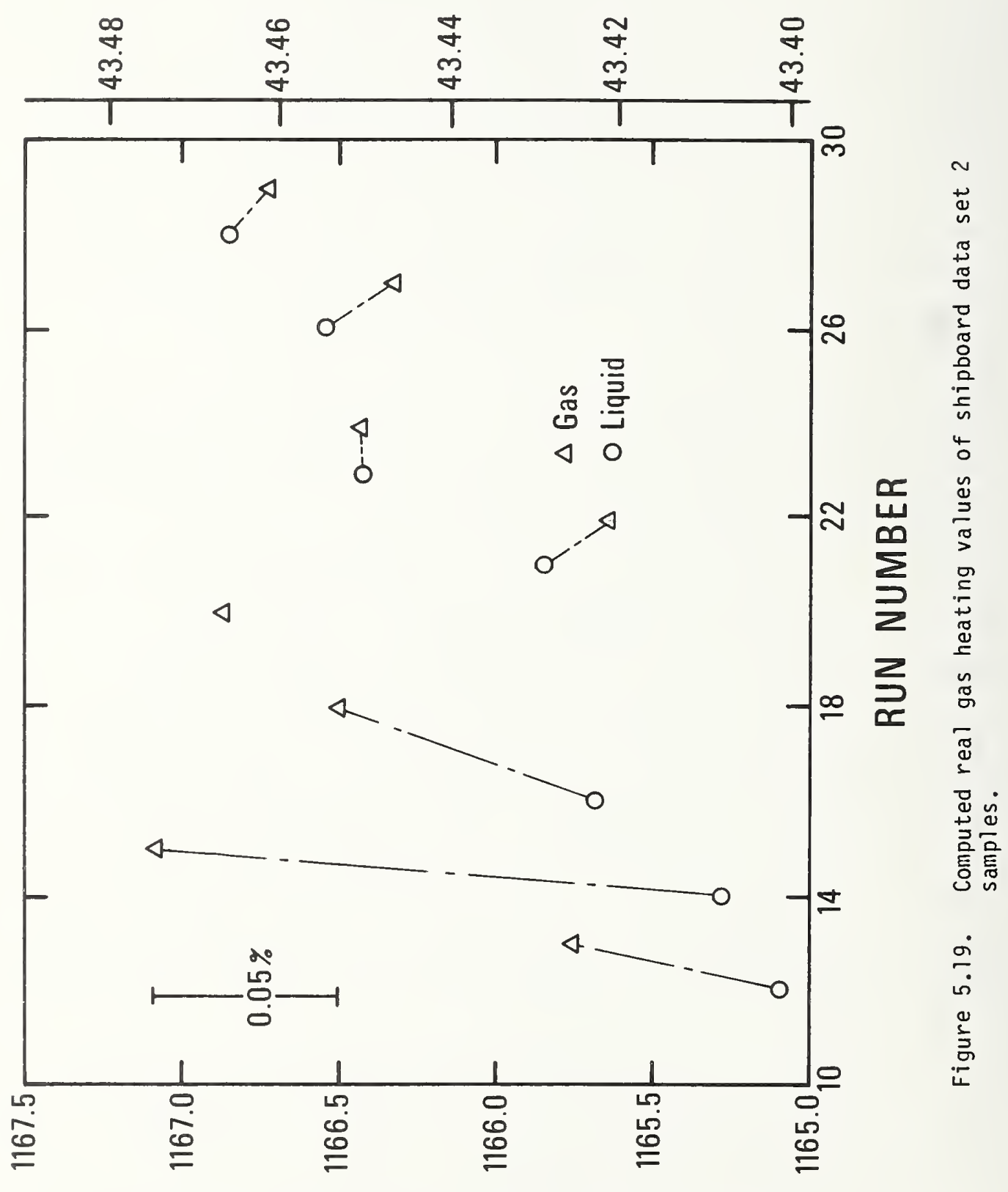

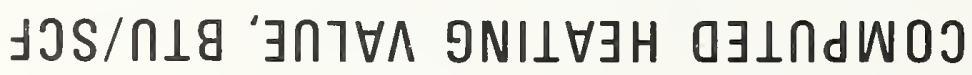


Table 5.15. Averaqe values and estimated standard deviations in composition, real aas heatina value, and liquid density for shipboard tests.

\begin{tabular}{|c|c|c|c|c|c|c|c|c|c|c|c|}
\hline \multirow{3}{*}{$\begin{array}{l}\text { Data } \\
\text { Set }\end{array}$} & \multirow[t]{3}{*}{ Sample } & \multirow{3}{*}{$\begin{array}{l}\text { Number } \\
\text { of } \\
\text { Points }\end{array}$} & \multicolumn{9}{|c|}{ Average Value and Estimated Standard Deviation in } \\
\hline & & & \multicolumn{7}{|c|}{ Composition, mol \% } & \multirow{2}{*}{$\begin{array}{l}\text { Heating } \\
\text { Value } \\
\text { BTU/SCF } \\
\left(\mathrm{MJ} / \mathrm{m}^{3}\right)\end{array}$} & \multirow{2}{*}{$\begin{array}{l}\text { Liquid } \\
\text { Density } \\
\mathrm{g} / \mathrm{cm}^{3}\end{array}$} \\
\hline & & & $\mathrm{N}_{2}$ & $\mathrm{CH}_{4}$ & $\mathrm{C}_{2} \mathrm{H}_{6}$ & $\mathrm{C}_{3} \mathrm{H}_{8}$ & i $\mathrm{C}_{4} \mathrm{H}_{10}$ & $\mathrm{nC}_{4} \mathrm{H}_{10}$ & $c_{5}^{+}$ & & \\
\hline \multirow[t]{2}{*}{$\mathrm{T}=114.6$} & L & 7 & $\begin{array}{l}0.201 \\
0.143\end{array}$ & $\begin{array}{r}85.864 \\
3.101\end{array}$ & $\begin{array}{r}10.063 \\
2.252\end{array}$ & $\begin{array}{l}2.983 \\
0.716\end{array}$ & $\begin{array}{l}0.452 \\
0.155\end{array}$ & $\begin{array}{l}0.416 \\
0.134\end{array}$ & $\begin{array}{l}0.020 \\
0.020\end{array}$ & $\begin{array}{c}1165.8 \\
35.9 \\
(43.428)\end{array}$ & $\begin{array}{l}0.4682 \\
0.0107\end{array}$ \\
\hline & G & 1 & 0.209 & 83.762 & 11.553 & 3.442 & 0.541 & 0.494 & 0.0 & $\begin{array}{c}1176.7 \\
(43.833)\end{array}$ & 0.4752 \\
\hline \multirow[t]{2}{*}{$\stackrel{2}{\mathrm{~T}=114.6}$} & L & 7 & $\begin{array}{l}0.110 \\
0.003\end{array}$ & $\begin{array}{r}85.149 \\
0.036\end{array}$ & $\begin{array}{r}10.558 \\
0.024\end{array}$ & $\begin{array}{l}3.176 \\
0.013\end{array}$ & $\begin{array}{l}0.511 \\
0.004\end{array}$ & $\begin{array}{l}0.460 \\
0.003\end{array}$ & $\begin{array}{l}0.045 \\
0.003\end{array}$ & $\begin{array}{c}1165.8 \\
0.5 \\
(43.428) \\
(0.020)\end{array}$ & $\begin{array}{l}0.4712 \\
0.0001\end{array}$ \\
\hline & G & 8 & $\begin{array}{l}0.109 \\
0.007\end{array}$ & $\begin{array}{r}85.112 \\
0.049\end{array}$ & $\begin{array}{r}10.573 \\
0.051\end{array}$ & $\begin{array}{l}3.184 \\
0.009\end{array}$ & $\begin{array}{l}0.515 \\
0.005\end{array}$ & $\begin{array}{l}0.460 \\
0.002\end{array}$ & $\begin{array}{l}0.047 \\
0.057\end{array}$ & $\begin{array}{c}1166.3 \\
0.5 \\
(43.446) \\
(0.020)\end{array}$ & $\begin{array}{l}0.4713 \\
0.0001\end{array}$ \\
\hline \multirow[t]{2}{*}{$\mathrm{T}=3114.6$} & L & 4 & $\begin{array}{l}0.015 \\
0.017\end{array}$ & $\begin{array}{r}82.544 \\
0.031\end{array}$ & $\begin{array}{r}12.353 \\
0.038\end{array}$ & $\begin{array}{l}3.863 \\
0.023\end{array}$ & $\begin{array}{l}0.623 \\
0.005\end{array}$ & $\begin{array}{l}0.563 \\
0.004\end{array}$ & $\begin{array}{l}0.040 \\
0.028\end{array}$ & $\begin{array}{c}1195.8 \\
0.41 \\
(44.547) \\
(.015)\end{array}$ & $\begin{array}{l}0.4799 \\
0.0001\end{array}$ \\
\hline & G & 4 & $\begin{array}{l}0.016 \\
0.016\end{array}$ & $\begin{array}{r}82.258 \\
0.563\end{array}$ & $\begin{array}{r}12.611 \\
0.496\end{array}$ & $\begin{array}{l}3.898 \\
0.101\end{array}$ & $\begin{array}{l}0.614 \\
0.027\end{array}$ & $\begin{array}{l}0.553 \\
0.002\end{array}$ & $\begin{array}{l}0.051 \\
0.008\end{array}$ & $\begin{array}{c}1198.3 \\
5.6 \\
(44.638) \\
(0.211)\end{array}$ & $\begin{array}{l}0.4806 \\
0.0016\end{array}$ \\
\hline \multirow[t]{2}{*}{$\begin{array}{c}4 \\
\mathrm{~T}=115.0\end{array}$} & L & 8 & $\begin{array}{l}0.0006 \\
0.0015\end{array}$ & $\begin{array}{r}79.045 \\
0.080\end{array}$ & $\begin{array}{r}14.515 \\
0.050\end{array}$ & $\begin{array}{l}4.854 \\
0.023\end{array}$ & $\begin{array}{l}0.800 \\
0.005\end{array}$ & $\begin{array}{l}0.719 \\
0.004\end{array}$ & $\begin{array}{l}0.067 \\
0.003\end{array}$ & $\begin{array}{c}1236.2 \\
0.9 \\
(46.050) \\
(.035)\end{array}$ & $\begin{array}{l}0.4914 \\
0.0009\end{array}$ \\
\hline & G & 4 & $\begin{array}{l}0.001 \\
0.002\end{array}$ & $\begin{array}{r}78.971 \\
0.134\end{array}$ & $\begin{array}{r}14.530 \\
0.075\end{array}$ & $\begin{array}{l}4.868 \\
0.024\end{array}$ & $\begin{array}{l}0.802 \\
0.008\end{array}$ & $\begin{array}{l}0.721 \\
0.004\end{array}$ & $\begin{array}{l}0.108 \\
0.082\end{array}$ & $\begin{array}{c}1237.9 \\
2.8 \\
(46.112) \\
(0.102)\end{array}$ & $\begin{array}{l}0.4916 \\
0.0007\end{array}$ \\
\hline \multirow[t]{2}{*}{$\begin{array}{c}5 \\
\mathrm{~T}=116.0\end{array}$} & L & 2 & 0.0 & $\begin{array}{r}78.367 \\
0.055\end{array}$ & $\begin{array}{r}15.042 \\
0.046\end{array}$ & $\begin{array}{l}5.000 \\
0.013\end{array}$ & $\begin{array}{l}0.808 \\
0.0015\end{array}$ & $\begin{array}{l}0.720 \\
0.006\end{array}$ & $\begin{array}{l}0.064 \\
0.010\end{array}$ & $\begin{array}{c}1242.6 \\
0.7 \\
(46.289) \\
(.027)\end{array}$ & $\begin{array}{l}0.4917 \\
0.0002\end{array}$ \\
\hline & G & 2 & $\begin{array}{l}0.001 \\
0.002\end{array}$ & $\begin{array}{r}78.280 \\
0.091\end{array}$ & $\begin{array}{r}15.139 \\
0.037\end{array}$ & $\begin{array}{l}5.006 \\
0.064\end{array}$ & $\begin{array}{l}0.800 \\
0.009\end{array}$ & $\begin{array}{l}0.714 \\
0.002\end{array}$ & $\begin{array}{l}0.062 \\
0.006\end{array}$ & $\begin{array}{c}1243.0 \\
0.9 \\
(46.304) \\
(0.035)\end{array}$ & $\begin{array}{l}0.4919 \\
0.0003\end{array}$ \\
\hline \multirow[t]{2}{*}{$\begin{array}{c}6^{\star} \\
T=116.5\end{array}$} & L & 7 & 0.0 & $\begin{array}{c}77.905 \\
0.09\end{array}$ & $\begin{array}{c}15.361 \\
0.07\end{array}$ & $\begin{array}{l}5.112 \\
0.022\end{array}$ & $\begin{array}{l}0.821 \\
0.006\end{array}$ & $\begin{array}{l}0.733 \\
0.005\end{array}$ & $\begin{array}{l}0.078 \\
0.007\end{array}$ & $\begin{array}{c}1247.5 \\
0.9 \\
(46.471) \\
(.035)\end{array}$ & $\begin{array}{l}0.4926 \\
0.0006\end{array}$ \\
\hline & G & 4 & 0.0 & $\begin{array}{r}78.216 \\
0.356\end{array}$ & $\begin{array}{r}15.229 \\
0.284\end{array}$ & $\begin{array}{l}5.081 \\
0.106\end{array}$ & $\begin{array}{l}0.692 \\
0.225\end{array}$ & $\begin{array}{l}0.724 \\
0.004\end{array}$ & $\begin{array}{l}0.057 \\
0.040\end{array}$ & $\begin{array}{c}1242.6 \\
5.6 \\
(46.287) \\
(0.209)\end{array}$ & $\begin{array}{l}0.4912 \\
0.0015\end{array}$ \\
\hline
\end{tabular}

*These tests occurred during unstable conditions (refer to text for details) and the values for the means and standard deviations are not meaningful. 
A commercial "primary standard" calibration gas was used for gas chromatograph calibrations. During the calibrations it became obvious that the reported and actual calibration gas compositions were different. This discrepancy was found by comparing the nitrogen to methane response factor ratio with the ratio obtained from Dietz's data [25]. Table 5.16 gives the manufacturer's stated composition and error limits along with the composition determined in our laboratory. Column configuration A was used with mixture $\mathrm{H}$ as the calibration gas. The difference between the stated and actual composition represents a 0.5 percent error in the heating value. This means that if the stated compositions had been used there would have been a bias of 0.5 percent in the computed heating value. This experience points out the importance of accurately knowing the composition of calibration gases used in custody transfer. If possible the stated composition should be verified by an independent gas analysis laboratory.

\subsubsection{LNG Flow Facility Test 2}

At this point, we had a full scale LNG sampling system which had worked in the field. However, another field test was necessary to determine:

a) the criteria for establishing sampling rate,

b) the effect of using steam versus electricity for sample vaporization,

c) the effect of not using a needle valve to control sampling rate, and

d) the effect of heat leak.

Figure 5.20 shows the flow schematic for this test. We built three vaporizers -- two steam heated and one electrically heated. One of the steam vaporizers had the same dimensions as the electric vaporizer; the second steam vaporizer had a 50 percent larger tube inner diameter and the tube length was 40 percent longer than the other two vaporizers. Table 5.17 gives the important dimensions of the vaporizers and sampling systems; figure 5.21 is a schematic of one of the sampling systems. The old test section was replaced with a test section containing two side taps mounted horizontally. The side taps were $1 / 4$ inch schedule 80 (13.7 mm 0.D. $x$ $7.67 \mathrm{~mm}$ I.D.) stainless steel pipe. Except for the vaporizers, all dimensions on both sampling systems were identical. Therefore, by operating two vaporizers simultaneously we made direct comparisons between vaporizer designs. The LNG sample lines to the vaporizers were wrapped with a $1 / 2$ inch $(13 \mathrm{~mm})$ thick layer of fiberglass pipe insulation and sealed with duct tape. Also, the steam vaporizers, steam inlet lines and condensate lines were insulated for personnel safety.

Valve Sl was a block valve (see figure 5.21) and valve s2 a metering valve; both valves were all welded stainless steel bellows valves. Neither valve was degreased before use and stem extensions were not used. 


\begin{tabular}{|c|c|c|c|}
\hline \multirow{7}{*}{ 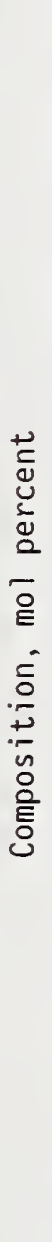 } & $\begin{array}{l}0 \\
\\
\underline{n}\end{array}$ & 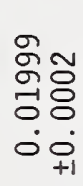 & $\begin{array}{l}\hat{8} \% \\
80 \\
0.0 \\
0\end{array}$ \\
\hline & $\stackrel{0}{\underline{J}}$ & 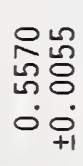 & 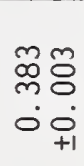 \\
\hline & $\stackrel{0}{\stackrel{\vec{I}}{J}}$ & 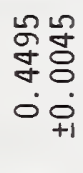 & 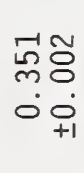 \\
\hline & $\underset{\omega}{I_{m}^{\infty}}$ & \begin{tabular}{l} 
No \\
\multirow{2}{}{} \\
$\sim$ \\
vo \\
+1
\end{tabular} & 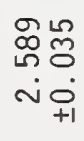 \\
\hline & $\frac{0}{I^{N}}$ & 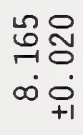 & $\begin{array}{l}\tilde{0} \\
\infty \\
\infty \\
\infty \\
\infty\end{array}$ \\
\hline & 范 & 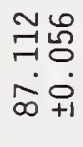 & 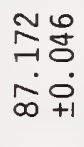 \\
\hline & $\mathcal{L}^{N}$ & 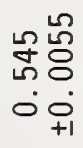 & $\begin{array}{l}\text { సुळ్ } \\
\emptyset \\
0 \\
0 \\
+1\end{array}$ \\
\hline & & 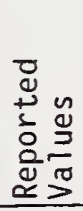 & 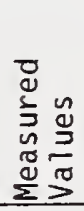 \\
\hline
\end{tabular}




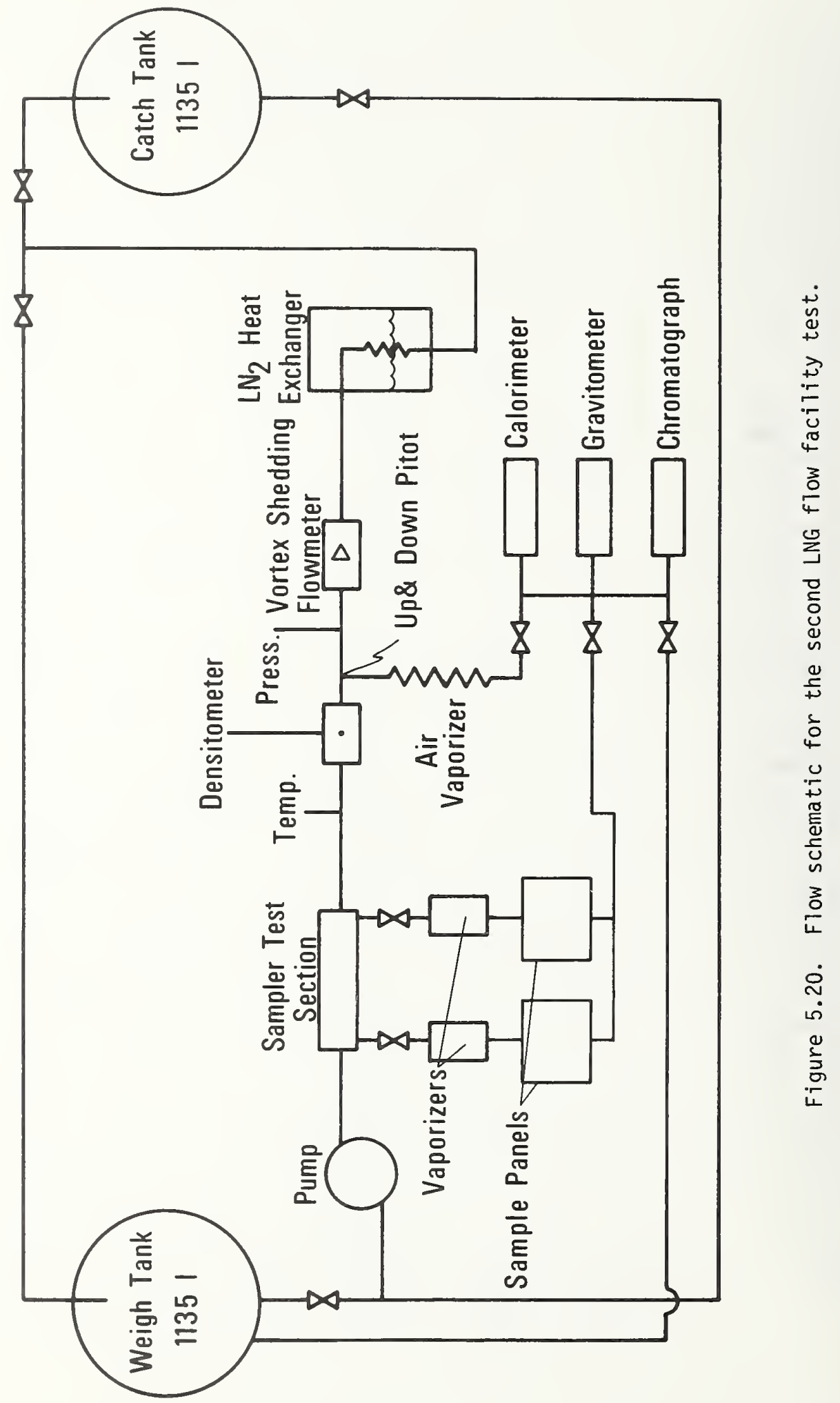


Table 5.17. Dimensions of LNG sampling system used in second flow facility tests (see figure 5.21 for schematic of sampling system).

\begin{tabular}{|c|c|c|c|}
\hline Component & $\begin{array}{l}\text { Length } \\
\text { Inches (mm) }\end{array}$ & $\begin{array}{c}\text { Outer Diameter } \\
\text { Inches (mm) }\end{array}$ & $\begin{array}{l}\text { Inner Diameter } \\
\text { Inches (mm) }\end{array}$ \\
\hline Test section & $36(914)$ & $3-1 / 8 \quad(79.4)$ & $2.812(71.42)$ \\
\hline $\begin{array}{l}\text { Side tap and line } \\
\text { between test section } \\
\text { and valve } \mathrm{Sl}^{1}\end{array}$ & $4-1 / 2 \quad(114)$ & $\begin{array}{l}0.540(13.7) \\
(1 / 4 \text { in. Sch } 80 \text { pipe }\end{array}$ & $0.302 \quad(7.67)$ \\
\hline $\begin{array}{l}\text { Line between valve sl } \\
\text { and filter (contained } \\
\text { a short radius } 90^{\circ} \text { bend) }\end{array}$ & 11 (279) & $0.25 \quad(6.4)$ & $0.180 \quad(4.57)$ \\
\hline $\begin{array}{l}\text { Line between filter } \\
\text { and valve } \mathrm{S} 2^{1}\end{array}$ & $2(51)$ & $0.25 \quad(6.4)$ & $0.180 \quad(4.57)$ \\
\hline $\begin{array}{l}\text { Line between valve } 52 \\
\text { and union at vaporizer }\end{array}$ & $13-1 / 2 \quad(343)$ & $0.25 \quad(6.4)$ & $0.180 \quad(4.57)$ \\
\hline Vaporizer 1 tubing & $36 \quad(914)$ & $1 / 8 \quad(3.18)$ & $0.101(2.56)$ \\
\hline Vaporizer 2 tubing & $50 \quad(1270)$ & $3 / 16 \quad(4.76)$ & $0.156(3.96)$ \\
\hline Vaporizer 3 tubing & $36(914)$ & $1 / 8 \quad(3.18)$ & $0.101 \quad(2.56)$ \\
\hline $\begin{array}{l}\text { For vaporizers } 1 \text { and } 2 \\
\text { steam casing (with } \\
\text { flat welded ends) }\end{array}$ & $10(254)$ & $6(152)$ & $5.5(140)$ \\
\hline $\begin{array}{l}\text { Impingement chamber } \\
\text { (with flat welded ends) }\end{array}$ & $1-1 / 2 \quad(38)$ & $1-1 / 2 \quad(38)$ & $1.376(34.95)$ \\
\hline $\begin{array}{l}\text { Line between impinge- } \\
\text { ment chamber and down- } \\
\text { stream union }\end{array}$ & $8(200)$ & $0.25 \quad(6.4)$ & $0.180 \quad(4.57)$ \\
\hline Accumulator ${ }^{1}$ & $16(406)$ & $5.125(130.2)$ & $4.805 \quad(122)$ \\
\hline
\end{tabular}




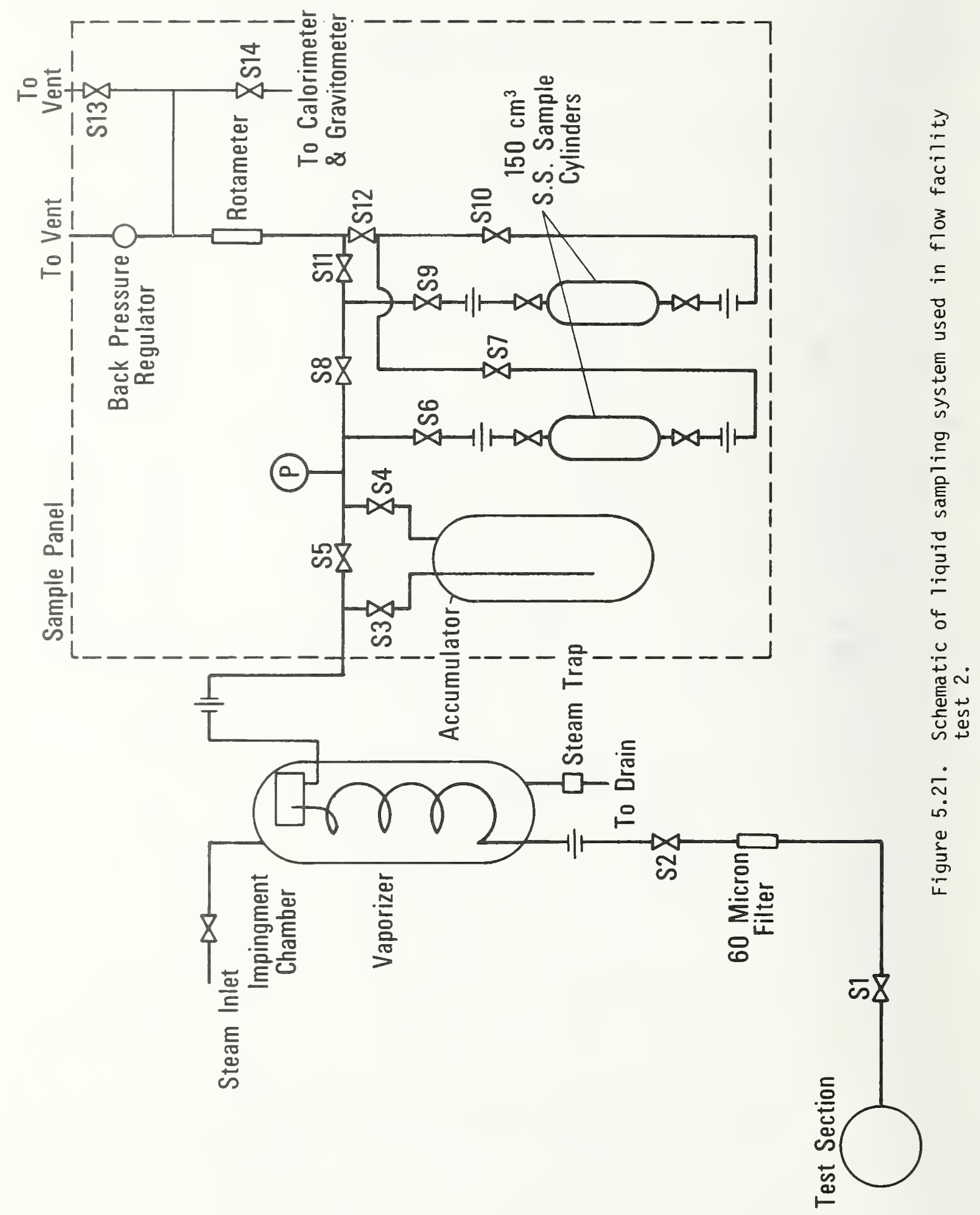


The two steam vaporizer tube lengths were twice the tube length computed by considering only the heat transfer resistance of a pure methane gas phase (see section 5.2.2 for more details). For this test we used a steam generator which produced roughly 50 psia (0.34 MPa) saturated steam.

To prevent the entrainment of fine droplets in the steam vaporizer outlet steam, an impingement chamber was included in each steam vaporizer. The stainless steel chamber consisted of a $1-1 / 2$ inch (38 mm) diameter cylinder $1-1 / 2$ inches $(38 \mathrm{~mm})$ long. It was constructed so that the vapor plus mist leaving the vaporizer tube contacted the upper surface of the chamber. The combination of impingement, sudden flow decrease and flow reversal hopefully would eliminate any remaining liquid droplets.

The electric vaporizer dimensions were chosen to correspond to one of the steam vaporizers so that a direct comparison between vaporizers could be made. However, the impingement chamber was not used with the electric vaporizer. This vaporizer consisted of thin wall $(0.012$ in $(0.30 \mathrm{~mm}))$ stainless steel tubing with electrical leads attached at each end. Since the tubing was used as the resistive heater a high amperage (18 amps) low voltage ( 4.3 volts) direct current was used. To prevent possible shorts, the vaporizer tube was epoxied into micarta couplings at each end.

Initially, the accumulator volume was two liters but the first day's test results showed that the accumulator was too small. Thereafter, a four liter accumulator was used.

Analysis of the LNG used in the first flow facility test showed relatively high concentration of $\mathrm{C}_{6}{ }^{+}$. To obtain a more representative LNG mixture, the LNG for this test was purchased from San Diego Gas and Electric Company. However, even this LNG contained approximately 0.08 mol percent $\mathrm{c}_{6}+$.

For sample analysis, column configuration A was used. Prepared mixture $\mathrm{H}$ (table 4.2) was used as the calibration gas. Both integrators $A$ and $B$ were connected to gas chromatograph II so that their results could be compared.

\subsubsection{Test results}

A total of seven tests were made in the flow facility over a four day period. Table 5.18 lists the pertinent operating parameters and lists a comparison of measured and computed heating values and specific gravities. The computed quantities are real gas values computed from the compositions using the A.G.A. methods [1]. Table 5.19 gives the average values and estimated standard deviation of the compositions and the liquid densities computed using the extended corresponding states method [3]. 


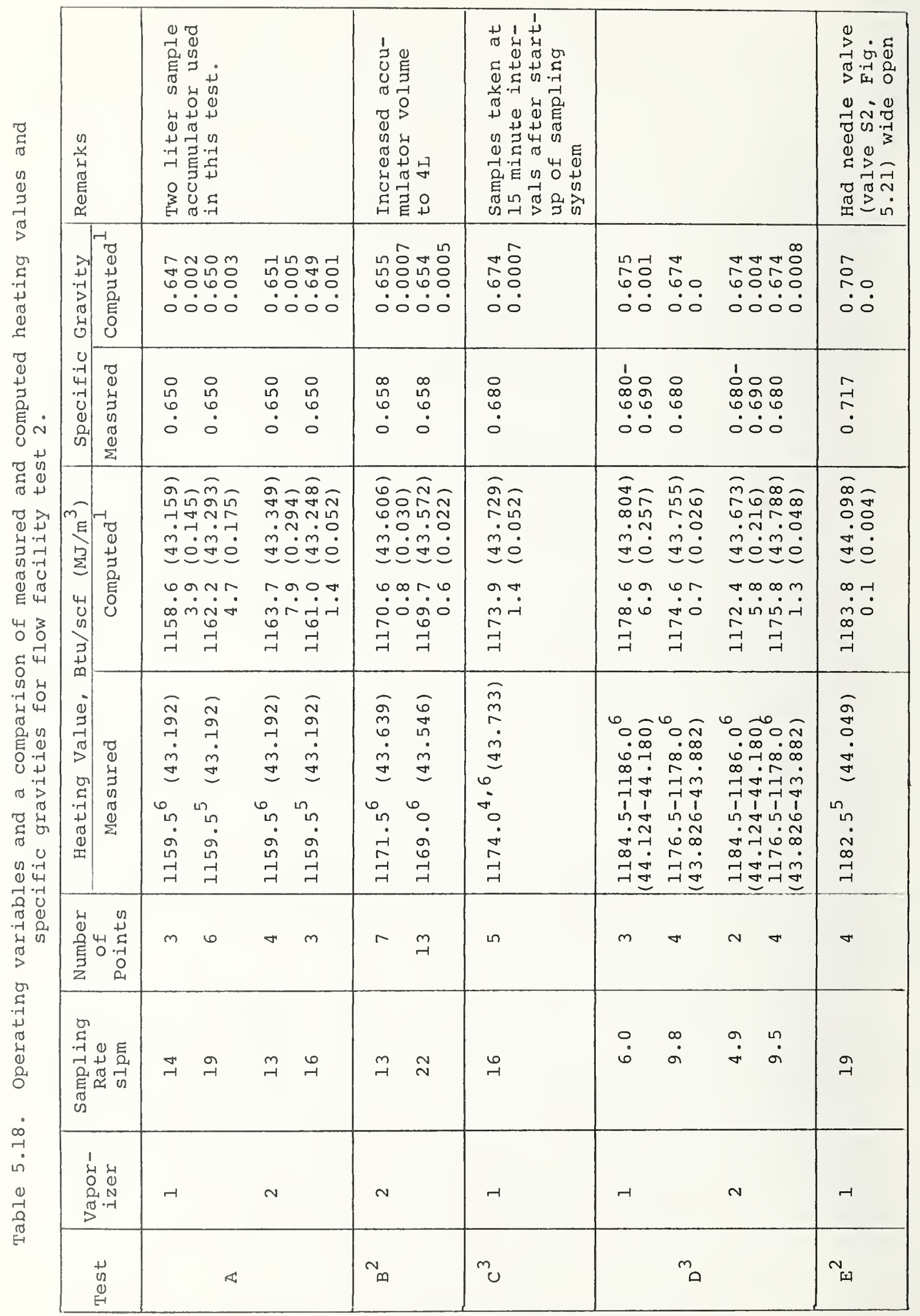



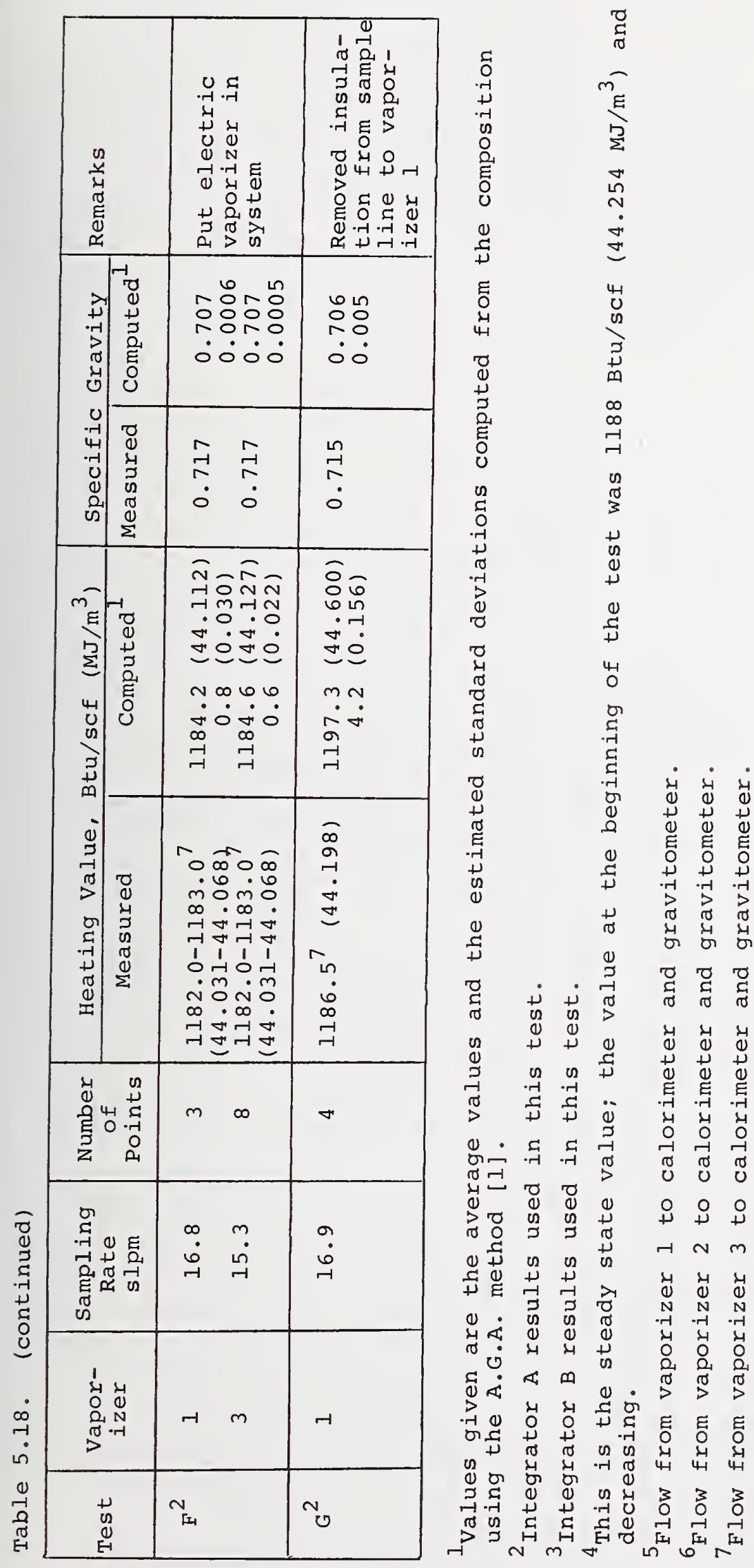
Table 5.19. Average values and estimated standard deviations in composition and liquid density for the second flow facility test.

\begin{tabular}{|c|c|c|c|c|c|c|c|c|c|c|c|c|}
\hline \multirow[t]{3}{*}{ Test } & \multirow[t]{3}{*}{ Vaporizer } & \multirow{3}{*}{$\begin{array}{l}\text { Sampling } \\
\text { Rate } \\
\text { slpm }\end{array}$} & \multirow{2}{*}{\multicolumn{9}{|c|}{$\frac{\text { Average Value and Estimated Standard Deviation in }}{\text { Composition, mol\% }}$}} & \multirow{3}{*}{$\begin{array}{l}\text { Liquid } \\
\text { Density } \\
9 / \mathrm{cm}^{3}\end{array}$} \\
\hline & & & & & & & & & & & & \\
\hline & & & $\mathrm{N}_{2}$ & $\mathrm{CH}_{4}$ & $\mathrm{C}_{2} \mathrm{H}_{6}$ & $\mathrm{C}_{3} \mathrm{H}_{8}$ & $\mathrm{iC}_{4} \mathrm{H}_{10}$ & $\mathrm{nC}_{4} \mathrm{H}_{10}$ & $i \mathrm{C}_{5} \mathrm{H}_{12}$ & $n \mathrm{CC}_{5} \mathrm{H}_{12}$ & $c_{6}^{+}$ & \\
\hline \multirow{4}{*}{$A^{1}$} & \multirow[t]{2}{*}{1} & 14 & 0.0 & $\begin{array}{r}84.997 \\
0.413\end{array}$ & $\begin{array}{r}12.005 \\
0.334\end{array}$ & $\begin{array}{l}2.414 \\
0.067\end{array}$ & $\begin{array}{l}0.190 \\
0.005\end{array}$ & $\begin{array}{l}0.226 \\
0.006\end{array}$ & $\begin{array}{l}0.048 \\
0.0004\end{array}$ & $\begin{array}{l}0.037 \\
0.001\end{array}$ & $\begin{array}{l}0.083 \\
0.0008\end{array}$ & $\begin{array}{l}0.4593 \\
0.0015\end{array}$ \\
\hline & & 19 & $\begin{array}{l}0.0009 \\
0.002\end{array}$ & $\begin{array}{r}84.609 \\
0.486\end{array}$ & $\begin{array}{r}12.324 \\
0.390\end{array}$ & $\begin{array}{l}2.469 \\
0.077\end{array}$ & $\begin{array}{l}0.193 \\
0.006\end{array}$ & $\begin{array}{l}0.232 \\
0.007\end{array}$ & $\begin{array}{l}0.049 \\
0.002\end{array}$ & $\begin{array}{l}0.038 \\
0.002\end{array}$ & $\begin{array}{l}0.084 \\
0.003\end{array}$ & $\begin{array}{l}0.4607 \\
0.0016\end{array}$ \\
\hline & \multirow[t]{2}{*}{2} & 13 & 0.0 & $\begin{array}{r}84.454 \\
0.831\end{array}$ & $\begin{array}{r}12.439 \\
0.673\end{array}$ & $\begin{array}{l}2.506 \\
0.132\end{array}$ & $\begin{array}{l}0.196 \\
0.010\end{array}$ & $\begin{array}{l}0.233 \\
0.013\end{array}$ & $\begin{array}{l}0.049 \\
0.002\end{array}$ & $\begin{array}{l}0.039 \\
0.002\end{array}$ & 0.084 & $\begin{array}{l}0.4610 \\
0.0022\end{array}$ \\
\hline & & 16 & 0.0 & $\begin{array}{r}84.669 \\
0.080\end{array}$ & $\begin{array}{r}12.302 \\
0.019\end{array}$ & $\begin{array}{l}2.466 \\
0.080\end{array}$ & $\begin{array}{l}0.187 \\
0.004\end{array}$ & $\begin{array}{l}0.220 \\
0.005\end{array}$ & $\begin{array}{l}0.044 \\
0.0008\end{array}$ & $\begin{array}{l}0.035 \\
0.001\end{array}$ & $\begin{array}{l}0.077 \\
0.001\end{array}$ & $\begin{array}{l}0.4603 \\
0.0006\end{array}$ \\
\hline \multirow{2}{*}{$B^{1}$} & \multirow[t]{2}{*}{2} & 13 & $\begin{array}{l}0.007 \\
0.005\end{array}$ & $\begin{array}{r}83.772 \\
0.075\end{array}$ & $\begin{array}{r}12.968 \\
0.064\end{array}$ & $\begin{array}{l}2.604 \\
0.013\end{array}$ & $\begin{array}{l}0.205 \\
0.001\end{array}$ & $\begin{array}{l}0.244 \\
0.001\end{array}$ & $\begin{array}{l}0.052 \\
0.0008\end{array}$ & $\begin{array}{l}0.058 \\
0.001\end{array}$ & $\begin{array}{l}0.090 \\
0.001\end{array}$ & $\begin{array}{l}0.4537 \\
0.0005\end{array}$ \\
\hline & & 22 & $\begin{array}{l}0.011 \\
0.003\end{array}$ & $\begin{array}{r}83.866 \\
0.050\end{array}$ & $\begin{array}{r}12.904 \\
0.037\end{array}$ & $\begin{array}{l}2.585 \\
0.016\end{array}$ & $\begin{array}{l}0.203 \\
0.002\end{array}$ & $\begin{array}{l}0.242 \\
0.002\end{array}$ & $\begin{array}{l}0.052 \\
0.0008\end{array}$ & $\begin{array}{l}0.057 \\
0.001\end{array}$ & $\begin{array}{l}0.090 \\
0.001\end{array}$ & $\begin{array}{l}0.4534 \\
0.0005\end{array}$ \\
\hline$c^{2}$ & 1 & 16 & $\begin{array}{l}1.611 \\
0.024\end{array}$ & $\begin{array}{r}80.026 \\
0.118\end{array}$ & $\begin{array}{r}14.712 \\
0.119\end{array}$ & $\begin{array}{l}2.959 \\
0.018\end{array}$ & $\begin{array}{l}0.293 \\
0.006\end{array}$ & $\begin{array}{l}0.345 \\
0.007\end{array}$ & $\begin{array}{l}0.067 \\
0.002\end{array}$ & $\begin{array}{l}0.053 \\
0.002\end{array}$ & $\begin{array}{l}0.114 \\
0.006\end{array}$ & $\begin{array}{l}0.4802 \\
0.0038\end{array}$ \\
\hline \multirow{4}{*}{$D^{2}$} & \multirow[t]{2}{*}{1} & 6.0 & $\begin{array}{l}1.444 \\
0.424\end{array}$ & $\begin{array}{r}79.903 \\
0.302\end{array}$ & $\begin{array}{r}14.932 \\
0.241\end{array}$ & $\begin{array}{l}3.012 \\
0.043\end{array}$ & $\begin{array}{l}0.238 \\
0.003\end{array}$ & $\begin{array}{l}0.280 \\
0.005\end{array}$ & $\begin{array}{l}0.052 \\
0.006\end{array}$ & $\begin{array}{l}0.042 \\
0.002\end{array}$ & $\begin{array}{l}0.095 \\
0.008\end{array}$ & $\begin{array}{l}0.4797 \\
0.0012\end{array}$ \\
\hline & & 9.8 & $\begin{array}{l}1.611 \\
0.024\end{array}$ & $\begin{array}{r}80.026 \\
0.118\end{array}$ & $\begin{array}{r}14.712 \\
0.119\end{array}$ & $\begin{array}{l}2.959 \\
0.018\end{array}$ & $\begin{array}{l}0.233 \\
0.002\end{array}$ & $\begin{array}{l}0.274 \\
0.003\end{array}$ & $\begin{array}{l}0.051 \\
0.001\end{array}$ & $\begin{array}{l}0.042 \\
0.002\end{array}$ & $\begin{array}{l}0.090 \\
0.005\end{array}$ & $\begin{array}{l}0.4768 \\
0.0010\end{array}$ \\
\hline & \multirow[t]{2}{*}{2} & 4.9 & $\begin{array}{l}1.665 \\
0.718\end{array}$ & $\begin{array}{r}79.978 \\
0.819\end{array}$ & $\begin{array}{r}14.771 \\
0.086\end{array}$ & $\begin{array}{l}2.889 \\
0.036\end{array}$ & $\begin{array}{l}0.228 \\
0.013\end{array}$ & $\begin{array}{l}0.269 \\
0.002\end{array}$ & $\begin{array}{l}0.050 \\
0.003\end{array}$ & $\begin{array}{l}0.040 \\
0.004\end{array}$ & $\begin{array}{l}0.102 \\
0.009\end{array}$ & $\begin{array}{l}0.4795 \\
0.0007\end{array}$ \\
\hline & & 9.5 & $\begin{array}{l}1.491 \\
0.024\end{array}$ & $\begin{array}{r}80.103 \\
0.132\end{array}$ & $\begin{array}{r}14.757 \\
0.082\end{array}$ & $\begin{array}{l}2.956 \\
0.025\end{array}$ & $\begin{array}{l}0.234 \\
0.014\end{array}$ & $\begin{array}{l}0.275 \\
0.003\end{array}$ & $\begin{array}{l}0.052 \\
0.003\end{array}$ & $\begin{array}{l}0.042 \\
0.002\end{array}$ & $\begin{array}{l}0.089 \\
0.005\end{array}$ & $\begin{array}{l}0.4770 \\
0.0008\end{array}$ \\
\hline$E^{1}$ & 1 & 19 & $\begin{array}{l}4.122 \\
0.008\end{array}$ & $\begin{array}{r}74.153 \\
0.013\end{array}$ & $\begin{array}{r}17.161 \\
0.013\end{array}$ & $\begin{array}{l}3.662 \\
0.006\end{array}$ & $\begin{array}{l}0.291 \\
0.0003\end{array}$ & $\begin{array}{l}0.347 \\
0.003\end{array}$ & $\begin{array}{l}0.077 \\
0.0007\end{array}$ & $\begin{array}{l}0.054 \\
0.0006\end{array}$ & $\begin{array}{l}0.133 \\
0.001\end{array}$ & $\begin{array}{l}0.5015 \\
0.0010\end{array}$ \\
\hline \multirow[b]{2}{*}{$F^{1}$} & 1 & 16.8 & $\begin{array}{l}4.138 \\
0.018\end{array}$ & $\begin{array}{r}74.083 \\
0.062\end{array}$ & $\begin{array}{r}17.202 \\
0.059\end{array}$ & $\begin{array}{l}3.669 \\
0.015\end{array}$ & $\begin{array}{l}0.292 \\
0.001\end{array}$ & $\begin{array}{l}0.349 \\
0.001\end{array}$ & $\begin{array}{l}0.077 \\
0.0002\end{array}$ & $\begin{array}{l}0.055 \\
0.0004\end{array}$ & $\begin{array}{l}0.134 \\
0.0003\end{array}$ & $\begin{array}{l}0.5020 \\
0.0010\end{array}$ \\
\hline & 3 & 15.3 & $\begin{array}{l}4.043 \\
0.026\end{array}$ & $\begin{array}{r}74.223 \\
0.049\end{array}$ & $\begin{array}{r}17.174 \\
0.038\end{array}$ & $\begin{array}{l}3.654 \\
0.020\end{array}$ & $\begin{array}{l}0.292 \\
0.0006\end{array}$ & $\begin{array}{l}0.348 \\
0.001\end{array}$ & $\begin{array}{l}0.077 \\
0.0003\end{array}$ & $\begin{array}{l}0.054 \\
0.0005\end{array}$ & $\begin{array}{l}0.134 \\
0.0005\end{array}$ & $\begin{array}{l}0.5020 \\
0.0012\end{array}$ \\
\hline$G^{1}$ & 1 & 16.9 & $\begin{array}{l}3.231 \\
0.279\end{array}$ & $\begin{array}{r}74.597 \\
0.129\end{array}$ & $\begin{array}{r}17.517 \\
0.139\end{array}$ & $\begin{array}{l}3.729 \\
0.019\end{array}$ & $\begin{array}{l}0.298 \\
0.003\end{array}$ & $\begin{array}{l}0.356 \\
0.002\end{array}$ & $\begin{array}{l}0.078 \\
0.001\end{array}$ & $\begin{array}{l}0.056 \\
0.0006\end{array}$ & $\begin{array}{l}0.136 \\
0.002\end{array}$ & $\begin{array}{l}0.5002 \\
0.0005\end{array}$ \\
\hline
\end{tabular}

\footnotetext{
IIntearator $A$ results used in this test.
}

${ }^{2}$ Integrator $B$ results used in this test. 


\section{Test A}

Because the sampling rates would be comparable to those used in laboratory tests, two liter accumulators were used in test $\mathrm{A}$. However, the test results suggested that the accumulator was too small. Figure 5.22 shows the deviation from the average heating value for this test. At the sample rates used in this test the accumulator residence time ranged between 10 and 18 seconds; this same range gave good results in laboratory tests. All remaining tests were made using four liter accumulators.

Test B

As shown in figure 5.23, results of test B clearly confirmed the need for the larger accumulator. Possible reasons for this include:

a) the use of a constant wall temperature vaporizer (as opposed to the constant heat flux vaporizer used in the laboratory apparatus), or

b) the presence of a finite heat leak into the sample line. Unfortunately, we did not have sufficient time to identify the reason for needing the longer residence time.

Two points were eliminated from figure 5.23 and from the statistical analysis of test B results. For no obvious reason, one sample had a methane content five standard deviations higher than the average value for the test (both integrators gave the same result). However, the second outlier was the first sample taken after changing the sampling rate; it was taken less than 20 minutes after the change. This suggested the possibility of flow transients affecting the sampling precision.

\section{Test $C$}

Test $C$ was a short test to determine if sampling system startup transients affected sampling precision. Figure 5.24 shows the deviation in heating value for this test. The deviations are relative to the average values obtained under steady conditions in test $D$ which was run on the same day. In this test, samples were taken every 15 minutes after putting the sampling system in operation. Although the scatter was greater, especially in the nitrogen, methane and ethane contents, there was no obvious trend with time. Another sample was rejected in Test $D$ which was one percent higher than the average heating value in that test; it too was drawn less than 30 minutes after changing sample rates. These results suggest that the sampling rate should be established at least 30 minutes before taking a sample.

Test $D$

Test $D$ was made to determine the sampling precision of the two steam vaporizers at low sampling rates. The initial sampling rates were 9.8 and $9.5 \mathrm{slpm}$ in vaporizers 1 and 2 , respectively. At these rates neither the gravitometer nor the calorimeter indicated the precision being diminished for either vaporizer. These sampling rates corresponded to a linear liquid 


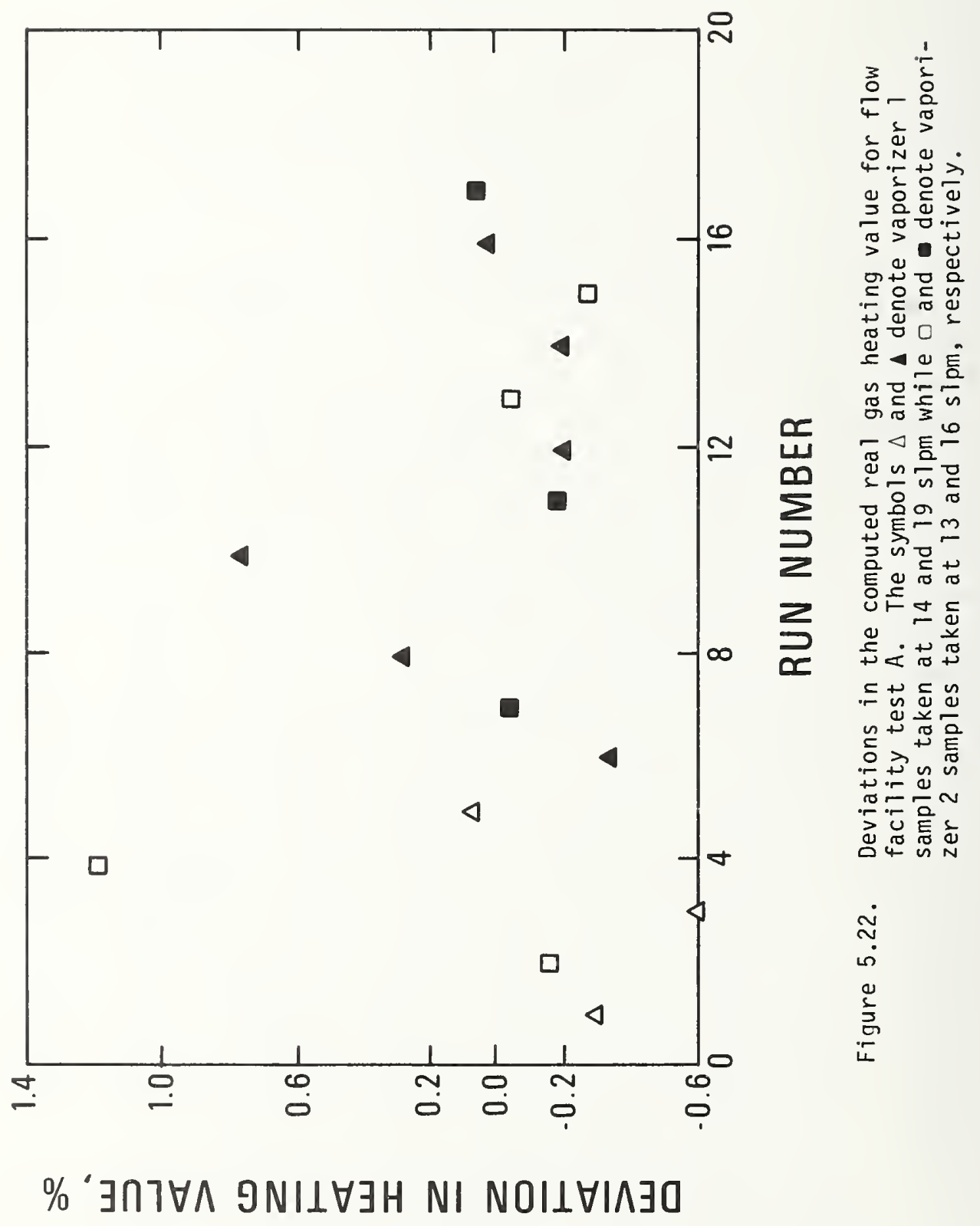




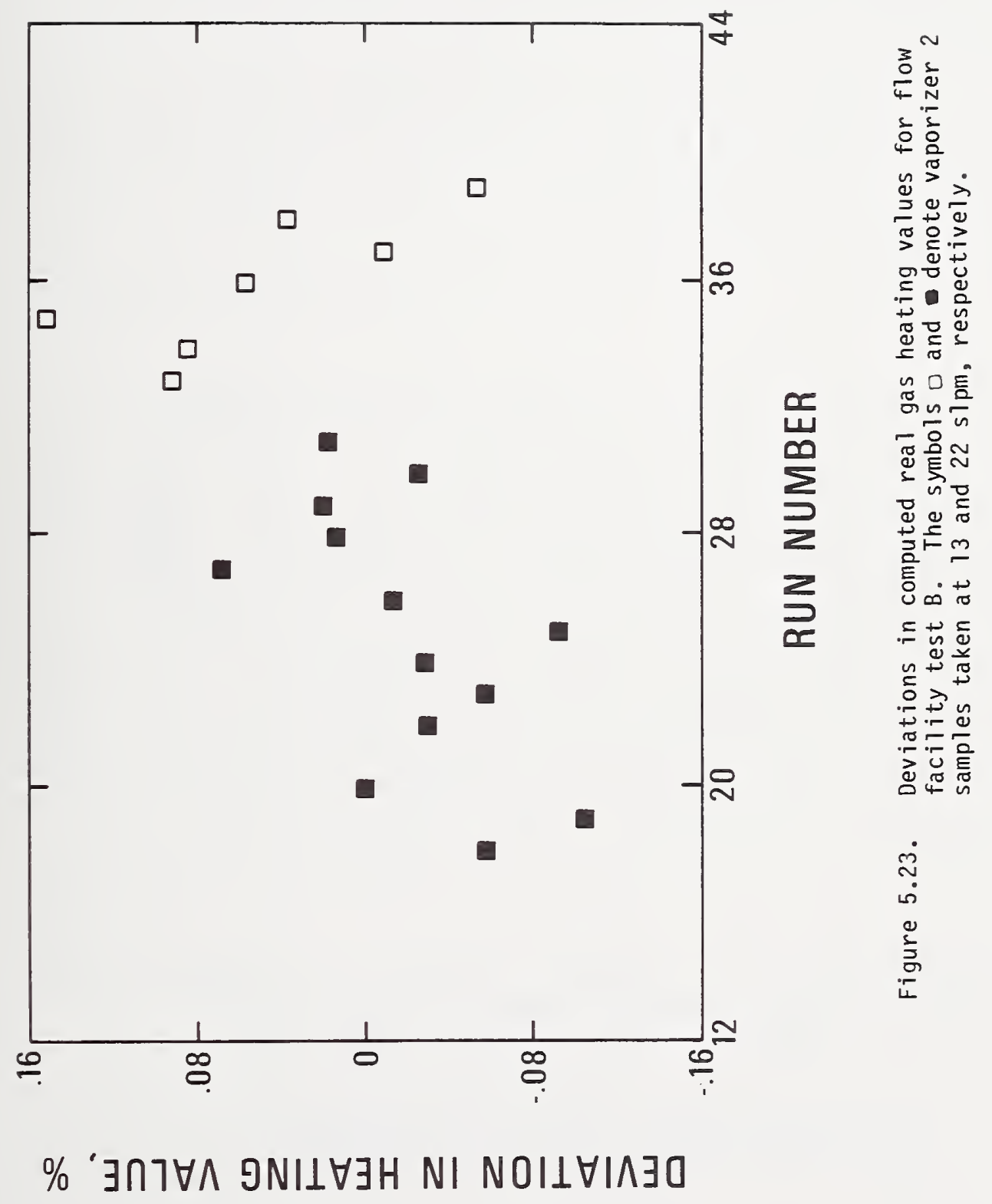




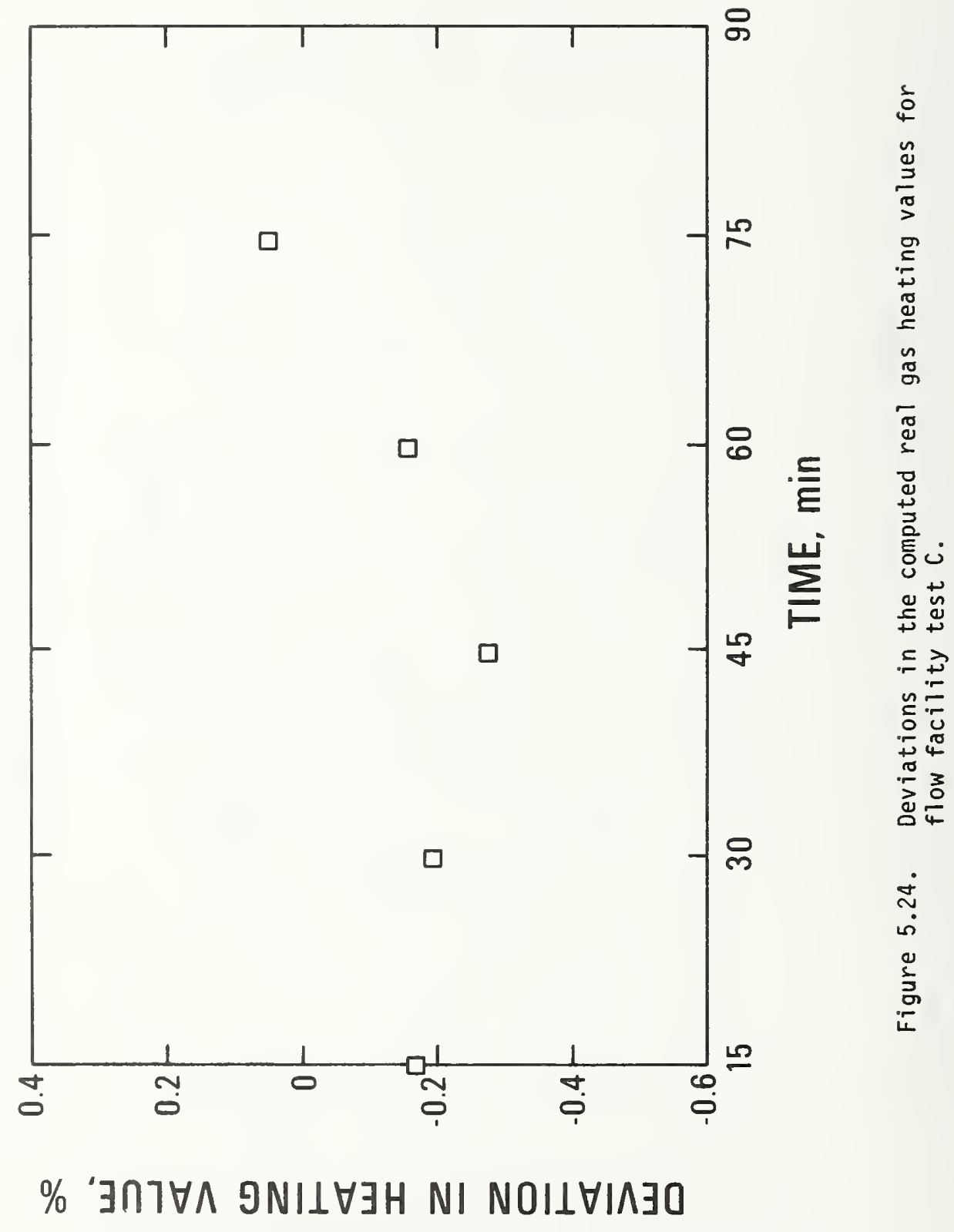


flow rate of $4.0 \mathrm{~cm} / \mathrm{s}$ and $1.6 \mathrm{~cm} / \mathrm{s}$ in vaporizer 1 and 2 , respectively. Next, the sampling rates were lowered so that the linear flow rates were $2.4 \mathrm{~cm} / \mathrm{s}$ and $0.8 \mathrm{~cm} / \mathrm{s}$ in vaporizers 1 and 2 , respectively. For both liquid vaporizers these rates the gravitometer indicated a poorer sampling precision but the calorimeter did not. Figure 5.25 shows the change in precision of the computed heating value when going to the lower sampling rate. If the linear flow rate in the sample vaporizer was the important factor in determining sampling precision at low sample rates, the vaporizer 2 results at $9.5 \mathrm{slpm}$ would have been much poorer than actually observed. This suggests that the poor precision at low sample rates originates at some point in the sampling system, other than in the vaporizer. It seemed plausible that the low sample flows could have been too low to provide adequate mixing in the acculuator. However, this probably was not the case because the accumulator residence time was $68 \mathrm{~s}$ in these tests; good results were obtained during shipboard tests with residence times of $120 \mathrm{~s}$. However, the shipboard accumulator was heated to induce mixing.

\section{Test E}

Figure 5.26 shows the deviation in computed heating values for test $\mathrm{E}$; this was a short test to see if the needle valve is necessary in a sampling system to prevent backflow. In this test the needle valve (valve s2, figure 5.21) was fully open. These results confirmed the laboratory results in that a needle valve is not necessary, at least when using a tube vaporizer where there is a finite pressure drop in the vaporizer. (However, the needle valve is useful for controlling sampling rates.) The pressure difference between the test section and sample panel varied between $0.5 \mathrm{psi}$ ( $3 \mathrm{kPa}$ ) and 1.5 psi (10 kPa) during this test; when using the needle valve to control the sample rate the pressure difference was typically 20 psi $(0.14 \mathrm{MPa})$ to 35 psi $(0.24 \mathrm{MPa}$ ). (No significance should be put on the unusually high precision of this test; these estimated standard deviations are smaller than that of analysis alone.)

\section{Test $F$}

Test $F$ was a comparison of electric (vaporizer 3) and steam (vaporizer 1) vaporizers. Figure 5.27 shows the deviation in computed heating value for this test. In this test the electric vaporizer had a heat input of 77 watts; at this power level, roughly half of the vaporizer was frostfree and the outlet temperature was roughly $100^{\circ} \mathrm{F}\left(38^{\circ} \mathrm{C}\right)$. As expected, the precision of the steam and electric vaporizers was comparable.

\section{Test $G$}

The last test considered the effect of heat leak on precision. Up to this point the sample lines had been insulated with fiberglass pipe insulation. During operation the lines felt slightly cool to the touch in most 


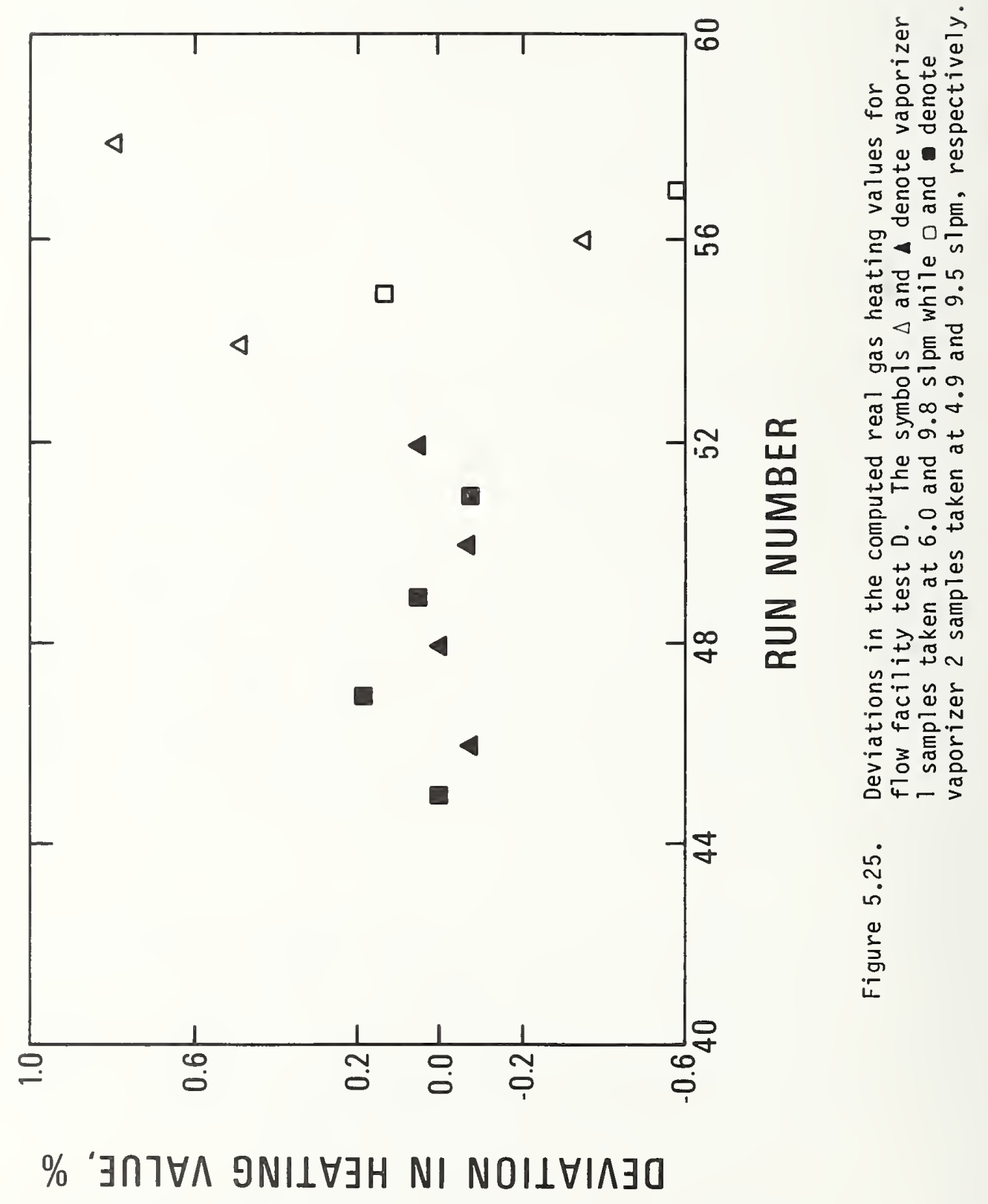




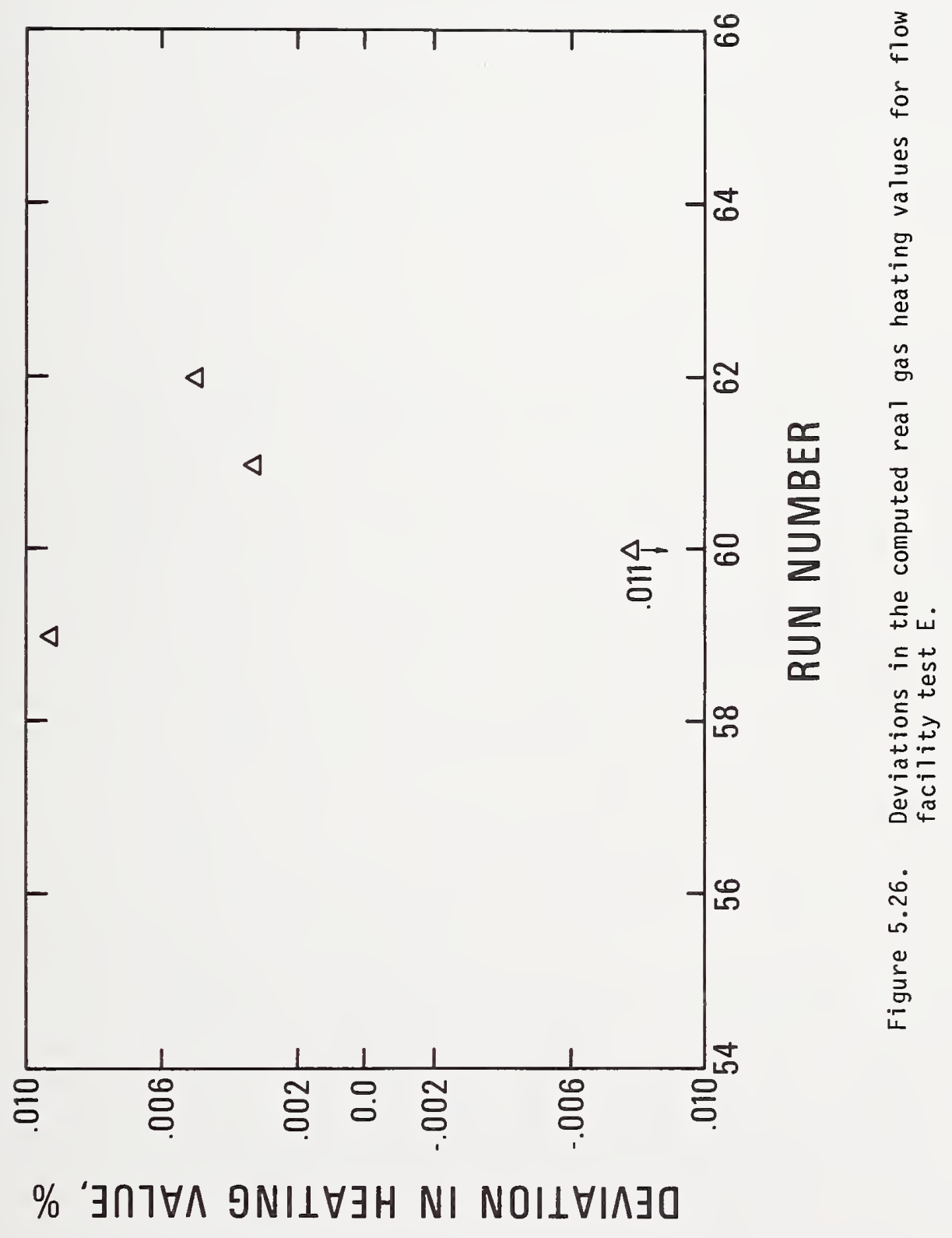




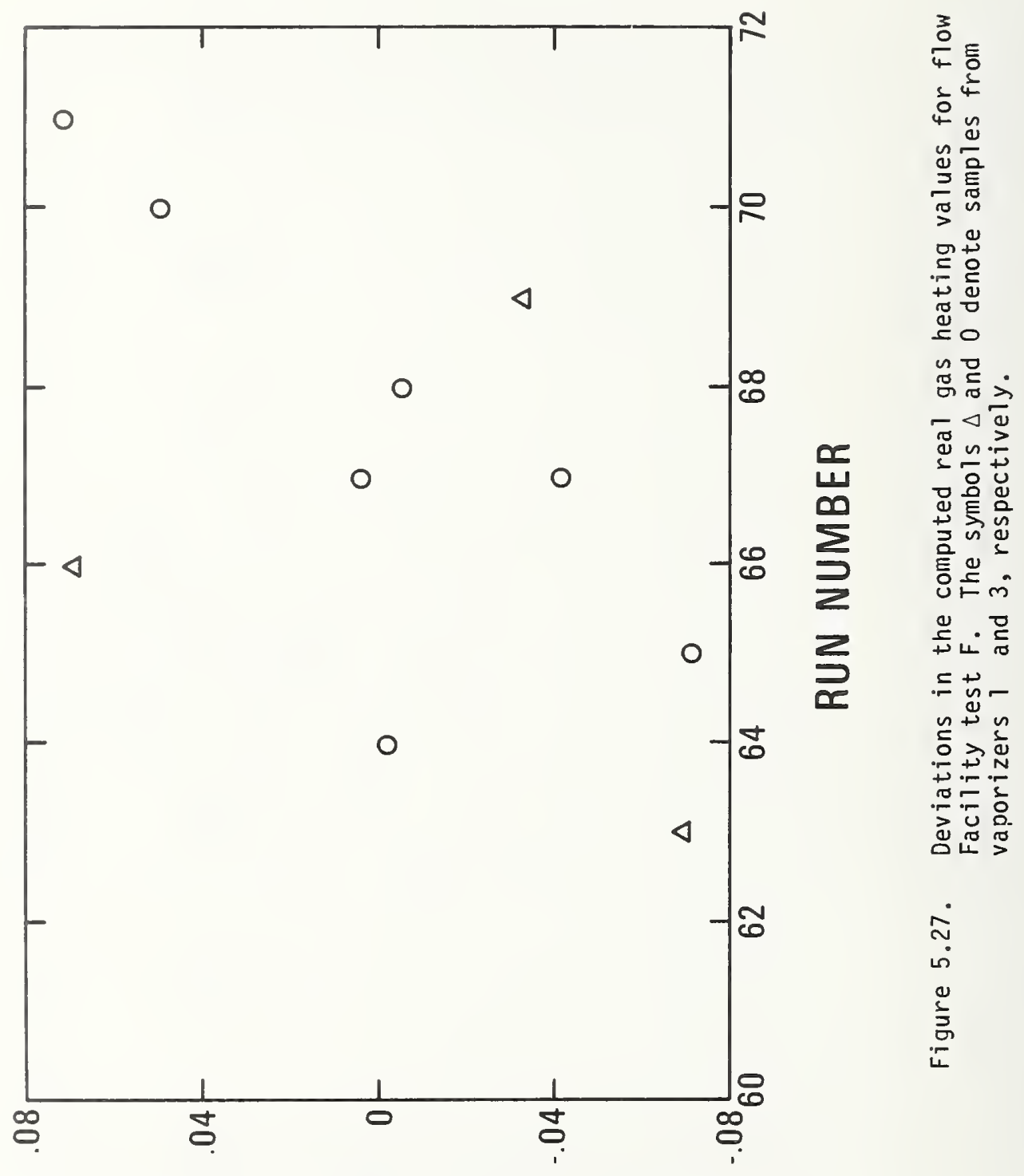

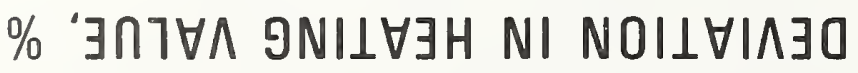


places; at the $90^{\circ}$ bend between the block valve (Valve Sl) and needle valve (Valve S2) there was a frost spot on the line to vaporizer 2 (or 3 ). No frost spots appeared on the sample line to vaporizer 1 . For this test, the insulation was removed from the sample line to vaporizer 1. Samples from this vaporizer were going to the calorimeter and gravitometer during the insulation removal. Before all of the insulation had been stripped away the calorimeter went off scale, indicating a heating value of greater than 1195 $\mathrm{Btu} / \mathrm{scf}\left(44.515 \mathrm{~mJ} / \mathrm{m}^{3}\right)$. As figure 5.28 shows, the computed heating values were significantly higher for the uninsulated sampling system. (The deviations are referenced to the average values obtained in test $F_{\text {.) }}$ The sample analyses indicated a 0.8 mole percent reduction in nitrogen which was statistically significant. Also, there was a 0.3 mole percent increase in the ethane content; but based on the limited number of samples, this increase could not be considered statistically significant. This indicates that backflashing occurred in the sample line and that it enriched the heavy components in the observed samples.

\section{General Comments}

Based on the shipboard tests, we expected frost to accumulate at the $90^{\circ}$ bend on the steam vaporizer sample outlet lines at sample rates above 10 slpm. The impingement chamber apparently worked satisfactorily because there never was any indication of frost at the bend. The sample lines were felt at and near the bends several times throughout the tests; there was never an indication that the line was cooler at the bend.

Throughout these tests, the comparison between the measured and computed heating values was fairly good considering that the $\mathrm{C}_{6}+$ fraction ranged between 0.08 and 0.13 mol percent. An analysis of the heavy fraction indicated that it had roughly equal parts of $C_{6}$ 's and $C_{7}$ 's. Therefore, the response factor for $\mathrm{C}_{6}+$ peaks, $\mathrm{K}_{\mathrm{C}_{6}}+$, was computed by

$$
\mathrm{K}_{\mathrm{C}_{6}+}=\mathrm{K}_{\mathrm{nC}_{4}}\left(\mathrm{D}_{\mathrm{nC}_{6}}+\mathrm{D}_{\mathrm{nC}_{7}}\right) / 2 \mathrm{D}_{\mathrm{nC}_{4}}
$$

where $\mathrm{K}_{\mathrm{nC}_{4}}$ is the measured response factor for normal butane and the D's are the response factor reported by Dietz [25].

Except for runs $E, F$ and $G$ (the final day's tests), the agreement between measured and computed specific gravities was excellent. It is not known why the final day's results were consistently low by 1.3 to 1.4 percent, especially since the heating values agreed to 0.14 percent or better.

The estimated standard deviation in the computed liquid densities listed in table 5.19 is much larger than observed in previous tests. However, the densities in the flow facility tests reflected both temperature and composition fluctuations. The temperature fluctuations, which were as large as $1.5 \mathrm{~K}$, make comparisons based on density meaningless. 


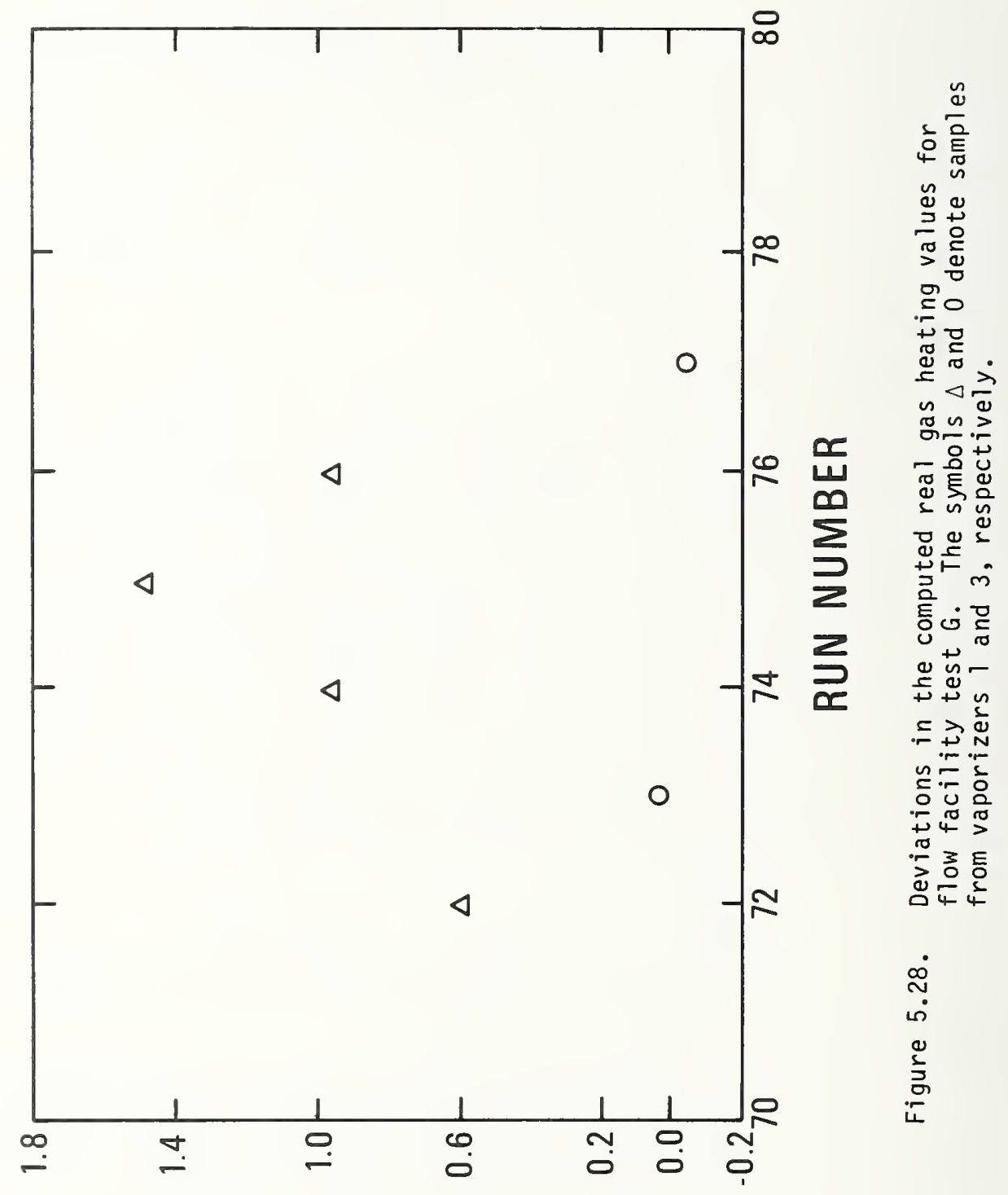

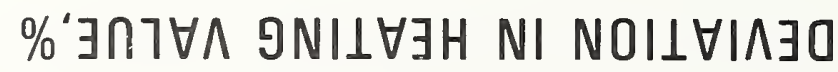


Throughout these tests, integrator A had difficulties in reliably measuring the $\mathrm{C}_{6}+$ peak area because the peak had a small peak height and wide peak width compared to the other peaks (see section 4.3.1.1 for more details). Except for the first day integrator B reported consistent $\mathrm{C}_{6}{ }^{+}$ peak areas. Therefore, the $\mathrm{C}_{6}{ }^{+}$peak area for integrator A was computed by assuming that the ratio of the $\mathrm{C}_{6}+$ peak area to that of the normal butane peak area was equal for both integrators; this ratio for integrator $B$ was constant to within \pm 2 percent throughout the tests. (A check showed that the ratios of iso to normal butane peak areas for the two integrators were equal to within one percent or better.)

During the first two days the two integrators reported comparable compositions for all components except iso and normal pentane; this difference was traced to calibration problems with integrator B. The typical spread between the calculated heating values for the two integrators was 0.05 to 0.14 percent; the difference in pentane contents reported by the two integrators accounted for this heating value difference.

On the third day (Test D) the program in integrator $A$ was altered to hopefully eliminate the scatter in detecting the $\mathrm{C}_{6}+$ peak. This change not only did not improve the $\mathrm{C}_{6}{ }^{+}$peak detection but it caused increased scatter in integrating the nitrogen and methane peaks. (In this chromatographic column arrangement, nitrogen and methane eluted after $\left.\mathrm{C}_{6}{ }^{+}\right)$The differences in computed heating values differed by as much as one percent with integrator A showing the most scatter.

On the last day the integrator A program was identical to the program used the second day. On this day integrator B gave erratic nitrogen contents even though no program changes were made. However, we noted that the peak width parameter (which was automatically updated after each peak) varied between 20 and 66 seconds. This variation affected the next (nitrogen) peak area measurement but not the methane peak area measurement. This is because the typical peak widths for nitrogen and methane were 20 and $60 \mathrm{~s}$, respectively. Agreement between the two integrators occurred only when the updated peak width parameter was between 20 and $30 \mathrm{~s}$.

\subsection{Conclusions and Recommendations}

This work has systematically considered many factors which could affect the precision and accuracy of the composition of samples withdrawn from a flowing LNG stream. Laboratory and field tests showed that it is feasible to obtain and analyze representative samples with a precision (based on three standard deviations) of better than \pm 0.30 percent in the computed heating value; this includes the gas analysis precision of \pm 0.06 percent. The accuracy of the measurement depends only on the gas analysis accuracy; both laboratory and shipboard tests showed that a properly designed and operated sampling system produces no statistically significant bias. A 
comparison of measured and computed heating values during the second flow facility test verified that the difference between the two values was within the combined uncertainty of the calorimeter measurement $( \pm 0.3$ percent [30]) and the sampling measurement process.

Table 5.20 summarizes the variables evaluated in the sampling tests and groups them according to their effect on sampling precision and accuracy. The test results indicated that heat leak causes backflashing of nitrogen (and probably methane) which enriches the samples in the heavy $\left(\mathrm{C}_{2}+\right.$ ) components. However, field tests showed that insulating the sample line with one inch (25 mm) thick layer of fiberglass pipe insulation sealed with duct tape eliminates the heat leak problem.

Table 5.20. Variables evaluated for their effect on LNG sampling precision and accuracy.

Variables affecting both sampling precision and accuracy:

- Heat leak to liquid sample line

Variables affecting sampling precision but not accuracy:

- Sampling rate

- Vaporizer design

- Time-averaging the vaporized sample

- Sampling rate transients

- Probe design

Variables not affecting sampling precision and accuracy:

- Temperature and pressure at the sampling point

- Pressure differential between the sampling point pressure and the equilibrium LNG pressure

- Flow rate past the sampling point

- Pressure drop in the liquid sample line between the sampling point and vaporizer

- Composition of the liquid being sampled.

Five variables were found to adversely affect sampling precision. Both laboratory and field tests showed that below a certain sampling rate, the sampling precision diminishes; this minimum sampling rate varied among various sampling system designs. A mechanism for the sampling rate's importance is unknown. Attempts to correlate the sampling rate with heat leak, accumulator residence time, linear flow rate in the liquid sample line and linear flow rate in the vaporizer failed. However, criteria for setting the minimum allowable sample rate must be found before general guidelines for LNG sampling system design can be established. The next section gives sampling rates for the recommended sampling system design. 
Laboratory results clearly indicated that a small diameter tube vaporizer was better than a vaporizer with a large cross sectional area. Tests also, showed that rapid sample vaporization gave the best results. However, there is no advantage in having the vaporizer outlet temperature above $100^{\circ} \mathrm{F}$ $\left(38^{\circ} \mathrm{C}\right)$. Both steam and electrically heated vaporizers produce comparable results.

The need to time-average the sample stream leaving the vaporizer in an accumulator arises from fractionation during vaporization. The minimum residence time necessary to obtain precise results depended upon the sampling system; residence times of 20 to $120 \mathrm{~s}$ gave good results.

Although the field tests were inconclusive, they indicated that taking samples within 30 minutes of a major change in sampling rate diminishes sampling precision. However, minor fluctuations and slow drifts in sampling rates did not affect the results.

The side tap probe was found to be more reliable than an upstream facing pitot tube. For unknown reasons the pitot tube occasionally gave erratic results.

The conclusion that certain variables did not affect sampling error must be considered valid only over the ranges tested; however, this range usually included the anticipated operating ranges of on and off-loading of LNG tankers.

There is no reason to expect the temperature and pressure to affect sampling error provided the conditions are far from the critical point of the LNG.

At some low value the difference between the pressure of the sampled liquid and the saturation pressure of the LNG (i.e., subcooling) in combination with heat leak should create premature vaporization which could adversely affect sampling precision; however, this effect was not detected at pressure differentials as low as $3.9 \mathrm{psi}(25 \mathrm{kPa}$ ) (this corresponds to $\sim 0.5 \mathrm{~K}$ subcooling).

LNG flow rates corresponding to Reynold's numbers ranging between 1500 and 50,000 did not affect sampling precision; it is unlikely that there would be any adverse effect on precision at the higher Reynold's numbers anticipated in on and off loading operations.

The fact that a pressure drop in the liquid sample line which is comparable to the pressure drop in the vaporizer is unnecessary eliminates the need for a liquid flow control valve. However, this conclusion is known to be valid only when using a tube vaporizer.

Finally, there is no problem in sampling LNG mixtures which contain up to 0.15 percent $C_{5}+$. The heavies would be a problem if they raised the sample dew point temperature to near ambient temperature. 
5.3.1. Recommended LNG Sampling System Design and Operating Criteria

Based on the laboratory and field test results, the following sampling system design criteria are recommended:

Probe - side tap mounted horizontally with the probe flush with the wall of the LNG pipe; probe inner diameter should be as small as feasible $(<0.25$ inch $(6.4 \mathrm{~mm}))$.

Liquid phase needle valve - optional, but useful for flow control.

Liquid sample line - use as small a bore tubing as feasible $(\leq 0.20$ inch $(5.1 \mathrm{~mm})$ ) and make the line as short as possible. (A filter is recommended to prevent line plugging.)

Sample vaporizer - use a coiled tube vaporizer with the tube inner diameter comparable to the sample line tubing. If steam is the vaporizing medium, use the design procedure outlined in section 5.2.2 with an impingement chamber. Electrically heated vaporizers can be designed using the same procedure as steam vaporizers; however, thin walled tubing is necessary to minimize the necessary amperage. Also, a thermostatic control is necessary to prevent the vaporizer from overheating if the sample flow rate decreases.

Accumulator - size for a residence time of at least $45 \mathrm{~s}$; the length to diameter ratio of the accumulator should be greater than 1.5 . The sample inlet line should extend to near the bottom of the vessel but the outlet line should not penetrate the vessel volume. Heating the bottom of the accumulator may produce improved mixing.

Insulation - the probe and liquid sample line should be insulated sufficiently to prevent moisture from condensing on the lines.

The following sample system operating conditions are within the range of values found to give good results in the field tests and therefore are recommended:

Sampling rate - greater than $20 \mathrm{slpm}$; this criteria applies only to the recommended sampling system.

Sample pressure - preferrably greater than 20 psig $(0.24 \mathrm{MPa})$ to provide sufficient gas sample for purging and replicate analyses from a $500 \mathrm{~cm}^{3}$ sample cylinder.

Vaporizer outlet temperature - 80 to $100^{\circ} \mathrm{F}\left(27\right.$ to $\left.38^{\circ} \mathrm{C}\right)$.

The shipboard tests and flow facility test 2 sampling systems both worked satisfactorily and may be considered proven sampling systems.

5.3.2. Recommendations for Future Work

All tests clearly indicated that sampling rate is an important operating variable but no criteria for establishing the minimum acceptable rate were found. The existing test results need to be carefully reexamined for clues to understanding how sampling rate affects sampling precision. Hopefully, this would provide the answer, or would at least suggest future tests. At this point, the need for time averaging denotes the lack of understanding of the sample vaporization process. Different vaporizer designs 
should be tested with the goal of understanding the vaporization process and eliminating the need for an accumulator, if possible. (These tests probably would provide some insight into the sample rate problem too.)

Resolving the uncertainties associated with the sampling rate and vaporizer design will likely allow establishment of general design and operating criteria. At this point a standard procedure should be developed for continuously sampling LNG from flowing streams.

Other types of LNG sampling techniques need to be studied. There should be additional work on systems for batch sampling LNG, e.g., Cook sampler. Also, reliable systems for sampling LNG from tanks need to be developed.

The goal of all future work should be to establish the basis for standard LNG sampling procedures which have an uncertainty comparable to that obtained from gas analysis alone. 
1. Caldwell, B. J., Fuel Gas Energy Metering, Transmission Measurement Committee Report Number 5 (revised), page 55 (1976), American Gas Association, Inc., Arlington, VA.

2. Armstrong, G. T., E. S. Domalski and J. I. Minor, Standard combustion data for the fuel gas industry, American Gas Association 1972 Operating Section Proceedings, page D-72 (1972).

3. McCarty, R. D., A comparison of mathematical models for the prediction of LNG densities, Nat. Bur. Stand. (U.S.) Internal Report, NBSIR 77-867 (Oct. 1977).

4. Hiza, M. J., An empirical excess volume model for estimating liquefied natural gas densities, submitted to Journal of Fluid Phase Equilibria (1977).

5. Natrella, M. G., Experimental Statistics, Handbook 9l, National Bureau of Standards (1963).

6. "Standard Method for Analysis of Natural Gas by Gas Chromatography," ASTM Designation: D1945-64 (Reapproved 1973).

7. "Standard Method for Analysis of Natural Gases and Related Types of Gaseous Mixtures by the Mass spectrometer," ASTM Designation: D1137-53.

8. Dalmaze, M. R., LNG sampling technique, Gaz Aujourdhui 96, 448 (Nov. 1972).

9. Trigo, J., System samples LNG accurately, Hydrocarbon Proc. p. 83 (April 1976).

10. The Cosmodyne Corporation, Cryogenic Sampler Bulletin TDS-8064, Torrance, Calif.

11. Cook, H. L., Method and apparatus for sampling refrigerated volatile liquids, U.S. Patent No. 3,487,692 (Jan. 1970).

12. Miller, A. J., Techniques for sampling natural gas, SNG, and LNG, Pipe Line Industry 39 (3), 70 (Sept. 1973).

13. "Standard Method of Sampling Natural Gas," ASTM Designation: Dl145-53.

14. Chapman, J. A. and G. D. Payne, Sampling system guidelines, paper presented at the 19 th Annual ISA Analysis Instrumentation Symp., April 2426, 1973, st. Louis, MO.

15. Turbett, J. R., Rockwell International, Atomics International Division, Golden, CO (private communication, 1977).

16. Conn, A. P., Transco, Houston, TX (private communication, 1976).

17. Method of Analysis for Natural Gas and Similar Gaseous Mixtures by Gas Chromatography, GPA Publication 2261-72, Gas Processors Association, Tulsa, OK.

18. Thompson, B., Fundamentals of Gas Analysis by Gas Chromatography, Varian Associates, Inc., Palo Alto, CA (1977). 
19. Purcell, J. E. and C. P. Gilson, Improved Analysis of Natural Gas, Chromatography Newsletter 1 (2), 45 (Nov. 1972), published by PerkinElmer Corp., Norwalk, CT.

20. Lawson, A. E., A versatile, low cost gas chromatograph, American Laboratory (May 1969).

21. Ludtke, P. R., Performance characteristics of a liquid helium pump, Nat. Bur. Stand. (U.S.) Internal Report, NBSIR 75-816 (July 1975).

22. Cook. H. L., Transco, Houston, TX (private communication, 1977).

23. Handbook of Chemistry and Physics, 45th Ed., p. D86, The Chemical Rubber Co., Cleveland, OH.

24. Childs, G. E., L. J. Ericks, and R. L. Powell, Thermal conductivity of solids at room temperature and below, Nat. Bur. Stand. (U.S.) Monograph 131, p. 257 (Sept. 1973).

25. Dietz, W. A., Response Factors for Gas Chromatographic Analyses, J. of Gas Chromatograph, p. 68 (Feb. 1967).

26. Mann, D. B., Cryogenic flowmetering research at NBS, Cryogenics 11, 179 (1971).

27. Brennan, J. A., Cryogenics Division, National Bureau of Standards, Boulder, CO (private communication, 1976).

28. Gcodwin, R. D., The thermophysical properties of methane from 90 to $500 \mathrm{~K}$ at pressure to 700 bar, Nat. Bur. Stand. (U.S.) Technical Note 653 (April 1974 ).

29. Hanley, H. J. M., W. M. Haynes, and R. D. MCCarty, The viscosity and thermal conductivity coefficients for dense gaseous and liquid methane, J. of Phys. and Chem. Ref. Data 6 (2), 597 (1977).

30. "Standard Method of Test for Calorific Value of Gases in Natural Gas Range by Continuous Recording Calorimater," ASTM Designation: D1145-53.

31. Hiza, M. J., W. M. Haynes and W. R. Parrish, Orthobaric liquid densities and excess volumes for binary mixtures of low molar-mass alkanes and nitrogen between 105 and $140 \mathrm{~K}$, J. Chem. Thermodynamics 9, 873 (1977). 
This appendix lists the compositions and computed ideal gas heating values obtained during the evaluation of gas analysis techniques. The heating values were computed using the values listed in table 2.2. To convert from $\mathrm{MJ} / \mathrm{m}^{3}$ to BTU/SCF multiply by 26.845 . Unless stated otherwise, all peak areas were measured using integrator $A$. Mix in these tables refers to the prepared mixtures listed in table 4.2 .

7.1.1. Comparison Between Mass spectrometry and Gas Chromatography. Table 7.1.1 lists the mass spectrometry analyses obtained from a local laboratory. The table lists the reported duplicate analyses on each sample. Table 7.1.2 lists the gas chromatograph analyses obtained using the two column configuration. 
Table 7.1.1. Results of mass spectrometer analyses.

\begin{tabular}{|c|c|c|c|c|c|c|c|c|}
\hline $\begin{array}{c}\text { Sample } \\
\text { ID }\end{array}$ & $\operatorname{Mix}$ & $\mathrm{N}_{2}$ & $\mathrm{CH}_{4}$ & $\mathrm{C}_{2} \mathrm{H}_{6}$ & $\begin{array}{l}01 \% \\
\mathrm{C}_{3} \mathrm{H}_{8}\end{array}$ & $i_{4} \mathrm{H}_{10}$ & $\mathrm{nC}_{4} \mathrm{H}_{10}$ & $\begin{array}{c}\text { Heating } \\
\text { Value } \\
\mathrm{MJ} / \mathrm{m}^{3}\end{array}$ \\
\hline $\begin{array}{l}441 \\
441 \\
445 \\
445 \\
442\end{array}$ & $\begin{array}{l}B \\
B \\
B \\
B \\
A\end{array}$ & $\begin{array}{l}5.62 \\
3.42 \\
1.81 \\
5.23 \\
8.53\end{array}$ & $\begin{array}{l}84.42 \\
86.61 \\
87.55 \\
84.89 \\
76.72\end{array}$ & $\begin{array}{l}8.34 \\
8.61 \\
8.49 \\
8.38 \\
4.21\end{array}$ & $\begin{array}{r}.35 \\
0.00 \\
.98 \\
.25 \\
5.97\end{array}$ & $\begin{array}{r}.70 \\
.80 \\
.62 \\
.68 \\
2.59\end{array}$ & $\begin{array}{r}.56 \\
.55 \\
.55 \\
.56 \\
1.99\end{array}$ & $\begin{array}{l}39.207 \\
39.394 \\
40.766 \\
39.295 \\
42.980\end{array}$ \\
\hline $\begin{array}{l}442 \\
444 \\
444 \\
443 \\
443\end{array}$ & $\begin{array}{l}A \\
A \\
A \\
D \\
D\end{array}$ & $\begin{array}{l}6.91 \\
8.45 \\
7.58 \\
1.16 \\
1.49\end{array}$ & $\begin{array}{l}78.49 \\
76.69 \\
77.57 \\
84.03 \\
83.12\end{array}$ & $\begin{array}{l}4.73 \\
4.22 \\
4.25 \\
4.93 \\
4.71\end{array}$ & $\begin{array}{l}4.92 \\
6.24 \\
6.14 \\
5.74 \\
6.59\end{array}$ & $\begin{array}{r}2.93 \\
2.45 \\
2.47 \\
.18 \\
.04\end{array}$ & $\begin{array}{l}2.01 \\
1.95 \\
1.99 \\
3.96 \\
4.06\end{array}$ & $\begin{array}{l}43.358 \\
42.318 \\
43.250 \\
45.380 \\
45.528\end{array}$ \\
\hline $\begin{array}{l}446 \\
446 \\
501 \\
501 \\
503\end{array}$ & $\begin{array}{l}\text { D } \\
\text { D } \\
B \\
B \\
B\end{array}$ & $\begin{array}{l}7.09 \\
5.23 \\
2.35 \\
1.50 \\
1.83\end{array}$ & $\begin{array}{l}78.22 \\
79.86 \\
87.77 \\
88.20 \\
88.13\end{array}$ & $\begin{array}{l}4.43 \\
4.37 \\
8.48 \\
8.95 \\
8.59\end{array}$ & $\begin{array}{r}6.19 \\
6.64 \\
0.00 \\
0.00 \\
.14\end{array}$ & $\begin{array}{l}.09 \\
.01 \\
.84 \\
.82 \\
.74\end{array}$ & $\begin{array}{r}3.98 \\
3.88 \\
.56 \\
.53 \\
.56\end{array}$ & $\begin{array}{l}43.189 \\
43.985 \\
40.391 \\
40.312 \\
40.523\end{array}$ \\
\hline $\begin{array}{l}503 \\
502 \\
502 \\
504 \\
504\end{array}$ & $\begin{array}{l}B \\
D \\
D \\
D \\
D\end{array}$ & $\begin{array}{l}1.68 \\
1.32 \\
1.23 \\
1.69 \\
1.23\end{array}$ & $\begin{array}{l}88.12 \\
82.53 \\
83.01 \\
82.76 \\
83.32\end{array}$ & $\begin{array}{l}8.82 \\
4.12 \\
4.46 \\
4.63 \\
4.52\end{array}$ & $\begin{array}{l}0.00 \\
7.73 \\
7.00 \\
6.62 \\
6.62\end{array}$ & $\begin{array}{l}.82 \\
.07 \\
.08 \\
.03 \\
.02\end{array}$ & $\begin{array}{r}.56 \\
4.23 \\
4.23 \\
4.28 \\
4.30\end{array}$ & $\begin{array}{l}40.732 \\
46.339 \\
46.059 \\
45.726 \\
45.371\end{array}$ \\
\hline $\begin{array}{l}505 \\
505 \\
506 \\
506\end{array}$ & $\begin{array}{l}c \\
c \\
c \\
c\end{array}$ & $\begin{array}{l}3.33 \\
1.03 \\
4.22 \\
1.21\end{array}$ & $\begin{array}{l}88.24 \\
90.55 \\
87.15 \\
90.53\end{array}$ & $\begin{array}{l}6.30 \\
6.53 \\
6.07 \\
6.67\end{array}$ & $\begin{array}{r}1.35 \\
1.04 \\
1.84 \\
.67\end{array}$ & $\begin{array}{l}.57 \\
.65 \\
.50 \\
.71\end{array}$ & $\begin{array}{l}.21 \\
.20 \\
.22 \\
.21\end{array}$ & $\begin{array}{l}39.549 \\
40.466 \\
39.473 \\
40.285\end{array}$ \\
\hline
\end{tabular}


Table 7.1.2. Results of gas chromatographic analyses.

\begin{tabular}{|c|c|c|c|c|c|c|c|c|}
\hline Date & $\operatorname{Mix}$ & $\mathrm{N}_{2}$ & $\mathrm{CH}_{4}$ & $\begin{array}{l}\text { Compos } \\
\mathrm{C}_{2} \mathrm{H}_{6}\end{array}$ & $\begin{array}{l}\text { nol } \% \\
\mathrm{C}_{3} \mathrm{H}_{8}\end{array}$ & ${ }^{i} C_{4} \mathrm{H}_{10}$ & $\mathrm{nC}_{4} \mathrm{H}_{10}$ & $\begin{array}{c}\text { Heating } \\
\text { Value } \\
\mathrm{MJ} / \mathrm{m}^{3}\end{array}$ \\
\hline $\begin{array}{ll}9 / 8 \\
9 / & 8 \\
9 / & 8 \\
9 / 10\end{array}$ & $\begin{array}{l}A \\
A \\
A \\
B\end{array}$ & $\begin{array}{l}1.352 \\
1.349 \\
4.330 \\
1.423\end{array}$ & $\begin{array}{l}88.111 \\
88.141 \\
81.301 \\
88.043\end{array}$ & $\begin{array}{l}8.408 \\
8.401 \\
4.765 \\
8.389\end{array}$ & $\begin{array}{r}.958 \\
.954 \\
4.803 \\
.980\end{array}$ & $\begin{array}{r}.485 \\
.477 \\
2.401 \\
.475\end{array}$ & $\begin{array}{r}.686 \\
.678 \\
2.400 \\
.690\end{array}$ & $\begin{array}{l}41.098 \\
41.081 \\
44.153 \\
41.073\end{array}$ \\
\hline $\begin{array}{l}9 / 10 \\
9 / 13 \\
9 / 13 \\
9 / 13\end{array}$ & $\begin{array}{l}P \\
\dot{B} \\
A \\
C\end{array}$ & $\begin{array}{r}1.260 \\
1.305 \\
1.290 \\
.660\end{array}$ & $\begin{array}{l}88.204 \\
88.106 \\
88.116 \\
90.514\end{array}$ & $\begin{array}{l}8.406 \\
8.422 \\
8.417 \\
6.041\end{array}$ & $\begin{array}{r}.975 \\
.991 \\
.991 \\
2.170\end{array}$ & $\begin{array}{l}.474 \\
.485 \\
.485 \\
.307\end{array}$ & $\begin{array}{l}.680 \\
.691 \\
.696 \\
.302\end{array}$ & $\begin{array}{l}41.127 \\
41.142 \\
41.148 \\
40.896\end{array}$ \\
\hline $\begin{array}{l}7 / 13 \\
7 / 13 \\
9 / 13 \\
9 / 14\end{array}$ & $\begin{array}{l}C \\
B \\
R \\
\text { P }\end{array}$ & $\begin{array}{r}.552 \\
1.331 \\
1.336 \\
1.291\end{array}$ & $\begin{array}{l}90.654 \\
88.109 \\
88.094 \\
88.199\end{array}$ & $\begin{array}{l}6.022 \\
8.394 \\
8.399 \\
8.379\end{array}$ & $\begin{array}{r}2.157 \\
.985 \\
.999 \\
.978\end{array}$ & $\begin{array}{l}.306 \\
.490 \\
.485 \\
.476\end{array}$ & $\begin{array}{l}.309 \\
.691 \\
.687 \\
.677\end{array}$ & $\begin{array}{l}40.931 \\
41.125 \\
41.125 \\
41.109\end{array}$ \\
\hline $\begin{array}{l}9 / 14 \\
9 / 14 \\
9 / 14 \\
9 / 14\end{array}$ & $\begin{array}{l}\text { A } \\
\text { A } \\
\text { A } \\
\text { A }\end{array}$ & $\begin{array}{l}1.297 \\
1.341 \\
4.503 \\
4.159\end{array}$ & $\begin{array}{l}88.189 \\
88.163 \\
80.947 \\
81.465\end{array}$ & $\begin{array}{l}8.379 \\
8.359 \\
4.736 \\
4.745\end{array}$ & $\begin{array}{r}.972 \\
.976 \\
4.921 \\
4.872\end{array}$ & $\begin{array}{r}.476 \\
.483 \\
2.432 \\
2.385\end{array}$ & $\begin{array}{r}.687 \\
.678 \\
2.462 \\
2.375\end{array}$ & $\begin{array}{l}41.112 \\
41.090 \\
44.224 \\
44.216\end{array}$ \\
\hline $\begin{array}{l}9 / 14 \\
9 / 14 \\
9 / 14 \\
9 / 14\end{array}$ & $\begin{array}{l}A \\
A \\
A \\
A\end{array}$ & $\begin{array}{l}4.056 \\
4.042 \\
4.031 \\
1.255\end{array}$ & $\begin{array}{l}81.507 \\
81.600 \\
81.564 \\
88.241\end{array}$ & $\begin{array}{l}4.756 \\
4.727 \\
4.734 \\
8.383\end{array}$ & $\begin{array}{r}4.899 \\
4.872 \\
4.889 \\
.971\end{array}$ & $\begin{array}{r}2.393 \\
2.381 \\
2.391 \\
.475\end{array}$ & $\begin{array}{r}2.390 \\
2.378 \\
2.390 \\
.675\end{array}$ & $\begin{array}{l}44.293 \\
44.255 \\
44.289 \\
41.117\end{array}$ \\
\hline $\begin{array}{l}9 / 29 \\
9 / 29 \\
9 / 29 \\
9 / 29\end{array}$ & $\begin{array}{l}B \\
B \\
D \\
D\end{array}$ & $\begin{array}{r}1.357 \\
1.347 \\
.009 \\
.008\end{array}$ & $\begin{array}{l}88.182 \\
88.103 \\
85 \cdot 342 \\
85.449\end{array}$ & $\begin{array}{l}8.344 \\
8.403 \\
5.086 \\
5.064\end{array}$ & $\begin{array}{r}.971 \\
.978 \\
4.873 \\
4.855\end{array}$ & $\begin{array}{r}.477 \\
.491 \\
0.000 \\
0.000\end{array}$ & $\begin{array}{r}.668 \\
.678 \\
4.690 \\
4.624\end{array}$ & $\begin{array}{l}41.064 \\
41.108 \\
45.828 \\
45.756\end{array}$ \\
\hline $\begin{array}{l}9 / 29 \\
9 / 29 \\
9 / 29 \\
9 / 29\end{array}$ & $\begin{array}{l}0 \\
0 \\
C \\
C\end{array}$ & $\begin{array}{l}.008 \\
.009 \\
.044 \\
.618\end{array}$ & $\begin{array}{l}85.386 \\
85.369 \\
90.505 \\
90.580\end{array}$ & $\begin{array}{l}5.065 \\
5.075 \\
6.033 \\
6.048\end{array}$ & $\begin{array}{l}4.872 \\
4.861 \\
2.171 \\
2.154\end{array}$ & $\begin{array}{r}0.000 \\
0.000 \\
.304 \\
.295\end{array}$ & $\begin{array}{r}4.670 \\
4.686 \\
.323 \\
.305\end{array}$ & $\begin{array}{l}45.804 \\
45.814 \\
40.929 \\
40.899\end{array}$ \\
\hline $\begin{array}{l}9 / 29 \\
10 / 2 \\
10 / 2 \\
10 / 1\end{array}$ & $\begin{array}{l}C \\
E \\
C \\
C\end{array}$ & $\begin{array}{r}.681 \\
1.382 \\
.625 \\
.626\end{array}$ & $\begin{array}{l}90.562 \\
85.887 \\
90.526 \\
90.562\end{array}$ & $\begin{array}{l}6.020 \\
8.504 \\
6.061 \\
6.044\end{array}$ & $\begin{array}{l}2.143 \\
2.940 \\
2.163 \\
2.155\end{array}$ & $\begin{array}{l}.297 \\
.527 \\
.310 \\
.305\end{array}$ & $\begin{array}{l}.297 \\
.710 \\
.315 \\
.308\end{array}$ & $\begin{array}{l}40.857 \\
42.313 \\
40.926 \\
40.907\end{array}$ \\
\hline $\begin{array}{ll}10 / & 1 \\
10 / & 1 \\
10 / & 1 \\
10 / 1\end{array}$ & $\begin{array}{l}C \\
C \\
D \\
D\end{array}$ & $\begin{array}{l}.623 \\
.620 \\
.011 \\
.008\end{array}$ & $\begin{array}{l}90.561 \\
90.538 \\
85.277 \\
85.166\end{array}$ & $\begin{array}{l}6.046 \\
6.066 \\
5.108 \\
5.104\end{array}$ & $\begin{array}{l}2.154 \\
2.164 \\
4.878 \\
4.897\end{array}$ & $\begin{array}{r}.306 \\
.306 \\
0.000 \\
0.000\end{array}$ & $\begin{array}{r}.310 \\
.306 \\
4.727 \\
4.826\end{array}$ & $\begin{array}{l}40.910 \\
40.919 \\
45.867 \\
45.961\end{array}$ \\
\hline $\begin{array}{ll}10 / 1 \\
10 / & 1 \\
10 / & 1 \\
10 / 4\end{array}$ & $\begin{array}{l}D \\
D \\
E \\
E\end{array}$ & $\begin{array}{r}.009 \\
.008 \\
1.375 \\
1.391\end{array}$ & $\begin{array}{l}85.285 \\
85.291 \\
85.877 \\
85.993\end{array}$ & $\begin{array}{l}5.082 \\
5.086 \\
8.495 \\
8.432\end{array}$ & $\begin{array}{l}4.877 \\
4.877 \\
3.010 \\
2.956\end{array}$ & $\begin{array}{r}0.000 \\
0.000 \\
.519 \\
.519\end{array}$ & $\begin{array}{r}4.748 \\
4.738 \\
.724 \\
.709\end{array}$ & $\begin{array}{l}45.877 \\
45.871 \\
42.329 \\
42.263\end{array}$ \\
\hline
\end{tabular}


Table 7.1.2. (Continued)

\begin{tabular}{|c|c|c|c|c|c|c|c|c|}
\hline \multirow{2}{*}{ Date } & \multirow{2}{*}{$\operatorname{Mix}$} & \multicolumn{6}{|c|}{ Composition, mol \% } & \multirow{2}{*}{$\begin{array}{l}\text { Value } \\
\mathrm{MJ} / \mathrm{m}^{3}\end{array}$} \\
\hline & & $\mathrm{N}_{2}$ & $\mathrm{CH}_{4}$ & $\mathrm{C}_{2} \mathrm{H}_{6}$ & $\mathrm{C}_{3} \mathrm{H}_{8}$ & $\mathrm{iC}_{4} \mathrm{H}_{10}$ & $\mathrm{nC}_{4} \mathrm{H}_{10}$ & \\
\hline $\begin{array}{l}10 / 4 \\
10 / 4 \\
10 / 4 \\
10 / 4\end{array}$ & $\begin{array}{l}c \\
c \\
c \\
c\end{array}$ & $\begin{array}{l}.645 \\
.631 \\
.632 \\
.639\end{array}$ & $\begin{array}{l}90.525 \\
90.563 \\
90.571 \\
90.541\end{array}$ & $\begin{array}{l}6.043 \\
6.042 \\
6.034 \\
6.056\end{array}$ & $\begin{array}{l}2.168 \\
2.159 \\
2.153 \\
2.158\end{array}$ & $\begin{array}{l}.305 \\
.299 \\
.301 \\
.301\end{array}$ & $\begin{array}{l}.315 \\
.305 \\
.309 \\
.305\end{array}$ & $\begin{array}{l}40.912 \\
40.900 \\
40.898 \\
40.901\end{array}$ \\
\hline
\end{tabular}


7.1.2. Statistical evaluation of gas chromatographic analyses.

Table 7.1.3 lists the data taken to determine the accuracy and precision of gas chromatographic analyses using the two column configuration. The first digit of the analysis number refers to the day while the remaining digits refer to the sequence number. In this table, mixtures A, B, C and D correspond to mixtures E, F, G and $C$ in table 4.2. Table 7.1.3.A lists the outlying analyses which were not included in the statistical evaluation. Table 7.1.4 gives the results of repetitive analyses of mixture $E$ which were made after the integrator was repaired (see section 4.2.). 
Table 7.1.3. Raw data for determining the precision and accuracy of gas chromatographic analyses.

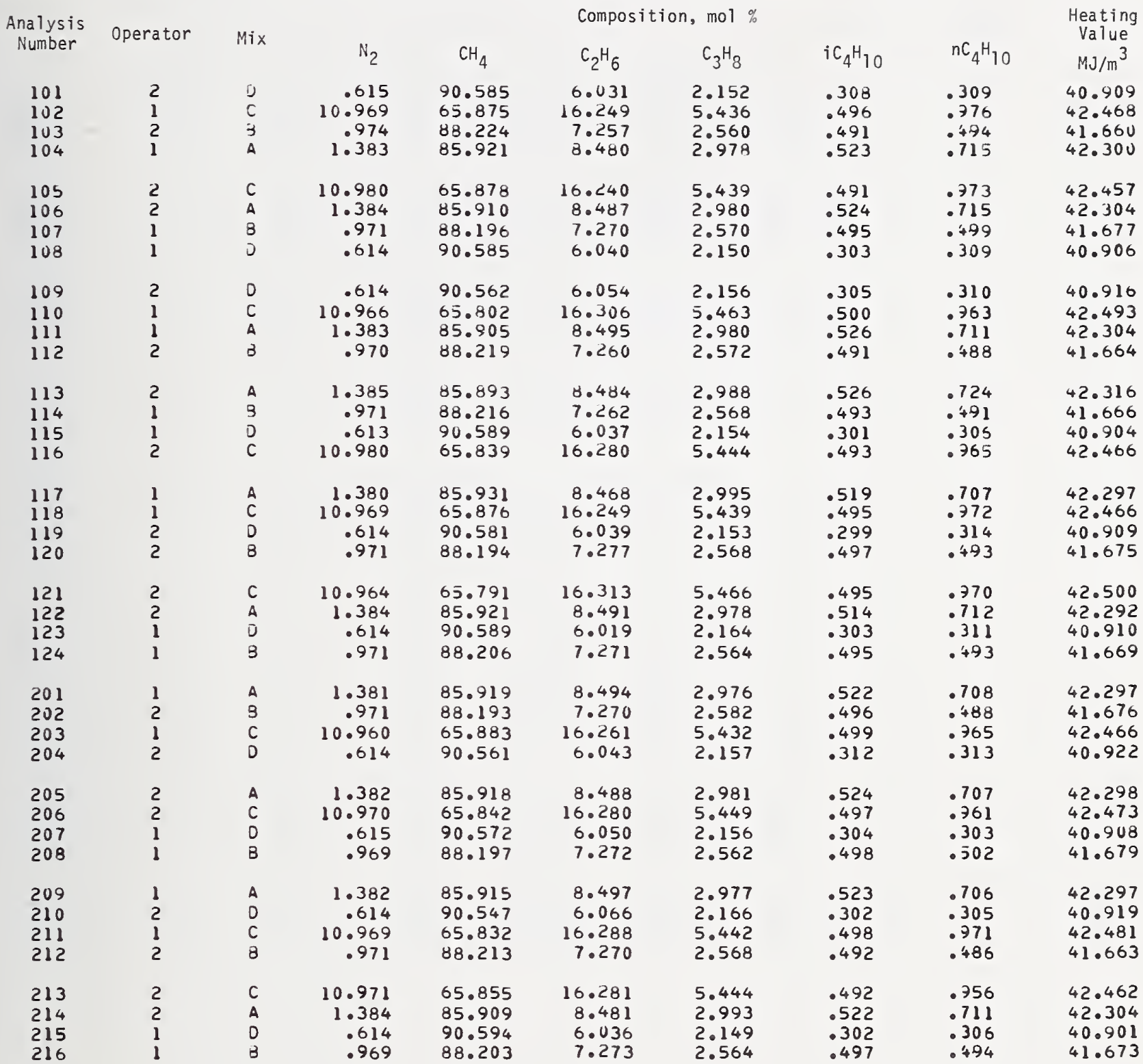


Table 7.1.3. (Continued)

Analysis Operator Mix
Number

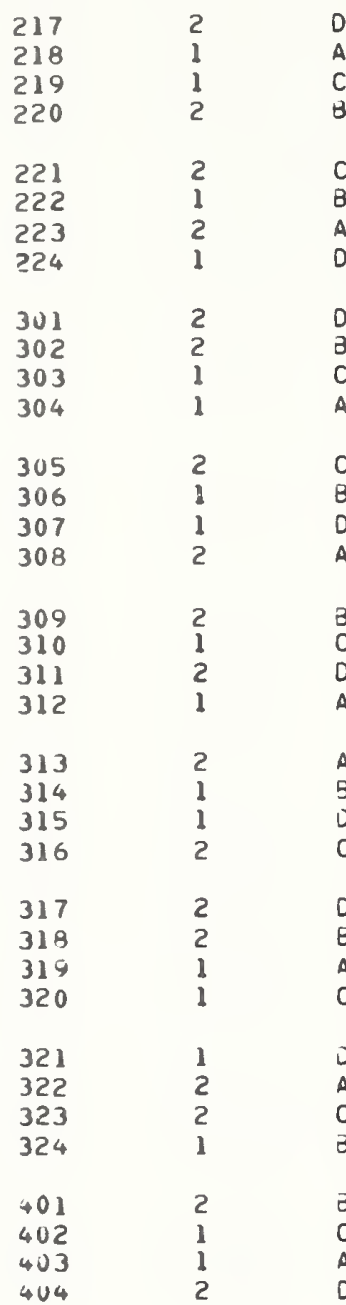

Composition, mol \%

$\mathrm{N}_{2} \quad \mathrm{CH}_{4}$

$\begin{array}{rr}.614 & 90.566 \\ 1.382 & 85.926 \\ 10.969 & 65.817 \\ .971 & 88.199 \\ 10.970 & 65.841 \\ .972 & 88.200 \\ 1.382 & 85.919 \\ .613 & 90.573\end{array}$

$$
\mathrm{C}_{2} \mathrm{H}_{6}
$$

6. 058

8.480

16.309

7.270

$\mathrm{C}_{3} \mathrm{H}_{8}$

2.150

2.981

5.444

2.573

16.270

7.262

8.494

6.037

5.459

5.459
2.578

2.975

2. 165

.614

$$
.972
$$

10.956

1. 385

90.593
88.195

65.740

85.919

6.032
7.279

16.360

8.494

2.155
2.562

5.480

2. 980

65.815

88.168

.971

.615

1. 383

90.565

85.888

16.289

7.304

6.049

5.453

2. 569

2.154

8.506

2. 983

.972
10.962

.613

1. 381

88.183

90.557

85.893

1. 383

.971

.614

10.980

85.870

88.170

90.555

65.823

.614

.969

1. 384

10.970

90.565

88.175

85.877

65.850

.617

1.383

10.965

.971

.968

10.980

1.383

.616
90.565

85.931

65.837

88.172

88.217

65.849

85.915

90.589
7.290

2.573
5.453

2. 165

2.984

6.052
8.504

8.527

7.298

6.053

16.281

2. 988

2.570

2.170

5.452

6.053

7.297

8.509

16.280

2. 156

2. 570

2.984

5.438

2. 152

2. 982

5.461

2.577

2.564

7.264

16.250

8.484

6.024
5.459

2.986

2. 166
Heating
Value

$\mathrm{MJ} / \mathrm{m}^{3}$

40.911

42.297

42.480

41.673

42.477

41.674

42.296

40.915

40.903

41.674

42.523

42.291

42.467

41.681

40.916

42.312

41.674

42.505

40.919

42.311

42.314

41.683

40.919

42.476

40.913

41.682

42.318

42.470

40.911

42.291

42.483

41.681

41.668

42.470

42.301

40.904 
Table 7.1.3. (Continued)

\begin{tabular}{|c|c|c|c|c|c|c|c|c|c|}
\hline \multirow{2}{*}{$\begin{array}{l}\text { Analys is } \\
\text { Number }\end{array}$} & \multirow{2}{*}{ Operator } & \multirow[t]{2}{*}{ Mix } & \multicolumn{6}{|c|}{ Composition, mol \% } & \multirow{2}{*}{$\begin{array}{l}\text { Heating } \\
\text { Value } \\
\mathrm{MJ} / \mathrm{m}^{3}\end{array}$} \\
\hline & & & $\mathrm{N}_{2}$ & $\mathrm{CH}_{4}$ & $\mathrm{C}_{2} \mathrm{H}_{6}$ & $\mathrm{C}_{3} \mathrm{H}_{8}$ & $i_{4} \mathrm{H}_{10}$ & $\mathrm{nC}_{4} \mathrm{H}_{10}$ & \\
\hline $\begin{array}{l}405 \\
406 \\
407 \\
408\end{array}$ & $\begin{array}{l}1 \\
2 \\
2 \\
1\end{array}$ & $\begin{array}{l}a \\
A \\
C \\
D\end{array}$ & $\begin{array}{r}.971 \\
1.383 \\
10.979 \\
.614\end{array}$ & $\begin{array}{l}88.206 \\
85.929 \\
65.863 \\
90.571\end{array}$ & $\begin{array}{r}7.272 \\
8.464 \\
16.248 \\
6.039\end{array}$ & $\begin{array}{l}2.568 \\
2.978 \\
5.433 \\
2.155\end{array}$ & $\begin{array}{l}.495 \\
.532 \\
.496 \\
.306\end{array}$ & $\begin{array}{r}.489 \\
.714 \\
.780 \\
.315\end{array}$ & $\begin{array}{l}41.668 \\
42.302 \\
42.406 \\
40.917\end{array}$ \\
\hline $\begin{array}{l}409 \\
410 \\
411 \\
412\end{array}$ & $\begin{array}{l}2 \\
1 \\
1 \\
2\end{array}$ & $\begin{array}{l}3 \\
C \\
A \\
D\end{array}$ & $\begin{array}{r}.970 \\
10.965 \\
1.383 \\
.614\end{array}$ & $\begin{array}{l}88.186 \\
65.794 \\
85.894 \\
90.562\end{array}$ & $\begin{array}{r}7.264 \\
16.264 \\
8.487 \\
6.042\end{array}$ & $\begin{array}{l}2.568 \\
5.496 \\
2.982 \\
2.167\end{array}$ & $\begin{array}{l}.505 \\
.505 \\
.530 \\
.303\end{array}$ & $\begin{array}{r}.507 \\
.375 \\
.724 \\
.312\end{array}$ & $\begin{array}{l}41.690 \\
42.516 \\
42.318 \\
40.919\end{array}$ \\
\hline $\begin{array}{l}413 \\
414 \\
415 \\
416\end{array}$ & $\begin{array}{l}2 \\
1 \\
1 \\
2\end{array}$ & $\begin{array}{l}A \\
D \\
B \\
C\end{array}$ & $\begin{array}{r}1.383 \\
.613 \\
.971 \\
10.976\end{array}$ & $\begin{array}{l}85.924 \\
90.568 \\
88.204 \\
65.868\end{array}$ & $\begin{array}{r}8.471 \\
6.044 \\
7.265 \\
16.245\end{array}$ & $\begin{array}{l}2.988 \\
2.155 \\
2.571 \\
5.447\end{array}$ & $\begin{array}{l}.524 \\
.306 \\
.496 \\
.495\end{array}$ & $\begin{array}{r}.710 \\
.314 \\
.492 \\
.769\end{array}$ & $\begin{array}{l}42.300 \\
40.917 \\
41.672 \\
42.464\end{array}$ \\
\hline $\begin{array}{l}417 \\
418 \\
419 \\
420\end{array}$ & $\begin{array}{l}2 \\
2 \\
1 \\
1\end{array}$ & $\begin{array}{l}B \\
D \\
C \\
A\end{array}$ & $\begin{array}{r}.971 \\
.015 \\
10.979 \\
1.983\end{array}$ & $\begin{array}{l}88.185 \\
90.583 \\
65.846 \\
85.905\end{array}$ & $\begin{array}{r}7.270 \\
6.036 \\
16.249 \\
8.498\end{array}$ & $\begin{array}{l}2.591 \\
2.153 \\
5.453 \\
2.984\end{array}$ & $\begin{array}{l}.495 \\
.306 \\
.504 \\
.523\end{array}$ & $\begin{array}{r}.488 \\
.308 \\
.769 \\
.707\end{array}$ & $\begin{array}{l}41.680 \\
40.908 \\
42.475 \\
42.302\end{array}$ \\
\hline $\begin{array}{l}421 \\
422 \\
423 \\
424\end{array}$ & $\begin{array}{l}1 \\
2 \\
2 \\
1\end{array}$ & $\begin{array}{l}\text { J } \\
A \\
C \\
D\end{array}$ & $\begin{array}{r}.972 \\
1.382 \\
10.981 \\
.615\end{array}$ & $\begin{array}{l}88.200 \\
85.927 \\
65.866 \\
90.577\end{array}$ & $\begin{array}{r}7.268 \\
8.474 \\
16.231 \\
6.042\end{array}$ & $\begin{array}{l}2.568 \\
2.982 \\
5.457 \\
2.156\end{array}$ & $\begin{array}{l}.495 \\
.526 \\
.503 \\
.302\end{array}$ & $\begin{array}{r}.497 \\
.710 \\
.761 \\
.308\end{array}$ & $\begin{array}{l}41.674 \\
42.299 \\
42.464 \\
40.908\end{array}$ \\
\hline
\end{tabular}


Table 7.1.3.A. Outlier analyses not used in statistical evaluation.

\begin{tabular}{|c|c|c|c|c|c|c|c|c|c|}
\hline \multirow{2}{*}{$\begin{array}{c}\text { Analysis } \\
\text { Number }\end{array}$} & \multirow{2}{*}{ Operator } & \multirow[t]{2}{*}{$\operatorname{Mix}$} & \multicolumn{6}{|c|}{ Composition, mol \% } & \multirow{2}{*}{$\begin{array}{c}\text { Heating } \\
\text { Value } \\
\mathrm{MJ} / \mathrm{m}^{3}\end{array}$} \\
\hline & & & $\mathrm{N}_{2}$ & $\mathrm{CH}_{4}$ & $\mathrm{C}_{2} \mathrm{H}_{6}$ & $\mathrm{C}_{3} \mathrm{H}_{8}$ & $\mathrm{iC}_{4} \mathrm{H}_{10}$ & $\mathrm{nC}_{4} \mathrm{H}_{10}$ & \\
\hline $\begin{array}{l}104 \\
109 \\
110 \\
121\end{array}$ & $\begin{array}{l}1 \\
2 \\
1 \\
2\end{array}$ & $\begin{array}{l}A \\
D \\
C \\
C\end{array}$ & $\begin{array}{r}1.393 \\
.328 \\
10.620 \\
10.690\end{array}$ & $\begin{array}{l}85.912 \\
90.846 \\
66.129 \\
66.041\end{array}$ & $\begin{array}{r}8.479 \\
6.055 \\
16.320 \\
16.330\end{array}$ & $\begin{array}{l}2.978 \\
2.156 \\
5.468 \\
5.472\end{array}$ & $\begin{array}{l}.523 \\
.305 \\
.500 \\
.496\end{array}$ & $\begin{array}{l}.715 \\
.310 \\
.764 \\
.771\end{array}$ & $\begin{array}{l}42.296 \\
41.024 \\
42.631 \\
42.613\end{array}$ \\
\hline $\begin{array}{l}202 \\
210 \\
217 \\
219\end{array}$ & $\begin{array}{l}2 \\
2 \\
2 \\
1\end{array}$ & $\begin{array}{l}3 \\
0 \\
C \\
C\end{array}$ & $\begin{array}{r}.982 \\
.444 \\
.502 \\
10.760\end{array}$ & $\begin{array}{l}88.183 \\
90.715 \\
90.677 \\
66.011\end{array}$ & $\begin{array}{r}7.269 \\
6.068 \\
6.059 \\
16.320\end{array}$ & $\begin{array}{l}2.582 \\
2.167 \\
2.150 \\
5.448\end{array}$ & $\begin{array}{r}.496 \\
.302 \\
.307 \\
.496\end{array}$ & $\begin{array}{l}.484 \\
.305 \\
.305 \\
.765\end{array}$ & $\begin{array}{l}41.671 \\
40.984 \\
40.954 \\
42.565\end{array}$ \\
\hline $\begin{array}{l}220 \\
303 \\
310 \\
317\end{array}$ & $\begin{array}{l}2 \\
1 \\
1 \\
2\end{array}$ & $\begin{array}{l}3 \\
C \\
C \\
D\end{array}$ & $\begin{array}{r}.918 \\
10.400 \\
10.680 \\
.628\end{array}$ & $\begin{array}{l}88.253 \\
66.252 \\
66.028 \\
90.550\end{array}$ & $\begin{array}{r}7.269 \\
16.390 \\
16.360 \\
6.054\end{array}$ & $\begin{array}{l}2.573 \\
5.490 \\
5.460 \\
2.156\end{array}$ & $\begin{array}{l}.491 \\
.498 \\
.505 \\
.300\end{array}$ & $\begin{array}{r}.496 \\
.769 \\
.768 \\
.312\end{array}$ & $\begin{array}{l}41.693 \\
42.749 \\
42.623 \\
40.904\end{array}$ \\
\hline $\begin{array}{l}323 \\
403 \\
410 \\
411\end{array}$ & $\begin{array}{l}2 \\
1 \\
1 \\
1\end{array}$ & $\begin{array}{l}C \\
A \\
C \\
A\end{array}$ & $\begin{array}{r}10.880 \\
1.392 \\
10.060 \\
.594\end{array}$ & $\begin{array}{l}65.900 \\
85.907 \\
66.527 \\
86.591\end{array}$ & $\begin{array}{r}16.290 \\
8.483 \\
16.429 \\
8.347\end{array}$ & $\begin{array}{l}5.466 \\
2.986 \\
5.501 \\
3.014\end{array}$ & $\begin{array}{l}.497 \\
.523 \\
.506 \\
.530\end{array}$ & $\begin{array}{l}.767 \\
.709 \\
.777 \\
.724\end{array}$ & $\begin{array}{l}42.524 \\
42.297 \\
42.908 \\
42.650\end{array}$ \\
\hline $\begin{array}{l}415 \\
416 \\
417 \\
420\end{array}$ & $\begin{array}{l}1 \\
2 \\
2 \\
1\end{array}$ & $\begin{array}{l}B \\
C \\
B \\
A\end{array}$ & $\begin{array}{r}.983 \\
10.999 \\
.945 \\
1.390\end{array}$ & $\begin{array}{l}88.194 \\
66.006 \\
88.208 \\
85.899\end{array}$ & $\begin{array}{r}7.264 \\
16.069 \\
7.272 \\
8.497\end{array}$ & $\begin{array}{l}2.571 \\
5.459 \\
2.592 \\
2.984\end{array}$ & $\begin{array}{l}.496 \\
.496 \\
.495 \\
.523\end{array}$ & $\begin{array}{l}.+92 \\
.971 \\
.+88 \\
.707\end{array}$ & $\begin{array}{l}41.667 \\
42.414 \\
41.691 \\
42.299\end{array}$ \\
\hline
\end{tabular}


Table 7.1.4. Raw data for determining the accuracy and precision of gas chromatographic analysis taken after integrator repair.

\begin{tabular}{|c|c|c|c|c|c|c|c|c|}
\hline $\begin{array}{l}\text { Analysis } \\
\text { Number }\end{array}$ & Time & $N_{2}$ & $\mathrm{CH}_{A}$ & $\begin{array}{l}\text { Compos } \\
\mathrm{C}_{2} \mathrm{H}_{6}\end{array}$ & $\begin{array}{l}\mathrm{C}_{3} \mathrm{H}_{8} \\
\text { ( }\end{array}$ & $\mathrm{iC}_{4} \mathrm{H}_{10}$ & $\mathrm{nC}_{4} \mathrm{H}_{10}$ & $\begin{array}{l}\text { Heating } \\
\text { Value } \\
\mathrm{MJ} / \mathrm{m}^{3}\end{array}$ \\
\hline $\begin{array}{l}101 \\
102 \\
103 \\
104 \\
105\end{array}$ & $\begin{array}{l}1117 \\
1133 \\
1149 \\
1204 \\
1219\end{array}$ & $\begin{array}{l}1 \cdot 383 \\
1 \cdot 382 \\
1 \cdot 382 \\
1 \cdot 383 \\
1 \cdot 381\end{array}$ & $\begin{array}{l}85.925 \\
85.933 \\
85.904 \\
85.913 \\
85.903\end{array}$ & $\begin{array}{l}8.477 \\
8.479 \\
8.487 \\
8.476 \\
8.504\end{array}$ & $\begin{array}{l}2.982 \\
2.980 \\
2.989 \\
2.998 \\
2.976\end{array}$ & $\begin{array}{l}.526 \\
.521 \\
.527 \\
.523 \\
.522\end{array}$ & $\begin{array}{l}.707 \\
.705 \\
.711 \\
.707 \\
.714\end{array}$ & $\begin{array}{l}42.297 \\
42.291 \\
42.308 \\
42.303 \\
42.305\end{array}$ \\
\hline $\begin{array}{l}106 \\
107 \\
108 \\
109 \\
110\end{array}$ & $\begin{array}{l}1234 \\
1250 \\
1305 \\
1321 \\
1336\end{array}$ & $\begin{array}{l}1 \cdot 384 \\
1 \cdot 383 \\
1 \cdot 383 \\
1 \cdot 378 \\
1 \cdot 381\end{array}$ & $\begin{array}{l}85.907 \\
85.908 \\
85.939 \\
85.960 \\
85.941\end{array}$ & $\begin{array}{l}8.501 \\
8.492 \\
8.469 \\
8.458 \\
8.470\end{array}$ & $\begin{array}{l}2.977 \\
2.979 \\
2.980 \\
2.971 \\
2.976\end{array}$ & $\begin{array}{l}.521 \\
.522 \\
.521 \\
.521 \\
.521\end{array}$ & $\begin{array}{l}.710 \\
.716 \\
.708 \\
.712 \\
.711\end{array}$ & $\begin{array}{l}42.299 \\
42.304 \\
42.290 \\
42.287 \\
42.292\end{array}$ \\
\hline $\begin{array}{l}111 \\
112 \\
113 \\
114 \\
115\end{array}$ & $\begin{array}{l}1351 \\
1407 \\
1422 \\
1437 \\
1452\end{array}$ & $\begin{array}{l}1 \cdot 381 \\
1 \cdot 383 \\
1 \cdot 383 \\
1 \cdot 382 \\
1.383\end{array}$ & $\begin{array}{l}85.927 \\
85.918 \\
85.930 \\
85.910 \\
85.915\end{array}$ & $\begin{array}{l}8.485 \\
8.493 \\
8.475 \\
8.493 \\
8.488\end{array}$ & $\begin{array}{l}2.975 \\
2.979 \\
2.981 \\
2.983 \\
2.980\end{array}$ & $\begin{array}{l}.524 \\
.521 \\
.521 \\
.522 \\
.525\end{array}$ & $\begin{array}{l}.709 \\
.706 \\
.710 \\
.710 \\
.709\end{array}$ & $\begin{array}{l}42.296 \\
42.295 \\
42.294 \\
42.302 \\
42.300\end{array}$ \\
\hline $\begin{array}{l}116 \\
117 \\
118 \\
119 \\
120\end{array}$ & $\begin{array}{l}1507 \\
1522 \\
1538 \\
1553 \\
1608\end{array}$ & $\begin{array}{l}1 \cdot 381 \\
1 \cdot 384 \\
1 \cdot 380 \\
1 \cdot 379 \\
1 \cdot 383\end{array}$ & $\begin{array}{l}85.927 \\
85.935 \\
85.936 \\
85.923 \\
85.935\end{array}$ & $\begin{array}{l}8.482 \\
8.476 \\
8.478 \\
8.489 \\
8.473\end{array}$ & $\begin{array}{l}2.983 \\
2.974 \\
2.976 \\
2.978 \\
2.975\end{array}$ & $\begin{array}{l}.522 \\
.524 \\
.522 \\
.520 \\
.523\end{array}$ & $\begin{array}{l}.705 \\
.707 \\
.709 \\
.711 \\
.711\end{array}$ & $\begin{array}{l}42.295 \\
42.290 \\
42.293 \\
42.298 \\
42.293\end{array}$ \\
\hline $\begin{array}{l}121 \\
122 \\
201 \\
202 \\
203\end{array}$ & $\begin{array}{l}1623 \\
1639 \\
1102 \\
1117 \\
1133\end{array}$ & $\begin{array}{l}1 \cdot 378 \\
1 \cdot 378 \\
1 \cdot 382 \\
1 \cdot 381 \\
1 \cdot 382\end{array}$ & $\begin{array}{l}85.943 \\
85.923 \\
85.907 \\
85.938 \\
85.922\end{array}$ & $\begin{array}{l}8.483 \\
8.489 \\
8.496 \\
8.474 \\
8.487\end{array}$ & $\begin{array}{l}2.973 \\
2.977 \\
2.985 \\
2.979 \\
2.975\end{array}$ & $\begin{array}{l}.520 \\
.524 \\
.522 \\
.522 \\
.521\end{array}$ & $\begin{array}{l}.703 \\
.709 \\
.709 \\
.706 \\
.713\end{array}$ & $\begin{array}{l}42.287 \\
42.300 \\
42.303 \\
42.291 \\
42.297\end{array}$ \\
\hline $\begin{array}{l}204 \\
205 \\
206 \\
207 \\
208\end{array}$ & $\begin{array}{l}1148 \\
1204 \\
1219 \\
1234 \\
1350\end{array}$ & $\begin{array}{l}1 \cdot 385 \\
1.378 \\
1 \cdot 387 \\
1.386 \\
1.386\end{array}$ & $\begin{array}{l}85.900 \\
85.967 \\
85.910 \\
85.911 \\
85.902\end{array}$ & $\begin{array}{l}8.507 \\
8.463 \\
8.500 \\
8.490 \\
8.503\end{array}$ & $\begin{array}{l}2.978 \\
2.966 \\
2.974 \\
2.984 \\
2.980\end{array}$ & $\begin{array}{l}.520 \\
.520 \\
.519 \\
.522 \\
.521\end{array}$ & $\begin{array}{l}.710 \\
.706 \\
.710 \\
.707 \\
.708\end{array}$ & $\begin{array}{l}42.300 \\
42.280 \\
42.294 \\
42.298 \\
42.299\end{array}$ \\
\hline $\begin{array}{l}209 \\
210 \\
211 \\
212 \\
213\end{array}$ & $\begin{array}{l}1306 \\
1331 \\
1336 \\
1352 \\
1407\end{array}$ & $\begin{array}{l}1 \cdot 385 \\
1 \cdot 386 \\
1 \cdot 383 \\
1 \cdot 384 \\
1 \cdot 385\end{array}$ & $\begin{array}{l}85.901 \\
85.905 \\
85.905 \\
85.892 \\
85.913\end{array}$ & $\begin{array}{l}8.498 \\
8.508 \\
8.500 \\
8.507 \\
8.490\end{array}$ & $\begin{array}{l}2.982 \\
2.977 \\
2.984 \\
2.989 \\
2.982\end{array}$ & $\begin{array}{l}.520 \\
.521 \\
.520 \\
.521 \\
.520\end{array}$ & $\begin{array}{l}.714 \\
.703 \\
.708 \\
.707 \\
.710\end{array}$ & $\begin{array}{l}42.303 \\
42.294 \\
42.301 \\
42.305 \\
42.297\end{array}$ \\
\hline $\begin{array}{l}214 \\
215 \\
216 \\
217 \\
218\end{array}$ & $\begin{array}{l}1422 \\
1438 \\
1453 \\
1508 \\
1524\end{array}$ & $\begin{array}{l}1.384 \\
1 \cdot 384 \\
1 \cdot 385 \\
1.385 \\
1.383\end{array}$ & $\begin{array}{l}85.913 \\
85.885 \\
85.906 \\
85.887 \\
85.886\end{array}$ & $\begin{array}{l}8.488 \\
8.513 \\
8.500 \\
8.500 \\
8.520\end{array}$ & $\begin{array}{l}2.982 \\
2.981 \\
2.979 \\
2.997 \\
2.980\end{array}$ & $\begin{array}{l}.523 \\
.524 \\
.524 \\
.524 \\
.521\end{array}$ & $\begin{array}{l}.710 \\
.713 \\
.707 \\
.708 \\
.711\end{array}$ & $\begin{array}{l}42.300 \\
42.310 \\
42.299 \\
42.310 \\
42.307\end{array}$ \\
\hline $\begin{array}{l}219 \\
220 \\
221 \\
222\end{array}$ & $\begin{array}{l}1539 \\
1554 \\
1609 \\
1624\end{array}$ & $\begin{array}{l}1.384 \\
1.384 \\
1.383 \\
1.384\end{array}$ & $\begin{array}{l}85.911 \\
85.902 \\
85.890 \\
85.908\end{array}$ & $\begin{array}{l}8.498 \\
8.499 \\
8.514 \\
8.494\end{array}$ & $\begin{array}{l}2.978 \\
2.986 \\
2.982 \\
2.982\end{array}$ & $\begin{array}{r}.523 \\
.523 \\
.523 \\
.522\end{array}$ & $\begin{array}{r}.706 \\
.706 \\
.708 \\
.710\end{array}$ & $\begin{array}{l}42.297 \\
42.302 \\
42.306 \\
42.301\end{array}$ \\
\hline
\end{tabular}


7.1.3. Evaluation of gas chromatograph column configuration and digital integrator.

Table 7.1.5 lists the data used in the evaluation of column configuration $A$; table 7.1.6 gives comparable data for column configuration B. Table 7.1.7 compares the two integrators. All of these tests used prepared mixture $\mathrm{H}$. 
Table 7.1.5. Column configuration A evaluation data.

\begin{tabular}{|c|c|c|c|c|c|c|c|c|c|}
\hline \multirow[b]{2}{*}{ Date } & \multirow[b]{2}{*}{$\mathrm{N}_{2}$} & \multicolumn{6}{|c|}{ Composition, mol \% } & \multirow[b]{2}{*}{$\mathrm{nC}_{5} \mathrm{H}_{12}$} & \multirow{2}{*}{$\begin{array}{c}\text { Heating } \\
\text { Value } \\
\mathrm{MJ} / \mathrm{m}^{3}\end{array}$} \\
\hline & & $\mathrm{CH}_{4}$ & $\mathrm{C}_{2} \mathrm{H}_{6}$ & $\mathrm{C}_{3} \mathrm{H}_{8}$ & ${ }^{i c_{4}} \mathrm{H}_{10}$ & $\mathrm{nC}_{4} \mathrm{H}_{10}$ & $i \mathrm{C}_{5} \mathrm{H}_{12}$ & & \\
\hline $\begin{array}{l}8 / 1 / 77 \\
8 / 1 / 77 \\
8 / 1 / 77 \\
8 / 1 / 77 \\
8 / 1 / 77\end{array}$ & $\begin{array}{r}.603 \\
.598 \\
.599 \\
.593 \\
.599\end{array}$ & $\begin{array}{l}90.123 \\
90.108 \\
90.112 \\
90.108 \\
90.115\end{array}$ & $\begin{array}{l}6.527 \\
6.540 \\
6.537 \\
6.543 \\
6.541\end{array}$ & $\begin{array}{l}2.197 \\
2.203 \\
2.200 \\
2.204 \\
2.194\end{array}$ & $\begin{array}{l}.291 \\
.291 \\
.292 \\
.290 \\
.291\end{array}$ & $\begin{array}{l}.238 \\
.239 \\
.239 \\
.239 \\
.238\end{array}$ & $\begin{array}{l}.009 \\
.010 \\
.010 \\
.010 \\
.011\end{array}$ & $\begin{array}{l}.013 \\
.011 \\
.012 \\
.012 \\
.011\end{array}$ & $\begin{array}{l}41.030 \\
41.039 \\
41.037 \\
41.043 \\
41.034\end{array}$ \\
\hline $\begin{array}{l}8 / 1 / 77 \\
8 / 1 / 77 \\
8 / 1 / 77 \\
8 / 1 / 77 \\
8 / 1 / 77\end{array}$ & $\begin{array}{l}.597 \\
.597 \\
.600 \\
.594 \\
.599\end{array}$ & $\begin{array}{l}90.104 \\
90.118 \\
90.109 \\
90.109 \\
90.102\end{array}$ & $\begin{array}{l}6.543 \\
6.545 \\
6.544 \\
6.549 \\
6.547\end{array}$ & $\begin{array}{l}2.203 \\
2.191 \\
2.196 \\
2.195 \\
2.198\end{array}$ & $\begin{array}{l}.292 \\
.292 \\
.291 \\
.291 \\
.291\end{array}$ & $\begin{array}{l}.239 \\
.236 \\
.238 \\
.239 \\
.239\end{array}$ & $\begin{array}{l}.010 \\
.010 \\
.010 \\
.010 \\
.010\end{array}$ & $\begin{array}{l}.012 \\
.012 \\
.012 \\
.013 \\
.013\end{array}$ & $\begin{array}{l}41.041 \\
41.033 \\
41.036 \\
41.041 \\
41.040\end{array}$ \\
\hline $\begin{array}{l}8 / 1 / 77 \\
8 / 1 / 77 \\
8 / 2 / 77 \\
8 / 2 / 77 \\
8 / 2 / 77\end{array}$ & $\begin{array}{l}.597 \\
.593 \\
.593 \\
.602 \\
.601\end{array}$ & $\begin{array}{l}90.117 \\
90.119 \\
90.114 \\
90.104 \\
90.119\end{array}$ & $\begin{array}{l}6.544 \\
6.542 \\
6.540 \\
6.536 \\
6.536\end{array}$ & $\begin{array}{l}2.192 \\
2.195 \\
2.201 \\
2.207 \\
2.193\end{array}$ & $\begin{array}{l}.291 \\
.291 \\
.292 \\
.291 \\
.291\end{array}$ & $\begin{array}{l}.238 \\
.240 \\
.239 \\
.238 \\
.239\end{array}$ & $\begin{array}{l}.010 \\
.010 \\
.009 \\
.010 \\
.011\end{array}$ & $\begin{array}{l}.012 \\
.011 \\
.012 \\
.011 \\
.011\end{array}$ & $\begin{array}{l}41.034 \\
41.037 \\
41.041 \\
41.038 \\
41.030\end{array}$ \\
\hline $\begin{array}{l}8 / 2 / 77 \\
8 / 2 / 77 \\
8 / 2 / 77 \\
8 / 2 / 77 \\
8 / 2 / 77\end{array}$ & $\begin{array}{l}.601 \\
.602 \\
.602 \\
.603 \\
.610\end{array}$ & $\begin{array}{l}90.115 \\
90.101 \\
90.114 \\
90.129 \\
90.106\end{array}$ & $\begin{array}{l}6.539 \\
6.542 \\
6.539 \\
6.532 \\
6.534\end{array}$ & $\begin{array}{l}2.193 \\
2.204 \\
2.195 \\
2.192 \\
2.193\end{array}$ & $\begin{array}{l}.291 \\
.291 \\
.291 \\
.288 \\
.291\end{array}$ & $\begin{array}{l}.238 \\
.238 \\
.238 \\
.235 \\
.238\end{array}$ & $\begin{array}{l}.010 \\
.010 \\
.010 \\
.009 \\
.013\end{array}$ & $\begin{array}{l}.012 \\
.012 \\
.012 \\
.011 \\
.013\end{array}$ & $\begin{array}{l}41.032 \\
41.039 \\
41.032 \\
41.022 \\
41.033\end{array}$ \\
\hline $\begin{array}{l}8 / 2 / 77 \\
8 / 2 / 77 \\
8 / 2 / 77 \\
8 / 2 / 77 \\
8 / 2 / 77\end{array}$ & $\begin{array}{l}.606 \\
.604 \\
.602 \\
.611 \\
.615\end{array}$ & $\begin{array}{l}90.099 \\
90.102 \\
90.098 \\
90.030 \\
90.090\end{array}$ & $\begin{array}{l}6.542 \\
6.542 \\
6.546 \\
6.609 \\
6.547\end{array}$ & $\begin{array}{l}2.202 \\
2.201 \\
2.200 \\
2.201 \\
2.196\end{array}$ & $\begin{array}{l}.291 \\
.290 \\
.291 \\
.291 \\
.291\end{array}$ & $\begin{array}{r}.238 \\
.238 \\
.240 \\
.238 \\
.240\end{array}$ & $\begin{array}{l}.010 \\
.010 \\
.010 \\
.010 \\
.010\end{array}$ & $\begin{array}{l}.012 \\
.012 \\
.013 \\
.010 \\
.011\end{array}$ & $\begin{array}{l}41.036 \\
41.036 \\
41.040 \\
41.050 \\
41.032\end{array}$ \\
\hline $\begin{array}{l}8 / 2 / 77 \\
8 / 2 / 77 \\
8 / 2 / 77\end{array}$ & $\begin{array}{l}.621 \\
.604 \\
.606\end{array}$ & $\begin{array}{l}90.111 \\
90.138 \\
90.079\end{array}$ & $\begin{array}{l}6.548 \\
6.545 \\
6.558\end{array}$ & $\begin{array}{l}2.167 \\
2.165 \\
2.204\end{array}$ & $\begin{array}{l}.291 \\
.290 \\
.291\end{array}$ & $\begin{array}{l}.241 \\
.237 \\
.240\end{array}$ & $\begin{array}{l}.010 \\
.010 \\
.010\end{array}$ & $\begin{array}{l}.012 \\
.011 \\
.012\end{array}$ & $\begin{array}{l}41.014 \\
41.014 \\
41.042\end{array}$ \\
\hline
\end{tabular}


Table 7.7.6. Column configuration B evaluation data.

\begin{tabular}{|c|c|c|c|c|c|c|c|c|c|}
\hline \multirow[b]{2}{*}{ Date } & \multicolumn{8}{|c|}{ Composition, mol \% } & \multirow{2}{*}{$\begin{array}{c}\text { Heating } \\
\text { Value } \\
\mathrm{MJ} / \mathrm{m}^{3}\end{array}$} \\
\hline & $\mathrm{N}_{2}$ & $\mathrm{CH}_{4}$ & $\mathrm{C}_{2} \mathrm{H}_{5}$ & $\mathrm{C}_{3} \mathrm{H}_{8}$ & ${ }^{i c_{4}} H_{10}$ & $\mathrm{nC}_{4} \mathrm{H}_{10}$ & ${ }_{i C_{5}} \mathrm{H}_{12}$ & $\mathrm{nC}_{5} \mathrm{H}_{12}$ & \\
\hline $\begin{array}{l}9 / 17 / 77 \\
9 / 17 / 77 \\
9 / 17 / 77 \\
9 / 17 / 77 \\
9 / 19 / 77\end{array}$ & $\begin{array}{l}.630 \\
.585 \\
.580 \\
.583 \\
.592\end{array}$ & $\begin{array}{l}90.108 \\
90.000 \\
90.098 \\
90.023 \\
90.080\end{array}$ & $\begin{array}{l}6.478 \\
6.602 \\
6.530 \\
6.586 \\
6.534\end{array}$ & $\begin{array}{l}2.190 \\
2.214 \\
2.196 \\
2.212 \\
2.199\end{array}$ & $\begin{array}{l}.290 \\
.293 \\
.291 \\
.292 \\
.291\end{array}$ & $\begin{array}{l}.282 \\
.286 \\
.283 \\
.284 \\
.283\end{array}$ & $\begin{array}{l}.013 \\
.009 \\
.008 \\
.008 \\
.010\end{array}$ & $\begin{array}{l}.0110 \\
.012 \\
.012 \\
.012 \\
.012\end{array}$ & $\begin{array}{l}41.039 \\
41.108 \\
41.076 \\
41.101 \\
41.075\end{array}$ \\
\hline $\begin{array}{l}9 / 19 / 77 \\
9 / 19 / 77 \\
9 / 19 / 77 \\
9 / 19 / 77 \\
9 / 19 / 77\end{array}$ & $\begin{array}{r}.594 \\
.610 \\
.591 \\
.595 \\
.591\end{array}$ & $\begin{array}{l}90.046 \\
90.082 \\
90.034 \\
90.031 \\
90.059\end{array}$ & $\begin{array}{l}6.556 \\
6.520 \\
6.572 \\
6.560 \\
6.553\end{array}$ & $\begin{array}{l}2.207 \\
2.192 \\
2.206 \\
2.214 \\
2.201\end{array}$ & $\begin{array}{l}.292 \\
.291 \\
.292 \\
.292 \\
.290\end{array}$ & $\begin{array}{l}.284 \\
.283 \\
.284 \\
.285 \\
.284\end{array}$ & $\begin{array}{l}.010 \\
.010 \\
.010 \\
.010 \\
.010\end{array}$ & $\begin{array}{l}.011 \\
.011 \\
.012 \\
.012 \\
.013\end{array}$ & $\begin{array}{l}41.056 \\
41.050 \\
41.092 \\
41.093 \\
41.083\end{array}$ \\
\hline $9 / 19 / 77$ & .592 & 90.052 & 6.555 & 2.203 & .292 & .283 & .010 & .013 & 41.085 \\
\hline
\end{tabular}


Table 7.1.7. Data for the comparison between integrators A and B.

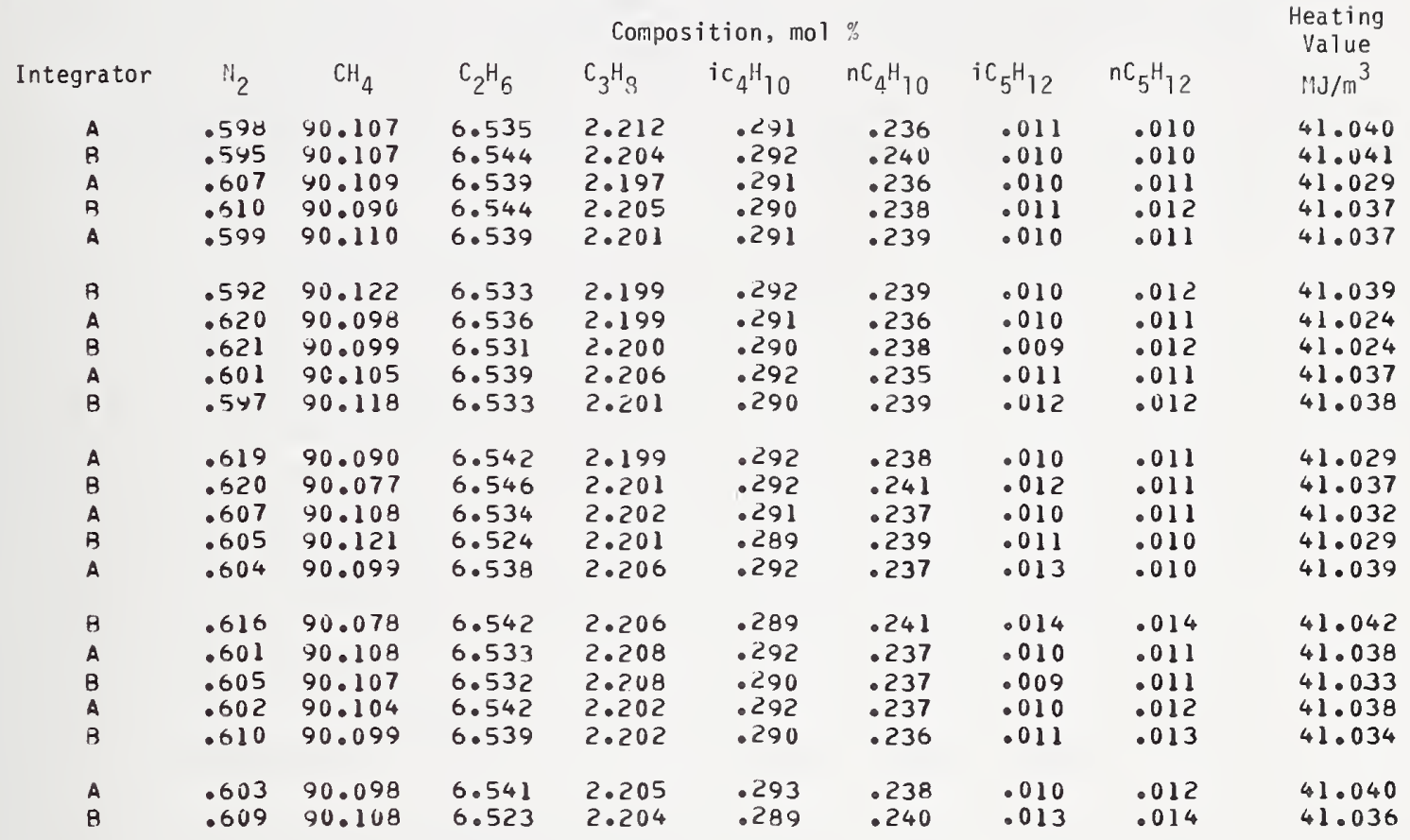


7.1.4. Determination of the effect of operating variables on gas chromatograph analysis accuracy and precision.

Table 7.1.8 lists the data for various sample pressures; table 7.1.9

lists the data for different carrier gas flow rates. Prepared mixture $\mathrm{H}$ was used throughout these tests. 
Table 7.1.8. Data for determining the effect of sample pressure on gas chromatograph analysis accuracy and precision.

\begin{tabular}{|c|c|c|c|c|c|c|c|c|c|c|}
\hline \multirow{2}{*}{$\begin{array}{c}\text { Sample } \\
\text { Pressure } \\
\mathrm{KPa}\end{array}$} & \multirow[b]{2}{*}{ Integrator } & \multirow[b]{2}{*}{$\mathrm{N}_{2}$} & \multicolumn{7}{|c|}{ Composition, mol \% } & \multirow{2}{*}{$\begin{array}{l}\text { Heating } \\
\text { Value } \\
\mathrm{MJ} / \mathrm{m}^{3}\end{array}$} \\
\hline & & & $\mathrm{CH}_{4}$ & $\mathrm{C}_{2} \mathrm{H}_{6}$ & $\mathrm{C}_{3} \mathrm{H}_{8}$ & $i \mathrm{C}_{4} \mathrm{H}_{10}$ & $\mathrm{nC}_{4} \mathrm{H}_{1 \cap}$ & ${ }^{i C_{5}} \mathrm{H}_{1}$ ? & $\mathrm{nC}_{5} \mathrm{H}_{1}$ ? & \\
\hline $\begin{array}{l}94 \\
94 \\
94 \\
94 \\
74\end{array}$ & $\begin{array}{l}A \\
B \\
A \\
B \\
A\end{array}$ & $\begin{array}{l}.594 \\
.597 \\
.598 \\
.605 \\
.599\end{array}$ & $\begin{array}{l}90.073 \\
90.062 \\
90.065 \\
90.066 \\
90.069\end{array}$ & $\begin{array}{l}6.534 \\
6.543 \\
6.529 \\
6.535 \\
6.537\end{array}$ & $\begin{array}{l}2.204 \\
2.201 \\
2.214 \\
2.201 \\
2.200\end{array}$ & $\begin{array}{l}.291 \\
.292 \\
.290 \\
.289 \\
.291\end{array}$ & $\begin{array}{l}.283 \\
.284 \\
.282 \\
.283 \\
.284\end{array}$ & $\begin{array}{l}.010 \\
.010 \\
.010 \\
.011 \\
.010\end{array}$ & $\begin{array}{l}.011 \\
.011 \\
.011 \\
.011 \\
.011\end{array}$ & $\begin{array}{l}41.076 \\
41.078 \\
41.078 \\
41.069 \\
41.074\end{array}$ \\
\hline $\begin{array}{l}74 \\
74 \\
74 \\
74 \\
94\end{array}$ & $\begin{array}{l}B \\
A \\
B \\
A \\
B\end{array}$ & $\begin{array}{l}.594 \\
.595 \\
.604 \\
.595 \\
.596\end{array}$ & $\begin{array}{l}90.071 \\
90.070 \\
90.065 \\
90.066 \\
90.057\end{array}$ & $\begin{array}{l}6.534 \\
6.533 \\
6.540 \\
6.539 \\
6.554\end{array}$ & $\begin{array}{l}2.201 \\
2.208 \\
2.198 \\
2.202 \\
2.194\end{array}$ & $\begin{array}{l}.293 \\
.290 \\
.289 \\
.290 \\
.293\end{array}$ & $\begin{array}{l}.284 \\
.284 \\
.283 \\
.285 \\
.286\end{array}$ & $\begin{array}{l}.009 \\
.011 \\
.008 \\
.010 \\
.009\end{array}$ & $\begin{array}{l}.013 \\
.011 \\
.013 \\
.012 \\
.011\end{array}$ & $\begin{array}{l}41.079 \\
41.077 \\
41.069 \\
41.079 \\
41.078\end{array}$ \\
\hline $\begin{array}{r}94 \\
74 \\
145 \\
145 \\
145\end{array}$ & $\begin{array}{l}A \\
B \\
A \\
B \\
A\end{array}$ & $\begin{array}{l}.592 \\
.589 \\
.605 \\
.601 \\
.605\end{array}$ & $\begin{array}{l}90.067 \\
90.067 \\
89.930 \\
89.951 \\
89.953\end{array}$ & $\begin{array}{l}6.538 \\
6.547 \\
6.621 \\
6.624 \\
6.619\end{array}$ & $\begin{array}{l}2.206 \\
2.199 \\
2.240 \\
2.225 \\
2.219\end{array}$ & $\begin{array}{l}.291 \\
.291 \\
.295 \\
.293 \\
.295\end{array}$ & $\begin{array}{l}.283 \\
.285 \\
.287 \\
.287 \\
.287\end{array}$ & $\begin{array}{l}.010 \\
.008 \\
.010 \\
.009 \\
.010\end{array}$ & $\begin{array}{r}.013 \\
.013 \\
.011 \\
.0110 \\
.011\end{array}$ & $\begin{array}{l}41.081 \\
41.081 \\
41.124 \\
41.113 \\
41.112\end{array}$ \\
\hline $\begin{array}{l}145 \\
145 \\
145 \\
145 \\
145\end{array}$ & $\begin{array}{l}B \\
A \\
B \\
A \\
B\end{array}$ & $\begin{array}{l}.605 \\
.606 \\
.601 \\
.608 \\
.606\end{array}$ & $\begin{array}{l}89.949 \\
89.940 \\
89.942 \\
89.943 \\
89.940\end{array}$ & $\begin{array}{l}6.617 \\
6.620 \\
6.629 \\
6.619 \\
6.623\end{array}$ & $\begin{array}{l}2 \cdot 225 \\
2 \cdot 231 \\
2 \cdot 225 \\
2 \cdot 225 \\
2 \cdot 226\end{array}$ & $\begin{array}{l}.295 \\
.295 \\
.294 \\
.296 \\
.293\end{array}$ & $\begin{array}{l}.290 \\
.288 \\
.288 \\
.288 \\
.289\end{array}$ & $\begin{array}{l}.009 \\
.010 \\
.009 \\
.010 \\
.010\end{array}$ & $\begin{array}{r}.011 \\
.011 \\
.012 \\
.012 \\
.013\end{array}$ & $\begin{array}{l}41 \cdot 114 \\
41.118 \\
41 \cdot 119 \\
41 \cdot 115 \\
41 \cdot 118\end{array}$ \\
\hline $\begin{array}{r}145 \\
145 \\
59 \\
59 \\
59\end{array}$ & $\begin{array}{l}A \\
B \\
A \\
B \\
A\end{array}$ & $\begin{array}{l}.605 \\
.602 \\
.587 \\
.618 \\
.592\end{array}$ & $\begin{array}{l}89.944 \\
89.942 \\
90.159 \\
90.121 \\
90.164\end{array}$ & $\begin{array}{l}6.624 \\
6.628 \\
6.480 \\
6.489 \\
6.473\end{array}$ & $\begin{array}{l}2.222 \\
2.221 \\
2.189 \\
2 \cdot 178 \\
2.185\end{array}$ & $\begin{array}{l}.295 \\
.295 \\
.286 \\
.286 \\
.286\end{array}$ & $\begin{array}{l}.288 \\
.290 \\
.279 \\
.284 \\
.279\end{array}$ & $\begin{array}{l}.010 \\
.010 \\
.0110 \\
.011 \\
.011\end{array}$ & $\begin{array}{l}.011 \\
.013 \\
.0111 \\
.013 \\
.010\end{array}$ & $\begin{array}{l}41.115 \\
41.119 \\
41.046 \\
41.039 \\
41.041\end{array}$ \\
\hline $\begin{array}{l}59 \\
59 \\
59 \\
59 \\
59\end{array}$ & $\begin{array}{l}B \\
A \\
B \\
A \\
B\end{array}$ & $\begin{array}{l}.607 \\
.590 \\
.607 \\
.592 \\
.589\end{array}$ & $\begin{array}{l}90.142 \\
90.173 \\
90.147 \\
90.169 \\
90.162\end{array}$ & $\begin{array}{l}6.483 \\
6.471 \\
6.482 \\
6.467 \\
6.480\end{array}$ & $\begin{array}{l}2.178 \\
2.177 \\
2.177 \\
2.183 \\
2.173\end{array}$ & $\begin{array}{l}.290 \\
.288 \\
.290 \\
.287 \\
.291\end{array}$ & $\begin{array}{l}.280 \\
.280 \\
.279 \\
.282 \\
.284\end{array}$ & $\begin{array}{l}.011 \\
.009 \\
.009 \\
.009 \\
.007\end{array}$ & $\begin{array}{l}.011 \\
.012 \\
.010 \\
.011 \\
.014\end{array}$ & $\begin{array}{l}41.039 \\
41.039 \\
41.034 \\
41.040 \\
41.046\end{array}$ \\
\hline $\begin{array}{l}59 \\
59\end{array}$ & $\begin{array}{l}A \\
B\end{array}$ & $\begin{array}{l}.601 \\
.616\end{array}$ & $\begin{array}{l}90.152 \\
90.139\end{array}$ & $\begin{array}{l}6.470 \\
6.476\end{array}$ & $\begin{array}{l}2.190 \\
2.180\end{array}$ & $\begin{array}{l}.287 \\
.289\end{array}$ & $\begin{array}{l}.279 \\
.281\end{array}$ & $\begin{array}{l}.010 \\
.009\end{array}$ & $\begin{array}{l}.011 \\
.011\end{array}$ & $\begin{array}{l}41.040 \\
41.033\end{array}$ \\
\hline
\end{tabular}


Table 7.1.9. Data for determining the effect of carrier gas flow rate on gas chromatograph analysis accuracy and precision.

Flow Rate $\mathrm{scm}^{3} / \mathrm{min}$

26.5

26.5

26.5

26.5

26.5

26.5

26.5

26.5

26.5

26.5

24.2

24.2

24.2

24.2

24.2

24.2

24.2

24.2

24.2

$24 \cdot 2$

27.6

27.6

27.6

27.6

27.6

27.6

27.6

27.6

27.6

27.6

Integrator

$\begin{array}{ll}\mathrm{N}_{2} & \mathrm{CH}_{4} \\ .599 & 90.068 \\ .603 & 90.065 \\ .597 & 90.071 \\ .594 & 90.073 \\ .599 & 90.068 \\ & \\ .599 & 90.057 \\ .598 & 90.056 \\ .599 & 90.065 \\ .600 & 90.072 \\ .595 & 90.071 \\ & \\ .606 & 90.040 \\ .525 & 90.114 \\ .607 & 90.065 \\ .522 & 90.153 \\ .610 & 90.045 \\ .518 & 90.127 \\ .610 & 90.043 \\ .514 & 90.138 \\ .609 & 90.049 \\ .511 & 90.141 \\ .607 & 90.062 \\ .614 & 89.921 \\ .608 & 90.053 \\ .612 & 89.924 \\ .604 & 90.109 \\ .617 & 89.920 \\ .608 & 90.093 \\ .616 & 89.875 \\ .607 & 90.046 \\ .615 & 89.883\end{array}$

Composition, mol :

\begin{tabular}{|c|c|c|c|c|c|}
\hline $\mathrm{C}_{2} \mathrm{H}_{6}$ & $\mathrm{C}_{3} \mathrm{H}_{8}$ & $i_{4} \mathrm{H}_{10}$ & $\mathrm{nC}_{4} \mathrm{H}_{10}$ & $i C_{5} \mathrm{H}_{12}$ & $\mathrm{nC}_{5} \mathrm{H}_{1}$ \\
\hline $\begin{array}{l}6.533 \\
6.539 \\
6.537 \\
6.532 \\
6.537\end{array}$ & $\begin{array}{l}2.202 \\
2.200 \\
2.198 \\
2.203 \\
2.200\end{array}$ & $\begin{array}{l}.292 \\
.290 \\
.291 \\
.291 \\
.291\end{array}$ & $\begin{array}{l}.283 \\
.283 \\
.283 \\
.285 \\
.284\end{array}$ & $\begin{array}{l}.010 \\
.009 \\
.010 \\
.010 \\
.010\end{array}$ & $\begin{array}{l}.012 \\
.0110 \\
.012 \\
.0112 \\
.011\end{array}$ \\
\hline $\begin{array}{l}6.544 \\
6.539 \\
6.539 \\
6.540 \\
6.541\end{array}$ & $\begin{array}{l}2.201 \\
2.209 \\
2.201 \\
2.191 \\
2.198\end{array}$ & $\begin{array}{l}.292 \\
.292 \\
.291 \\
.293 \\
.291\end{array}$ & $\begin{array}{l}.283 \\
.284 \\
.284 \\
.283 \\
.284\end{array}$ & $\begin{array}{l}.011 \\
.010 \\
.009 \\
.010 \\
.009\end{array}$ & $\begin{array}{l}.01 \\
.01 \\
.01 \\
.01 \\
.01\end{array}$ \\
\hline $\begin{array}{l}6.531 \\
6.547 \\
6.517 \\
6.533 \\
6.528\end{array}$ & $\begin{array}{l}2.227 \\
2.214 \\
2.218 \\
2.198 \\
2.224\end{array}$ & $\begin{array}{l}.293 \\
.294 \\
.292 \\
.291 \\
.293\end{array}$ & $\begin{array}{l}.284 \\
.287 \\
.283 \\
.284 \\
.283\end{array}$ & $\begin{array}{l}.010 \\
.010 \\
.010 \\
.010 \\
.010\end{array}$ & $\begin{array}{l}.00 \\
.00 \\
.00 \\
.00\end{array}$ \\
\hline $\begin{array}{l}6.552 \\
6.535 \\
6.551 \\
6.534 \\
6.551\end{array}$ & $\begin{array}{l}2.206 \\
2.221 \\
2.205 \\
2.216 \\
2.205\end{array}$ & $\begin{array}{l}.293 \\
.292 \\
.291 \\
.292 \\
.291\end{array}$ & $\begin{array}{l}.286 \\
.283 \\
.285 \\
.283 \\
.284\end{array}$ & $\begin{array}{l}.009 \\
.010 \\
.009 \\
.010 \\
.010\end{array}$ & $\begin{array}{l}.00 \\
.00 \\
.00 \\
.00 \\
.00\end{array}$ \\
\hline $\begin{array}{l}6.537 \\
6.630 \\
6.537 \\
6.632 \\
6.523\end{array}$ & $\begin{array}{l}2.201 \\
2.230 \\
2.204 \\
2.229 \\
2.168\end{array}$ & $\begin{array}{l}.292 \\
.297 \\
.293 \\
.296 \\
.291\end{array}$ & $\begin{array}{l}.279 \\
.289 \\
.284 \\
.289 \\
.283\end{array}$ & $\begin{array}{l}.010 \\
.009 \\
.010 \\
.009 \\
.010\end{array}$ & $\begin{array}{l}.01 \\
.0 \\
.0 \\
.0 \\
.0\end{array}$ \\
\hline $\begin{array}{l}6.630 \\
6.544 \\
6.662 \\
6.545 \\
6.655\end{array}$ & $\begin{array}{l}2.224 \\
2.157 \\
2.240 \\
2.203 \\
2.234\end{array}$ & $\begin{array}{l}.297 \\
.293 \\
.298 \\
.292 \\
.297\end{array}$ & $\begin{array}{l}.288 \\
.284 \\
.288 \\
.285 \\
.292\end{array}$ & $\begin{array}{l}.0110 \\
.011 \\
.009 \\
.010 \\
.011\end{array}$ & $\begin{array}{l}.0 \\
.0 \\
.0 \\
.0 \\
.0\end{array}$ \\
\hline
\end{tabular}

Heating

value

$\mathrm{MJ} / \mathrm{m}^{3}$

41.075

41.069

41.074

41.078

41.074

41.078

41.081

41.074

41.070

41.074

41.083

41.115

41.072

41.097

41.077

41.111

41.076

41.108

41.073

41.109

41.069

41.119

41.074

41.118

41.049

41.117

41.050

41.134

41.077

41.134 
APPENDIX 7.2. RECOMMENDED CRITERIA FOR SELECTING A GAS CHROMATOGRAPH FOR USE IN ANALYZING VAPORIZED LNG SAMPLES

Based on our experiences during this project, we recommend the following features be incorporated into any gas chromatographs used for analyzing vaporized LNG samples:

a) automatic valve switching,

b) hot-wire filament detector with a thermal protect device to minimize the risk of oxidizing the filaments; the detector cavity should have minimal gas volume,

c) a separate electrical input line for the detector power supply,

d) carrier gas flow control by pressure instead of mass flow, and

e) valve and column ovens which are accesible for leak checking all fittings.

As a precaution, we recommend that the thermal conductivity detector power input be connected to a constant voltage transformer.

For the digital integrator we recommend that the "memory protect" feature be used; also, it is recommended that a constant voltage transformer be used with the digital integrator. 
APPENDIX 7.3. METHOD FOR COMPUTING THE UNCERTAINTY OF A GAS ANALYSIS AND A METHOD FOR REJECTING A GIVEN ANALYSIS

This appendix suggests useful statistical techniques for computing the uncertainty in composition measurement; also, it describes a simple procedure for rejecting a given analysis from a set of replicate analyses of the same sample. Examples are given for both methods.

7.3.1. Computing the composition uncertainty of a given sample.

As mentioned in section 2.2., a logical way to estimate the error in a measurement process is to treat the error as composed of two parts -- accuracy and precision. By following the recommendations of section 4.6 .1 , the only source of bias in a gas chromatograph analysis is the error in the calibration gas composition. The total uncertainty ( \pm D) (and how they estimated it) of each component's composition should be given by the supplier of the calibration gas. If possible, the composition should be verified by another gas analysis facility.

The size of the random error (i.e., standard deviation) will be unique to each gas chromatograph-integrator system; however, comparable systems should have comparable standard deviations. Test results showed that the standard deviation for calibration and analyses can be assumed equal. If we make $\mathrm{N}_{C}$ calibration runs before analyzing a gas sample $\mathrm{N}_{\mathrm{A}}$ times, the value and total uncertainty of a given component (or derived property such as heating value) will be

$$
\bar{x} \pm\left(D+s \cdot t \sqrt{1 / N_{A}+1 / N_{C}}\right)
$$

$\mathrm{N}_{\mathrm{A}}$

where $\bar{x}$ is the average value (i.e., $\bar{x}=\sum_{i=1} x_{i}$ ), s is an estimate, based on replicate measurements, of the standard deviation and $t$ the student's $t$ statistic for the desired confidence interval (e.g., 99 percent). There are two choices for the value of $s$-- one is to compute $s$ from measurements on the given sample, i.e.

$$
s=\sqrt{\sum_{i=1}^{N_{A}}\left(x_{i}-\bar{x}_{i}\right)^{2} /\left(N_{A}-1\right)}
$$

The second, and preferred, choice is to use the composite standard deviation, $s_{p}$ ' which is based on all previous sets of analyses. Since $s_{p}$ is computed from many analyses it more closely represents the true standard deviation of the measurement process. The composite, or pooled, standard deviation is given by

$$
s_{p}=\sqrt{\left(\sum_{j=1}^{M}\left(N_{A j}-1\right) s_{j}^{2}\right) / \sum_{j=1}^{M}\left(N_{A j}-1\right)}
$$


where $\mathrm{N}_{\mathrm{Aj}}$ is the number of replicate analyses taken on the $j$ th sample, $s_{j}$ is the estimated standard deviation for that set (computed using 7.3.2) and $M$ is the total number of samples analyzed.

The student's $t$ statistic used will depend upon the chosen confidence interval and the chosen standard deviation ( $s$ or $s_{p}$ ).

This approach could be applied to the sampling system if several samples could be taken during a period when the LNG composition is constant.

Example 1

The results of four replicate analyses of a sample give the following methane contents: $90.080,90.032,90.080$ and $90.070 \mathrm{~mol}$ percent. Prior to these analyses, there were three calibration runs in which the response factors for each component were averaged. The stated uncertainty in the methane content of the calibration gas is \pm 0.003 mol percent.

The average methane value is $90.066 \mathrm{~mol}$ percent and the estimated standard deviation, $s$, is 0.023 . Using these values, the student's $t$ statistic for three degrees of freedom (i.e., $\mathrm{N}_{\mathrm{A}}-1$ ) and a 99 percent confidence interval from table 7.3 .1 of 5.841 , we obtain the total uncertainty in the methane content:

$$
\begin{aligned}
& \pm\left(D+s \cdot t \sqrt{1 / N_{A}+1 / N_{C}}\right) \\
& \pm(0.003+0.023 \cdot 5.841 \sqrt{1 / 4+1 / 3}) \\
& \pm 0.106 \mathrm{~mol} \%
\end{aligned}
$$

However, prior to this analysis, a sufficient number of analyses were made so that $\sum_{j}\left(N_{A j}-1\right)=52$ (which is the number of degrees of freedom), and the composite standard deviation, $s_{p}$ ' is 0.020 . Based on 52 degrees of freedom, $t$ is approximately 2.68 and the total uncertainty becomes

$$
\pm(0.003+0.020 \cdot 2.68 \sqrt{1 / 4+1 / 3})= \pm 0.044 \mathrm{~mol} \%
$$

This value is 60 percent smaller than the other; also, it is more representative of the expected uncertainty.

The size of the confidence level depends upon the number of analyses; however, the width decreases as the square root of $1 / \mathrm{N}_{\mathrm{A}}$. This makes it unattractive to make more than three or four analyses. If there had been ten analyses instead of four in the above example the confidence interval would be \pm 0.038 ; this is only 13 percent smaller than when using four analyses. i.e.,

The value of $s_{p}$ can be updated using the above data and equation 7.3 .3 ,

$$
s_{p}=\sqrt{\left(52 \cdot(0.020)^{2}+3(0.023)^{2}\right) /(52+3)}=0.0202
$$

which is a negligible change in this case. 
Table 7.3.1. Values of the Student's $t$ distribution used to calculate confidence intervals for the mean [5].

\section{Degrees of Freedom}

1

2

3

4

5

6

7

8

9

10

11

12

13

14

15

16

17

18

19

20

21

22

23

24

25

26

27

28

29

30

40

60

120

$\infty$

Student's t Distribution Confidence Interval $95 \%$

$99 \%$

12.706
4.303
3.182
2.776
2.571
2.447

63.657

9.925

5.841

4.604

4.032

2.447

2.306

2.262

2.228

2.201

2.179

2.160

2.145

2.131

2. 120

2.110

2. 101

2.093

2.086

2.080

2. 074

2. 069

2. 064

2.060

3.707

3.499

3.355

3.250

3.169

3.106

3.055

3.012

2.977

2.947

2.921

2.898

2.878

2.861

2.845

2.831

2.819

2.807

2.797

2.787

2.056

2.052

2.048

2.045

2. 042

2.779

2.771

2.763

2.756

2.750

2.021

2. 000

1.980

1.960
2.704

2. 660

2.617

2.576

7.3.2. Methods of rejecting an analysis.

To reject a given analysis we need to run two or more analyses and compute the difference, $R$, between the maximum and minimum measured values. one of these two points can be rejected if

$$
R=x_{\max }-x_{\min }>A \cdot s_{p}
$$

where $A$ is a function of the number of analyses, $N_{A}$ (ref. [5], p. 17-3). Table 7.3.2 lists the values of $A$. Using this criterion, only one out of one hundred rejected analyses will be rejected when it should not have been. 
Table 7.3.2. Values of $A$ as a function of $N_{A}$.

\begin{tabular}{|r|c|}
\hline$N_{A}$ & A \\
2 & \\
3 & 3.64 \\
4 & 4.12 \\
5 & 4.40 \\
6 & 4.60 \\
7 & 4.76 \\
8 & 4.88 \\
9 & 4.99 \\
10 & 5.08 \\
\hline
\end{tabular}

\section{Example 2}

Three replicate analyses are run and the measured methane contents are 90.132, 90.021 and $90.032 \mathrm{~mol}$ percent. From previous analyses we know that $s_{p}$ is 0.020 . Can the first value be rejected?

Using equation 7.3 .4 ,

$$
\begin{aligned}
\mathrm{R}=90.132 & -90.021 \stackrel{?}{>} 4.12 \cdot 0.020 \\
0.111 & >0.082 .
\end{aligned}
$$

Therefore, the first point should be rejected. However, if the first value had been $90.103 \mathrm{~mol}$ percent, it would not be rejected using this procedure. 
This appendix lists all of the measured operating variables in the sampling tests according to run number. The sample analysis along with the computed liquid density are listed after operating variables for each test. All compositions were measured using integrator A unless stated otherwise.

7.4.1. Laboratory Test Data

In table 7.4.1 "Mix" refers to samples of the mixture present in the apparatus during the given test, e.g., 1; analyses of the corresponding gas cylinder will have a Mix number greater than 100, e.g., 101. Mix 100 represents analyses of the calibration gas (see table 4.2 , mixture E). The listed heating values are ideal gas values computed using the values given in table 2.2; to convert from $\mathrm{MJ} / \mathrm{m}^{3}$ to Btu/scf multiply by 26.845 . 
Table 7.4.1. Laboratory Test Data Probe Test 1 (runs 20 through 32 were not used in any statistical evaluation).

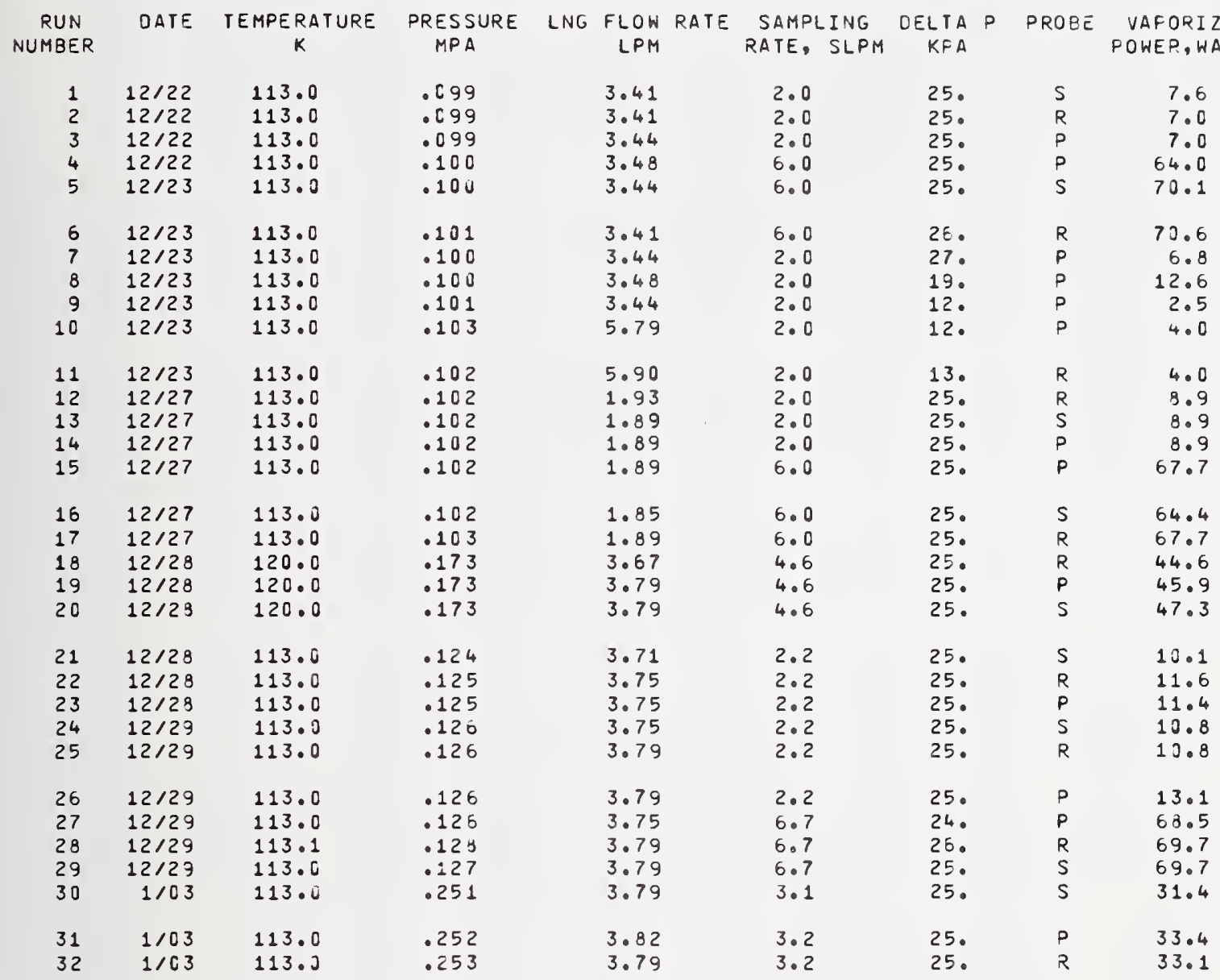


Tab]e 7.4.1. Probe Test 1 (continued)

\begin{tabular}{|c|c|c|c|c|c|c|c|c|c|c|}
\hline $\begin{array}{c}\text { Run } \\
\text { Number }\end{array}$ & Time & $\operatorname{Mix}$ & $\mathrm{N}_{2}$ & $\mathrm{CH}_{4}$ & $\mathrm{C}_{2} \mathrm{H}_{6}$ & $\mathrm{C}_{3} \mathrm{H}_{8}$ & ${ }^{i C_{4}} \mathrm{H}_{10}$ & $\mathrm{nC}_{4} \mathrm{H}_{10}$ & $\begin{array}{l}\text { Value } \\
\mathrm{MJ} / \mathrm{m}^{3}\end{array}$ & $\begin{array}{l}\text { Density } \\
\mathrm{gm} / \mathrm{cm}^{3}\end{array}$ \\
\hline 1 & 1307 & 1 & 0.033 & 85.648 & $11.68 j$ & 1.401 & .541 & .730 & 42.982 & .4691 \\
\hline 2 & 1346 & 1 & נטסם.0 & 35.667 & 11.640 & 1.399 & .554 & .740 & 42.989 & .4691 \\
\hline 2 & 1404 & 1 & 3.000 & 85.692 & 11.620 & 1.391 & .553 & $.7+4$ & 42.981 & $.4 E 90$ \\
\hline 2 & 1426 & 101 & 0.000 & 85.619 & 11.720 & 1.386 & .539 & .736 & 42.988 & .4691 \\
\hline 3 & 1451 & 1 & 0.0 ن 0 & 85.557 & 11.760 & 1.399 & .544 & .740 & 43.015 & .4694 \\
\hline 3 & 1507 & 1 & 0.300 & 85.533 & 11.760 & 1.403 & .552 & .751 & 43.033 & .4695 \\
\hline 3 & 1524 & 1 & 0.000 & 85.540 & 11.759 & 1.404 & .548 & .743 & 43.023 & .4694 \\
\hline 4 & 1547 & 1 & 0.003 & 85.699 & 11.660 & 1.381 & .544 & .726 & 42.964 & $.4 \varepsilon 89$ \\
\hline 4 & 1602 & 1 & 0.500 & 85.691 & $11.65 \mathrm{~J}$ & 1.382 & .543 & .734 & 42.968 & .4689 \\
\hline 5 & 1012 & 1 & 0.000 & 85.611 & 11.699 & 1.401 & .547 & .742 & 43.003 & .4692 \\
\hline 5 & 1031 & 101 & 0.000 & 85.610 & 11.710 & 1.391 & .555 & .734 & 43.000 & .4692 \\
\hline 6 & 1059 & 1 & 0.000 & 85.675 & 11.649 & 1.390 & .550 & .736 & 42.980 & .4690 \\
\hline 6 & 1115 & 1 & 0.000 & 85.649 & 11.600 & 1.384 & .548 & .739 & 42.986 & .4691 \\
\hline 7 & 1251 & 1 & 0.000 & 85.723 & 11.619 & 1.378 & .547 & .733 & 42.959 & .4689 \\
\hline 7 & 1308 & 1 & 0.003 & 85.707 & 11.640 & 1.375 & .548 & .730 & 42.962 & .4689 \\
\hline 8 & 1347 & 1 & 0.000 & 85.663 & 11.650 & 1.394 & .551 & .741 & 42.988 & .4691 \\
\hline 8 & 1404 & 1 & {$[.00 J$} & 85.693 & $11.63 \mathrm{~J}$ & 1.395 & .549 & .733 & 42.974 & .4690 \\
\hline 8 & 1422 & 101 & $C .003$ & 85.608 & 11.720 & 1.394 & .547 & .731 & 42.995 & $.4 E 92$ \\
\hline 9 & 1447 & 1 & 0.000 & 85.723 & 11.610 & 1.380 & .548 & .739 & 42.954 & .4689 \\
\hline 9 & 1504 & 1 & 0.003 & 85.734 & 11.609 & 1.371 & .549 & .737 & 42.957 & .4683 \\
\hline 10 & 1531 & 1 & 0.000 & 85.533 & 11.730 & 1.417 & .574 & .775 & 071 & .4698 \\
\hline 10 & 1549 & 1 & 0.000 & 85.517 & 11.730 & 1.415 & .571 & .758 & 43.061 & .4697 \\
\hline 11 & 1607 & 1 & 0.000 & 85.679 & 11.640 & 1.383 & .548 & .745 & 42.982 & .4691 \\
\hline 11 & 1623 & 1 & 0.003 & 95.695 & 11.641 & 1.380 & .547 & .737 & 42.970 & $.4 E 90$ \\
\hline 11 & 1641 & 101 & $0.60 \mathrm{~J}$ & 85.555 & 11.741 & 1.405 & .554 & .745 & 43.025 & .4694 \\
\hline 12 & 1019 & 1 & 0.000 & 85.672 & 11.675 & 1.377 & .540 & .736 & 42.971 & .4690 \\
\hline 12 & 1038 & 1 & 0.003 & 85.691 & 11.637 & 1.384 & .546 & .742 & 42.974 & .4690 \\
\hline 12 & 1057 & 1 & 0.000 & 85.674 & 11.664 & 1.379 & .544 & .739 & 42.975 & .4690 \\
\hline 12 & 956 & 101 & 0.600 & 85.591 & 12.739 & 1.394 & .543 & .734 & 43.005 & .4692 \\
\hline 13 & 1144 & 1 & 0.003 & 85.683 & 11.649 & 1.386 & .544 & .738 & 42.974 & .4690 \\
\hline 13 & 1203 & 1 & 0.000 & 85.728 & 11.630 & 1.380 & .537 & .725 & 42.948 & .4688 \\
\hline 14 & 1235 & 1 & 0.000 & 85.664 & 11.621 & 1.409 & .557 & .749 & 42.999 & .4692 \\
\hline 14 & 1252 & 1 & 0.003 & 85.666 & 11.621 & 1.407 & .553 & .753 & 42.998 & .4692 \\
\hline 15 & 1336 & 1 & 0.003 & 85.648 & 11.689 & 1.393 & $.54 \mathrm{C}$ & .730 & 42.979 & .4691 \\
\hline 15 & 1354 & 1 & 0.000 & 85.649 & 11.685 & 1.397 & .539 & .730 & 42.980 & .4691 \\
\hline 15 & 1410 & 1 & 0.000 & 85.643 & 11.674 & 1.400 & .543 & .740 & 42.990 & $.4 E 91$ \\
\hline 16 & 1605 & 1 & 0.003 & 85.764 & 11.611 & 1.371 & .534 & .720 & 42.931 & .4686 \\
\hline 16 & 1621 & 1 & 0.000 & 85.703 & 11.659 & 1.378 & .537 & .723 & 42.954 & .4688 \\
\hline 16 & 1546 & 101 & 0.000 & 85.672 & 11.699 & 1.375 & .536 & .718 & 42.958 & .4689 \\
\hline 17 & 1642 & 1 & 0.000 & 85.637 & 11.670 & 1.381 & .536 & .726 & 42.960 & .4689 \\
\hline 17 & 1658 & 1 & 0.000 & 85.696 & 11.669 & 1.378 & .534 & .723 & 42.954 & .4688 \\
\hline 18 & 1002 & 1 & 0.000 & 85.713 & 11.660 & 1.377 & .529 & .720 & 42.945 & .4589 \\
\hline 18 & 1018 & 1 & 0.000 & 85.707 & 11.667 & 1.384 & .527 & .715 & 42.944 & .4589 \\
\hline 18 & 1034 & 1 & 0.000 & 85.723 & $11.67 \mathrm{~J}$ & 1.373 & .525 & .739 & 42.932 & .4588 \\
\hline 19 & 1112 & 1 & 0.003 & 85.565 & 11.719 & 1.420 & .548 & .748 & 43.025 & .4596 \\
\hline 19 & 1130 & 1 & 0.000 & 85.511 & 11.759 & 1.420 & .553 & .758 & 43.048 & .4598 \\
\hline 19 & 1147 & 1 & 0.000 & 85.487 & 11.785 & 1.419 & .550 & .759 & 43.054 & .4599 \\
\hline 19 & 1203 & 1 & 0.003 & 85.503 & 11.771 & 1.425 & .550 & .751 & 43.047 & .4598 \\
\hline 20 & 1251 & 1 & 0. ن 00 & 85.713 & 11.660 & $2.38 \mathrm{~J}$ & .534 & .712 & 42.944 & .4589 \\
\hline 20 & 1308 & 1 & 0.000 & 85.727 & 11.651 & 1.382 & .524 & .716 & 42.937 & .4588 \\
\hline
\end{tabular}


Table 7.4.1. Probe Test 1 (continued)

\begin{tabular}{|c|c|c|c|c|c|c|c|c|c|c|}
\hline $\begin{array}{c}\text { Run } \\
\text { Number }\end{array}$ & Time & Mix & $\mathrm{N}_{2}$ & $\mathrm{CH}_{4}$ & $\mathrm{C}_{2} \mathrm{H}_{6}$ & $\mathrm{C}_{3} \mathrm{H}_{8}$ & $i_{4} \mathrm{H}_{10}$ & $\mathrm{nC}_{4} \mathrm{H}_{10}$ & $\begin{array}{l}\text { Value } \\
\mathrm{MJ} / \mathrm{m}^{3}\end{array}$ & $\begin{array}{r}\text { Density } \\
\mathrm{gm} / \mathrm{cm}^{3}\end{array}$ \\
\hline $\begin{array}{l}20 \\
21 \\
21 \\
22\end{array}$ & $\begin{array}{l}1224 \\
1521 \\
1555 \\
1513\end{array}$ & $\begin{array}{r}101 \\
2 \\
2 \\
2\end{array}$ & $\begin{array}{r}0.003 \\
.543 \\
.542 \\
.558\end{array}$ & $\begin{array}{l}85.635 \\
85.181 \\
85.200 \\
84.947\end{array}$ & $\begin{array}{l}11.721 \\
11.619 \\
11.610 \\
11.75 \mathrm{~J}\end{array}$ & $\begin{array}{l}1.390 \\
1.385 \\
1.383 \\
1.426\end{array}$ & $\begin{array}{l}.527 \\
.540 \\
.535 \\
.557\end{array}$ & $\begin{array}{l}.727 \\
.733 \\
.730 \\
.762\end{array}$ & $\begin{array}{l}42.973 \\
42.752 \\
42.742 \\
42.845\end{array}$ & $\begin{array}{r}.4591 \\
.4703 \\
.4703 \\
.4712\end{array}$ \\
\hline 22 & 1645 & 2 & .542 & 84.952 & 11.749 & 1.436 & .557 & .764 & 42.858 & .4712 \\
\hline $\begin{array}{l}23 \\
23 \\
24 \\
24 \\
25\end{array}$ & $\begin{array}{l}1708 \\
1724 \\
1043 \\
1059 \\
1136\end{array}$ & $\begin{array}{l}2 \\
2 \\
2 \\
2 \\
2\end{array}$ & $\begin{array}{l}.544 \\
.544 \\
.546 \\
.546 \\
.547\end{array}$ & $\begin{array}{l}35.162 \\
85.147 \\
85.231 \\
85.223 \\
85.289\end{array}$ & $\begin{array}{l}11.649 \\
11.660 \\
11.580 \\
11.590 \\
11.520\end{array}$ & $\begin{array}{l}1.380 \\
1.387 \\
1.384 \\
1.378 \\
1.381\end{array}$ & $\begin{array}{l}.531 \\
.535 \\
.535 \\
.532 \\
.537\end{array}$ & $\begin{array}{l}.734 \\
.728 \\
.724 \\
.730 \\
.726\end{array}$ & $\begin{array}{l}42.750 \\
42.756 \\
42.728 \\
42.73 i \\
42.712\end{array}$ & $\begin{array}{l}.4703 \\
.4704 \\
.4702 \\
.4702 \\
.4700\end{array}$ \\
\hline $\begin{array}{l}25 \\
25 \\
26 \\
26 \\
26\end{array}$ & $\begin{array}{l}1152 \\
1213 \\
1236 \\
1251 \\
1309\end{array}$ & $\begin{array}{r}2 \\
102 \\
2 \\
2 \\
2\end{array}$ & $\begin{array}{l}.548 \\
.026 \\
.548 \\
.548 \\
.546\end{array}$ & $\begin{array}{l}85.279 \\
85.877 \\
85.095 \\
85.045 \\
85.063\end{array}$ & $\begin{array}{l}11.538 \\
11.510 \\
11.639 \\
11.649 \\
11.639\end{array}$ & $\begin{array}{l}1.370 \\
1.346 \\
1.415 \\
1.442 \\
1.434\end{array}$ & $\begin{array}{l}.538 \\
.538 \\
.555 \\
.563 \\
.554\end{array}$ & $\begin{array}{l}.727 \\
.704 \\
.748 \\
.753 \\
.764\end{array}$ & $\begin{array}{l}42.712 \\
42.868 \\
42.798 \\
42.827 \\
42.822\end{array}$ & $\begin{array}{r}.4700 \\
.4683 \\
.4707 \\
.4710 \\
.4709\end{array}$ \\
\hline $\begin{array}{l}27 \\
27 \\
27 \\
28 \\
28\end{array}$ & $\begin{array}{l}1341 \\
1357 \\
1420 \\
1446 \\
1503\end{array}$ & $\begin{array}{r}2 \\
2 \\
100 \\
2 \\
2\end{array}$ & $\begin{array}{r}.548 \\
.547 \\
1.384 \\
.549 \\
.549\end{array}$ & $\begin{array}{l}85.225 \\
85.234 \\
85.887 \\
85.263 \\
85.269\end{array}$ & $\begin{array}{r}11.579 \\
11.579 \\
8.505 \\
11.569 \\
11.560\end{array}$ & $\begin{array}{l}1.380 \\
1.376 \\
2.989 \\
1.372 \\
1.377\end{array}$ & $\begin{array}{l}.538 \\
.537 \\
.523 \\
.527 \\
.532\end{array}$ & $\begin{array}{l}.730 \\
.727 \\
.712 \\
.720 \\
.713\end{array}$ & $\begin{array}{l}42.732 \\
42.727 \\
42.423 \\
42.706 \\
42.705\end{array}$ & $\begin{array}{r}.4702 \\
.4701 \\
.4717 \\
.4699 \\
.4698\end{array}$ \\
\hline $\begin{array}{l}29 \\
29 \\
29 \\
30 \\
30\end{array}$ & $\begin{array}{l}1542 \\
1557 \\
1525 \\
1000 \\
1026\end{array}$ & $\begin{array}{r}2 \\
2 \\
101 \\
3 \\
3\end{array}$ & $\begin{array}{r}.548 \\
.547 \\
0.000 \\
4.339 \\
4.339\end{array}$ & $\begin{array}{l}85.240 \\
85.265 \\
85.731 \\
81.962 \\
81.968\end{array}$ & $\begin{array}{l}11.580 \\
11.569 \\
11.660 \\
11.160 \\
11.140\end{array}$ & $\begin{array}{l}1.379 \\
1.369 \\
1.371 \\
1.324 \\
1.334\end{array}$ & $\begin{array}{l}.533 \\
.529 \\
.535 \\
.520 \\
.519\end{array}$ & $\begin{array}{l}.720 \\
.721 \\
.703 \\
.695 \\
.701\end{array}$ & $\begin{array}{l}42.719 \\
42.708 \\
42.932 \\
41.104 \\
41.107\end{array}$ & $\begin{array}{r}.4701 \\
.4700 \\
.4687 \\
.4789 \\
.4789\end{array}$ \\
\hline $\begin{array}{l}31 \\
31 \\
31 \\
32 \\
32\end{array}$ & $\begin{array}{l}1113 \\
1131 \\
1159 \\
1225 \\
1242\end{array}$ & $\begin{array}{r}3 \\
3 \\
101 \\
3 \\
3\end{array}$ & $\begin{array}{l}4.330 \\
4.335 \\
0.000 \\
4.333 \\
4.340\end{array}$ & $\begin{array}{l}81.891 \\
81.908 \\
85.615 \\
82.007 \\
81.993\end{array}$ & $\begin{array}{l}11.200 \\
11.180 \\
11.719 \\
11.130 \\
11.139\end{array}$ & $\begin{array}{l}1.353 \\
1.350 \\
1.396 \\
1.324 \\
1.324\end{array}$ & $\begin{array}{l}.523 \\
.525 \\
.546 \\
.513 \\
.515\end{array}$ & $\begin{array}{l}.703 \\
.702 \\
.724 \\
.694 \\
.690\end{array}$ & $\begin{array}{l}41.144 \\
41.135 \\
42.989 \\
41.090 \\
41.089\end{array}$ & $\begin{array}{r}.4792 \\
.4791 \\
.4693 \\
.4788 \\
.4788\end{array}$ \\
\hline
\end{tabular}


Table 7.4.1. Probe Test 2

RUN DATE TEMPERATURE PRESSURE LNG FLOW RATE SAMPLING DELTA P PROBE VAPORIZER NUMBER K MPA LPM RATE, SLPM KPA POWER,WATIS

\begin{tabular}{|c|c|c|c|c|c|c|c|c|}
\hline 33 & $1 / 03$ & 113.0 & .147 & 3.75 & 2.4 & 26. & $R$ & 16.2 \\
\hline 34 & $1 / 03$ & 113.0 & .148 & 3.71 & 2.4 & 25. & $\rho$ & 17.4 \\
\hline 35 & $1 / 03$ & 113.0 & .148 & 3.79 & 2.4 & 26. & $s$ & 18.9 \\
\hline 36 & $1 / 03$ & 113.0 & .148 & 3.79 & 2.4 & 25. & $R$ & 16.0 \\
\hline 37 & $1 / 03$ & 113.0 & .148 & 3.79 & 2.4 & 25. & $s$ & 16.0 \\
\hline 38 & $1 / 03$ & 113.0 & .148 & 3.79 & 2.4 & 25. & $\mathbf{P}$ & 16.0 \\
\hline 39 & $1 / 04$ & 113.0 & .142 & 3.82 & 7.1 & 25. & $s$ & 94.1 \\
\hline 40 & $1 / 04$ & $113 \cdot 0$ & .149 & 3.79 & 7.3 & 25. & $R$ & 78.3 \\
\hline 41 & $1 / 04$ & 113.0 & .147 & 3.79 & 2.4 & 25. & $P$ & 73.5 \\
\hline 42 & $1 / 04$ & 113.0 & .147 & 3.79 & $7 \cdot 2$ & 25. & $R$ & 77.4 \\
\hline 43 & $1 / 04$ & 113.0 & .147 & 3.75 & $7 \cdot 2$ & 25. & s & 77.9 \\
\hline 44 & $1 / 04$ & 113.0 & .147 & 3.75 & 7.2 & 25. & $\mathbf{P}$ & 77.9 \\
\hline 45 & $1 / 04$ & 113.0 & .150 & 3.75 & 2.4 & 25. & $P$ & 18.9 \\
\hline 46 & $1 / 04$ & 113.0 & .150 & 3.79 & 2.4 & 25. & $\mathrm{~s}$ & 36.5 \\
\hline 47 & $1 / 04$ & 113.0 & .149 & 3.75 & 2.4 & 25. & $R$ & 13.7 \\
\hline 48 & $1 / 04$ & 113.0 & .150 & 3.75 & 2.4 & 25. & $\mathrm{R}$ & 18.7 \\
\hline 49 & $1 / 05$ & 113.0 & .148 & 3.75 & 2.4 & 25. & $R$ & 19.1 \\
\hline 50 & $1 / 05$ & 113.0 & .148 & 3.79 & 2.4 & 25. & s & 19.4 \\
\hline 51 & $1 / 05$ & 113.0 & .149 & 3.75 & 2.4 & 25. & $\mathbf{P}$ & 19.4 \\
\hline 52 & $1 / 05$ & 113.0 & .149 & 3.82 & $7 \cdot 2$ & 25. & $s$ & 71.4 \\
\hline 53 & $1 / 05$ & 113.0 & .150 & 3.79 & 7.1 & 26. & $P$ & 66.0 \\
\hline 54 & $1 / 05$ & 113.0 & .150 & 3.79 & 7.0 & 25 . & $R$ & 74.8 \\
\hline 55 & $1 / 05$ & 113.0 & .152 & 3.79 & 5.8 & 26. & s & 58.5 \\
\hline 56 & $1 / 05$ & 113.0 & .150 & 3.79 & 5.5 & 26. & $P$ & 54.8 \\
\hline 57 & $1 / 05$ & 113.0 & .155 & 3.63 & 5.6 & 24. & $R$ & 52.2 \\
\hline
\end{tabular}


Table 7.4.1. Probe Test 2 (continued)

\begin{tabular}{|c|c|c|c|c|c|c|c|c|c|c|}
\hline $\begin{array}{c}\text { Run } \\
\text { Number }\end{array}$ & Time & $\operatorname{Mix}$ & $\mathrm{N}_{2}$ & $\mathrm{CH}_{4}$ & $\mathrm{C}_{2} \mathrm{H}_{6}$ & $\mathrm{C}_{3} \mathrm{H}_{8}$ & $i_{4} \mathrm{H}_{10}$ & $\mathrm{nC}_{4} \mathrm{H}_{10}$ & $\begin{array}{l}\text { Value } \\
\mathrm{MJ} / \mathrm{m}^{3}\end{array}$ & $\begin{array}{r}\text { Density } \\
\mathrm{gm} / \mathrm{cm}^{3}\end{array}$ \\
\hline 33 & 1323 & 4 & 1.340 & 83.913 & 11.970 & 1.450 & .569 & .757 & 42.632 & .474 \\
\hline 33 & 1340 & 4 & 1.341 & 83.927 & 11.960 & 1.450 & .566 & .756 & 42.625 & .474 \\
\hline 34 & 1426 & 4 & 1.342 & 83.907 & 11.970 & 1.445 & .570 & .766 & 42.637 & .474 \\
\hline 35 & 1448 & 4 & 1.339 & 83.960 & 11.950 & 1.419 & .570 & .762 & 42.614 & .473 \\
\hline 35 & 1505 & 4 & 1.338 & 83.985 & 11.939 & 1.429 & .552 & .757 & 42.598 & .473 \\
\hline 36 & 1548 & 4 & 1.341 & 83.885 & 11.959 & 1.458 & .577 & .780 & 42.659 & .47 \\
\hline 36 & 1603 & 4 & 1.335 & 83.919 & 11.940 & 1.449 & .581 & .776 & 42.651 & .47 \\
\hline 36 & 1620 & 101 & 0.003 & 85.713 & 11.674 & 1.379 & .534 & .700 & 42.937 & .46 \\
\hline 37 & 1639 & 4 & 1.338 & 83.777 & 12.040 & 1.480 & .581 & .785 & 42.703 & \\
\hline 37 & 1655 & 4 & 1.336 & 83.779 & 12.030 & 1.490 & .587 & .778 & 42.706 & .47 \\
\hline 38 & 1727 & 4 & 1.338 & 83.798 & 12.000 & 1.491 & .589 & .784 & 42.704 & .47 \\
\hline 38 & 826 & 4 & 1.336 & 83.753 & 12.020 & 1.493 & .589 & .809 & 42.733 & .47 \\
\hline 39 & 1006 & 4 & 1.341 & 83.946 & 11.979 & 1.425 & .555 & .754 & 42.606 & .47 \\
\hline 39 & 1022 & 4 & 1.340 & 83.946 & 11.979 & 1.426 & .555 & .754 & 42.607 & - \\
\hline 39 & 856 & 101 & 0.000 & 85.605 & 11.729 & 1.392 & .536 & .738 & 42.994 & .46 \\
\hline 40 & 1039 & 4 & 1.341 & 83.961 & 11.970 & 1.425 & .551 & .752 & 42.598 & .47 \\
\hline 40 & 1055 & 4 & 1.350 & 83.934 & 11.969 & 1.430 & .559 & .758 & 42.609 & .47 \\
\hline 40 & 1111 & 4 & 1.338 & 83.952 & 11.979 & 1.417 & .555 & .759 & 42.606 & .47 \\
\hline 41 & 1201 & 4 & 1.339 & 84.090 & 11.870 & 1.403 & .548 & .750 & 42.554 & .47 \\
\hline 41 & 1217 & 4 & 1.338 & 84.084 & 11.879 & 1.408 & .546 & .745 & 42.554 & .47 \\
\hline 42 & 1250 & 4 & 1.340 & 83.952 & 11.969 & 1.438 & .549 & .752 & 42.604 & .47 \\
\hline 43 & 1319 & 4 & 1.354 & 83.798 & 12.080 & 1.437 & .560 & .771 & 42.655 & .47 \\
\hline 43 & 1336 & 4 & 1.343 & 83.964 & 11.959 & 1.424 & .553 & .757 & 42.600 & .47 \\
\hline 44 & 1424 & 4 & 1.340 & 83.947 & 11.980 & 1.425 & .555 & .754 & 42.606 & .47 \\
\hline 44 & 1440 & 4 & 1.340 & 83.956 & 11.969 & 1.429 & .552 & .754 & 42.603 & .47 \\
\hline 45 & 1459 & 4 & 1.338 & 83.898 & 11.990 & 1.440 & .563 & .771 & 42.640 & .47 \\
\hline 45 & 1515 & 4 & 1.351 & 83.887 & 11.990 & 1.450 & .561 & .762 & 42.631 & .47 \\
\hline 46 & 1533 & 4 & 1.336 & 83.984 & 11.961 & 1.425 & .547 & .747 & 42.590 & .47 \\
\hline 46 & 1550 & 4 & 1.337 & 83.962 & 11.980 & 1.423 & .553 & .745 & 597 & 0.4 \\
\hline 47 & 1609 & 4 & 1.338 & 83.942 & 11.980 & 1.424 & .557 & .759 & 42.613 & .47 \\
\hline 47 & 1625 & 4 & 1.340 & 83.905 & 11.989 & 1.440 & .560 & .766 & 42.632 & .47 \\
\hline 48 & 1644 & 4 & 1.338 & 83.953 & 11.950 & 1.424 & .561 & .774 & 42.620 & .47 \\
\hline 48 & 1700 & 4 & 1.341 & 83.939 & 11.968 & 1.429 & .557 & .766 & 42.616 & .473 \\
\hline 48 & 1716 & 101 & 0.000 & 85.649 & 11.702 & 1.377 & .543 & .729 & 976 & .465 \\
\hline 49 & 911 & 4 & 1.340 & 83.965 & 11.961 & 1.423 & .563 & .748 & 42.601 & .47 \\
\hline 49 & 944 & 4 & 1.331 & 83.965 & 11.969 & 1.419 & .558 & .758 & 42.609 & .47 \\
\hline 50 & 1008 & 4 & 1.337 & 83.997 & 11.940 & 1.421 & .555 & .751 & 42.591 & .47 \\
\hline 50 & 1024 & 4 & 1.340 & 83.993 & 11.930 & 1.431 & .555 & .751 & 42.593 & .47 \\
\hline 51 & 1044 & 4 & 1.339 & 83.862 & 11.999 & 1.456 & .570 & .775 & 660 & .47 \\
\hline 51 & 1059 & 4 & 1.352 & 83.853 & 11.999 & 1.459 & .571 & .766 & 42.650 & .47 \\
\hline 51 & 1120 & 101 & 0.000 & 85.617 & 11.730 & 1.389 & .538 & .726 & 42.984 & .46 \\
\hline 52 & 1143 & 4 & 1.335 & 83.967 & 11.970 & 1.424 & .557 & .748 & 601 & .47 \\
\hline 52 & 1159 & 4 & 1.332 & 83.969 & 11.980 & 1.418 & .559 & .742 & 42.598 & .473 \\
\hline 53 & 1221 & 4 & 1.337 & 83.974 & 11.971 & 1.429 & .552 & .737 & 42.590 & .47 \\
\hline 53 & 1255 & 4 & 1.334 & 83.984 & 11.961 & 1.429 & .549 & .743 & 42.591 & .47 \\
\hline 54 & 1321 & 4 & 1.340 & 83.954 & 11.969 & 1.427 & .555 & .755 & 42.605 & .47 \\
\hline 54 & 1337 & 4 & 1.340 & 83.954 & 11.969 & 1.432 & .555 & .750 & 42.604 & .47 \\
\hline 54 & 1350 & 101 & 0.000 & 85.634 & 11.709 & 1.400 & .537 & .720 & 42.978 & .46 \\
\hline 55 & 1459 & 4 & 1.337 & 83.994 & 11.951 & 1.428 & .550 & .740 & 585 & .47 \\
\hline 55 & 1517 & 4 & 1.339 & 83.957 & 11.970 & 1.437 & .554 & .743 & 42.600 & .47 \\
\hline
\end{tabular}


Table 7.4.7. Probe Test 2 (continued)

\begin{tabular}{|c|c|c|c|c|c|c|c|c|c|c|}
\hline $\begin{array}{l}\text { Run } \\
\text { Number }\end{array}$ & Time & $\operatorname{Mix}$ & $\mathrm{N}_{2}$ & $\mathrm{CH}_{4}$ & $\mathrm{C}_{2} \mathrm{H}_{6}$ & $\mathrm{C}_{3} \mathrm{H}_{8}$ & $i_{4} \mathrm{H}_{30}$ & $\mathrm{nC}_{4} \mathrm{H}_{10}$ & $\begin{array}{l}\text { Value } \\
\mathrm{MJ} / \mathrm{m}^{3}\end{array}$ & $\begin{array}{l}\text { Density } \\
\mathrm{gmi} / \mathrm{cm}^{3}\end{array}$ \\
\hline 56 & 1538 & 4 & 1.341 & 83.969 & 11.970 & 1.420 & .552 & .748 & 42.593 & .4738 \\
\hline 56 & 1554 & 4 & 1.334 & 83.967 & 11.970 & 1.439 & .551 & .740 & 598 & .473 \\
\hline 57 & 1611 & 4 & 1.343 & 83.963 & 11.950 & 1.432 & .559 & .753 & 603 & .473 \\
\hline 57 & 1628 & 4 & 1.336 & 967 & 11.950 & 1.435 & .561 & .751 & 607 & .473 \\
\hline 57 & 1640 & 101 & 0.000 & 85.607 & 11.720 & 1.404 & .539 & .730 & 42.993 & 4692 \\
\hline
\end{tabular}


Table 7.4.1. Probe Test 3

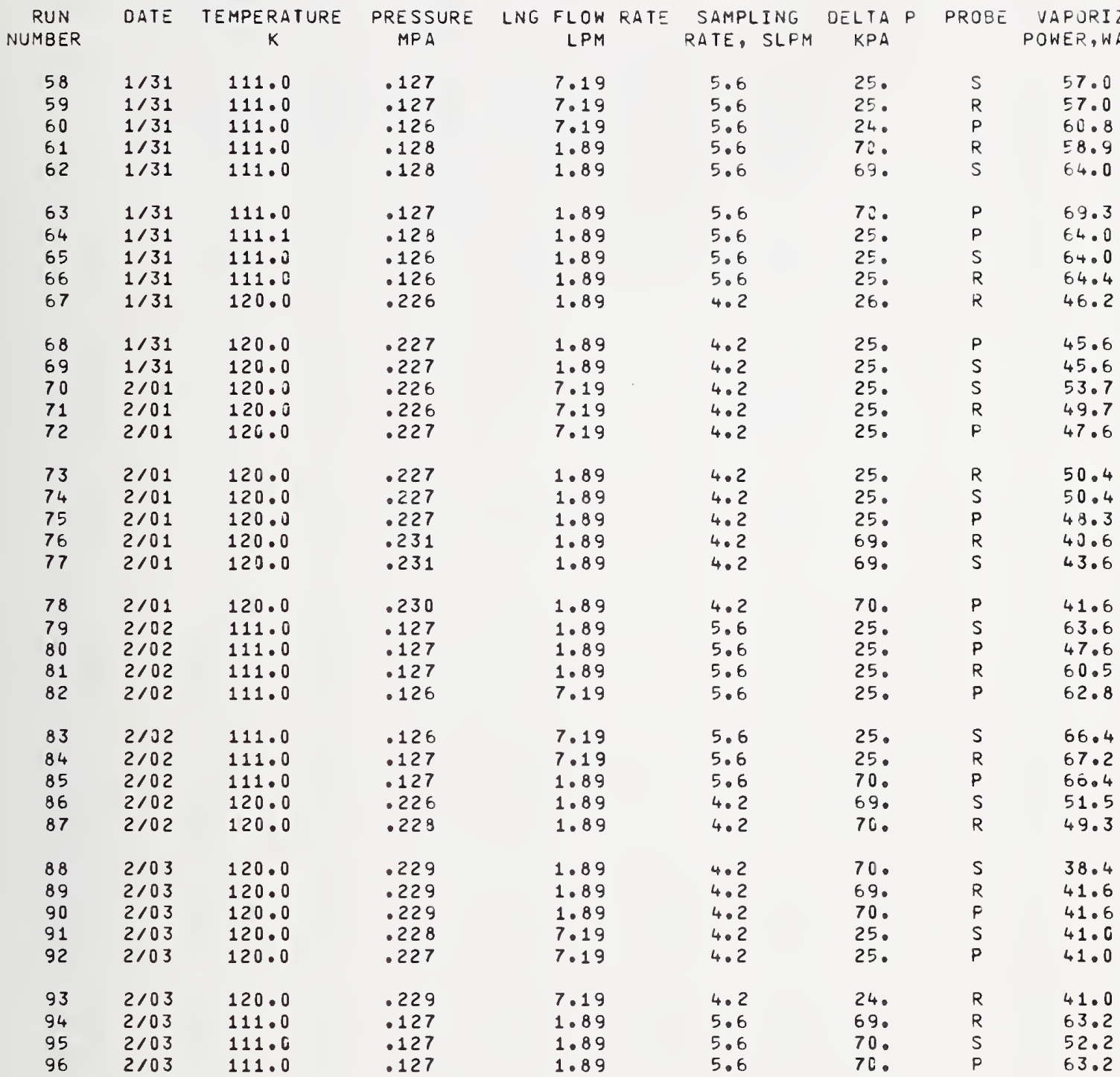


Table 7.4.1. Probe Test 3 (continued)

\begin{tabular}{|c|c|c|c|c|c|c|c|c|c|c|}
\hline $\begin{array}{c}\text { Run } \\
\text { Number }\end{array}$ & Time & $\operatorname{Mix}$ & $\mathrm{N}_{2}$ & $\mathrm{CH}_{4}$ & $\mathrm{C}_{2} \mathrm{H}_{6}$ & $\mathrm{C}_{3} \mathrm{H}_{8}$ & $i_{4} \mathrm{H}_{10}$ & $\mathrm{nC}_{4} \mathrm{H}_{10}$ & $\begin{array}{l}\text { Value } \\
\mathrm{MJ} / \mathrm{m}^{3}\end{array}$ & $\begin{array}{r}\text { Density } \\
\mathrm{gm} / \mathrm{cm}^{3}\end{array}$ \\
\hline $\begin{array}{l}58 \\
58 \\
59 \\
60 \\
60\end{array}$ & $\begin{array}{l}1058 \\
1035 \\
1124 \\
1148 \\
1205\end{array}$ & $\begin{array}{r}5 \\
105 \\
5 \\
5 \\
5\end{array}$ & $\begin{array}{l}1.219 \\
1.256 \\
1.220 \\
1.223 \\
1.222\end{array}$ & $\begin{array}{l}84.565 \\
84.606 \\
84.546 \\
84.430 \\
84.447\end{array}$ & $\begin{array}{l}9.510 \\
9.476 \\
9.535 \\
9.574 \\
9.552\end{array}$ & $\begin{array}{l}3.524 \\
3.493 \\
3.514 \\
3.554 \\
3.558\end{array}$ & $\begin{array}{l}.481 \\
.479 \\
.482 \\
.494 \\
.494\end{array}$ & $\begin{array}{l}.701 \\
.690 \\
.704 \\
.725 \\
.728\end{array}$ & $\begin{array}{l}43.028 \\
42.976 \\
43.032 \\
43.093 \\
43.091\end{array}$ & $\begin{array}{r}.4788 \\
.4786 \\
.4789 \\
.4794 \\
.4793\end{array}$ \\
\hline $\begin{array}{l}61 \\
62 \\
62 \\
62 \\
63\end{array}$ & $\begin{array}{l}1222 \\
1247 \\
1326 \\
1311 \\
1354\end{array}$ & $\begin{array}{r}5 \\
5 \\
105 \\
105 \\
5\end{array}$ & $\begin{array}{l}1.218 \\
1.219 \\
1.240 \\
1.237 \\
1.214\end{array}$ & $\begin{array}{l}84.609 \\
84.563 \\
84.578 \\
84.565 \\
84.515\end{array}$ & $\begin{array}{l}9.500 \\
9.527 \\
9.511 \\
9.526 \\
9.561\end{array}$ & $\begin{array}{l}3.495 \\
3.505 \\
3.503 \\
3.500 \\
3.521\end{array}$ & $\begin{array}{l}.481 \\
.481 \\
.479 \\
.480 \\
.484\end{array}$ & $\begin{array}{l}.697 \\
.705 \\
.689 \\
.692 \\
.705\end{array}$ & $\begin{array}{l}43.006 \\
43.026 \\
42.997 \\
43.004 \\
43.048\end{array}$ & $\begin{array}{r}.4786 \\
.4788 \\
.4787 \\
.4787 \\
.4790\end{array}$ \\
\hline $\begin{array}{l}64 \\
65 \\
66 \\
67 \\
68\end{array}$ & $\begin{array}{l}1419 \\
1441 \\
1504 \\
1533 \\
1557\end{array}$ & $\begin{array}{l}5 \\
5 \\
5 \\
5 \\
5\end{array}$ & $\begin{array}{l}1.218 \\
1.213 \\
1.215 \\
1.215 \\
1.221\end{array}$ & $\begin{array}{l}84.585 \\
84.588 \\
84.547 \\
84.551 \\
84.532\end{array}$ & $\begin{array}{l}9.519 \\
9.519 \\
9.525 \\
9.535 \\
9.546\end{array}$ & $\begin{array}{l}3.505 \\
3.505 \\
3.523 \\
3.514 \\
3.513\end{array}$ & $\begin{array}{l}.479 \\
.479 \\
.483 \\
.483 \\
.483\end{array}$ & $\begin{array}{l}.694 \\
.696 \\
.707 \\
.702 \\
.705\end{array}$ & $\begin{array}{l}43.013 \\
43.016 \\
43.040 \\
43.034 \\
43.036\end{array}$ & $\begin{array}{r}.4785 \\
.4787 \\
.4789 \\
.4662 \\
.4663\end{array}$ \\
\hline $\begin{array}{l}69 \\
69 \\
70 \\
70 \\
71\end{array}$ & $\begin{array}{l}1622 \\
1641 \\
1019 \\
1037 \\
1118\end{array}$ & $\begin{array}{r}5 \\
105 \\
5 \\
105 \\
5\end{array}$ & $\begin{array}{l}1 \cdot 217 \\
1 \cdot 242 \\
1 \cdot 223 \\
1 \cdot 241 \\
1 \cdot 223\end{array}$ & $\begin{array}{l}84.560 \\
84.547 \\
84.577 \\
84.587 \\
84.528\end{array}$ & $\begin{array}{l}9.529 \\
9.524 \\
9.504 \\
9.499 \\
9.518\end{array}$ & $\begin{array}{l}3.506 \\
3.507 \\
3.501 \\
3.486 \\
3.523\end{array}$ & $\begin{array}{l}.479 \\
.482 \\
.488 \\
.482 \\
.492\end{array}$ & $\begin{array}{l}.709 \\
.698 \\
.708 \\
.705 \\
.716\end{array}$ & $\begin{array}{l}43.029 \\
43.012 \\
43.023 \\
42.999 \\
43.050\end{array}$ & $\begin{array}{r}.4662 \\
.4662 \\
.4662 \\
.4661 \\
.4664\end{array}$ \\
\hline $\begin{array}{l}72 \\
73 \\
74 \\
74 \\
75\end{array}$ & $\begin{array}{l}1144 \\
1214 \\
1238 \\
1255 \\
1314\end{array}$ & $\begin{array}{l}5 \\
5 \\
5 \\
5 \\
5\end{array}$ & $\begin{array}{l}1.223 \\
1.218 \\
1.270 \\
1.219 \\
1.217\end{array}$ & $\begin{array}{l}84.612 \\
84.585 \\
84.527 \\
84.574 \\
84.588\end{array}$ & $\begin{array}{l}9.509 \\
9.512 \\
9.509 \\
9.517 \\
9.526\end{array}$ & $\begin{array}{l}3.476 \\
3.506 \\
3.505 \\
3.501 \\
3.491\end{array}$ & $\begin{array}{l}.482 \\
.481 \\
.483 \\
.486 \\
.483\end{array}$ & $\begin{array}{l}.698 \\
.698 \\
.706 \\
.703 \\
.695\end{array}$ & $\begin{array}{l}42.997 \\
43.016 \\
43.003 \\
43.023 \\
43.011\end{array}$ & $\begin{array}{r}.4660 \\
.4661 \\
.4663 \\
.4662 \\
.4661\end{array}$ \\
\hline $\begin{array}{l}76 \\
77 \\
78 \\
78 \\
79\end{array}$ & $\begin{array}{l}1512 \\
1534 \\
1602 \\
1621 \\
1038\end{array}$ & $\begin{array}{r}5 \\
5 \\
5 \\
105 \\
5\end{array}$ & $\begin{array}{l}1.219 \\
1.216 \\
1.221 \\
1.252 \\
1.218\end{array}$ & $\begin{array}{l}84.582 \\
84.522 \\
84.538 \\
84.500 \\
84.455\end{array}$ & $\begin{array}{l}9.515 \\
9.550 \\
9.572 \\
9.568 \\
9.615\end{array}$ & $\begin{array}{l}3.492 \\
3.528 \\
3.485 \\
3.498 \\
3.518\end{array}$ & $\begin{array}{l}.484 \\
.482 \\
.486 \\
.485 \\
.483\end{array}$ & $\begin{array}{l}.708 \\
.703 \\
.699 \\
.697 \\
.711\end{array}$ & $\begin{array}{l}43.020 \\
43.045 \\
43.025 \\
43.017 \\
43.065\end{array}$ & $\begin{array}{r}.4661 \\
.4663 \\
.4662 \\
.4663 \\
.4791\end{array}$ \\
\hline $\begin{array}{l}79 \\
79 \\
79 \\
80 \\
80\end{array}$ & $\begin{array}{l}1058 \\
1137 \\
1155 \\
1217 \\
1238\end{array}$ & $\begin{array}{r}5 \\
5 \\
105 \\
5 \\
105\end{array}$ & $\begin{array}{l}1.204 \\
1.219 \\
1.237 \\
1.214 \\
1.235\end{array}$ & $\begin{array}{l}84.561 \\
84.520 \\
84.485 \\
84.506 \\
84.523\end{array}$ & $\begin{array}{l}9.529 \\
9.551 \\
9.595 \\
9.540 \\
9.557\end{array}$ & $\begin{array}{l}3.520 \\
3.525 \\
3.501 \\
3.526 \\
3.502\end{array}$ & $\begin{array}{l}.488 \\
.484 \\
.480 \\
.491 \\
.479\end{array}$ & $\begin{array}{l}.698 \\
.701 \\
.702 \\
.723 \\
.704\end{array}$ & $\begin{array}{l}43.040 \\
43.043 \\
43.032 \\
43.066 \\
43.024\end{array}$ & $\begin{array}{r}.4788 \\
.4789 \\
.4790 \\
.4791 \\
.4789\end{array}$ \\
\hline $\begin{array}{l}81 \\
82 \\
83 \\
84 \\
84\end{array}$ & $\begin{array}{l}1301 \\
1325 \\
1351 \\
1413 \\
1459\end{array}$ & $\begin{array}{l}5 \\
5 \\
5 \\
5 \\
5\end{array}$ & $\begin{array}{l}1.216 \\
1.219 \\
1.219 \\
1.225 \\
1.214\end{array}$ & $\begin{array}{l}84.535 \\
84.588 \\
84.540 \\
84.355 \\
84.512\end{array}$ & $\begin{array}{l}9.556 \\
9.535 \\
9.527 \\
9.636 \\
9.537\end{array}$ & $\begin{array}{l}3.507 \\
3.488 \\
3.520 \\
3.576 \\
3.539\end{array}$ & $\begin{array}{l}.482 \\
.477 \\
.484 \\
.489 \\
.484\end{array}$ & $\begin{array}{l}.704 \\
.693 \\
.710 \\
.719 \\
.714\end{array}$ & $\begin{array}{l}43.036 \\
43.005 \\
43.041 \\
43.113 \\
43.059\end{array}$ & $\begin{array}{r}.4789 \\
.4786 \\
.4789 \\
.4795 \\
.4790\end{array}$ \\
\hline $\begin{array}{l}85 \\
86 \\
87 \\
88 \\
38\end{array}$ & $\begin{array}{r}1516 \\
1539 \\
1626 \\
959 \\
941\end{array}$ & $\begin{array}{r}5 \\
5 \\
5 \\
5 \\
105\end{array}$ & $\begin{array}{l}1.217 \\
1.213 \\
1.215 \\
1.216 \\
1.238\end{array}$ & $\begin{array}{l}84.507 \\
84.530 \\
84.509 \\
84.549 \\
84.543\end{array}$ & $\begin{array}{l}9.572 \\
9.564 \\
9.559 \\
9.548 \\
9.537\end{array}$ & $\begin{array}{l}3.515 \\
3.511 \\
3.532 \\
3.510 \\
3.499\end{array}$ & $\begin{array}{l}.485 \\
.480 \\
.483 \\
.478 \\
.484\end{array}$ & $\begin{array}{l}.704 \\
.702 \\
.702 \\
.699 \\
.699\end{array}$ & $\begin{array}{l}43.047 \\
43.038 \\
43.050 \\
43.028 \\
43.015\end{array}$ & $\begin{array}{r}.4790 \\
.4663 \\
.4664 \\
.4662 \\
.4662\end{array}$ \\
\hline
\end{tabular}


Table 7.4.1. Probe Test 3 (continued)

\begin{tabular}{|c|c|c|c|c|c|c|c|c|c|c|}
\hline $\begin{array}{c}\text { Run } \\
\text { Number }\end{array}$ & Time & $\operatorname{Mix}$ & $\mathrm{N}_{2}$ & $\mathrm{CH}_{4}$ & $\mathrm{C}_{2} \mathrm{H}_{6}$ & $\mathrm{C}_{3} \mathrm{H}_{8}$ & ${ }^{i C_{4}} \mathrm{H}_{10}$ & $\mathrm{nC}_{4} \mathrm{H}_{10}$ & Value & $\begin{array}{r}\text { Density } \\
\mathrm{gm} / \mathrm{cm}^{3}\end{array}$ \\
\hline $\begin{array}{l}93 \\
93 \\
94 \\
94 \\
95\end{array}$ & $\begin{array}{l}1257 \\
1315 \\
1333 \\
1350 \\
1423\end{array}$ & $\begin{array}{r}5 \\
105 \\
5 \\
5 \\
5\end{array}$ & $\begin{array}{l}1.223 \\
1.239 \\
1.212 \\
1.216 \\
1.217\end{array}$ & $\begin{array}{l}84.527 \\
84.547 \\
84.527 \\
84.522 \\
84.509\end{array}$ & $\begin{array}{l}9.552 \\
9.534 \\
9.564 \\
9.559 \\
9.546\end{array}$ & $\begin{array}{l}3.519 \\
3.499 \\
3.499 \\
3.508 \\
3.511\end{array}$ & $\begin{array}{l}.479 \\
.482 \\
.489 \\
.487 \\
.493\end{array}$ & $\begin{array}{l}.700 \\
.700 \\
.709 \\
.708 \\
.724\end{array}$ & $\begin{array}{l}43.033 \\
43.013 \\
43.045 \\
43.045 \\
43.061\end{array}$ & $\begin{array}{l}.4663 \\
.4662 \\
.4789 \\
.4789 \\
.4791\end{array}$ \\
\hline $\begin{array}{l}96 \\
96\end{array}$ & $\begin{array}{l}1451 \\
1511\end{array}$ & $\begin{array}{l}5 \\
5\end{array}$ & $\begin{array}{l}1.224 \\
1.217\end{array}$ & $\begin{array}{l}85.100 \\
84.539\end{array}$ & $\begin{array}{l}8.931 \\
9.554\end{array}$ & $\begin{array}{l}3.548 \\
3.500\end{array}$ & $\begin{array}{l}.48 E \\
.482\end{array}$ & $\begin{array}{l}.711 \\
.708\end{array}$ & $\begin{array}{l}42.888 \\
43.034\end{array}$ & $\begin{array}{r}.4776 \\
.4789\end{array}$ \\
\hline
\end{tabular}


Table 7.4.1. Probe Test 4

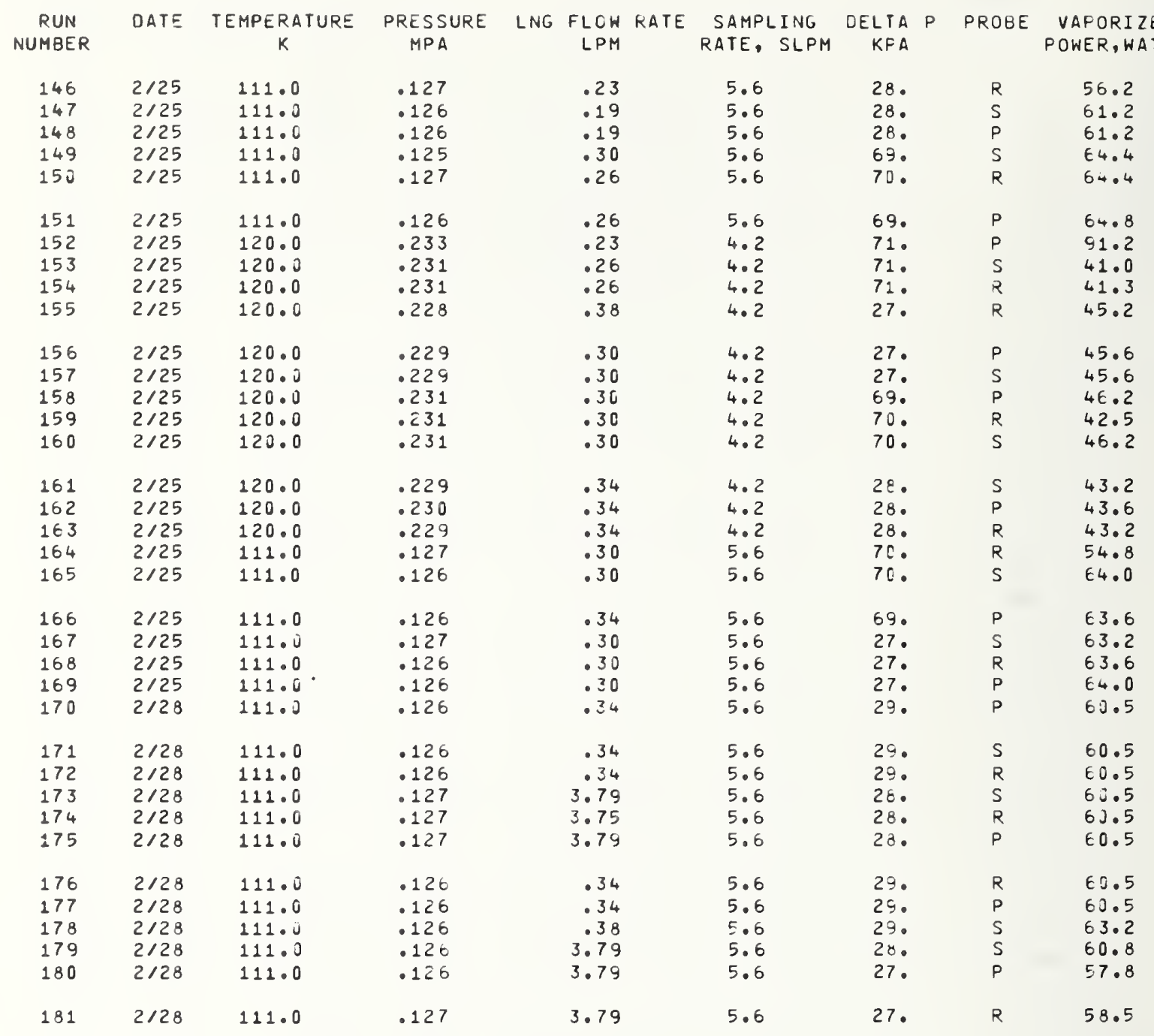


Table 7.4.1. Probe Test 4 (continued)

\begin{tabular}{|c|c|c|c|c|c|c|c|c|c|c|}
\hline Number & Time & Mix & $\mathrm{N}_{2}$ & $\mathrm{CH}_{4}$ & $\mathrm{C}_{2} \mathrm{H}_{6}$ & $\mathrm{C}_{3} \mathrm{H}_{8}$ & $\mathrm{iC}_{4} \mathrm{H}_{10}$ & $\mathrm{nC}_{4} \mathrm{H}_{10}$ & $\begin{array}{l}\text { Value } \\
\mathrm{MJ} / \mathrm{m}^{3}\end{array}$ & $\begin{array}{l}\text { Density } \\
\mathrm{gm} / \mathrm{cm}^{3}\end{array}$ \\
\hline 146 & $\begin{array}{r}945 \\
1009\end{array}$ & $\begin{array}{l}5 \\
5\end{array}$ & 1.214 & 84.616 & 9.508 & 3.486 & .486 & .697 & 43.003 & $\begin{array}{r}.4786 \\
4786\end{array}$ \\
\hline 147 & 1000 & 5 & 1.214 & 84.606 & 9.507 & 3.503 & .479 & .692 & 43.508 & .4786 \\
\hline 148 & 1018 & 5 & 1.214 & 84.586 & 9.541 & 3.480 & .480 & .700 & +3.012 & .4787 \\
\hline $1+9$ & 1033 & 5 & 1.212 & 84.570 & 9.530 & 3.501 & .484 & .703 & 43.328 & .4788 \\
\hline 150 & 1043 & 5 & 1.213 & 34.637 & 9.492 & 3.479 & .478 & .701 & 42.997 & .4785 \\
\hline 151 & 1133 & 5 & 1.213 & 84.618 & 9.513 & 3.478 & .478 & .700 & 43.002 & .4786 \\
\hline 152 & 1134 & 5 & 1.208 & 84.593 & 9.519 & 3.493 & .481 & .706 & 43.021 & .4661 \\
\hline 153 & 1149 & 5 & 1.211 & 84.602 & 9.514 & 3.489 & .482 & .702 & 43.014 & .4660 \\
\hline 154 & 1209 & 5 & 1.236 & 84.559 & 9.543 & 3.500 & .483 & .704 & 43.034 & .4662 \\
\hline 154 & 1230 & $1 \cup 5$ & 1.252 & 84.539 & 9.538 & 3.495 & .430 & .701 & 43.0003 & .4662 \\
\hline 155 & 1250 & 5 & 1.20 .8 & 84.538 & 9.527 & 3.490 & .482 & .7 ن 5 & 43.022 & .4661 \\
\hline 156 & 1307 & 5 & 1.204 & 84.597 & 9.521 & 3.493 & .481 & .704 & 43.022 & .4661 \\
\hline 157 & 1323 & 5 & 1.209 & 34.572 & 9.531 & 3.500 & .483 & .705 & 43.029 & .4662 \\
\hline 158 & 1341 & 5 & 1.213 & 84.607 & 9.500 & 3.502 & .479 & .700 & 43.012 & .4660 \\
\hline 159 & 1356 & 5 & 1.205 & 84.581 & 9.541 & 3.490 & .479 & .704 & 43.024 & .4661 \\
\hline 160 & 1412 & 5 & 1.208 & 84.610 & 9.517 & 3.485 & .480 & .700 & 43.010 & .4660 \\
\hline 161 & 1428 & 5 & 1.206 & 84.624 & 9.509 & 3.482 & .481 & .698 & 43.006 & .4659 \\
\hline 162 & 1443 & 5 & 1.211 & 84.614 & 9.498 & 3.490 & .482 & .705 & 43.013 & .4660 \\
\hline 163 & 1518 & 5 & 1.209 & 84.615 & 9.508 & 3.481 & .479 & .708 & 43.011 & .4660 \\
\hline 164 & 1536 & 5 & 1.213 & 84.637 & 9.504 & 3.470 & .480 & .697 & 42.994 & .4735 \\
\hline 164 & 1551 & 105 & 1.236 & 84.536 & 9.533 & 3.518 & .479 & .699 & 43.021 & .4789 \\
\hline 165 & 1611 & 5 & 1.208 & 84.612 & 9.509 & 3.491 & .486 & .700 & $43 \cdot 012$ & .4786 \\
\hline 166 & 1632 & 5 & 1.212 & 84.570 & 9.535 & 3.492 & .484 & .702 & 43.023 & .4787 \\
\hline 167 & 1650 & 5 & 1.211 & 84.586 & 9.522 & 3.500 & .482 & .700 & 43.020 & .4787 \\
\hline 168 & 1707 & 5 & 1.210 & 84.604 & 9.525 & 3.481 & .477 & .703 & 43.010 & .4786 \\
\hline 169 & 1725 & 5 & 1.209 & 84.477 & 9.525 & 3.550 & .499 & .740 & 43.099 & .4793 \\
\hline 169 & 2740 & 105 & $1.2+1$ & 84.565 & 9.513 & 3.504 & .481 & .696 & 43.005 & .4788 \\
\hline 169 & 1756 & 100 & 1.381 & 85.917 & 8.497 & 2.971 & .521 & .713 & 42.410 & .4745 \\
\hline 170 & 916 & 5 & 1.214 & 84.631 & 9.487 & 3.488 & .477 & .703 & 43.301 & .4786 \\
\hline 170 & 855 & 105 & 1.239 & 84.578 & 9.515 & 3.494 & .479 & .695 & 42.998 & .4787 \\
\hline 171 & 931 & 5 & 1.212 & 34.530 & 9.540 & 3.528 & .483 & .707 & 43.048 & .4789 \\
\hline 172 & 952 & 5 & 1.212 & 84.659 & 9.476 & 3.481 & .480 & .692 & 42.938 & .4784 \\
\hline 172 & 1003 & 5 & 1.210 & 84.658 & 9.480 & 3.485 & .476 & .691 & 42.988 & .4784 \\
\hline 173 & 1025 & 5 & 1.212 & 84.532 & 9.556 & 3.510 & .485 & .705 & 043 & .4789 \\
\hline 174 & 1044 & 5 & 1.215 & 84.539 & 9.529 & 3.521 & .487 & .709 & 43.045 & .4789 \\
\hline 175 & 1102 & 5 & 1.214 & 84.685 & 9.458 & 3.472 & .475 & .696 & 42.976 & .4784 \\
\hline 175 & 1118 & 5 & 1.212 & 34.664 & 9.434 & 3.494 & .477 & .699 & 42.987 & .4784 \\
\hline 176 & 1134 & 5 & 1.210 & 84.547 & 9.551 & 3.523 & .479 & .690 & 43.031 & .4788 \\
\hline 177 & 1154 & $\Xi$ & 1.211 & 84.540 & 9.531 & 3.535 & .483 & .700 & 044 & .4789 \\
\hline 177 & 1225 & 105 & 1.241 & 84.571 & 9.526 & 3.492 & .481 & .689 & 42.996 & .4787 \\
\hline 178 & 1243 & 5 & 1.213 & 84.596 & 9.538 & 3.479 & .477 & .698 & 43.007 & .4786 \\
\hline 179 & 1300 & 5 & 1.215 & 84.631 & 9.490 & 3.487 & .479 & .698 & 42.999 & .4785 \\
\hline 179 & 1316 & 5 & 1.213 & 84.628 & 9.481 & 3.506 & .479 & .693 & 43.003 & .4786 \\
\hline 180 & 1331 & 5 & 1.207 & 84.606 & 9.505 & 3.496 & .482 & .705 & 43.019 & .4787 \\
\hline 181 & 1350 & 5 & 1.211 & 84.635 & 9.502 & 3.483 & .476 & .693 & 42.995 & .4785 \\
\hline 181 & 1407 & 105 & 1.243 & 84.587 & 9.505 & 3.494 & .481 & .694 & 42.995 & .4787 \\
\hline
\end{tabular}


Table 7.4.1. Vaporizer Test 1

\begin{tabular}{|c|c|c|c|c|c|c|c|c|c|c|}
\hline $\begin{array}{c}\text { RUN } \\
\text { NUMBER }\end{array}$ & DATE & $\begin{array}{c}\text { TEMPERATURE } \\
K\end{array}$ & $\begin{array}{l}\text { FRESSURE } \\
\text { MPA }\end{array}$ & LNG & $\begin{array}{l}\text { FLOW } \\
\text { LPM }\end{array}$ & RATE & $\begin{array}{l}\text { SAMPLING } \\
\text { RATE, SLPM }\end{array}$ & $\underset{\text { KPA }}{\text { DELTA }}$ & VAPORIZER & $\begin{array}{r}\text { VAPORIZ } \\
\text { POWER, WA }\end{array}$ \\
\hline 100 & $2 / 22$ & 111.0 & .126 & & 7.53 & & 5.6 & 25 . & $R$ & 64.8 \\
\hline 101 & $2 / 22$ & 111.0 & .126 & & 7.57 & & 5.6 & 25. & $A$ & \\
\hline 102 & $2 / 22$ & 111.0 & .128 & & 1.93 & & 5.6 & 69. & $A$ & \\
\hline 103 & $2 / 22$ & 111.0 & .128 & & 3.90 & & 2.0 & 25 & $\Delta$ & \\
\hline 104 & $2 / 22$ & 111.0 & .128 & & 3.86 & & 5.6 & 25. & R & 64.4 \\
\hline 105 & $2 / 22$ & 111.0 & .128 & & 3.86 & & 5.6 & 25. & A & \\
\hline 106 & $2 / 22$ & 111.0 & .128 & & 7.57 & & 2.0 & 25. & A & \\
\hline 107 & $2 / 22$ & 111.0 & .128 & & 3.79 & & 2.0 & 70. & $R$ & 14.3 \\
\hline 108 & $2 / 22$ & 111.0 & .128 & & 3.71 & & 2.0 & 76. & $\mathrm{~F}$ & 15.6 \\
\hline 109 & $2 / 23$ & 120.0 & .231 & & 3.90 & & 4.2 & 25. & A & \\
\hline 110 & $2 / 23$ & 120.0 & .229 & & 3.82 & & 4.2 & 25 & R & 43.9 \\
\hline 111 & $2 / 23$ & 120.0 & $.23 u$ & & 7.80 & & 1.5 & 25. & A & \\
\hline 112 & $2 / 23$ & 120.0 & .229 & & 3.94 & & 1.5 & 69 . & R & 22.0 \\
\hline 113 & $2 / 23$ & 120.0 & .236 & & 3.86 & & 1.5 & 70 & A & \\
\hline 114 & $2 / 23$ & 120.0 & .230 & & 3.82 & & 4.2 & $7 i$ & A & \\
\hline 115 & $2 / 23$ & 120.0 & .229 & & 7.80 & & 4.2 & 25. & A & \\
\hline 116 & $2 / 23$ & 120.0 & .228 & & 7.83 & & 4.2 & 25. & $R$ & 59.8 \\
\hline 117 & $2 / 23$ & 120.0 & .228 & & 3.86 & & 1.5 & 25. & A & \\
\hline 118 & $2 / 23$ & 111.0 & .130 & & 4.05 & & $2 \cdot 5$ & $7 C$. & A & \\
\hline 119 & $2 / 23$ & 111.0 & .130 & & 4.01 & & 2.0 & 70. & $R$ & 15.6 \\
\hline 120 & $2 / 23$ & 111.0 & .129 & & 7.80 & & 2.0 & 25. & A & \\
\hline 121 & $2 / 23$ & 111.0 & .127 & & 4.09 & & 5.6 & 45. & A & \\
\hline 122 & $2 / 23$ & 111.0 & .128 & & 3.97 & & 5.6 & 25. & $R$ & 64.0 \\
\hline 123 & $2 / 23$ & 111.0 & .126 & & 3.94 & & 5.6 & 25. & A & \\
\hline 124 & $2 / 23$ & 111.0 & .127 & & 3.97 & & 2.0 & 24. & A & \\
\hline 125 & $2 / 23$ & 111.0 & .126 & & 7.65 & & 5.6 & $2 \varepsilon$. & $R$ & 63.6 \\
\hline 126 & $2 / 23$ & 111.0 & .126 & & 7.61 & & 5.6 & 25. & A & \\
\hline 127 & $2 / 24$ & 120.0 & .230 & & 8.02 & & 1.5 & 25. & A & \\
\hline 128 & $2 / 24$ & 120.0 & $.23 \mathrm{~J}$ & & 3.82 & & 4.2 & 70. & A & \\
\hline 129 & $2 / 24$ & 120.0 & .228 & & 3.82 & & 1.5 & 70. & $R$ & 10.2 \\
\hline 130 & $2 / 24$ & 120.0 & .228 & & 3.82 & & 1.5 & $7 L$. & A & \\
\hline 131 & $2 / 24$ & 120.0 & .229 & & 3.90 & & 1.5 & 69. & $R$ & 9.9 \\
\hline 132 & $2 / 24$ & 120.0 & .229 & & 7.83 & & 4.2 & 25. & A & \\
\hline 133 & $2 / 24$ & 120.0 & .228 & & 3.82 & & 4.2 & 25. & A & \\
\hline 134 & $2 / 24$ & 120.0 & .227 & & 3.86 & & 1.5 & 24. & A & \\
\hline 135 & $2 / 24$ & 120.0 & .228 & & 3.86 & & 4.2 & 25. & R & 45.2 \\
\hline 136 & $2 / 24$ & 120.0 & .228 & & 7.87 & & 4.2 & 25. & $R$ & 46.9 \\
\hline 137 & $2 / 24$ & 120.0 & .233 & & 3.90 & & 10.6 & 70. & A & \\
\hline 138 & $2 / 24$ & 120.0 & .228 & & 3.97 & & 4.2 & 70 & A & \\
\hline 139 & $2 / 24$ & 120.0 & .229 & & 3.97 & & 1.8 & 69. & A & \\
\hline 140 & $2 / 24$ & 120.0 & .228 & & 7.83 & & 10.8 & 25. & A & \\
\hline 141 & $2 / 24$ & 120.0 & .234 & & 3.82 & & 10.6 & 25. & A & \\
\hline 142 & $2 / 24$ & 111.0 & .129 & & 3.82 & & 10.1 & 25. & A & \\
\hline 143 & $2 / 24$ & 111.0 & .125 & & 7.72 & & 10.0 & 24. & A & \\
\hline 144 & $2 / 24$ & 111.0 & .130 & & 3.86 & & $10 \cdot 2$ & 75. & $A$ & \\
\hline 145 & $2 / 24$ & 111.0 & .127 & & 3.86 & & 10.1 & 25. & A & \\
\hline
\end{tabular}


Table 7.4.1. Vaporizer Test 1 (continued)

\begin{tabular}{|c|c|c|c|c|c|c|c|c|c|c|}
\hline $\begin{array}{l}\text { Run } \\
\text { Number }\end{array}$ & Time & $\operatorname{Mix}$ & $\mathrm{N}_{2}$ & $\mathrm{CH}_{4}$ & $\mathrm{C}_{2} \mathrm{H}_{6}$ & $\mathrm{C}_{3} \mathrm{H}_{8}$ & $\mathrm{iC}_{4} \mathrm{H}_{10}$ & $\mathrm{nC}_{4} \mathrm{H}_{10}$ & $\begin{array}{l}\text { Value } \\
\mathrm{MJ} / \mathrm{m}^{3}\end{array}$ & $\begin{array}{r}\text { Density } \\
\mathrm{gm} / \mathrm{cm}^{3}\end{array}$ \\
\hline 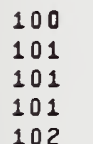 & $\begin{array}{l}1118 \\
1147 \\
1203 \\
1219 \\
1239\end{array}$ & $\begin{array}{l}5 \\
5 \\
5 \\
5 \\
5\end{array}$ & $\begin{array}{l}1.225 \\
1.242 \\
1.240 \\
1.239 \\
1.227\end{array}$ & $\begin{array}{l}84.536 \\
84.653 \\
84.631 \\
84.657 \\
84.704\end{array}$ & $\begin{array}{l}9.545 \\
9.391 \\
9.408 \\
9.412 \\
9.469\end{array}$ & $\begin{array}{l}3.504 \\
3.530 \\
3.537 \\
3.501 \\
3.461\end{array}$ & $\begin{array}{l}.486 \\
.483 \\
.483 \\
.482 \\
.463\end{array}$ & $\begin{array}{l}.705 \\
.700 \\
.701 \\
.709 \\
.676\end{array}$ & $\begin{array}{l}43.032 \\
42.990 \\
43.000 \\
42.987 \\
42.941\end{array}$ & $\begin{array}{l}.4789 \\
.4786 \\
.4787 \\
.4786 \\
4787\end{array}$ \\
\hline $\begin{array}{l}102 \\
103 \\
103 \\
104 \\
104\end{array}$ & $\begin{array}{l}1305 \\
1323 \\
1338 \\
1359 \\
1415\end{array}$ & $\begin{array}{l}5 \\
5 \\
5 \\
5 \\
5\end{array}$ & $\begin{array}{l}1.224 \\
1.209 \\
1.213 \\
1.219 \\
1.217\end{array}$ & $\begin{array}{l}84.704 \\
84.713 \\
84.216 \\
84.209 \\
84.447 \\
84.502\end{array}$ & $\begin{array}{l}9.469 \\
9.441 \\
9.661 \\
9.656 \\
9.571 \\
9.522\end{array}$ & $\begin{array}{l}3.461 \\
3.477 \\
3.714 \\
3.717 \\
3.534 \\
3.532\end{array}$ & $\begin{array}{l}.463 \\
.468 \\
.496 \\
.500 \\
.500 \\
.499\end{array}$ & $\begin{array}{l}.676 \\
.677 \\
.705 \\
.705 \\
.729 \\
.728\end{array}$ & $\begin{array}{l}42.941 \\
42.949 \\
43.198 \\
43.200 \\
43.090 \\
43.075\end{array}$ & $\begin{array}{l}.4782 \\
.4782 \\
.4801 \\
.4802 \\
.4793 \\
.4792\end{array}$ \\
\hline $\begin{array}{l}105 \\
105 \\
106 \\
106 \\
106\end{array}$ & $\begin{array}{l}1434 \\
1451 \\
1510 \\
1526 \\
1552\end{array}$ & $\begin{array}{r}5 \\
5 \\
5 \\
5 \\
105\end{array}$ & $\begin{array}{l}1.275 \\
1.279 \\
1.190 \\
1.189 \\
1.247\end{array}$ & $\begin{array}{l}85.237 \\
85.221 \\
83.681 \\
83.687 \\
84.507\end{array}$ & $\begin{array}{r}9.144 \\
9.151 \\
10.490 \\
10.490 \\
9.530\end{array}$ & $\begin{array}{l}3.262 \\
3.273 \\
3.474 \\
3.477 \\
3.534\end{array}$ & $\begin{array}{l}.441 \\
.441 \\
.472 \\
.473 \\
.482\end{array}$ & $\begin{array}{l}.642 \\
.635 \\
.693 \\
.684 \\
.700\end{array}$ & $\begin{array}{l}42.671 \\
42.672 \\
43.275 \\
43.270 \\
43.029\end{array}$ & $\begin{array}{r}.4762 \\
.4762 \\
.4809 \\
.4808 \\
.4790\end{array}$ \\
\hline $\begin{array}{l}107 \\
107 \\
108 \\
109 \\
110\end{array}$ & $\begin{array}{r}1617 \\
1634 \\
1652 \\
854 \\
919\end{array}$ & $\begin{array}{l}5 \\
5 \\
5 \\
5 \\
5\end{array}$ & $\begin{array}{l}1.220 \\
1.217 \\
1.214 \\
1.206 \\
1.218\end{array}$ & $\begin{array}{l}84.503 \\
84.505 \\
84.520 \\
84.098 \\
84.766\end{array}$ & $\begin{array}{l}9.548 \\
9.548 \\
9.533 \\
9.768 \\
9.380\end{array}$ & $\begin{array}{l}3.532 \\
3.526 \\
3.533 \\
3.688 \\
3.462\end{array}$ & $\begin{array}{l}.488 \\
.489 \\
.491 \\
.509 \\
.479\end{array}$ & $\begin{array}{l}.709 \\
.715 \\
.709 \\
.731 \\
.695\end{array}$ & $\begin{array}{l}43.056 \\
43.059 \\
43.057 \\
43.248 \\
42.950\end{array}$ & $\begin{array}{r}.4790 \\
.4791 \\
.4790 \\
.4680 \\
.4655\end{array}$ \\
\hline $\begin{array}{l}110 \\
111 \\
111 \\
112 \\
112\end{array}$ & $\begin{array}{r}935 \\
957 \\
1016 \\
1034 \\
1055\end{array}$ & $\begin{array}{l}5 \\
5 \\
5 \\
5 \\
5\end{array}$ & $\begin{array}{l}1.219 \\
1.223 \\
1.220 \\
1.209 \\
1.207\end{array}$ & $\begin{array}{l}34.758 \\
85.114 \\
85.046 \\
84.542 \\
84.574\end{array}$ & $\begin{array}{r}9.376 \\
10.090 \\
10.084 \\
9.537 \\
9.511\end{array}$ & $\begin{array}{l}3.472 \\
3.053 \\
3.100 \\
3.517 \\
3.515\end{array}$ & $\begin{array}{l}.482 \\
.233 \\
.246 \\
.486 \\
.487\end{array}$ & $\begin{array}{l}.694 \\
.287 \\
.304 \\
.709 \\
.706\end{array}$ & $\begin{array}{l}42.956 \\
42.368 \\
42.419 \\
43.046 \\
43.037\end{array}$ & $\begin{array}{r}.4656 \\
.4612 \\
.4616 \\
.4663 \\
.4662\end{array}$ \\
\hline $\begin{array}{l}113 \\
113 \\
114 \\
115 \\
115\end{array}$ & $\begin{array}{l}1151 \\
1212 \\
1230 \\
1248 \\
1305\end{array}$ & $\begin{array}{r}5 \\
5 \\
5 \\
5 \\
105\end{array}$ & $\begin{array}{l}1.201 \\
1.203 \\
1.209 \\
1.214 \\
1.251\end{array}$ & $\begin{array}{l}85.519 \\
85.529 \\
83.762 \\
84.906 \\
84.623\end{array}$ & $\begin{array}{l}9.802 \\
9.786 \\
9.940 \\
9.364 \\
9.490\end{array}$ & $\begin{array}{l}2.774 \\
2.776 \\
3.800 \\
3.393 \\
3.477\end{array}$ & $\begin{array}{l}.299 \\
.299 \\
.527 \\
.461 \\
.473\end{array}$ & $\begin{array}{l}.405 \\
.407 \\
.763 \\
.663 \\
.685\end{array}$ & $\begin{array}{l}42.292 \\
42.290 \\
43.401 \\
42.865 \\
42.964\end{array}$ & $\begin{array}{r}.4602 \\
.4602 \\
.4693 \\
.4648 \\
.4659\end{array}$ \\
\hline $\begin{array}{l}116 \\
117 \\
118 \\
119 \\
119\end{array}$ & $\begin{array}{l}1327 \\
1355 \\
1420 \\
1509 \\
1437\end{array}$ & $\begin{array}{r}5 \\
5 \\
5 \\
5 \\
105\end{array}$ & $\begin{array}{l}1.217 \\
1.215 \\
1.200 \\
1.214 \\
1.236\end{array}$ & $\begin{array}{l}84.514 \\
84.343 \\
83.566 \\
84.632 \\
84.583\end{array}$ & $\begin{array}{l}9.514 \\
9.784 \\
9.863 \\
9.509 \\
9.512\end{array}$ & $\begin{array}{l}3.540 \\
3.818 \\
3.955 \\
3.499 \\
3.492\end{array}$ & $\begin{array}{l}.495 \\
.367 \\
.566 \\
.477 \\
.482\end{array}$ & $\begin{array}{l}.720 \\
.472 \\
.852 \\
.699 \\
.695\end{array}$ & $\begin{array}{l}43.067 \\
42.985 \\
43.576 \\
43.010 \\
43.000\end{array}$ & $\begin{array}{r}.4665 \\
.4660 \\
.4831 \\
.4786 \\
.4787\end{array}$ \\
\hline $\begin{array}{l}120 \\
120 \\
121 \\
122 \\
123\end{array}$ & $\begin{array}{l}1534 \\
1550 \\
1609 \\
1630 \\
1649\end{array}$ & $\begin{array}{l}5 \\
5 \\
5 \\
5 \\
5\end{array}$ & $\begin{array}{l}1.261 \\
1.265 \\
1.209 \\
1.214 \\
1.208\end{array}$ & $\begin{array}{l}87.825 \\
87.828 \\
84.562 \\
84.557 \\
84.520\end{array}$ & $\begin{array}{l}8.980 \\
9.013 \\
9.572 \\
9.506 \\
9.635\end{array}$ & $\begin{array}{l}1.769 \\
1.770 \\
3.502 \\
3.527 \\
3.487\end{array}$ & $\begin{array}{l}.128 \\
.124 \\
.473 \\
.487 \\
.471\end{array}$ & $\begin{array}{r}.037 \\
0.000 \\
.682 \\
.709 \\
.679\end{array}$ & $\begin{array}{l}41.015 \\
40.988 \\
43.015 \\
43.042 \\
43.020\end{array}$ & $\begin{array}{r}.4626 \\
.4624 \\
.4787 \\
.4789 \\
.4787\end{array}$ \\
\hline $\begin{array}{l}124 \\
125 \\
125 \\
126 \\
126\end{array}$ & $\begin{array}{l}1707 \\
1726 \\
1741 \\
1801 \\
1817\end{array}$ & $\begin{array}{r}5 \\
5 \\
5 \\
5 \\
105\end{array}$ & $\begin{array}{l}1.190 \\
1.214 \\
1.214 \\
1.208 \\
1.241\end{array}$ & $\begin{array}{l}83.549 \\
84.457 \\
84.497 \\
84.732 \\
84.609\end{array}$ & $\begin{array}{r}10.300 \\
9.466 \\
9.432 \\
9.499 \\
9.496\end{array}$ & $\begin{array}{l}3.809 \\
3.635 \\
3.632 \\
3.451 \\
3.486\end{array}$ & $\begin{array}{l}.477 \\
.503 \\
.505 \\
.453 \\
.476\end{array}$ & $\begin{array}{l}.675 \\
.726 \\
.720 \\
.657 \\
.692\end{array}$ & $\begin{array}{l}43.399 \\
43.119 \\
43.105 \\
42.927 \\
42.982\end{array}$ & $\begin{array}{r}.4818 \\
.4795 \\
.4794 \\
.4780 \\
.4786\end{array}$ \\
\hline $\begin{array}{l}127 \\
128 \\
129 \\
129 \\
130\end{array}$ & $\begin{array}{r}913 \\
931 \\
946 \\
1003 \\
1019\end{array}$ & $\begin{array}{l}5 \\
5 \\
5 \\
5 \\
5\end{array}$ & $\begin{array}{l}1.175 \\
1.202 \\
1.199 \\
1.199 \\
1.177\end{array}$ & $\begin{array}{l}84.322 \\
84.800 \\
83.794 \\
83.786 \\
84.120\end{array}$ & $\begin{array}{r}9.605 \\
9.425 \\
10.159 \\
10.159 \\
10.690\end{array}$ & $\begin{array}{l}3.720 \\
3.416 \\
3.644 \\
3.655 \\
3.164\end{array}$ & $\begin{array}{l}.493 \\
.470 \\
.489 \\
.487 \\
.356\end{array}$ & $\begin{array}{l}.685 \\
.687 \\
.715 \\
.714 \\
.493\end{array}$ & $\begin{array}{l}43.179 \\
42.928 \\
43.306 \\
43.310 \\
42.896\end{array}$ & $\begin{array}{r}.4672 \\
.4653 \\
.4685 \\
.4686 \\
.4653\end{array}$ \\
\hline
\end{tabular}


Table 7.4.1. Vaporizer Test 1 (continued)

\begin{tabular}{|c|c|c|c|c|c|c|c|c|c|c|}
\hline $\begin{array}{c}\text { Run } \\
\text { Number }\end{array}$ & Time & $\operatorname{Mix}$ & $\mathrm{N}_{2}$ & $\mathrm{CH}_{4}$ & $\mathrm{C}_{2} \mathrm{H}_{6}$ & $\mathrm{C}_{3} \mathrm{H}_{8}$ & $\mathrm{iC}_{4} \mathrm{H}_{10}$ & $\mathrm{nc}_{4} \mathrm{H}_{10}$ & $\begin{array}{l}\text { Value } \\
\mathrm{MJ} / \mathrm{m}^{3}\end{array}$ & $\begin{array}{c}\text { Density } \\
\mathrm{gm} / \mathrm{cm}^{3}\end{array}$ \\
\hline 131 & 1043 & 5 & 1.207 & 84.322 & 9.500 & 3.690 & .521 & $\begin{array}{r}.760 \\
698\end{array}$ & 43.207 & .4676 \\
\hline 131 & 1139 & 105 & 1.234 & 84.567 & 9.530 & 3.493 & .479 & .698 & +3.006 & .4661 \\
\hline 132 & 1201 & 5 & 1.231 & 84.756 & 9.373 & 3.465 & .480 & .696 & 42.946 & .4656 \\
\hline 133 & 1218 & 5 & 1.209 & 84.147 & 9.778 & 3.635 & .500 & .732 & 43.212 & .4677 \\
\hline 134 & 1237 & 5 & 1.205 & 84.077 & 9.520 & 4.204 & .445 & .549 & 43.261 & .4681 \\
\hline 135 & 1306 & 5 & 1.209 & 84.443 & 9.498 & 3.584 & .517 & .749 & 43.133 & .4670 \\
\hline 136 & 1328 & 5 & 1.215 & 84.611 & 9.501 & 3.501 & .477 & .695 & 43.006 & .466 \\
\hline 137 & 1354 & 5 & 1.214 & 84.609 & 9.504 & 3.496 & .479 & .698 & 43.008 & .466 \\
\hline 138 & 1413 & 5 & 1.224 & 82.574 & 10.579 & 4.179 & .585 & .859 & $43.92 C$ & .473 \\
\hline 139 & 1455 & 5 & 1.200 & 83.838 & 12.260 & 2.559 & .143 & 0.000 & 42.397 & .462 \\
\hline 140 & 1511 & 5 & 1.210 & 84.562 & 9.531 & 3.506 & .483 & .708 & 43.035 & .466 \\
\hline 141 & 1529 & 5 & 1.213 & 84.579 & 9.510 & 3.500 & .486 & .707 & 43.024 & .456 \\
\hline 142 & 1550 & 5 & 1.212 & 84.303 & 9.523 & 3.650 & .526 & .785 & 43.214 & .480 \\
\hline 143 & 1607 & 5 & 1.214 & 84.577 & 9.519 & 3.498 & .481 & .711 & 43.026 & .478 \\
\hline 144 & 1627 & 5 & 1.195 & 84.528 & 9.553 & 3.528 & .484 & .711 & 43.062 & .479 \\
\hline 145 & 1647 & 5 & 1.240 & 84.379 & 9.573 & 3.587 & .494 & .727 & 43.106 & .479 \\
\hline 145 & 1705 & 105 & 1.238 & 84.557 & 9.527 & 3.493 & .482 & .703 & 43.010 & .478 \\
\hline
\end{tabular}


Table 7.4.1. Vaporizer Test 2

\begin{tabular}{|c|c|c|c|c|c|c|c|c|c|c|}
\hline $\begin{array}{c}\text { RUN } \\
\text { NUMBER }\end{array}$ & DATE & $\begin{array}{c}\text { TEMPERATURE } \\
K\end{array}$ & $\begin{array}{l}\text { PFESSURE } \\
\text { MPA }\end{array}$ & LNG & $\begin{array}{l}\text { FLOW } \\
\text { LPM }\end{array}$ & RATE & $\begin{array}{l}\text { SAMPLING } \\
\text { RATE, SLPM }\end{array}$ & $\begin{array}{l}\text { DELTA } P \\
\text { KPA }\end{array}$ & VAPORIZER & $\begin{array}{l}\text { VAPORI ZER } \\
\text { POWER, WATTS }\end{array}$ \\
\hline $\begin{array}{l}182 \\
183 \\
184 \\
185\end{array}$ & $\begin{array}{l}3 / 01 \\
3 / 01 \\
3 / 01 \\
3 / 01\end{array}$ & $\begin{array}{l}111.0 \\
111.0 \\
111.0 \\
111.0\end{array}$ & $\begin{array}{l}.127 \\
.126 \\
.124 \\
.125\end{array}$ & & $\begin{array}{l}3.75 \\
3.75 \\
7.53 \\
7.53\end{array}$ & & $\begin{array}{r}10.1 \\
6.7 \\
6.6 \\
10.0\end{array}$ & $\begin{array}{l}33 . \\
33 . \\
27 \\
27\end{array}$ & $\begin{array}{l}A \\
A \\
A \\
A\end{array}$ & \\
\hline $\begin{array}{l}186 \\
187 \\
188 \\
189 \\
190\end{array}$ & $\begin{array}{l}3 / 01 \\
3 / 01 \\
3 / 01 \\
3 / 01 \\
3 / 01\end{array}$ & $\begin{array}{l}111.0 \\
111.0 \\
111.0 \\
111.0 \\
111.0\end{array}$ & $\begin{array}{l}.125 \\
.128 \\
.126 \\
.126 \\
.125\end{array}$ & & $\begin{array}{l}3.79 \\
3.79 \\
7.57 \\
7.57 \\
7.57\end{array}$ & & $\begin{array}{r}6.7 \\
10.1 \\
10.0 \\
6.7 \\
6.7\end{array}$ & $\begin{array}{l}28^{\circ} \\
28^{\circ} \\
260^{\circ} \\
25 \circ^{\circ} \\
26 .\end{array}$ & $\begin{array}{l}A \\
A \\
A \\
A \\
R\end{array}$ & 77.0 \\
\hline
\end{tabular}


Table 7.4.1. Vaporizer Test 2 (continued)

\begin{tabular}{|c|c|c|c|c|c|c|c|c|c|c|}
\hline $\begin{array}{c}\text { Run } \\
\text { Number }\end{array}$ & Time & $\operatorname{Mix}$ & $\mathrm{N}_{2}$ & $\mathrm{CH}_{4}$ & $\mathrm{C}_{2} \mathrm{H}_{6}$ & $\mathrm{C}_{3} \mathrm{H}_{8}$ & $i_{4} \mathrm{H}_{10}$ & $\mathrm{nC}_{4} \mathrm{H}_{10}$ & $\begin{array}{l}\text { Value } \\
\mathrm{MJ} / \mathrm{m}^{3}\end{array}$ & $\begin{array}{r}\text { Density } \\
\mathrm{gm} / \mathrm{cm}^{3}\end{array}$ \\
\hline 182 & 1010 & 5 & 1.243 & 84.596 & 9.479 & 3.491 & $.48 \bar{c}$ & .710 & 43.000 & .4787 \\
\hline 183 & 1028 & 5 & 1.211 & 84.590 & 9.461 & 3.498 & $.49 E$ & .744 & +3.051 &.+789 \\
\hline 183 & 1051 & 105 & 1.249 & 84.541 & 9.544 & 3.492 & $.48 \mathrm{C}$ & .694 & 43.001 & .4788 \\
\hline 184 & 1206 & 5 & 1.207 & 84.422 & 9.737 & 3.513 & .463 & .653 & $43.04 C$ & .4789 \\
\hline 184 & 1149 & 105 & 1.248 & 84.517 & 9.543 & 3.509 & .483 & .700 & 43.019 & .4789 \\
\hline 185 & 1224 & 5 & 1.204 & 84.610 & 9.503 & 3.504 & .481 & - $E 98$ & 43.018 & .4786 \\
\hline 186 & 1252 & 5 & 1.239 & 84.601 & 9.393 & 3.537 & $.50 c$ & .728 & 43.035 & .4789 \\
\hline 187 & 1311 & 5 & 1.206 & 84.618 & 9.491 & 3.490 & $.43 E$ & .701 & 43.017 & .4786 \\
\hline 188 & 1328 & 5 & 1.206 & 84.309 & 9.628 & 3.593 & .509 & .758 & 43.175 & .4799 \\
\hline 188 & 1344 & 5 & $1 .<01$ & 84.349 & 9.597 & 3.582 & .509 & .762 & 43.167 & .4798 \\
\hline 189 & 1359 & 5 & 1.177 & 84.154 & 9.633 & 3.679 & .542 & .815 & 43.314 & .4808 \\
\hline 189 & 1415 & 5 & 1.176 & 84.179 & 9.610 & 3.685 & .541 & .809 & 43.305 & .4808 \\
\hline 190 & 1439 & 5 & 1.214 & 84.569 & 9.530 & 3.508 & .481 & .698 & 43.024 & .4788 \\
\hline
\end{tabular}


Table 7.4.1. General Test 1

\begin{tabular}{|c|c|c|c|c|c|c|c|c|c|c|c|c|c|}
\hline $\begin{array}{c}\text { RUN } \\
\text { NUMBER }\end{array}$ & DATE & $\begin{array}{c}\text { TEMPERATURE } \\
K\end{array}$ & $\begin{array}{l}\text { PRESSURE } \\
\text { MPA }\end{array}$ & LNG & $\begin{array}{l}F L O \\
L P\end{array}$ & RA & RATE & $\begin{array}{l}\text { SAMPLING } \\
\text { RATE, SLPM }\end{array}$ & $\begin{array}{l}\text { CELT, } \\
\text { KP }\end{array}$ & $P$ & PROBE & $\begin{array}{l}\text { VAPORI ZER } \\
\text { POWER, WATTS }\end{array}$ & ATOR \\
\hline
\end{tabular}

\begin{tabular}{|c|c|c|c|c|c|c|c|c|c|}
\hline $\begin{array}{l}191 \\
192 \\
193 \\
194 \\
195\end{array}$ & $\begin{array}{l}4 / 14 \\
4 / 14 \\
4 / 14 \\
4 / 14 \\
4 / 14\end{array}$ & $\begin{array}{l}123 \cdot 3 \\
123 \cdot 0 \\
123 \cdot 0 \\
123 \cdot 0 \\
123.0\end{array}$ & $\begin{array}{l}.248 \\
.258 \\
.248 \\
.254 \\
.252\end{array}$ & $\begin{array}{l}4.24 \\
4.16 \\
4.16 \\
4.01 \\
4.01\end{array}$ & $\begin{array}{l}5.0 \\
5.1 \\
4.9 \\
5.1 \\
5.1\end{array}$ & $\begin{array}{l}350^{\circ} \\
34 . \\
34 \circ^{\circ} \\
350^{\circ} \\
35 .\end{array}$ & $\begin{array}{l}R \\
R \\
R \\
R \\
R\end{array}$ & $\begin{array}{l}59.7 \\
59.7 \\
59.3 \\
62.8 \\
62.8\end{array}$ & $\begin{array}{l}\text { NO } \\
\text { YES } \\
\text { YES } \\
\text { NO } \\
\text { YES }\end{array}$ \\
\hline $\begin{array}{l}196 \\
197 \\
198 \\
199 \\
200\end{array}$ & $\begin{array}{l}4 / 14 \\
4 / 14 \\
4 / 14 \\
4 / 14 \\
4 / 14\end{array}$ & $\begin{array}{l}123.0 \\
123 \cdot 0 \\
123 \cdot 0 \\
123 \cdot 0 \\
123.0\end{array}$ & $\begin{array}{l}.247 \\
.248 \\
.245 \\
.251 \\
.252\end{array}$ & $\begin{array}{l}4.01 \\
4.05 \\
4.05 \\
4.05 \\
4.09\end{array}$ & $\begin{array}{l}5.0 \\
5.0 \\
5.0 \\
5.0 \\
5.4\end{array}$ & $\begin{array}{l}350^{\circ} \\
35{ }^{\circ} \\
35 \circ^{\circ} \\
350^{\circ} \\
34 .\end{array}$ & $\begin{array}{l}R \\
R \\
P \\
P \\
P\end{array}$ & $\begin{array}{l}62.8 \\
62.4 \\
62.0 \\
62.0 \\
62.4\end{array}$ & $\begin{array}{l}\text { YES } \\
\text { NO } \\
\text { NO } \\
\text { YES } \\
\text { YES }\end{array}$ \\
\hline $\begin{array}{l}201 \\
202 \\
203 \\
204 \\
205\end{array}$ & $\begin{array}{l}4 / 14 \\
4 / 15 \\
4 / 15 \\
4 / 15 \\
4 / 15\end{array}$ & $\begin{array}{l}123 \cdot 0 \\
123 \cdot 0 \\
123 \cdot 0 \\
123 \cdot 0 \\
123.0\end{array}$ & $\begin{array}{l}.250 \\
.250 \\
.249 \\
.249 \\
.243\end{array}$ & $\begin{array}{l}4.09 \\
4.13 \\
4.13 \\
4.13 \\
4.13\end{array}$ & $\begin{array}{l}5.0 \\
5.0 \\
5.0 \\
5.0 \\
5.0\end{array}$ & $\begin{array}{l}34{ }^{\circ} \\
35 \circ^{\circ} \\
35^{\circ} \\
36{ }^{\circ} \\
36 .\end{array}$ & $\begin{array}{l}P \\
R \\
R \\
S \\
S\end{array}$ & $\begin{array}{l}62.0 \\
62.4 \\
62.4 \\
62.8 \\
62.4\end{array}$ & $\begin{array}{l}\text { NO } \\
\text { NO } \\
\text { YES } \\
\text { NO } \\
\text { YES }\end{array}$ \\
\hline $\begin{array}{l}206 \\
207 \\
208 \\
209 \\
210\end{array}$ & $\begin{array}{l}4 / 15 \\
4 / 15 \\
4 / 15 \\
4 / 18 \\
4 / 18\end{array}$ & $\begin{array}{l}123 \cdot 0 \\
123 \cdot 0 \\
123 \cdot 0 \\
123 \cdot 0 \\
123.0\end{array}$ & $\begin{array}{l}.248 \\
.248 \\
.248 \\
.250 \\
.250\end{array}$ & $\begin{array}{l}4 \cdot 24 \\
4 \cdot 16 \\
4 \cdot 16 \\
4 \cdot 16 \\
4.24\end{array}$ & $\begin{array}{l}5.0 \\
5.0 \\
5.0 \\
5.0 \\
5.0\end{array}$ & $\begin{array}{l}34^{\circ} \\
35 \circ^{\circ} \\
35 \circ^{\circ} \\
35{ }^{\circ} \\
35{ }^{\circ}\end{array}$ & $\begin{array}{l}P \\
P \\
S \\
R \\
S\end{array}$ & $\begin{array}{l}62.8 \\
62.8 \\
62.8 \\
55.5 \\
62.0\end{array}$ & $\begin{array}{l}\text { NO } \\
\text { YES } \\
\text { NO } \\
\text { YES } \\
\text { YES }\end{array}$ \\
\hline $\begin{array}{l}211 \\
212 \\
213 \\
214 \\
215\end{array}$ & $\begin{array}{l}4 / 18 \\
4 / 18 \\
4 / 19 \\
4 / 19 \\
4 / 19\end{array}$ & $\begin{array}{l}123 \cdot 0 \\
123 \cdot 0 \\
123 \cdot 0 \\
123 \cdot 0 \\
123.0\end{array}$ & $\begin{array}{l}.251 \\
.251 \\
.248 \\
.248 \\
.248\end{array}$ & $\begin{array}{l}4.20 \\
4.24 \\
4.24 \\
4.24 \\
4.24\end{array}$ & $\begin{array}{l}5.0 \\
5.0 \\
5.0 \\
5.0 \\
5.0\end{array}$ & $\begin{array}{l}35{ }^{\circ} \\
35{ }^{\circ} \\
35{ }^{\circ} \\
350^{\circ} \\
35 .\end{array}$ & $\begin{array}{l}P \\
P \\
R \\
R \\
S\end{array}$ & $\begin{array}{l}59.3 \\
53.3 \\
57.0 \\
57.0 \\
57.4\end{array}$ & $\begin{array}{l}\text { YES } \\
\text { NO } \\
\text { NO } \\
\text { YES } \\
\text { YES }\end{array}$ \\
\hline $\begin{array}{l}216 \\
217 \\
218 \\
219 \\
220\end{array}$ & $\begin{array}{l}4 / 19 \\
4 / 19 \\
4 / 19 \\
4 / 19 \\
4 / 19\end{array}$ & $\begin{array}{l}123 \cdot 0 \\
123 \cdot 0 \\
123 \cdot 0 \\
123 \cdot 0 \\
123 \cdot 0\end{array}$ & $\begin{array}{l}.247 \\
.248 \\
.248 \\
.247 \\
.248\end{array}$ & $\begin{array}{l}4.24 \\
4.24 \\
4.24 \\
4.24 \\
4.24\end{array}$ & $\begin{array}{l}5.0 \\
5.0 \\
5.0 \\
5.0 \\
5.0\end{array}$ & $\begin{array}{l}35 . \\
35 \circ^{\circ} \\
35 . \\
35{ }^{\circ} \\
35 .\end{array}$ & $\begin{array}{l}S \\
P \\
P \\
S \\
S\end{array}$ & $\begin{array}{l}57.8 \\
57.8 \\
57.8 \\
57.8 \\
57.8\end{array}$ & $\begin{array}{l}\text { NO } \\
\text { YES } \\
\text { NO } \\
\text { NO } \\
\text { YES }\end{array}$ \\
\hline $\begin{array}{l}221 \\
222 \\
223 \\
224 \\
225\end{array}$ & $\begin{array}{l}4 / 19 \\
4 / 19 \\
4 / 19 \\
4 / 19 \\
4 / 19\end{array}$ & $\begin{array}{l}123.0 \\
123.0 \\
123.0 \\
123.0 \\
123.0\end{array}$ & $\begin{array}{l}.246 \\
.247 \\
.246 \\
.248 \\
.246\end{array}$ & $\begin{array}{l}4.13 \\
4.13 \\
4.13 \\
4.16 \\
4.16\end{array}$ & $\begin{array}{l}5.0 \\
5.0 \\
5.0 \\
5.0 \\
5.0\end{array}$ & $\begin{array}{l}35{ }^{\circ} \\
35{ }^{\circ} \\
35{ }^{\circ} \\
350^{\circ} \\
35\end{array}$ & $\begin{array}{l}P \\
P \\
R \\
R \\
P\end{array}$ & $\begin{array}{l}57.8 \\
57.8 \\
57.8 \\
57.8 \\
57.8\end{array}$ & $\begin{array}{l}\text { YES } \\
\text { NO } \\
\text { YES } \\
\text { NO } \\
\text { NO }\end{array}$ \\
\hline $\begin{array}{l}226 \\
227 \\
228 \\
229 \\
230\end{array}$ & $\begin{array}{l}4 / 19 \\
4 / 20 \\
4 / 20 \\
4 / 20 \\
4 / 20\end{array}$ & $\begin{array}{l}123 \cdot 0 \\
123 \cdot 0 \\
123 \cdot 0 \\
123 \cdot 0 \\
123 \cdot 0\end{array}$ & $\begin{array}{l}.248 \\
.247 \\
.249 \\
.249 \\
.249\end{array}$ & $\begin{array}{l}4.13 \\
4.05 \\
4.01 \\
4.01 \\
4.01\end{array}$ & $\begin{array}{l}5.0 \\
5.0 \\
5.0 \\
5.0 \\
5.0\end{array}$ & $\begin{array}{l}35 . \\
35{ }^{\circ} \\
35 . \\
35 . \\
35 .\end{array}$ & $\begin{array}{l}P \\
R \\
R \\
S \\
S\end{array}$ & $\begin{array}{l}57 \cdot 8 \\
57.8 \\
57.8 \\
57.8 \\
57.8\end{array}$ & $\begin{array}{l}\text { YES } \\
\text { YES } \\
\text { NO } \\
\text { YES } \\
\text { NO }\end{array}$ \\
\hline $\begin{array}{l}231 \\
232 \\
233 \\
234 \\
235\end{array}$ & $\begin{array}{l}4 / 20 \\
4 / 20 \\
4 / 20 \\
4 / 20 \\
4 / 20\end{array}$ & $\begin{array}{l}123 \cdot 0 \\
123 \cdot 0 \\
123 \cdot 0 \\
123 \cdot 0 \\
123 \cdot 0\end{array}$ & $\begin{array}{l}.249 \\
.248 \\
.248 \\
.246 \\
.249\end{array}$ & $\begin{array}{l}4.01 \\
4.01 \\
4.01 \\
4.01 \\
4.01\end{array}$ & $\begin{array}{l}5.0 \\
5.0 \\
5.0 \\
5.0 \\
5.0\end{array}$ & $\begin{array}{l}35{ }^{\circ} \\
35{ }^{\circ} \\
35{ }^{\circ} \\
35 . \\
35 .\end{array}$ & $\begin{array}{l}R \\
R \\
P \\
P \\
S\end{array}$ & $\begin{array}{l}57.8 \\
57.8 \\
57.8 \\
57.8 \\
57.8\end{array}$ & $\begin{array}{l}\text { YES } \\
\text { NO } \\
\text { YES } \\
\text { NO } \\
\text { YES }\end{array}$ \\
\hline $\begin{array}{l}236 \\
237 \\
238\end{array}$ & $\begin{array}{l}4 / 20 \\
4 / 20 \\
4 / 20\end{array}$ & $\begin{array}{l}123 \cdot 0 \\
123 \cdot 0 \\
123 \cdot 0\end{array}$ & $\begin{array}{l}.248 \\
.246 \\
.246\end{array}$ & $\begin{array}{l}4.01 \\
3.97 \\
3.97\end{array}$ & $\begin{array}{l}5.0 \\
5.0 \\
5.0\end{array}$ & $\begin{array}{l}35 . \\
35 . \\
35 .\end{array}$ & $\begin{array}{l}S \\
S \\
S\end{array}$ & $\begin{array}{l}57.8 \\
81.8 \\
81.8\end{array}$ & $\begin{array}{l}\text { NO } \\
\text { YES } \\
\text { YES }\end{array}$ \\
\hline
\end{tabular}


Table 7.4.1. General Test 1 (continued)

\begin{tabular}{|c|c|c|c|c|c|c|c|c|c|c|}
\hline $\begin{array}{c}\text { Run } \\
\text { Number }\end{array}$ & Time & Mix & $N_{2}$ & $\mathrm{CH}_{4}$ & $\mathrm{C}_{2} \mathrm{H}_{6}$ & $\mathrm{C}_{3} \mathrm{H}_{8}$ & $i_{4} \mathrm{H}_{10}$ & $\mathrm{nC}_{4} \mathrm{H}_{10}$ & $\begin{array}{l}\text { Value } \\
\mathrm{MJ} / \mathrm{m}^{3}\end{array}$ & $\begin{array}{r}\text { Density } \\
\mathrm{gm} / \mathrm{cm}^{3}\end{array}$ \\
\hline 191 & 1131 & 6 & .621 & 87.724 & 6.633 & 4.016 & .426 & .581 & 42.566 & .4541 \\
\hline 191 & 1147 & 6 & .622 & 87.709 & 6.622 & 4.035 & .427 & .585 & 42.578 & .4542 \\
\hline 192 & 1218 & 6 & .628 & 87.345 & 6.800 & 4.205 & .437 & .586 & 42.731 & .4555 \\
\hline 193 & 1236 & 6 & .627 & 87.388 & 6.743 & 4.196 & .442 & .604 & 42.730 & .4555 \\
\hline 193 & 1316 & 106 & .477 & 87.822 & 6.665 & 4.017 & .428 & .591 & 42.641 & .4538 \\
\hline 194 & 1338 & 6 & .623 & 87.771 & 6.592 & 4.011 & .428 & .578 & 42.552 & .4539 \\
\hline 195 & 1358 & 6 & .619 & 87.399 & 6.800 & 4.108 & .455 & .619 & 42.723 & .4554 \\
\hline 196 & 1417 & 6 & .621 & 87.344 & 6.719 & 4.257 & .440 & .620 & 42.771 & .4558 \\
\hline 197 & 1440 & 6 & .622 & 87.766 & 6.609 & 3.999 & .425 & .579 & 42.547 & .4539 \\
\hline 197 & 1459 & 106 & .481 & 87.851 & 6.650 & 4.022 & .427 & .569 & 42.619 & .4536 \\
\hline 198 & 1525 & 6 & .620 & 87.746 & 6.612 & 4.007 & .429 & .586 & 42.563 & .4540 \\
\hline 199 & 1544 & $x$ & .625 & 87.483 & 6.616 & 4.173 & .465 & .638 & 42.730 & .4554 \\
\hline 200 & 1603 & 6 & .627 & 87.799 & 6.553 & 4.012 & .428 & .581 & 42.541 & .4539 \\
\hline 201 & 1621 & 6 & $.62 \mathrm{~J}$ & 87.782 & 6.591 & 4.001 & .427 & .579 & 42.546 & .4539 \\
\hline 201 & 1638 & 106 & .491 & 87.894 & 6.632 & 3.987 & .427 & .569 & 42.590 & .4535 \\
\hline 202 & 1104 & 6 & .619 & 87.755 & 6.611 & 3.998 & .433 & .585 & 42.560 & .4540 \\
\hline 203 & 1126 & 6 & .614 & 87.762 & 6.433 & 4.152 & .444 & .595 & 42.616 & .4544 \\
\hline 204 & 1149 & 6 & .621 & 87.747 & 6.624 & 4.003 & .424 & .581 & 42.555 & .4540 \\
\hline 205 & 1206 & 6 & .629 & 88.309 & 6.279 & 3.805 & .412 & .566 & 42.319 & .4519 \\
\hline 206 & 1228 & 6 & .620 & 87.773 & 6.602 & 3.995 & .425 & .585 & 42.549 & .4539 \\
\hline 207 & 1245 & 6 & .621 & 87.637 & 6.607 & 4.062 & .447 & .626 & 42.641 & .4547 \\
\hline 208 & 1305 & 6 & .620 & 87.749 & 6.613 & 4.003 & .427 & .588 & 42.561 & .4540 \\
\hline 208 & 1322 & 6 & .619 & 87.776 & 6.590 & 4.002 & .426 & .588 & 42.553 & .4539 \\
\hline 208 & 1340 & 106 & .477 & 87.838 & 6.641 & 4.018 & .434 & .592 & 42.641 & .4538 \\
\hline 209 & 1339 & 6 & .613 & 87.726 & 6.667 & 3.938 & .444 & $.6 \mathrm{~J} 8$ & 42.571 & .4541 \\
\hline 209 & 1140 & 106 & .475 & 87.818 & 6.666 & 4.026 & .430 & .585 & 42.644 & .4538 \\
\hline 209 & 1257 & 106 & .477 & 87.793 & 6.668 & 4.032 & .434 & .596 & 42.659 & .4540 \\
\hline 209 & 1313 & 106 & .477 & 87.872 & 6.637 & 4.008 & .427 & .579 & 42.617 & .4536 \\
\hline 210 & 1405 & 6 & .619 & 87.715 & 6.673 & 4.050 & .414 & .530 & 42.545 & .4539 \\
\hline 211 & 1436 & 6 & .605 & 88.802 & 5.897 & 3.707 & .423 & .566 & 42.174 & .4504 \\
\hline 212 & 1457 & 6 & .618 & 87.725 & 6.612 & 4.031 & .429 & .586 & 42.577 & .4541 \\
\hline 213 & 944 & 6 & .612 & 87.692 & 6.646 & 4.030 & .435 & .585 & $42 \cdot 592$ & .4542 \\
\hline 213 & 909 & 106 & .476 & 87.819 & 6.644 & 4.041 & .432 & .588 & 42.650 & .4539 \\
\hline 214 & 1000 & 6 & .616 & 87.641 & 6.686 & 4.050 & .431 & .576 & 42.603 & .4543 \\
\hline 215 & 1016 & 6 & .621 & 87.940 & 6.413 & 4.025 & .421 & .580 & 42.504 & .4535 \\
\hline 216 & 1034 & 6 & .613 & 87.673 & 6.668 & 4.034 & .430 & .582 & 42.594 & .4542 \\
\hline 217 & 1050 & 6 & .616 & 87.636 & 6.672 & 4.083 & .430 & .566 & 42.606 & .4544 \\
\hline 218 & 1109 & 6 & .614 & 87.678 & 6.661 & 4.037 & .428 & .582 & 42.592 & .4542 \\
\hline 219 & 1127 & 6 & .613 & 87.674 & 6.668 & 4.035 & .428 & .582 & 42.593 & .4542 \\
\hline 220 & 1142 & 6 & .610 & 87.541 & 6.706 & 4.117 & .435 & .591 & 42.665 & .4548 \\
\hline 220 & 1259 & 106 & .474 & 87.816 & 6.667 & 4.030 & .426 & .586 & 42.645 & .4538 \\
\hline 220 & 1315 & $10 E$ & .476 & 87.787 & 6.677 & 4.040 & .432 & .588 & 42.659 & .4540 \\
\hline 221 & 1331 & 6 & .649 & 88.154 & 6.146 & $4 \cdot 030$ & .432 & .588 & 42.437 & .4530 \\
\hline 222 & 1348 & 6 & .613 & 87.790 & 6.610 & 3.976 & .425 & .586 & 42.544 & .4538 \\
\hline 223 & 1404 & 6 & .609 & 88.404 & 6.021 & 3.925 & .445 & .597 & 42.375 & .4522 \\
\hline 224 & 1422 & 6 & .613 & 87.688 & 6.663 & 4.029 & .427 & .580 & 42.585 & .4542 \\
\hline 225 & 1437 & 6 & .614 & 87.686 & 6.657 & 4.031 & .431 & .581 & 42.589 & .4542 \\
\hline 226 & 1453 & 6 & .615 & 87.518 & 6.816 & 4.108 & .406 & .537 & 42.619 & .4545 \\
\hline 227 & 951 & 6 & .630 & 88.048 & 6.333 & 3.961 & .434 & .589 & 42.462 & .4531 \\
\hline 228 & 1009 & 6 & .611 & 87.669 & 6.655 & 4.047 & .432 & .586 & 42.604 & .4543 \\
\hline
\end{tabular}


Table 7.4.1. General Test 1 (continued)

\begin{tabular}{|c|c|c|c|c|c|c|c|c|c|c|}
\hline $\begin{array}{c}\text { Run } \\
\text { Number }\end{array}$ & Time & $\operatorname{Mix}$ & $\mathrm{N}_{2}$ & $\mathrm{CH}_{4}$ & $\mathrm{C}_{2} \mathrm{H}_{6}$ & $\mathrm{C}_{3} \mathrm{H}_{3}$ & ${ }^{i C_{4}} H_{10}$ & $\mathrm{nC}_{4} \mathrm{H}_{10}$ & $\begin{array}{l}\text { Value } \\
\mathrm{MJ} / \mathrm{m}^{3}\end{array}$ & $\begin{array}{c}\text { Density } \\
\mathrm{gm} / \mathrm{cm}^{3}\end{array}$ \\
\hline $\begin{array}{l}229 \\
230 \\
231 \\
232 \\
233\end{array}$ & $\begin{array}{l}1025 \\
1054 \\
1113 \\
1130 \\
1145\end{array}$ & $\begin{array}{l}6 \\
6 \\
6 \\
6 \\
6\end{array}$ & $\begin{array}{l}.607 \\
.612 \\
.604 \\
.610 \\
.625\end{array}$ & $\begin{array}{l}87.166 \\
87.687 \\
87.826 \\
87.728 \\
88.660\end{array}$ & $\begin{array}{l}6.857 \\
6.666 \\
\epsilon .571 \\
6.638 \\
6.120\end{array}$ & $\begin{array}{l}4.237 \\
4.011 \\
3.977 \\
4.012 \\
3.699\end{array}$ & $\begin{array}{l}.485 \\
.435 \\
.433 \\
.432 \\
.385\end{array}$ & $\begin{array}{l}.649 \\
.589 \\
.590 \\
.580 \\
.511\end{array}$ & $\begin{array}{l}42.867 \\
42.591 \\
42.547 \\
42.574 \\
42.147\end{array}$ & $\begin{array}{l}.4565 \\
.4542 \\
.4538 \\
.4541 \\
.4564\end{array}$ \\
\hline $\begin{array}{l}234 \\
235 \\
236 \\
236 \\
236\end{array}$ & $\begin{array}{l}1213 \\
1229 \\
1245 \\
1031 \\
1419\end{array}$ & $\begin{array}{r}6 \\
6 \\
6 \\
106 \\
106\end{array}$ & $\begin{array}{l}.613 \\
.625 \\
.612 \\
.477 \\
.477\end{array}$ & $\begin{array}{l}87.692 \\
89.171 \\
87.732 \\
87.820 \\
87.815\end{array}$ & $\begin{array}{l}6.657 \\
5.930 \\
6.629 \\
6.665 \\
6.669\end{array}$ & $\begin{array}{l}4.028 \\
3.418 \\
4.013 \\
4.021 \\
4.014\end{array}$ & $\begin{array}{l}.427 \\
.372 \\
.433 \\
.433 \\
.435\end{array}$ & $\begin{array}{l}.583 \\
.484 \\
.581 \\
.584 \\
.591\end{array}$ & $\begin{array}{l}42.586 \\
41.901 \\
42.573 \\
42.641 \\
42.646\end{array}$ & $\begin{array}{r}.4542 \\
.4483 \\
.4541 \\
.4538 \\
.4538\end{array}$ \\
\hline $\begin{array}{l}236 \\
237 \\
238\end{array}$ & $\begin{array}{l}1434 \\
1450 \\
1508\end{array}$ & $\begin{array}{r}106 \\
6 \\
6\end{array}$ & $\begin{array}{l}.477 \\
.594 \\
.672\end{array}$ & $\begin{array}{l}87.806 \\
87.516 \\
91.750\end{array}$ & $\begin{array}{l}6.677 \\
6.904 \\
4.564\end{array}$ & $\begin{array}{l}4.015 \\
4.036 \\
2.475\end{array}$ & $\begin{array}{l}.435 \\
.406 \\
.238\end{array}$ & $\begin{array}{l}.591 \\
.544 \\
.301\end{array}$ & $\begin{array}{l}42.649 \\
42.617 \\
40.696\end{array}$ & $\begin{array}{l}.4539 \\
.4544 \\
.4377\end{array}$ \\
\hline
\end{tabular}


Table 7.4.1. General Test 2

\begin{tabular}{|c|c|c|c|c|c|c|c|c|c|c|c|}
\hline $\begin{array}{c}\text { RUN } \\
\text { NUMBER }\end{array}$ & DATE & $\begin{array}{c}\text { TEMPERA TURE } \\
K\end{array}$ & $\begin{array}{l}\text { PRESSURE } \\
\text { MPA }\end{array}$ & LNG & $\begin{array}{l}\text { FLOW RATE } \\
\text { LPM }\end{array}$ & $\begin{array}{l}\text { SAMPLING } \\
\text { RATE, SLPM }\end{array}$ & $\begin{array}{r}\text { DELTA } \\
\text { KPA }\end{array}$ & $P$ & PROBE & $\begin{array}{l}\text { VAPORIZER } \\
\text { POWER, WATTS }\end{array}$ & $\begin{array}{l}\text { ACCUMULAT } \\
\text { BYPASSEO }\end{array}$ \\
\hline 239 & $4 / 21$ & 123.0 & .248 & & 3.97 & 5.0 & 35. & & S & 0.0 & YES \\
\hline 240 & $4 / 21$ & $123 \cdot 0$ & .247 & & 3.97 & 5.0 & 35. & & S & 0.0 & NO \\
\hline 241 & $4 / 21$ & 123.0 & .246 & & 3.97 & 5.0 & 35. & & S & 0.0 & YES \\
\hline 242 & $4 / 21$ & 123.0 & .248 & & 3.97 & 5.0 & 35. & & S & 0.0 & NO \\
\hline 243 & $4 / 21$ & 123.0 & .248 & & 3.97 & 5.0 & 35. & & s & 0.0 & YES \\
\hline 244 & $4 / 21$ & 123.0 & .247 & & 3.97 & 5.0 & 35. & & S & 0.0 & NO \\
\hline 245 & $4 / 21$ & 123.0 & .248 & & 3.97 & 5.0 & $3 E$. & & S & 99.6 & NO \\
\hline 246 & $4 / 21$ & $123 \cdot 0$ & .247 & & 3.97 & 5.0 & 35. & & S & 98.6 & YES \\
\hline 247 & $4 / 21$ & 123.0 & .247 & & 3.97 & 5.0 & 35. & & S & 97.5 & NO \\
\hline 248 & $4 / 21$ & $123 \cdot 0$ & .246 & & 3.97 & 5.0 & 35. & & $S$ & 98.1 & YES \\
\hline 249 & $4 / 21$ & 123.0 & .247 & & 3.97 & 5.0 & 35. & & s & 90.1 & YES \\
\hline 250 & $4 / 21$ & 123.0 & .247 & & 3.97 & 5.0 & 35. & & s & 98.1 & NO \\
\hline 251 & $4 / 22$ & 113.0 & .243 & & 4.16 & 5.0 & 35. & & S & 0.0 & NO \\
\hline 252 & $4 / 22$ & 113.0 & .247 & & 4.16 & 5.0 & 35. & & S & 0.0 & YES \\
\hline 253 & $4 / 22$ & 113.0 & .248 & & 4.16 & 5.0 & 35. & & S & 0.0 & NO \\
\hline 254 & $4 / 22$ & 113.0 & .250 & & 4.16 & 5.0 & 35. & & $s$ & 0.0 & YES \\
\hline 255 & $4 / 22$ & 113.0 & .240 & & 4.24 & 5.0 & 35. & & S & 0.0 & NO \\
\hline 256 & $4 / 22$ & 113.0 & .245 & & 4.20 & 5.0 & 35. & & $S$ & 0.0 & YES \\
\hline 257 & $4 / 22$ & 113.0 & .245 & & 4.13 & 5.0 & 35. & & s & 98.6 & NO \\
\hline 258 & $4 / 22$ & 113.0 & .246 & & 4.16 & 5.0 & 34 & & S & 97.5 & YES \\
\hline 259 & $4 / 22$ & 113.0 & .245 & & 4.16 & 5.0 & 35. & & s & 97.0 & NO \\
\hline 260 & $4 / 22$ & 113.0 & .244 & & 4.16 & 5.0 & 35. & & $\mathrm{~s}$ & 97.0 & YES \\
\hline 261 & $4 / 22$ & 113.0 & .245 & & 4.16 & 5.0 & 35. & & $S$ & 96.5 & NO \\
\hline 262 & $4 / 22$ & 113.0 & .245 & & 4.16 & 5.0 & 35. & & S & 96.5 & YES \\
\hline 263 & $4 / 25$ & $123 \cdot 0$ & .247 & & 5.22 & 5.0 & 35. & & $S$ & 63.2 & NO \\
\hline 264 & $4 / 25$ & 123.0 & .246 & & 4.24 & 5.0 & 35. & & s & 62.0 & NO \\
\hline
\end{tabular}


Tabie 7.4.1. General Test 2 (continued)

\begin{tabular}{|c|c|c|c|c|c|c|c|c|c|c|}
\hline $\begin{array}{c}\text { Run } \\
\text { Number }\end{array}$ & Time & Mix & $\mathrm{N}_{2}$ & $\mathrm{CH}_{4}$ & $\mathrm{C}_{2} \mathrm{H}_{6}$ & $\mathrm{C}_{3} \mathrm{H}_{8}$ & ${ }^{i C_{4}} \mathrm{H}_{10}$ & $\mathrm{nC}_{4} \mathrm{H}_{10}$ & $\begin{array}{l}\text { Heating } \\
\text { Value } \\
\mathrm{MJ} / \mathrm{m}^{3}\end{array}$ & $\begin{array}{r}\text { Density } \\
\mathrm{gm} / \mathrm{cm}^{3}\end{array}$ \\
\hline $\begin{array}{l}239 \\
239 \\
239 \\
240 \\
241\end{array}$ & $\begin{array}{r}1040 \\
903 \\
1025 \\
1056 \\
1119\end{array}$ & $\begin{array}{r}6 \\
106 \\
106 \\
6 \\
6\end{array}$ & $\begin{array}{l}.592 \\
.479 \\
.480 \\
.604 \\
.639\end{array}$ & $\begin{array}{l}85.782 \\
87.774 \\
87.917 \\
87.475 \\
87.927\end{array}$ & $\begin{array}{l}7.651 \\
6.674 \\
6.669 \\
6.734 \\
6.561\end{array}$ & $\begin{array}{l}4.393 \\
4.060 \\
4.019 \\
4.162 \\
3.953\end{array}$ & $\begin{array}{l}.602 \\
.431 \\
.427 \\
.442 \\
.394\end{array}$ & $\begin{array}{l}.980 \\
.533 \\
.588 \\
.584 \\
.526\end{array}$ & $\begin{array}{l}43.564 \\
42.662 \\
42.638 \\
42.700 \\
42.430\end{array}$ & $\begin{array}{l}.4623 \\
.4540 \\
.4538 \\
.4551 \\
.4530\end{array}$ \\
\hline $\begin{array}{l}242 \\
243 \\
244 \\
244 \\
245\end{array}$ & $\begin{array}{l}1134 \\
1149 \\
1205 \\
1326 \\
1342\end{array}$ & $\begin{array}{r}6 \\
6 \\
6 \\
106 \\
6\end{array}$ & $\begin{array}{l}.608 \\
.640 \\
.606 \\
.479 \\
.608\end{array}$ & $\begin{array}{l}87.724 \\
87.576 \\
87.652 \\
87.794 \\
87.696\end{array}$ & $\begin{array}{l}6.654 \\
6.769 \\
6.668 \\
6.672 \\
6.665\end{array}$ & $\begin{array}{l}4.021 \\
4.041 \\
4.048 \\
4.033 \\
4.022\end{array}$ & $\begin{array}{l}.421 \\
.418 \\
.436 \\
.432 \\
.428\end{array}$ & $\begin{array}{l}.573 \\
.554 \\
.590 \\
.591 \\
.582\end{array}$ & $\begin{array}{l}42.569 \\
42.583 \\
42.616 \\
42.654 \\
42.586\end{array}$ & $\begin{array}{l}.4540 \\
.4544 \\
.4544 \\
.4539 \\
.4542\end{array}$ \\
\hline $\begin{array}{l}246 \\
247 \\
248 \\
249 \\
250\end{array}$ & $\begin{array}{l}1357 \\
1415 \\
1431 \\
1453 \\
1508\end{array}$ & $\begin{array}{l}6 \\
6 \\
6 \\
6 \\
6\end{array}$ & $\begin{array}{l}.610 \\
.604 \\
.611 \\
.605 \\
.603\end{array}$ & $\begin{array}{l}87.627 \\
87.713 \\
87.843 \\
87.668 \\
87.669\end{array}$ & $\begin{array}{l}6.747 \\
6.657 \\
6.533 \\
6.659 \\
6.668\end{array}$ & $\begin{array}{l}4.012 \\
4.019 \\
4.011 \\
4.045 \\
4.039\end{array}$ & $\begin{array}{l}.424 \\
.427 \\
.425 \\
.431 \\
.434\end{array}$ & $\begin{array}{l}.580 \\
.580 \\
.577 \\
.592 \\
.582\end{array}$ & $\begin{array}{l}42.598 \\
42.582 \\
42.535 \\
42.610 \\
42.602\end{array}$ & $\begin{array}{r}.4543 \\
.4541 \\
.4537 \\
.4543 \\
.4543\end{array}$ \\
\hline $\begin{array}{l}251 \\
251 \\
252 \\
253 \\
254\end{array}$ & $\begin{array}{l}1151 \\
1132 \\
1207 \\
1222 \\
1242\end{array}$ & $\begin{array}{r}6 \\
106 \\
6 \\
6 \\
6\end{array}$ & $\begin{array}{l}.602 \\
.477 \\
.613 \\
.600 \\
.538\end{array}$ & $\begin{array}{l}87.650 \\
87.824 \\
87.419 \\
87.587 \\
88.876\end{array}$ & $\begin{array}{l}6.706 \\
6.658 \\
6.598 \\
6.703 \\
6.667\end{array}$ & $\begin{array}{l}4.058 \\
4.028 \\
4.195 \\
4.068 \\
3.393\end{array}$ & $\begin{array}{l}.422 \\
.431 \\
.472 \\
.441 \\
.246\end{array}$ & $\begin{array}{l}.562 \\
.583 \\
.703 \\
.601 \\
.281\end{array}$ & $\begin{array}{l}42.599 \\
42.641 \\
42.802 \\
42.653 \\
41.852\end{array}$ & $\begin{array}{r}.4684 \\
.4680 \\
.4700 \\
.4688 \\
.4619\end{array}$ \\
\hline $\begin{array}{l}255 \\
256 \\
256 \\
257 \\
258\end{array}$ & $\begin{array}{l}1301 \\
1318 \\
1334 \\
1359 \\
1419\end{array}$ & $\begin{array}{r}6 \\
6 \\
106 \\
6 \\
6\end{array}$ & $\begin{array}{l}.599 \\
.665 \\
.477 \\
.601 \\
.603\end{array}$ & $\begin{array}{l}87.574 \\
88.716 \\
87.838 \\
87.698 \\
87.798\end{array}$ & $\begin{array}{l}6.744 \\
6.627 \\
6.643 \\
6.660 \\
6.601\end{array}$ & $\begin{array}{l}4.081 \\
3.215 \\
4.032 \\
4.023 \\
3.999\end{array}$ & $\begin{array}{l}.430 \\
.325 \\
.436 \\
.430 \\
.427\end{array}$ & $\begin{array}{l}.573 \\
.449 \\
.580 \\
.588 \\
.572\end{array}$ & $\begin{array}{l}42.640 \\
41.903 \\
42.635 \\
42.595 \\
42.548\end{array}$ & $\begin{array}{r}.4687 \\
.4630 \\
.4679 \\
.4683 \\
.4679\end{array}$ \\
\hline $\begin{array}{l}258 \\
259 \\
260 \\
261 \\
261\end{array}$ & $\begin{array}{l}1436 \\
1519 \\
1502 \\
1559 \\
1617\end{array}$ & $\begin{array}{r}106 \\
6 \\
6 \\
6 \\
6\end{array}$ & $\begin{array}{l}.480 \\
.601 \\
.598 \\
.602 \\
.604\end{array}$ & $\begin{array}{l}87.864 \\
87.731 \\
87.495 \\
87.715 \\
87.688\end{array}$ & $\begin{array}{l}6.634 \\
6.643 \\
6.767 \\
6.656 \\
6.672\end{array}$ & $\begin{array}{l}4.015 \\
4.015 \\
4.120 \\
4.022 \\
4.026\end{array}$ & $\begin{array}{l}.430 \\
.427 \\
.436 \\
.427 \\
.430\end{array}$ & $\begin{array}{l}.578 \\
.583 \\
.585 \\
.579 \\
.580\end{array}$ & $\begin{array}{l}42.620 \\
42.579 \\
42.684 \\
42.583 \\
42.592\end{array}$ & $\begin{array}{r}.4678 \\
.4682 \\
.4690 \\
.4682 \\
.4683\end{array}$ \\
\hline $\begin{array}{l}261 \\
261 \\
262 \\
263 \\
264\end{array}$ & $\begin{array}{l}1634 \\
1651 \\
1536 \\
1153 \\
1425\end{array}$ & $\begin{array}{r}106 \\
106 \\
6 \\
6 \\
6\end{array}$ & $\begin{array}{l}.481 \\
.481 \\
.597 \\
.600 \\
.600\end{array}$ & $\begin{array}{l}87.855 \\
87.822 \\
87.357 \\
87.662 \\
87.696\end{array}$ & $\begin{array}{l}6.630 \\
6.638 \\
6.854 \\
6.656 \\
6.661\end{array}$ & $\begin{array}{l}4.024 \\
4.037 \\
4.164 \\
4.063 \\
4.029\end{array}$ & $\begin{array}{l}.429 \\
.434 \\
.439 \\
.433 \\
.431\end{array}$ & $\begin{array}{l}.582 \\
.588 \\
.589 \\
.586 \\
.583\end{array}$ & $\begin{array}{l}42.626 \\
42.645 \\
42.740 \\
42.618 \\
42.596\end{array}$ & $\begin{array}{l}.4678 \\
.4680 \\
.4695 \\
.4544 \\
.4542\end{array}$ \\
\hline
\end{tabular}


Table 7.4.1. General Test 3

\begin{tabular}{|c|c|c|c|c|c|c|c|c|c|c|c|c|}
\hline $\begin{array}{c}\text { RUN } \\
\text { NUMBER }\end{array}$ & DATE & $\begin{array}{c}\text { TEMPERATURE } \\
K\end{array}$ & $\begin{array}{l}\text { PRESSURE } \\
\text { MPA }\end{array}$ & LNG & $\begin{array}{l}\text { FLOW } \\
\text { LPM }\end{array}$ & RATE & $\begin{array}{l}\text { SAMPLING } \\
\text { RATE, SLPM }\end{array}$ & $\begin{array}{r}\text { DELIA } \\
\text { KPA }\end{array}$ & $P$ & PROBE & $\begin{array}{l}\text { VAPORIZER } \\
\text { POWER, WATTS }\end{array}$ & $\begin{array}{l}\text { PROBE HEA } \\
\text { POWER, WAT }\end{array}$ \\
\hline $\begin{array}{l}265 \\
266 \\
267 \\
208 \\
269\end{array}$ & $\begin{array}{l}4 / 25 \\
4 / 25 \\
4 / 25 \\
4 / 25 \\
4 / 26\end{array}$ & $\begin{array}{l}123.0 \\
123.0 \\
123.0 \\
123.0 \\
123.0\end{array}$ & $\begin{array}{l}.245 \\
.246 \\
.245 \\
.245 \\
.244\end{array}$ & & $\begin{array}{l}4.20 \\
4.20 \\
4.20 \\
4.20 \\
4.16\end{array}$ & & $\begin{array}{l}5.0 \\
5.0 \\
5.0 \\
5.0 \\
5.0\end{array}$ & $\begin{array}{l}35 . \\
35 \\
35 \\
35 \\
35\end{array}$ & & $\begin{array}{l}S \\
S \\
S \\
S \\
P\end{array}$ & $\begin{array}{l}62.0 \\
62.0 \\
62.0 \\
62.0 \\
62.8\end{array}$ & $\begin{array}{r}.1 \\
.4 \\
1.7 \\
6.7 \\
0.0\end{array}$ \\
\hline $\begin{array}{l}27: \\
271 \\
272 \\
273 \\
274\end{array}$ & $\begin{array}{l}4 / 26 \\
4 / 26 \\
4 / 26 \\
4 / 26 \\
4 / 26\end{array}$ & $\begin{array}{l}123 . v \\
123 . v \\
123.0 \\
123.0 \\
\$ 23 . v\end{array}$ & $\begin{array}{l}.244 \\
.244 \\
.244 \\
.244 \\
.244\end{array}$ & & $\begin{array}{l}4.16 \\
4.16 \\
4.16 \\
4.16 \\
4.16\end{array}$ & & $\begin{array}{l}5.0 \\
5.0 \\
5.0 \\
5.0 \\
5.0\end{array}$ & $\begin{array}{l}35 . \\
35 \\
35 \\
35 \\
35\end{array}$ & & $\begin{array}{l}P \\
P \\
P \\
P \\
P\end{array}$ & $\begin{array}{l}62.0 \\
62.0 \\
\epsilon 2.0 \\
62.0 \\
62.0\end{array}$ & $\begin{array}{r}.1 \\
.4 \\
1.0 \\
1.7 \\
3.8\end{array}$ \\
\hline $\begin{array}{l}275 \\
299 \\
300 \\
3 ن 1 \\
302\end{array}$ & $\begin{array}{l}4 / 26 \\
4 / 29 \\
4 / 29 \\
4 / 29 \\
4 / 29\end{array}$ & $\begin{array}{l}123 \cdot v \\
123 \cdot 0 \\
123.0 \\
123.6 \\
123.0\end{array}$ & $\begin{array}{l}.244 \\
.244 \\
.244 \\
.244 \\
.244\end{array}$ & & $\begin{array}{l}4.16 \\
4.16 \\
4.16 \\
4.16 \\
4.16\end{array}$ & & $\begin{array}{l}5.0 \\
5.0 \\
5.0 \\
5.0 \\
5.0\end{array}$ & $\begin{array}{l}35 . \\
35 . \\
35 . \\
35 \\
35\end{array}$ & & $\begin{array}{l}P \\
P \\
P \\
P \\
P\end{array}$ & $\begin{array}{l}62.0 \\
62.8 \\
62.4 \\
62.4 \\
62.4\end{array}$ & $\begin{array}{l}6.7 \\
0.0 \\
0.0 \\
0.3 \\
0.0\end{array}$ \\
\hline $\begin{array}{l}303 \\
364 \\
345 \\
366 \\
357\end{array}$ & $\begin{array}{l}4 / 29 \\
4 / 29 \\
4 / 29 \\
4 / 29 \\
4 / 29\end{array}$ & $\begin{array}{l}123 \cdot 0 \\
123 \cdot 6 \\
1<3.6 \\
123.6 \\
1<3.6\end{array}$ & $\begin{array}{l}.243 \\
.244 \\
.243 \\
.244 \\
.243\end{array}$ & & $\begin{array}{l}4.16 \\
4.16 \\
4.13 \\
4.13 \\
4.13\end{array}$ & & $\begin{array}{l}5.0 \\
5.0 \\
5.0 \\
5.0 \\
5.0\end{array}$ & $\begin{array}{l}35 . \\
35 . \\
35 . \\
35 \\
35\end{array}$ & & $\begin{array}{l}P \\
P \\
P \\
P \\
P\end{array}$ & $\begin{array}{l}62.4 \\
62.4 \\
62.4 \\
62.4 \\
62.4\end{array}$ & $\begin{array}{l}0.0 \\
0.0 \\
0.0 \\
0.0 \\
0.0\end{array}$ \\
\hline $\begin{array}{l}308 \\
309 \\
316\end{array}$ & $\begin{array}{l}4 / 29 \\
4 / 29 \\
4 / 29\end{array}$ & $\begin{array}{l}1<3 . i \\
123.0 \\
123 . i\end{array}$ & $\begin{array}{l}.244 \\
.244 \\
.243\end{array}$ & & $\begin{array}{l}4.13 \\
4.16 \\
4.16\end{array}$ & & $\begin{array}{l}5.0 \\
5.0 \\
5.0\end{array}$ & $\begin{array}{l}35 \\
35 \\
35\end{array}$ & & $\begin{array}{l}P \\
P \\
P\end{array}$ & $\begin{array}{l}62.4 \\
62.4 \\
62.4\end{array}$ & $\begin{array}{l}0.0 \\
0.0 \\
0.0\end{array}$ \\
\hline
\end{tabular}


Table 7.4.1. General Test 3 (continued)

\begin{tabular}{|c|c|c|c|c|c|c|c|c|c|c|}
\hline $\begin{array}{c}\text { Run } \\
\text { Number }\end{array}$ & Time & Mix & $\mathrm{N}_{2}$ & $\mathrm{CH}_{4}$ & $\mathrm{C}_{2} \mathrm{H}_{6}$ & $\mathrm{C}_{3} \mathrm{H}_{8}$ & $i_{4} \mathrm{H}_{10}$ & $\mathrm{nC}_{4} \mathrm{H}_{10}$ & $\begin{array}{c}\text { Heating } \\
\text { Value } \\
\mathrm{MJ} / \mathrm{m}^{3}\end{array}$ & $\begin{array}{c}\text { Density } \\
\mathrm{gm} / \mathrm{cm}^{3}\end{array}$ \\
\hline $\begin{array}{l}265 \\
266 \\
267 \\
268 \\
268\end{array}$ & $\begin{array}{l}1443 \\
1459 \\
1518 \\
1534 \\
1552\end{array}$ & $\begin{array}{r}6 \\
6 \\
6 \\
6 \\
146\end{array}$ & $\begin{array}{l}.00 J \\
.601 \\
.597 \\
.011 \\
.477\end{array}$ & $\begin{array}{l}87.680 \\
87.691 \\
87.705 \\
87.694 \\
87.836\end{array}$ & $\begin{array}{l}6.669 \\
6.082 \\
0.662 \\
0.679 \\
0.645\end{array}$ & $\begin{array}{l}4.033 \\
4.016 \\
4.031 \\
4.021 \\
4.032\end{array}$ & $\begin{array}{l}.429 \\
.429 \\
.428 \\
.426 \\
.429\end{array}$ & $\begin{array}{l}.589 \\
.581 \\
.578 \\
.580 \\
.584\end{array}$ & $\begin{array}{l}42.491 \\
42.478 \\
42.478 \\
42.476 \\
42.524\end{array}$ & $\begin{array}{l}.4542 \\
.4541 \\
.4541 \\
.4541 \\
.4538\end{array}$ \\
\hline $\begin{array}{l}268 \\
265 \\
269 \\
269 \\
270\end{array}$ & $\begin{array}{r}15 \cup 4 \\
1.26 \\
y 43 \\
959 \\
1048\end{array}$ & $\begin{array}{r}106 \\
6 \\
106 \\
100 \\
6\end{array}$ & $\begin{array}{l}.473 \\
.597 \\
.477 \\
.478 \\
.598\end{array}$ & $\begin{array}{l}87.618 \\
87.671 \\
87.626 \\
87.824 \\
87.692\end{array}$ & $\begin{array}{l}6.672 \\
6.675 \\
6.663 \\
0.650 \\
6.689\end{array}$ & $\begin{array}{l}4.023 \\
4.1547 \\
4.023 \\
4.030 \\
4.019\end{array}$ & $\begin{array}{l}.428 \\
.433 \\
.436 \\
.429 \\
.427\end{array}$ & $\begin{array}{l}.581 \\
.576 \\
.582 \\
.578 \\
.575\end{array}$ & $\begin{array}{l}42.524 \\
42.495 \\
42.524 \\
42.525 \\
42.476\end{array}$ & $\begin{array}{l}.4538 \\
.4543 \\
.4538 \\
.4538 \\
.4541\end{array}$ \\
\hline $\begin{array}{l}271 \\
272 \\
272 \\
273 \\
274\end{array}$ & $\begin{array}{l}1164 \\
1165 \\
1143 \\
1159 \\
1217\end{array}$ & $\begin{array}{r}6 \\
\dot{c} \\
10 c \\
6 \\
6\end{array}$ & $\begin{array}{r}.593 \\
.597 \\
.077 \\
.599 \\
.599\end{array}$ & $\begin{array}{l}87.409 \\
87.092 \\
87.794 \\
87.7 \cup 6 \\
87.7 \cup 6\end{array}$ & $\begin{array}{l}6.825 \\
6.678 \\
6.693 \\
6.685 \\
6.673\end{array}$ & $\begin{array}{l}4.140 \\
4.021 \\
4.021 \\
4.010 \\
4.017\end{array}$ & $\begin{array}{l}.440 \\
.429 \\
.433 \\
.427 \\
.420\end{array}$ & $\begin{array}{l}.593 \\
.583 \\
.583 \\
.574 \\
.570\end{array}$ & $\begin{array}{l}42.61 \hat{\imath} \\
4 \hat{2} .483 \\
42.535 \\
42.468 \\
42.473\end{array}$ & $\begin{array}{r}.4552 \\
.4542 \\
.4539 \\
.4541 \\
.4541\end{array}$ \\
\hline $\begin{array}{l}275 \\
299 \\
249 \\
340 \\
341\end{array}$ & $\begin{array}{r}1233 \\
937 \\
922 \\
953 \\
i 611\end{array}$ & $\begin{array}{r}6 \\
6 \\
136 \\
6 \\
6\end{array}$ & $\begin{array}{l}.0 \mathrm{~J} \\
.593 \\
.477 \\
.530 \\
.588\end{array}$ & $\begin{array}{l}87.710 \\
87.595 \\
87.817 \\
37.680 \\
87.610\end{array}$ & $\begin{array}{l}6.662 \\
0.690 \\
0.602 \\
6.685 \\
6.729\end{array}$ & $\begin{array}{l}4.018 \\
4.088 \\
4.029 \\
4.038 \\
4.056\end{array}$ & $\begin{array}{l}.432 \\
.437 \\
.432 \\
.427 \\
.434\end{array}$ & $\begin{array}{l}.578 \\
.595 \\
.583 \\
.582 \\
.583\end{array}$ & $\begin{array}{l}+2.473 \\
42.545 \\
42.530 \\
42.495 \\
+2.524\end{array}$ & $\begin{array}{r}.4541 \\
.4546 \\
.4538 \\
.4542 \\
.4545\end{array}$ \\
\hline $\begin{array}{l}301 \\
302 \\
303 \\
304 \\
365\end{array}$ & $\begin{array}{l}1030 \\
1049 \\
1108 \\
1125 \\
1341\end{array}$ & $\begin{array}{l}0 \\
b \\
6 \\
E \\
E\end{array}$ & $\begin{array}{l}.592 \\
.589 \\
.592 \\
.593 \\
.587\end{array}$ & $\begin{array}{l}87.590 \\
87.617 \\
87.675 \\
87.649 \\
87.601\end{array}$ & $\begin{array}{l}6.715 \\
6.706 \\
0.678 \\
0.689 \\
0.729\end{array}$ & $\begin{array}{l}4.080 \\
4.065 \\
4.043 \\
4.056 \\
4.070\end{array}$ & $\begin{array}{l}.431 \\
.433 \\
.436 \\
.432 \\
.431\end{array}$ & $\begin{array}{r}.584 \\
.590 \\
.583 \\
.584 \\
.582\end{array}$ & $\begin{array}{l}42.530 \\
42.527 \\
42.497 \\
42.511 \\
42.529\end{array}$ & $\begin{array}{r}.4545 \\
.4545 \\
.4543 \\
.4544 \\
.4545\end{array}$ \\
\hline $\begin{array}{l}365 \\
366 \\
307 \\
3 i 7 \\
306\end{array}$ & $\begin{array}{l}1319 \\
1359 \\
14: 8 \\
1437 \\
1454\end{array}$ & $\begin{array}{r}106 \\
6 \\
6 \\
6 \\
6\end{array}$ & $\begin{array}{l}.478 \\
.593 \\
.591 \\
.592 \\
.588\end{array}$ & $\begin{array}{l}87.794 \\
87.646 \\
87.56 u \\
87.614 \\
87.666\end{array}$ & $\begin{array}{l}0.679 \\
0.698 \\
6.708 \\
0.083 \\
6.684\end{array}$ & $\begin{array}{l}4.030 \\
4.051 \\
4.087 \\
4.086 \\
4.047\end{array}$ & $\begin{array}{l}.431 \\
.431 \\
.437 \\
.436 \\
.432\end{array}$ & $\begin{array}{l}.509 \\
.584 \\
.597 \\
.590 \\
.584\end{array}$ & $\begin{array}{l}42.539 \\
42.510 \\
42.549 \\
42.534 \\
42.505\end{array}$ & $\begin{array}{r}.4539 \\
.4544 \\
.4547 \\
.4546 \\
.4543\end{array}$ \\
\hline $\begin{array}{l}30 y \\
3: 0 \\
310\end{array}$ & $\begin{array}{l}25.5 \\
1531 \\
1549\end{array}$ & $\begin{array}{r}c \\
\varepsilon \\
156\end{array}$ & $\begin{array}{l}.591 \\
.590 \\
.481\end{array}$ & $\begin{array}{l}87.667 \\
87.687 \\
87.822\end{array}$ & $\begin{array}{l}0.683 \\
6.668 \\
0.6+8\end{array}$ & $\begin{array}{l}4.040 \\
4.044 \\
4.032\end{array}$ & $\begin{array}{l}.432 \\
.430 \\
.433\end{array}$ & $\begin{array}{r}.587 \\
.581 \\
.584\end{array}$ & $\begin{array}{l}42.503 \\
42.494 \\
42.528\end{array}$ & $\begin{array}{l}.4543 \\
.4542 \\
.4538\end{array}$ \\
\hline
\end{tabular}


Table 7.4.1. General Test 4

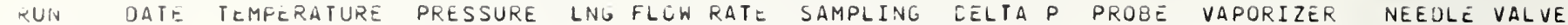
NUMBEK K MPA LPM RATE, SLFM KFA

\begin{tabular}{|c|c|c|c|c|}
\hline$\angle 70^{\circ}$ & $4 / 20$ & $1<3 . j$ & .244 & 4.10 \\
\hline 277 & $4 / 20$ & $=43.0$ & .244 & 4.13 \\
\hline $27 \%$ & $4 / 20$ & $1=3.6$ & .244 & 4.16 \\
\hline 279 & $4 / 20$ & $1: 3 . j$ & .244 & 4.16 \\
\hline 200 & 4126 & 123.0 & .244 & 4.16 \\
\hline$<81$ & +127 & $1<3.4$ & .244 & 4.16 \\
\hline 282 & -127 & $1<3.0$ & .244 & $-.2 \bar{u}$ \\
\hline 283 & $4 / 27$ & 123.0 & .243 & 4.16 \\
\hline 284 & -127 & $i<3.0$ & .243 & 4.16 \\
\hline 205 & $4 / 27$ & $1<3.1$ & .244 & 4.16 \\
\hline 280 & $4 / 27$ & 123.0 & .254 & $+.1 E$ \\
\hline 287 & $4 / 27$ & 123.4 & .244 & 4.16 \\
\hline 235 & $4 / 27$ & 123.0 & .243 & 4.10 \\
\hline $20 y$ & $4 / 27$ & $1<3 . j$ & .244 & 4.16 \\
\hline 290 & $+/ 27$ & $1<3 . i$ & .244 & 4.16 \\
\hline$\therefore 91$ & $4 / 27$ & 123.0 & .243 & 4.20 \\
\hline 292 & $4 / 27$ & 123.6 & .243 & 4.20 \\
\hline 311 & $5 / 42$ & 123.0 & .242 & 4.16 \\
\hline 312 & $5 / 32$ & 123.0 & .242 & 4.13 \\
\hline 313 & $5 / 02$ & 123.0 & .242 & 4.13 \\
\hline 314 & $5 / \cup 2$ & 163.0 & .243 & 4.13 \\
\hline $3: 5$ & $5 / 02$ & $1<3 . j$ & .242 & 4.13 \\
\hline 316 & $5 / 02$ & $1<3.0$ & .242 & 4.13 \\
\hline 317 & $5 / 02$ & 123.0 & .242 & 4.16 \\
\hline 310 & $5 / \overline{2}$ & 123. & .242 & 4.13 \\
\hline 319 & $5 / 02$ & 123.0 & .242 & 4.13 \\
\hline $32 v$ & $5 / 02$ & $1<3.0$ & .242 & 4.13 \\
\hline 321 & $5 / 02$ & $123 \cdot \bar{u}$ & .242 & 4.13 \\
\hline
\end{tabular}

4.10

.16

4.16

. 16

4.16

$+.11$

4.16

4.16

4.16

$5.0 \quad 35$.

5.0

35.

5.0

35.

5.0

5.3

35. FOWER, WATTS

THROT TLED

4.13
4.13

5.0

b. 0

$5 . \mathrm{J}$

5.3

5.0

35.

35.

35.

35.

35.

5.0

5.0

5.0

5.0

35

$$
35 .
$$

35.

5.0

35.

\section{0}

5.0

4.9

4.9
4.9

35.

35 .

35.

35.

62.0
62.0
62.0
62.0

E2. 4

YES

NO

YES

NO

62.4

62.4

62.4

62.4

62.4

NO

YES

HO

YES

62.0

NO

YES

62.4

62.4

62.4

62.4

YES

NO

YES

62.4

62.4

62.4
62.4

62.4

NO

YES

NO

NO

\section{0}

4.9

35.

4.9

4.9

35.

62.4

NO

NO

62.4

62.4

62.8

62.8

NO

NO

4.9

35.

4.9
4.9

35.

62.8

62.8

62.8 
Table 7.4.1. General Test 4 (continued)

\begin{tabular}{|c|c|c|c|c|c|c|c|c|c|c|}
\hline $\begin{array}{c}\text { Run } \\
\text { Number }\end{array}$ & Time & $\operatorname{Mix}$ & $\mathrm{N}_{2}$ & $\mathrm{CH}_{4}$ & $\mathrm{C}_{2} \mathrm{H}_{5}$ & $\mathrm{C}_{3} \mathrm{H}_{8}$ & $i_{4} \mathrm{C}_{4}{ }_{10}$ & $\mathrm{nC}_{4} \mathrm{H}_{10}$ & $\begin{array}{l}\text { Value } \\
\mathrm{MJ} / \mathrm{m}^{3}\end{array}$ & $\begin{array}{c}\text { Density } \\
\mathrm{gm} / \mathrm{cm}^{3}\end{array}$ \\
\hline $\begin{array}{l}<76 \\
277 \\
278 \\
279 \\
280\end{array}$ & $\begin{array}{l}1+1 j \\
1+54 \\
15 j 9 \\
1525 \\
1544\end{array}$ & $\begin{array}{l}\varepsilon \\
6 \\
6 \\
\epsilon \\
6\end{array}$ & $\begin{array}{l}.593 \\
.596 \\
.597 \\
.590 \\
.598\end{array}$ & $\begin{array}{l}87.715 \\
87.675 \\
87.712 \\
87.7+2 \\
87.701\end{array}$ & $\begin{array}{l}0.666 \\
6.687 \\
6.604 \\
0.601 \\
6.670\end{array}$ & $\begin{array}{l}4.014 \\
4.029 \\
4.024 \\
4.002 \\
4.024\end{array}$ & $\begin{array}{l}.429 \\
.432 \\
.427 \\
.428 \\
.433\end{array}$ & $\begin{array}{l}.579 \\
.582 \\
.576 \\
.571 \\
.574\end{array}$ & $\begin{array}{l}42.471 \\
42.491 \\
4 \hat{c} .473 \\
42.457 \\
42.478\end{array}$ & $\begin{array}{r}.4541 \\
.4542 \\
.4541 \\
.4539 \\
.4541\end{array}$ \\
\hline $\begin{array}{l}280 \\
200 \\
281 \\
28 c \\
203\end{array}$ & $\begin{array}{r}1006 \\
2022 \\
926 \\
1011 \\
1026\end{array}$ & $\begin{array}{r}1 \cup 6 \\
1 \cup 6 \\
t \\
6 \\
0\end{array}$ & $\begin{array}{l}.487 \\
.483 \\
.295 \\
.596 \\
.594\end{array}$ & $\begin{array}{l}87.856 \\
87.035 \\
87.584 \\
87.715 \\
87.606\end{array}$ & $\begin{array}{l}0.648 \\
6.059 \\
0.700 \\
6.672 \\
6.680\end{array}$ & $\begin{array}{l}3.999 \\
4.014 \\
4.083 \\
4.015 \\
4.032\end{array}$ & $\begin{array}{l}.431 \\
.433 \\
.441 \\
.427 \\
.429\end{array}$ & $\begin{array}{l}.580 \\
.581 \\
.598 \\
.574 \\
.580\end{array}$ & $\begin{array}{l}42.502 \\
+2.518 \\
+2.547 \\
42.469 \\
42.488\end{array}$ & $\begin{array}{r}.4536 \\
.4538 \\
.4547 \\
.4540 \\
.4542\end{array}$ \\
\hline $\begin{array}{l}284 \\
285 \\
285 \\
235 \\
286\end{array}$ & $\begin{array}{l}1041 \\
1050 \\
1312 \\
1327 \\
1342\end{array}$ & $\begin{array}{r}c \\
t \\
106 \\
10 t \\
t\end{array}$ & $\begin{array}{l}.594 \\
.593 \\
.481 \\
.476 \\
.594\end{array}$ & $\begin{array}{l}87.659 \\
87.092 \\
87.823 \\
87.838 \\
87.669\end{array}$ & $\begin{array}{l}6.697 \\
0.075 \\
6.663 \\
6.647 \\
6.697\end{array}$ & $\begin{array}{l}4.144 \\
4.033 \\
4.023 \\
4.025 \\
4.022\end{array}$ & $\begin{array}{l}.426 \\
.427 \\
.431 \\
.433 \\
.428\end{array}$ & $\begin{array}{l}.580 \\
.580 \\
.579 \\
.581 \\
.590\end{array}$ & $\begin{array}{l}42.497 \\
42.480 \\
42.522 \\
42.523 \\
42.495\end{array}$ & $\begin{array}{l}.4543 \\
.4542 \\
.4538 \\
.4538 \\
.4542\end{array}$ \\
\hline $\begin{array}{l}287 \\
208 \\
259 \\
293 \\
291\end{array}$ & $\begin{array}{l}1+11 \\
1416 \\
1435 \\
i 456 \\
1010\end{array}$ & $\begin{array}{l}0 \\
6 \\
6 \\
6 \\
6\end{array}$ & $\begin{array}{l}.590 \\
.595 \\
.590 \\
.595 \\
.593\end{array}$ & $\begin{array}{l}87.691 \\
87.701 \\
37.076 \\
87.706 \\
87.716\end{array}$ & $\begin{array}{l}6.079 \\
6.675 \\
6.687 \\
6.670 \\
6.673\end{array}$ & $\begin{array}{l}4.030 \\
4.028 \\
4.029 \\
4.023 \\
4.023\end{array}$ & $\begin{array}{l}.425 \\
.428 \\
.431 \\
.425 \\
.426\end{array}$ & $\begin{array}{l}.579 \\
.573 \\
.581 \\
.582 \\
.572\end{array}$ & $\begin{array}{l}42.482 \\
42.477 \\
42.490 \\
42.478 \\
42.471\end{array}$ & $\begin{array}{r}.4541 \\
.4541 \\
.4542 \\
.4541 \\
.4540\end{array}$ \\
\hline $\begin{array}{l}692 \\
292 \\
311 \\
311 \\
311\end{array}$ & $\begin{array}{r}1527 \\
1543 \\
1046 \\
939 \\
750\end{array}$ & $\begin{array}{r}6 \\
106 \\
6 \\
106 \\
106\end{array}$ & $\begin{array}{l}.593 \\
.477 \\
.554 \\
.478 \\
.475\end{array}$ & $\begin{array}{l}87.734 \\
57.768 \\
37.630 \\
87.806 \\
87.809\end{array}$ & $\begin{array}{l}0.651 \\
6.672 \\
0.754 \\
6.677 \\
6.669\end{array}$ & $\begin{array}{l}4.015 \\
4.065 \\
4.078 \\
4.028 \\
4.031\end{array}$ & $\begin{array}{l}.427 \\
.432 \\
.437 \\
.428 \\
.429\end{array}$ & $\begin{array}{l}.581 \\
.586 \\
.597 \\
.584 \\
.587\end{array}$ & $\begin{array}{l}42.469 \\
42.556 \\
42.557 \\
42.531 \\
42.535\end{array}$ & $\begin{array}{r}.4540 \\
.4540 \\
.4545 \\
.4538 \\
.4538\end{array}$ \\
\hline $\begin{array}{l}312 \\
313 \\
314 \\
315 \\
316\end{array}$ & $\begin{array}{l}11 \cup 2 \\
11<2 \\
1140 \\
11=6 \\
1215\end{array}$ & $\begin{array}{l}6 \\
6 \\
6 \\
6 \\
6\end{array}$ & $\begin{array}{l}.557 \\
.555 \\
.554 \\
.555 \\
.557\end{array}$ & $\begin{array}{l}87.66 J \\
87.656 \\
87.655 \\
87.662 \\
87.690\end{array}$ & $\begin{array}{l}6.714 \\
6.716 \\
6.727 \\
6.716 \\
6.692\end{array}$ & $\begin{array}{l}4.049 \\
4.046 \\
4.053 \\
4.052 \\
4.054\end{array}$ & $\begin{array}{l}.431 \\
.435 \\
.429 \\
.430 \\
.429\end{array}$ & $\begin{array}{l}.589 \\
.592 \\
.583 \\
.585 \\
.578\end{array}$ & $\begin{array}{l}42.530 \\
42.536 \\
42.530 \\
42.529 \\
42.516\end{array}$ & $\begin{array}{r}.4543 \\
.4544 \\
.4543 \\
.4543 \\
.4542\end{array}$ \\
\hline $\begin{array}{l}316 \\
317 \\
317 \\
318 \\
319\end{array}$ & $\begin{array}{l}1335 \\
1407 \\
1426 \\
1443 \\
1501\end{array}$ & $\begin{array}{r}146 \\
6 \\
\epsilon \\
6 \\
6\end{array}$ & $\begin{array}{l}.473 \\
.558 \\
.554 \\
.555 \\
.556\end{array}$ & $\begin{array}{l}87.815 \\
87.654 \\
87.683 \\
37.663 \\
87.625\end{array}$ & $\begin{array}{l}6.668 \\
6.720 \\
6.701 \\
6.714 \\
6.719\end{array}$ & $\begin{array}{l}4.026 \\
4.053 \\
4.052 \\
4.055 \\
4.086\end{array}$ & $\begin{array}{l}.430 \\
.431 \\
.429 \\
.436 \\
.431\end{array}$ & $\begin{array}{l}.589 \\
.585 \\
.581 \\
.583 \\
.584\end{array}$ & $\begin{array}{l}42.535 \\
42.530 \\
42.521 \\
42.529 \\
42.548\end{array}$ & $\begin{array}{r}.4538 \\
.4543 \\
.4542 \\
.4543 \\
.4545\end{array}$ \\
\hline $\begin{array}{l}320 \\
321 \\
321 \\
321 \\
321\end{array}$ & $\begin{array}{l}1517 \\
1534 \\
1550 \\
1609 \\
1636\end{array}$ & $\begin{array}{r}6 \\
6 \\
6 \\
106 \\
106\end{array}$ & $\begin{array}{l}.554 \\
.555 \\
.553 \\
.477 \\
.480\end{array}$ & $\begin{array}{l}87.668 \\
87.620 \\
87.630 \\
67.809 \\
87.876\end{array}$ & $\begin{array}{l}6.706 \\
6.719 \\
6.736 \\
6.666 \\
6.622\end{array}$ & $\begin{array}{l}4.061 \\
4.085 \\
4.064 \\
4.032 \\
4.017\end{array}$ & $\begin{array}{l}.431 \\
.431 \\
.431 \\
.431 \\
.428\end{array}$ & $\begin{array}{l}.580 \\
.590 \\
.586 \\
.585 \\
.578\end{array}$ & $\begin{array}{l}42.528 \\
42.554 \\
42.544 \\
42.534 \\
42.503\end{array}$ & $\begin{array}{r}.4543 \\
.4545 \\
.4544 \\
.4539 \\
.4536\end{array}$ \\
\hline
\end{tabular}


Table 7.4.1. General Test 5

\begin{tabular}{|c|c|c|c|c|c|c|c|c|c|c|c|}
\hline $\begin{array}{c}\text { RUN } \\
\text { NUMBER }\end{array}$ & DATE & $\begin{array}{c}\text { TEMPERATURE } \\
K\end{array}$ & $\begin{array}{l}\text { PRESSURE } \\
\text { MPA }\end{array}$ & LNG & $\begin{array}{l}\text { FLOW RATE } \\
\text { LPM }\end{array}$ & $\begin{array}{l}\text { SAMPLING } \\
\text { RATE, SLPM }\end{array}$ & $\begin{array}{r}\text { OELTA } \\
\text { KPA }\end{array}$ & $P$ & PROBE & $\begin{array}{l}\text { VAPORIZER } \\
\text { POWER, WATTS }\end{array}$ & $\begin{array}{l}\text { ACCUM RESIDENCE } \\
\text { TIME, S }\end{array}$ \\
\hline $\begin{array}{l}293 \\
294 \\
295 \\
296 \\
297\end{array}$ & $\begin{array}{l}4 / 29 \\
4 / 28 \\
4 / 28 \\
4 / 28 \\
4 / 28\end{array}$ & $\begin{array}{l}112.0 \\
112.0 \\
112.0 \\
112.0 \\
112.0\end{array}$ & $\begin{array}{l}.116 \\
.116 \\
.116 \\
.117 \\
.116\end{array}$ & & $\begin{array}{l}1.97 \\
1.93 \\
1.93 \\
1.89 \\
1.89\end{array}$ & $\begin{array}{r}12.2 \\
8.6 \\
5.9 \\
12.2 \\
8.6\end{array}$ & $\begin{array}{l}56 . \\
56 . \\
56 . \\
55 . \\
55 .\end{array}$ & & $\begin{array}{l}S \\
S \\
S \\
S \\
S\end{array}$ & $\begin{array}{r}144.0 \\
120.4 \\
79.0 \\
160.0 \\
117.2\end{array}$ & $\begin{array}{l}10.5 \\
15.0 \\
21.8 \\
10.5 \\
15.0\end{array}$ \\
\hline 298 & $4 / 28$ & 112.0 & .117 & & 1.93 & 12.2 & 55. & & s & 160.0 & 10.5 \\
\hline
\end{tabular}


Table 7.4.1. General Test 5 (continued)

$\begin{array}{ccccccccccc}\begin{array}{c}\text { Run } \\ \text { Number }\end{array} & \text { Time } & \text { Mix } & \mathrm{N}_{2} & \mathrm{CH}_{4} & \mathrm{C}_{2} \mathrm{H}_{6} & \mathrm{C}_{3} \mathrm{H}_{8} & \mathrm{iC}_{4} \mathrm{H}_{10} & \mathrm{nC}_{4} \mathrm{H}_{10} & \begin{array}{c}\text { Heative } \\ \text { Value } \\ 293\end{array} \\ 1308 & 6 & .590 & 87.627 & 6.733 & 4.043 & .429 & .578 & 42.622 & .4698 \\ 294 & 1348 & 6 & .590 & 87.678 & 6.690 & 4.031 & .432 & .579 & 42.606 & .4696 \\ 295 & 1409 & 6 & .591 & 87.690 & 6.672 & 4.037 & .430 & .580 & 42.604 & .4696 \\ 296 & 1426 & 6 & .589 & 87.670 & 6.695 & 4.035 & .431 & .580 & 42.610 & .4697 \\ 297 & 1441 & 6 & .591 & 87.694 & 6.676 & 4.031 & .427 & .582 & 42.600 & .4696 \\ 298 & 1459 & 6 & .592 & 87.676 & 6.682 & 4.036 & .432 & .583 & 42.609 & .4697\end{array}$


Table 7.4.1. General Test 6

\begin{tabular}{|c|c|c|c|c|c|c|c|c|c|c|}
\hline $\begin{array}{c}\text { RUN } \\
\text { NUMBER }\end{array}$ & DATE & $\begin{array}{c}\text { TEMPERATURE } \\
K\end{array}$ & $\begin{array}{l}\text { PRESSURE } \\
\text { MPA }\end{array}$ & LNG & $\begin{array}{l}\text { FLOW RATE } \\
\text { LPM }\end{array}$ & $\begin{array}{l}\text { SAMPLING } \\
\text { RATE, SLPM }\end{array}$ & $\begin{array}{r}\text { DELTA } \\
\text { KPA }\end{array}$ & $P$ & PROBE & $\begin{array}{l}\text { VAPORIZER } \\
\text { POWER, WATTS }\end{array}$ \\
\hline 322 & $5 / 11$ & 123.5 & .222 & & $4 \cdot 16$ & 4.7 & 35. & & S & 62.4 \\
\hline 323 & $5 / 11$ & 123.5 & .222 & & 4.16 & 4.7 & 35. & & s & 62.4 \\
\hline 324 & $5 / 11$ & 123.5 & .222 & & 4.20 & 4.7 & 35. & & s & 62.4 \\
\hline 325 & $5 / 11$ & 123.5 & .222 & & 4.16 & 4.7 & 35. & & s & $\epsilon 2.4$ \\
\hline 326 & $5 / 11$ & 123.5 & .222 & & 4.09 & 4.7 & 35. & & 5 & 99.1 \\
\hline 327 & $5 / 11$ & 123.5 & .223 & & 4.13 & 4.7 & 35. & & $s$ & 99.1 \\
\hline 328 & $5 / 12$ & 121.5 & .222 & & 4.16 & 4.7 & 35. & & s & 99.1 \\
\hline 329 & $5 / 12$ & 121.5 & .222 & & 4.16 & 4.7 & 35. & & s & 99.1 \\
\hline 330 & $5 / 12$ & 121.5 & .223 & & 4.16 & 4.7 & 35. & & $S$ & 99.1 \\
\hline 331 & $5 / 12$ & $121 \cdot 5$ & .223 & & 4.16 & 4.7 & 35. & & S & 99.1 \\
\hline 332 & $5 / 12$ & 121.5 & .202 & & 4.28 & 4.5 & 36. & & $S$ & 62.4 \\
\hline 333 & $5 / 12$ & 121.5 & .222 & & 4.24 & 4.7 & 35. & & s & $\in 2.4$ \\
\hline 334 & $5 / 12$ & 121.5 & .223 & & 4.28 & 4.7 & 35. & & S & 62.4 \\
\hline 335 & $5 / 16$ & 120.0 & .276 & & $4.1 \epsilon$ & 5.3 & $3 E$. & & $S$ & $\in 2.3$ \\
\hline 336 & $5 / 16$ & 120.0 & $.270^{\circ}$ & & $4 \cdot 16$ & 5.3 & 35. & & S & 62.8 \\
\hline 337 & $5 / 16$ & 120.0 & .276 & & 4.16 & 5.3 & 34. & & $P$ & $E 2.8$ \\
\hline 338 & $5 / 16$ & 120.0 & .277 & & 4.16 & 5.3 & 34. & & $P$ & 62.8 \\
\hline 339 & $5 / 17$ & 120.0 & .277 & & 4.16 & 5.3 & 34. & & $P$ & $\epsilon 2.8$ \\
\hline 340 & $5 / 16$ & 120.0 & .277 & & 4.16 & 5.3 & 35 . & & $\mathrm{P}$ & 62.8 \\
\hline 341 & $5 / 16$ & 120.0 & .274 & & 4.16 & 5.3 & 35. & & P & E2. 8 \\
\hline
\end{tabular}


Table 7.4.1. General Test 6 (continued)

\begin{tabular}{|c|c|c|c|c|c|c|c|c|c|c|c|c|c|c|c|}
\hline $\begin{array}{l}\text { Run } \\
\text { Number }\end{array}$ & Time & Mix & $\mathrm{N}_{2}$ & $\mathrm{CH}_{4}$ & $\mathrm{C}_{2} \mathrm{H}_{6}$ & $\mathrm{C}_{3} \mathrm{H}_{8}$ & $i_{4} \mathrm{H}_{10}$ & $\mathrm{nC}_{4} \mathrm{H}_{10}$ & $i_{5}{ }^{H} 12$ & ${ }^{n C_{5}} \mathrm{H}_{12}$ & $C_{6}+$ & $\mathrm{CO}_{2}$ & $\mathrm{O}_{2}$ & $\begin{array}{l}\text { Value } \\
M J / m^{3}\end{array}$ & $\begin{array}{r}\text { Density } \\
\mathrm{gm} / \mathrm{cm}^{3}\end{array}$ \\
\hline $\begin{array}{l}322 \\
323 \\
324 \\
325 \\
326\end{array}$ & $\begin{array}{l}1120 \\
1147 \\
1214 \\
1306 \\
1511\end{array}$ & $\begin{array}{l}7 \\
7 \\
7 \\
7 \\
7\end{array}$ & $\begin{array}{r}.129 \\
.127 \\
.127 \\
.133 \\
.140\end{array}$ & $\begin{array}{l}84.280 \\
84.307 \\
84.274 \\
84.331 \\
84.319\end{array}$ & $\begin{array}{l}10.850 \\
10.841 \\
10.841 \\
10.830 \\
10.831\end{array}$ & $\begin{array}{l}3.419 \\
3.397 \\
3.424 \\
3.401 \\
3.390\end{array}$ & $\begin{array}{r}.326 \\
.325 \\
.328 \\
.324 \\
.324\end{array}$ & $\begin{array}{l}.744 \\
.742 \\
.746 \\
.737 \\
.736\end{array}$ & $\begin{array}{l}.125 \\
.124 \\
.123 \\
.122 \\
.124\end{array}$ & $\begin{array}{r}.1140 \\
.1110 \\
.1110 \\
.1120 \\
.1130\end{array}$ & $\begin{array}{l}0.000 \\
0.000 \\
0.000 \\
0.000 \\
0.000\end{array}$ & $\begin{array}{l}.008 \\
.009 \\
.009 \\
.007 \\
.007\end{array}$ & $\begin{array}{l}.005 \\
.017 \\
.017 \\
.003 \\
.015\end{array}$ & $\begin{array}{l}43.931 \\
43.905 \\
43.925 \\
43.901 \\
43.891\end{array}$ & $\begin{array}{r}.461 \\
.461 \\
.461 \\
.461 \\
.461\end{array}$ \\
\hline $\begin{array}{l}327 \\
328 \\
329 \\
330 \\
331\end{array}$ & $\begin{array}{l}1553 \\
1106 \\
1134 \\
1220 \\
1256\end{array}$ & $\begin{array}{l}7 \\
8 \\
8 \\
8 \\
8\end{array}$ & $\begin{array}{l}.134 \\
.721 \\
.721 \\
.721 \\
.709\end{array}$ & $\begin{array}{l}84.328 \\
83.855 \\
83.857 \\
83.849 \\
63.851\end{array}$ & $\begin{array}{l}10.843 \\
10.781 \\
10.780 \\
10.790 \\
10.790\end{array}$ & $\begin{array}{l}3.387 \\
3.335 \\
3.335 \\
3.336 \\
3.338\end{array}$ & $\begin{array}{r}.323 \\
.322 \\
.321 \\
.321 \\
.322\end{array}$ & $\begin{array}{l}.736 \\
.730 \\
.732 \\
.731 \\
.732\end{array}$ & $\begin{array}{r}.123 \\
.122 \\
.122 \\
.122 \\
.125\end{array}$ & $\begin{array}{r}.1120 \\
.1100 \\
.1110 \\
.1120 \\
.1130\end{array}$ & $\begin{array}{l}0.000 \\
0.000 \\
0.000 \\
0.000 \\
0.000\end{array}$ & $\begin{array}{r}0.000 \\
.006 \\
.006 \\
.004 \\
.007\end{array}$ & $\begin{array}{r}.014 \\
.018 \\
.015 \\
.014 \\
.013\end{array}$ & $\begin{array}{l}43.894 \\
43.613 \\
43.615 \\
43.620 \\
43.632\end{array}$ & $\begin{array}{r}.461 \\
.465 \\
.465 \\
.465 \\
.465\end{array}$ \\
\hline $\begin{array}{l}332 \\
333 \\
334 \\
334 \\
334\end{array}$ & $\begin{array}{l}1442 \\
1507 \\
1558 \\
1623 \\
1648\end{array}$ & $\begin{array}{r}8 \\
8 \\
8 \\
8 \\
100\end{array}$ & $\begin{array}{r}.720 \\
.715 \\
.712 \\
.713 \\
1.382\end{array}$ & $\begin{array}{l}83.819 \\
83.852 \\
33.856 \\
83.864 \\
85.968\end{array}$ & $\begin{array}{r}10.800 \\
10.799 \\
10.781 \\
10.789 \\
8.489\end{array}$ & $\begin{array}{l}3.348 \\
3.333 \\
3.343 \\
3.339 \\
2.939\end{array}$ & $\begin{array}{r}.321 \\
.322 \\
.322 \\
.322 \\
.517\end{array}$ & $\begin{array}{l}.734 \\
.727 \\
.731 \\
.724 \\
.735\end{array}$ & $\begin{array}{r}.123 \\
.122 \\
.120 \\
.123 \\
0.000\end{array}$ & $\begin{array}{r}.1130 \\
.1110 \\
.1120 \\
.1110 \\
0.0000\end{array}$ & $\begin{array}{r}.000 \\
0.000 \\
.001 \\
C .000 \\
C .000\end{array}$ & $\begin{array}{r}.006 \\
.007 \\
.005 \\
0.000 \\
0.060\end{array}$ & $\begin{array}{r}.016 \\
.012 \\
.017 \\
.016 \\
0.000\end{array}$ & $\begin{array}{l}43.633 \\
43.619 \\
43.624 \\
43.620 \\
42.380\end{array}$ & $\begin{array}{l}.465 \\
.465 \\
.465 \\
.465 \\
.459\end{array}$ \\
\hline $\begin{array}{l}334 \\
335 \\
336 \\
337 \\
338\end{array}$ & $\begin{array}{l}1713 \\
1115 \\
1139 \\
1222 \\
1252\end{array}$ & $\begin{array}{r}100 \\
9 \\
9 \\
9 \\
9\end{array}$ & $\begin{array}{l}1.379 \\
2.373 \\
2.366 \\
2.369 \\
2.365\end{array}$ & $\begin{array}{l}85.953 \\
82.427 \\
82.363 \\
82.388 \\
82.342\end{array}$ & $\begin{array}{r}8.503 \\
10.571 \\
10.600 \\
10.590 \\
10.590\end{array}$ & $\begin{array}{l}2.956 \\
3.320 \\
3.336 \\
3.322 \\
3.323\end{array}$ & $\begin{array}{r}.518 \\
.315 \\
.319 \\
.316 \\
.315\end{array}$ & $\begin{array}{l}.697 \\
.731 \\
.742 \\
.734 \\
.728\end{array}$ & $\begin{array}{r}0.000 \\
.122 \\
.125 \\
.123 \\
.122\end{array}$ & $\begin{array}{r}0.1000 \\
.1130 \\
.1210 \\
.1330 \\
.1120\end{array}$ & $\begin{array}{r}0.000 \\
.002 \\
c .000 \\
0.000 \\
.087\end{array}$ & $\begin{array}{r}0.000 \\
.010 \\
. C 11 \\
.011 \\
.009\end{array}$ & $\begin{array}{r}0.000 \\
.016 \\
.316 \\
.914 \\
.006\end{array}$ & $\begin{array}{l}42.385 \\
42.921 \\
42.962 \\
42.953 \\
43.050\end{array}$ & $\begin{array}{r}.459 \\
.471 \\
.471 \\
.471 \\
.471\end{array}$ \\
\hline $\begin{array}{l}339 \\
339 \\
340 \\
341\end{array}$ & $\begin{array}{l}1327 \\
1352 \\
1512 \\
1541\end{array}$ & $\begin{array}{l}9 \\
9 \\
9 \\
9\end{array}$ & $\begin{array}{l}2.361 \\
2.362 \\
2.375 \\
2.376\end{array}$ & $\begin{array}{l}82.363 \\
82.363 \\
82.361 \\
82.369\end{array}$ & $\begin{array}{l}10.580 \\
10.593 \\
10.619 \\
10.610\end{array}$ & $\begin{array}{l}3.313 \\
3.309 \\
3.328 \\
3.328\end{array}$ & $\begin{array}{l}.314 \\
.313 \\
.314 \\
.318\end{array}$ & $\begin{array}{l}.729 \\
.728 \\
.732 \\
.734\end{array}$ & $\begin{array}{l}.125 \\
.124 \\
.122 \\
.121\end{array}$ & $\begin{array}{r}.1140 \\
.1110 \\
.1140 \\
.1160\end{array}$ & $\begin{array}{r}.087 \\
.073 \\
.015 \\
0.000\end{array}$ & $\begin{array}{l}.003 \\
.012 \\
.006 \\
.009\end{array}$ & $\begin{array}{r}.005 \\
.015 \\
.015 \\
.019\end{array}$ & $\begin{array}{l}43.050 \\
43.018 \\
42.959 \\
42.939\end{array}$ & $\begin{array}{r}.471 \\
.471 \\
.471 \\
.471\end{array}$ \\
\hline
\end{tabular}


7.4.2. Confirmation Test Data

Table 7.4.2 lists the raw data for shipboard tests. The analyses showing zero butanes content are boil off gas samples and have been omitted from all statistical evaluations. Table 7.4.3 lists the second flow facility test data. The runs corresponding to each test were:

Test A
Test B
Test C
Test D
Test $E$
Test $F$
Test $G$

Runs 1 through 17

Runs 18 through 39

Runs 40 through 44

Runs 45 through 58

Runs 59 through 62

Runs 63 through 71

Runs 72 through 77 . The heating values are

real gas values computed using the A.G.A. method [1]; liquid densities were computed using the extended corresponding states method [3]. Two sets of heating values and specific gravities are given for the flow facility tests. The values listed with the operating variables are measured while those listed with the composition are computed from the given composition. 
Table 7.4.2. Shipboard Test Data

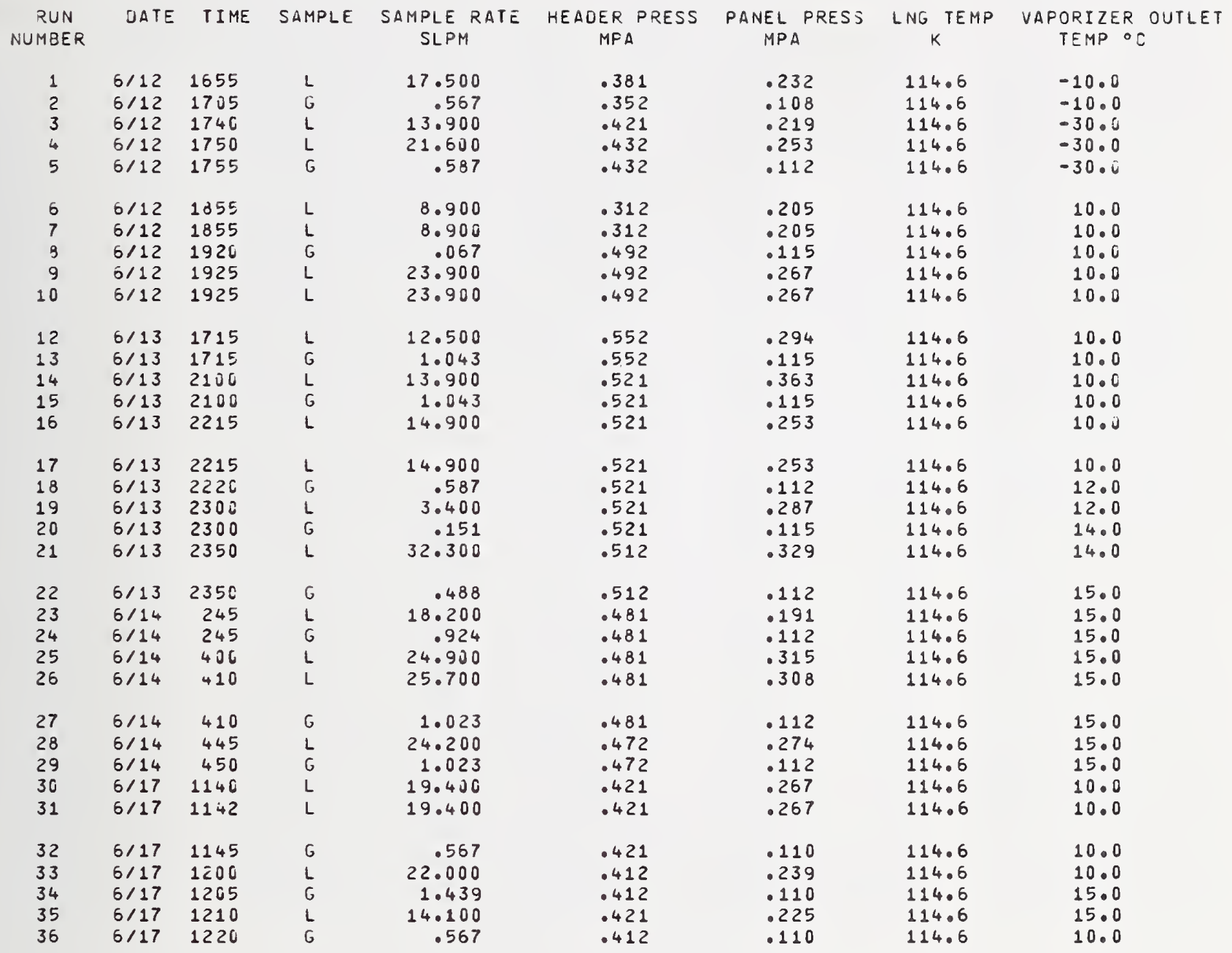


Table 7.4.2. Shipboard Test Data (continued)

\begin{tabular}{|c|c|c|c|c|c|c|c|c|}
\hline $\begin{array}{c}\text { RUN } \\
\text { NUMBER }\end{array}$ & DATE & TIME & SAMPLE & $\begin{array}{l}\text { SAMPLE RATE } \\
\text { SLPM }\end{array}$ & $\begin{array}{c}\text { HEADER PRESS } \\
\text { MPA }\end{array}$ & $\begin{array}{l}\text { PANEL PRESS } \\
\text { MPA }\end{array}$ & ${ }_{K}^{\text {LNG }}$ & $\begin{array}{l}\text { VAPORIZEF } \\
\text { TEMP }\end{array}$ \\
\hline $\begin{array}{l}37 \\
38 \\
39 \\
40 \\
41\end{array}$ & $\begin{array}{l}6 / 17 \\
6 / 17 \\
6 / 17 \\
6 / 18 \\
6 / 18\end{array}$ & $\begin{array}{l}1230 \\
1235 \\
1240 \\
1455 \\
1500\end{array}$ & $\begin{array}{l}L \\
G \\
L \\
L \\
G\end{array}$ & $\begin{array}{r}13.000 \\
1.221 \\
18.500 \\
18.200 \\
.468\end{array}$ & $\begin{array}{l}.412 \\
.412 \\
.452 \\
.421 \\
.101\end{array}$ & $\begin{array}{l}.212 \\
.110 \\
.205 \\
.225 \\
.105\end{array}$ & $\begin{array}{l}114.6 \\
114.6 \\
114.6 \\
115.0 \\
115.0\end{array}$ & $\begin{array}{l}10.0 \\
20.0 \\
20.0 \\
20.0 \\
20.0\end{array}$ \\
\hline $\begin{array}{l}42 \\
43 \\
44 \\
45 \\
46\end{array}$ & $\begin{array}{l}6 / 18 \\
6 / 18 \\
6 / 18 \\
6 / 18 \\
6 / 18\end{array}$ & $\begin{array}{l}1520 \\
1550 \\
1555 \\
1605 \\
1610\end{array}$ & $\begin{array}{l}\mathrm{L} \\
\mathrm{L} \\
\mathrm{G} \\
\mathrm{L} \\
\mathrm{G}\end{array}$ & $\begin{array}{r}17.900 \\
19.100 \\
.330 \\
21.300 \\
.429\end{array}$ & $\begin{array}{l}.432 \\
.501 \\
.512 \\
.532 \\
.532\end{array}$ & $\begin{array}{l}.205 \\
.232 \\
.106 \\
.239 \\
.107\end{array}$ & $\begin{array}{l}115.0 \\
115.0 \\
115.0 \\
115.0 \\
115.0\end{array}$ & $\begin{array}{l}20.0 \\
20.0 \\
20.0 \\
20.0 \\
20.0\end{array}$ \\
\hline $\begin{array}{l}47 \\
48 \\
49 \\
50 \\
51\end{array}$ & $\begin{array}{l}6 / 18 \\
6 / 18 \\
6 / 18 \\
6 / 18 \\
6 / 18\end{array}$ & $\begin{array}{l}1625 \\
1640 \\
1640 \\
1720 \\
1722\end{array}$ & $\begin{array}{l}L \\
L \\
G \\
G \\
L\end{array}$ & $\begin{array}{r}21.000 \\
25.600 \\
.389 \\
.468 \\
20.100\end{array}$ & $\begin{array}{l}.532 \\
.532 \\
.532 \\
.521 \\
.521\end{array}$ & $\begin{array}{l}.239 \\
.253 \\
.108 \\
.108 \\
.232\end{array}$ & $\begin{array}{l}115.0 \\
115.0 \\
115.0 \\
115.0 \\
115.0\end{array}$ & $\begin{array}{l}20.0 \\
20.0 \\
20.0 \\
20.0 \\
20.0\end{array}$ \\
\hline $\begin{array}{l}52 \\
53 \\
54 \\
55 \\
56\end{array}$ & $\begin{array}{l}6 / 18 \\
6 / 21 \\
6 / 21 \\
6 / 21 \\
6 / 21\end{array}$ & $\begin{array}{l}1735 \\
1708 \\
1720 \\
1720 \\
1736\end{array}$ & $\begin{array}{l}\mathrm{L} \\
\mathrm{L} \\
\mathrm{G} \\
\mathrm{L} \\
\mathrm{G}\end{array}$ & $\begin{array}{r}22.300 \\
20.400 \\
.587 \\
24.300 \\
1.677\end{array}$ & $\begin{array}{l}.521 \\
.412 \\
.452 \\
.452 \\
.352\end{array}$ & $\begin{array}{l}.219 \\
.225 \\
.112 \\
.239 \\
.112\end{array}$ & $\begin{array}{l}115.0 \\
116.0 \\
116.0 \\
116.0 \\
116.0\end{array}$ & $\begin{array}{r}20.0 \\
0.0 \\
50.0 \\
0.0 \\
25.0\end{array}$ \\
\hline $\begin{array}{l}57 \\
58 \\
59 \\
60 \\
61\end{array}$ & $\begin{array}{l}6 / 21 \\
6 / 22 \\
6 / 22 \\
6 / 22 \\
6 / 22\end{array}$ & $\begin{array}{l}1735 \\
2110 \\
2114 \\
2125 \\
2230\end{array}$ & $\begin{array}{l}L \\
G \\
L \\
L \\
G\end{array}$ & $\begin{array}{r}6.200 \\
.785 \\
23.300 \\
18.300 \\
1.003\end{array}$ & $\begin{array}{l}.352 \\
.501 \\
.501 \\
.501 \\
.501\end{array}$ & $\begin{array}{l}.225 \\
.108 \\
.294 \\
.253 \\
.108\end{array}$ & $\begin{array}{l}116.0 \\
116.5 \\
116.5 \\
116.5 \\
116.5\end{array}$ & $\begin{array}{r}0.0 \\
25.0 \\
0.0 \\
0.0 \\
25.0\end{array}$ \\
\hline $\begin{array}{l}62 \\
63 \\
64 \\
65 \\
66\end{array}$ & $\begin{array}{l}6 / 22 \\
6 / 22 \\
6 / 22 \\
6 / 22 \\
6 / 22\end{array}$ & $\begin{array}{l}2255 \\
2305 \\
2310 \\
2325 \\
2330\end{array}$ & $\begin{array}{l}\mathrm{L} \\
\mathrm{G} \\
\mathrm{L} \\
\mathrm{L} \\
\mathrm{G}\end{array}$ & $\begin{array}{r}24.300 \\
1.003 \\
24.300 \\
24.300 \\
1.003\end{array}$ & $\begin{array}{l}.501 \\
.501 \\
.501 \\
.501 \\
.501\end{array}$ & $\begin{array}{l}.239 \\
.108 \\
.239 \\
.239 \\
.108\end{array}$ & $\begin{array}{l}116.5 \\
116.5 \\
116.5 \\
116.5 \\
116.5\end{array}$ & $\begin{array}{r}0.0 \\
25.0 \\
0.0 \\
0.0 \\
25.0\end{array}$ \\
\hline $\begin{array}{l}67 \\
68\end{array}$ & $\begin{array}{l}6 / 22 \\
6 / 22\end{array}$ & $\begin{array}{l}2345 \\
2400\end{array}$ & $\begin{array}{l}L \\
L\end{array}$ & $\begin{array}{l}25.900 \\
29.000\end{array}$ & $\begin{array}{l}.501 \\
.501\end{array}$ & $\begin{array}{r}.239 \\
.212\end{array}$ & $\begin{array}{l}116.5 \\
116.5\end{array}$ & $\begin{array}{l}25.0 \\
25.0\end{array}$ \\
\hline
\end{tabular}


Table 7.4.2. Shipboard Test Data (continued)

\begin{tabular}{|c|c|c|c|c|c|c|c|c|}
\hline $\begin{array}{c}\text { Run } \\
\text { Number }\end{array}$ & Time & $\mathrm{N}_{2}$ & $\mathrm{CH}_{4}$ & $\mathrm{C}_{2} \mathrm{H}_{6}$ & $\mathrm{C}_{3} \mathrm{H}_{8}$ & $i_{4} \mathrm{H}_{10}$ & $\mathrm{nC}_{4} \mathrm{H}_{10}$ & $C_{5}$ \\
\hline $\begin{array}{l}1 \\
2 \\
3 \\
4 \\
5\end{array}$ & $\begin{array}{l}1655 \\
1705 \\
1740 \\
1750 \\
1755\end{array}$ & $\begin{array}{r}.114 \\
9.724 \\
.119 \\
.105 \\
.993\end{array}$ & $\begin{array}{l}83.827 \\
74.976 \\
84.090 \\
83.994 \\
83.300\end{array}$ & $\begin{array}{l}11.565 \\
10.943 \\
11.291 \\
11.535 \\
11.575\end{array}$ & $\begin{array}{l}3.457 \\
3.337 \\
3.432 \\
3.360 \\
3.214\end{array}$ & $\begin{array}{l}.542 \\
.533 \\
.560 \\
.527 \\
.479\end{array}$ & $\begin{array}{l}.496 \\
.487 \\
.507 \\
.480 \\
.441\end{array}$ & $\begin{array}{l}0.00 \\
0.00 \\
0.00 \\
0.00 \\
0.00\end{array}$ \\
\hline $\begin{array}{r}6 \\
7 \\
8 \\
9 \\
10\end{array}$ & $\begin{array}{l}1855 \\
1855 \\
1920 \\
1925 \\
1925\end{array}$ & $\begin{array}{l}.413 \\
.409 \\
.209 \\
.125 \\
.123\end{array}$ & $\begin{array}{l}90.401 \\
90.401 \\
83.762 \\
84.142 \\
84.196\end{array}$ & $\begin{array}{r}6.762 \\
6.781 \\
11.553 \\
11.286 \\
11.224\end{array}$ & $\begin{array}{l}1.934 \\
1.940 \\
3.442 \\
3.378 \\
3.383\end{array}$ & $\begin{array}{l}.225 \\
.225 \\
.541 \\
.540 \\
.542\end{array}$ & $\begin{array}{r}.220 \\
.219 \\
.494 \\
.495 \\
.493\end{array}$ & $\begin{array}{r}.0 \\
.0 \\
0.0 \\
.0 \\
.0\end{array}$ \\
\hline $\begin{array}{l}12 \\
12 \\
13 \\
14 \\
15\end{array}$ & $\begin{array}{l}1625 \\
1715 \\
1715 \\
2100 \\
2100\end{array}$ & $\begin{array}{r}2.879 \\
.118 \\
.111 \\
.110 \\
.093\end{array}$ & $\begin{array}{l}97.080 \\
85.200 \\
85.139 \\
85.177 \\
85.025\end{array}$ & $\begin{array}{r}.041 \\
10.511 \\
10.564 \\
10.545 \\
10.681\end{array}$ & $\begin{array}{l}0.000 \\
3.161 \\
3.173 \\
3.163 \\
3.189\end{array}$ & $\begin{array}{r}0.000 \\
.507 \\
.510 \\
.507 \\
.511\end{array}$ & $\begin{array}{l}0.000 \\
.457 \\
.461 \\
.457 \\
.459\end{array}$ & $\begin{array}{r}0.0 \\
.0 \\
.0 \\
.0 \\
.0\end{array}$ \\
\hline $\begin{array}{l}16 \\
18 \\
19 \\
20 \\
21\end{array}$ & $\begin{array}{l}2215 \\
2200 \\
2300 \\
2300 \\
2344\end{array}$ & $\begin{array}{r}.108 \\
.112 \\
.113 \\
.110 \\
2.751\end{array}$ & $\begin{array}{l}85.140 \\
85.096 \\
85.243 \\
85.071 \\
96.080\end{array}$ & $\begin{array}{r}10.574 \\
10.574 \\
10.642 \\
10.591 \\
.935\end{array}$ & $\begin{array}{r}3.174 \\
3.184 \\
3.069 \\
3.197 \\
.234\end{array}$ & $\begin{array}{r}.508 \\
.525 \\
.464 \\
.521 \\
0.000\end{array}$ & $\begin{array}{l}.457 \\
.466 \\
.424 \\
.460 \\
0.000\end{array}$ & $\begin{array}{r}.0 \\
.0 \\
.0 \\
.0 \\
0.0\end{array}$ \\
\hline $\begin{array}{l}21 \\
21 \\
22 \\
23 \\
24\end{array}$ & $\begin{array}{r}2344 \\
2350 \\
2350 \\
245 \\
245\end{array}$ & $\begin{array}{r}2.729 \\
.110 \\
.110 \\
.108 \\
.108\end{array}$ & $\begin{array}{l}96.096 \\
85.141 \\
85.170 \\
85.124 \\
85.114\end{array}$ & $\begin{array}{r}.935 \\
10.555 \\
10.529 \\
10.557 \\
10.566\end{array}$ & $\begin{array}{r}.240 \\
3.179 \\
3.172 \\
3.175 \\
3.186\end{array}$ & $\begin{array}{r}0.000 \\
.514 \\
.516 \\
.516 \\
.511\end{array}$ & $\begin{array}{l}0.000 \\
.459 \\
.461 \\
.465 \\
.459\end{array}$ & $\begin{array}{l}0.0 \\
.0 \\
.0 \\
.0 \\
.0\end{array}$ \\
\hline $\begin{array}{l}25 \\
26 \\
27 \\
28 \\
29\end{array}$ & $\begin{array}{l}400 \\
410 \\
410 \\
445 \\
450\end{array}$ & $\begin{array}{l}.109 \\
.110 \\
.109 \\
.110 \\
.116\end{array}$ & $\begin{array}{l}84.791 \\
85.090 \\
85.108 \\
85.169 \\
85.172\end{array}$ & $\begin{array}{l}10.981 \\
10.577 \\
10.574 \\
10.517 \\
10.508\end{array}$ & $\begin{array}{l}3.123 \\
3.200 \\
3.191 \\
3.181 \\
3.183\end{array}$ & $\begin{array}{l}.502 \\
.514 \\
.515 \\
.513 \\
.511\end{array}$ & $\begin{array}{l}.451 \\
.452 \\
.458 \\
.451 \\
.459\end{array}$ & $\begin{array}{l}.0 \\
.0 \\
.0 \\
.0 \\
.0\end{array}$ \\
\hline $\begin{array}{l}30 \\
31 \\
32 \\
33 \\
34\end{array}$ & $\begin{array}{l}1140 \\
1142 \\
1145 \\
1200 \\
1205\end{array}$ & $\begin{array}{r}.029 \\
.013 \\
.003 \\
0.003 \\
.029\end{array}$ & $\begin{array}{l}82.571 \\
82.312 \\
82.409 \\
82.511 \\
82.394\end{array}$ & $\begin{array}{l}12 \cdot 317 \\
12.564 \\
12.428 \\
12.396 \\
12.361\end{array}$ & $\begin{array}{l}3.850 \\
3.865 \\
3.925 \\
3.897 \\
3.979\end{array}$ & $\begin{array}{l}.625 \\
.628 \\
.621 \\
.628 \\
.631\end{array}$ & $\begin{array}{l}.560 \\
.565 \\
.552 \\
.568 \\
.562\end{array}$ & $\begin{array}{r}.0 \\
.0 \\
.0 \\
0.0 \\
.0\end{array}$ \\
\hline
\end{tabular}

Heating

value

$\mathrm{MJ} / \mathrm{m}^{3}$

Density

43.883

39.977

43.813

43.796

43.314

41.077

41.064

43.833

43.791

43.781

36.694

43.401

43.426

43.408

43.475

43.423

43.453

43.322

43.467

37.131

37.143

43.429

43.421

43.450

43.451

43.504

43.455

43.447

43.429

43.424

44.534

44.631

44.624

44.549

44.622 $\mathrm{gm} / \mathrm{cm}^{3}$

.4751

.4987

.4745

.4743

.4756

.4526

.4525

.4752

.4743

.4742

.4262

.4710

.4712

.4710

.4715

- 4711

.4714

.4704

.4715

.4298

.4298

.4712

.4711

.4713

.4713

.4719

.4714

.4713

.4712

.4712

- 4798

.4805

.4804

.4798

.4805 
Table 7.4.2. Shipboard Test Data (continued)

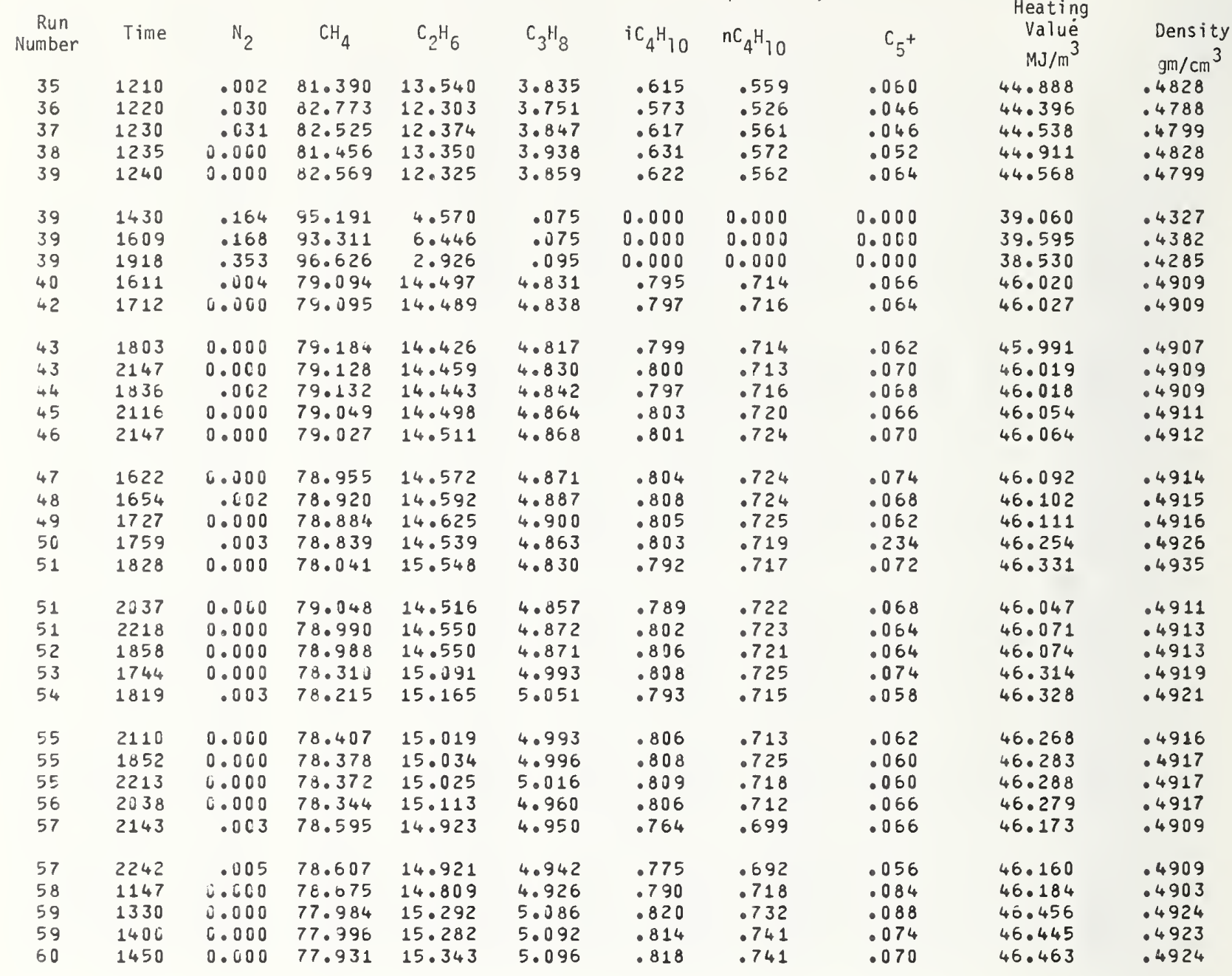


Table 7.4.2. Shipboard Test Data (continued)

$\begin{array}{ccccc}\begin{array}{c}\text { Run } \\ \text { Number }\end{array} & \text { Time } & \mathrm{N}_{2} & \mathrm{CH}_{4} & \mathrm{C}_{2} \mathrm{H}_{6} \\ 60 & 2145 & 0.000 & 77.929 & 15.356 \\ 61 & 2150 & 0.000 & 77.912 & 15.347 \\ 62 & 2220 & 0.000 & 77.857 & 15.375 \\ 62 & 2252 & 0.000 & 77.877 & 15.425 \\ 62 & 2113 & 0.000 & 77.894 & 15.360 \\ 63 & 2324 & 0.000 & 77.953 & 15.329 \\ 64 & 1624 & 0.000 & 77.820 & 15.401 \\ 64 & 1502 & 0.000 & 78.125 & 15.199 \\ 64 & 1859 & 0.000 & 77.773 & 15.487 \\ 64 & 2043 & 0.0 \mathrm{CO} & 77.309 & 15.349 \\ 65 & 1719 & 0.000 & 77.869 & 15.376 \\ 66 & 2301 & 0.000 & 78.324 & 15.431 \\ 67 & 1757 & 0.000 & 77.874 & 15.380 \\ 68 & 1828 & 0.000 & 77.825 & 15.428\end{array}$

Composition, mol\%

$\mathrm{C}_{3} \mathrm{H}_{8} \quad \mathrm{iC}_{4} \mathrm{H}_{10} \quad \mathrm{nC}_{4} \mathrm{H}_{10} \quad \mathrm{C}_{5}{ }^{+}$

5.100

5.131

5.135

5.145

5.122

.815

.724

$.817 \quad .726$

$.824 \quad .735$

$.823 \quad .730$

$.822 \quad .734$

5.103

5.136

.808

.734

5.066

5.120

5.113

.824

.727

.743

$.808 \quad .733$

$.828 \quad .728$

.830

.728

5. 121

.820

5.164

5.110

5.130

.731

.727

.730

.827

.818

.731

.076

.066

.074

0.000

.068

.080

.076

. 0 E 8

.064

.072

.084

0.000

.080

.066

$\begin{array}{ll}\begin{array}{c}\text { Heating } \\ \text { Value }\end{array} & \text { Densicy } \\ \mathrm{MJ} / \mathrm{m}^{3} & \mathrm{gm} / \mathrm{cm}^{3} \\ 46.459 & .4924 \\ 46.467 & .4925 \\ 46.499 & .4927 \\ 46.430 & .4922 \\ 46.478 & .4926 \\ 46.454 & .4924 \\ 46.516 & .4928 \\ 46.388 & .4919 \\ 46.508 & .4928 \\ 46.475 & .4925 \\ 46.496 & .4927 \\ 46.043 & .4896 \\ 46.490 & .4926 \\ 46.495 & .4927\end{array}$


Table 7.4.2. LNG Flow Facility Test 2 Data.

\begin{tabular}{|c|c|c|c|c|c|c|c|c|c|}
\hline $\begin{array}{c}\text { RUN } \\
\text { NUMBER }\end{array}$ & JATE & TIME & $\begin{array}{l}\text { VAPORIZER } \\
\text { IVUMJER }\end{array}$ & $\begin{array}{c}\text { TEST SECTION } \\
\text { PRESS,MPA }\end{array}$ & $\begin{array}{c}\text { PANEL PRESS } \\
\text { MPA }\end{array}$ & $\begin{array}{l}\text { SAMPLINJ } \\
\text { RATE, SLPM }\end{array}$ & $\begin{array}{l}\text { TEMPERATURE } \\
K\end{array}$ & $\begin{array}{l}\text { HEATING VALUE } \\
\text { MJ/M }\end{array}$ & $\begin{array}{l}\text { SPECIFIC } \\
\text { GRAVITY }\end{array}$ \\
\hline 1 & $3 / \cup 9$ & 1.25 & 1 & $.3+2$ & .249 & 12.26 & 124.4 & 43.192 & .650 \\
\hline 2 & $3 / .9$ & 1 J 25 & c & $.3+2$ & .256 & 13.56 & 124.4 & 43.192 & .650 \\
\hline 3 & $8 / 49$ & 110 & 1 & .344 & .257 & 12.42 & 124.4 & 43.192 & .650 \\
\hline 4 & $8 / 09$ & 1130 & 2 & .344 & .244 & $1 \tilde{c} .64$ & 124.4 & 43.192 & .650 \\
\hline 5 & $8 / 49$ & 1320 & 1 & .459 & .307 & 10.59 & 125.2 & 43.211 & .650 \\
\hline 6 & $0 / 49$ & 1525 & 1 & .459 & .232 & 18.19 & 125.8 & 43.211 & .650 \\
\hline 7 & $8 / \cup 9$ & 1525 & 2 & .459 & .218 & 18.53 & 125.8 & 43.211 & . ESO \\
\hline d & $8 / 49$ & 1000 & 1 & .451 & .265 & 19.00 & 125.2 & 43.192 & .650 \\
\hline 10 & $8 / 69$ & 1615 & 1 & .451 & .251 & 19.14 & 125.4 & 43.192 & .650 \\
\hline 11 & $3 / 49$ & 1015 & 2 & .451 & .230 & 15.13 & 125.4 & 43.192 & .650 \\
\hline 12 & $3 / \cup 9$ & 1036 & 1 & .441 & .248 & 19.42 & 124.3 & 43.192 & .650 \\
\hline 13 & $8 / 59$ & 1036 & 2 & .441 & .220 & 13.43 & 124.3 & 43.192 & .650 \\
\hline 14 & $8 /, 9$ & 1045 & 1 & .443 & .243 & 19.14 & 124.7 & 43.192 & .650 \\
\hline 15 & $0 /: 9$ & 1045 & i & .443 & .222 & 13.43 & 124.7 & 43.192 & .650 \\
\hline 16 & $8 / 9$ & $17 \mathrm{u}$ & 1 & .449 & .256 & 19.42 & 124.8 & 43.192 & .650 \\
\hline 17 & $8 / 45$ & 17 u & 2 & .449 & .228 & 15.13 & 124.8 & 43.192 & .650 \\
\hline 18 & $8 / 10$ & 1430 & 2 & .484 & .291 & 18.29 & 132.7 & 43.528 & .658 \\
\hline 19 & $8 / 20$ & $11 \cup 6$ & 2 & .487 & .266 & $2 u \cdot 92$ & 132.6 & 43.546 & .658 \\
\hline 20 & $0 / i i$ & $1 i 3 i$ & 2 & .476 & .249 & 21.74 & 131.9 & 43.546 & .658 \\
\hline 21 & $8 / 10$ & 1145 & 2 & .497 & .284 & 22.33 & 133.1 & 43.546 & .658 \\
\hline 22 & $3 / 10$ & 1200 & 2 & .493 & .293 & 22.68 & 132.8 & 43.546 & .658 \\
\hline 23 & $8 /: 3$ & 1220 & 2 & .481 & .281 & 22.08 & 132.4 & 43.546 & .658 \\
\hline 24 & $8 / 10$ & 1230 & 2 & .481 & .281 & 21.54 & 132.4 & 43.528 & .658 \\
\hline 25 & $0 / 10$ & 1245 & 2 & .481 & .302 & 22.68 & 132.4 & 43.528 & .658 \\
\hline 26 & $8 / 10$ & $130 \mathrm{~L}$ & 2 & .487 & .287 & 22.68 & 132.8 & 43.528 & .658 \\
\hline 27 & $8 / 10$ & 1330 & 2 & .479 & .272 & 21.26 & 132.5 & 43.546 & .658 \\
\hline 28 & $8 / 10$ & $1+U U$ & 2 & .480 & .280 & 22.68 & 132.5 & 43.546 & .658 \\
\hline 29 & $8 / 10$ & 1415 & 2 & .474 & .274 & 22.68 & 132.4 & 43.546 & .658 \\
\hline 30 & $8 / 10$ & 1430 & 2 & .492 & .285 & 22.39 & 133.1 & 43.546 & .658 \\
\hline 31 & $3 / i i$ & 1445 & 2 & .489 & .283 & 22.39 & 133.0 & 43.546 & .658 \\
\hline 32 & $8 / 10$ & 1530 & 2 & .522 & .336 & 13.49 & 134.5 & 43.621 & .660 \\
\hline 33 & $8 / 10$ & 1545 & 2 & .481 & .288 & 12.94 & 132.3 & 43.677 & .660 \\
\hline 34 & $8 / 10$ & 1600 & 2 & .481 & .288 & 12.94 & 132.1 & 43.639 & .658 \\
\hline 35 & $9 / 14$ & 1015 & 2 & .493 & .320 & 13.81 & 132.6 & 43.639 & .658 \\
\hline 36 & $8 / 10$ & 1630 & 2 & .489 & .310 & 13.65 & 132.5 & 43.639 & .658 \\
\hline 37 & $8 / 10$ & 1645 & 2 & .480 & .300 & 13.45 & 132.4 & 43.639 & .658 \\
\hline 38 & $8 / 10$ & 1700 & 2 & .491 & .298 & 13.29 & 132.7 & 43.639 & .658 \\
\hline 39 & $3 / 10$ & 1715 & 2 & .489 & .303 & 13.45 & 132.6 & 43.639 & .658 \\
\hline 40 & $8 / 11$ & 1140 & 2 & .494 & .280 & 19.44 & 122.8 & 44.254 & .690 \\
\hline 41 & $8 / 11$ & 1155 & 2 & .435 & .255 & 16.03 & 118.6 & 43.863 & .680 \\
\hline 42 & $8 / 11$ & 1210 & 2 & .413 & .247 & 16.03 & 115.7 & 43.695 & .680 \\
\hline 43 & $3 / 11$ & 1225 & 2 & .498 & .291 & 16.03 & 122.8 & 43.733 & .680 \\
\hline 44 & $8 / 11$ & 1245 & 2 & .481 & .254 & 15.09 & 121.8 & 43.733 & .680 \\
\hline 45 & $8 / 11$ & 1400 & 2 & .408 & .233 & 9.06 & 122.3 & 43.844 & .680 \\
\hline 40 & $8 / 11$ & 1400 & 1 & .468 & .254 & 9.60 & 122.3 & 43.844 & .680 \\
\hline
\end{tabular}


Table 7.4.2. LNG Flow Facility Test 2 Data (continued).

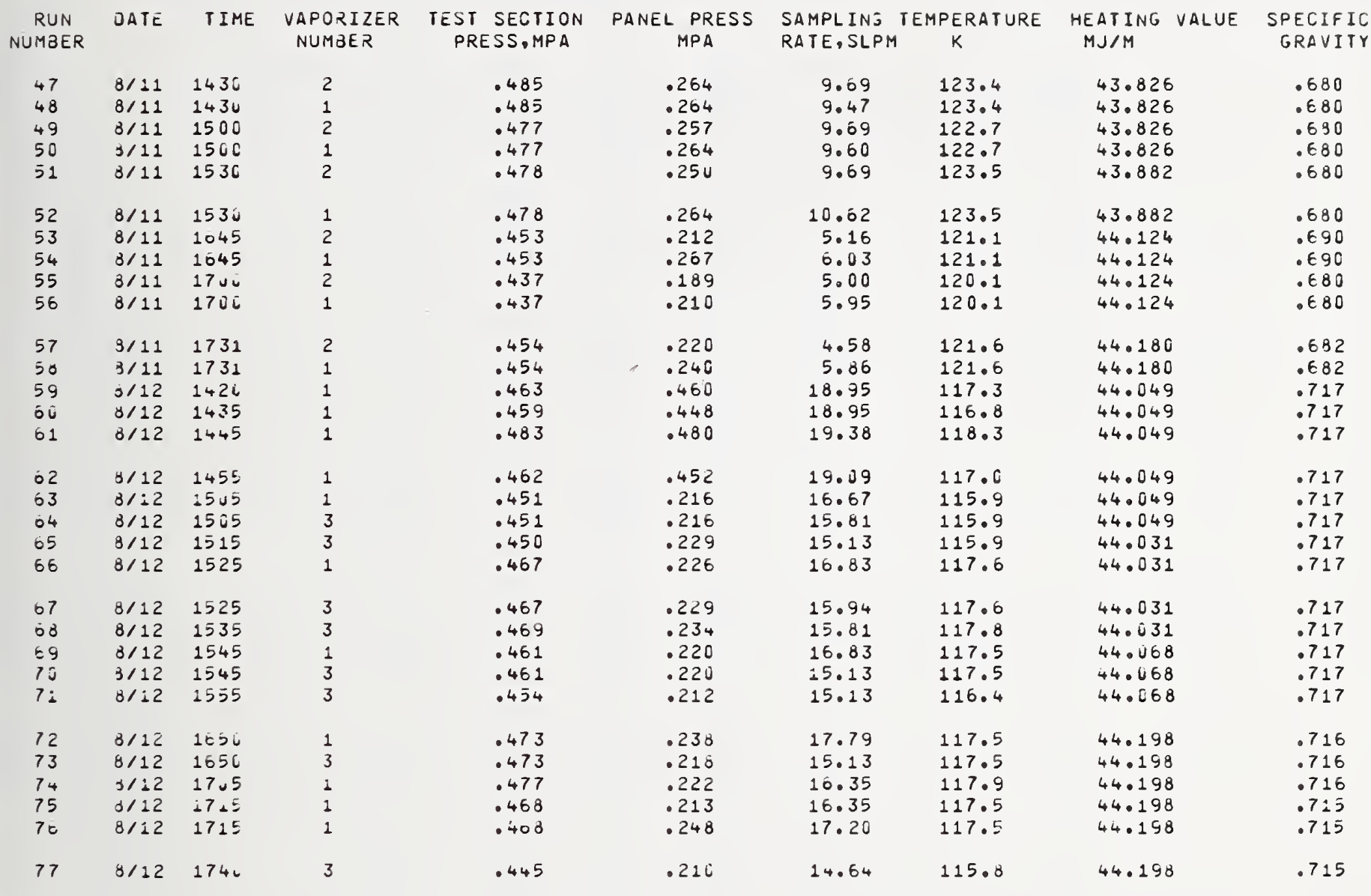


Table 7.4.2. LNG Flow Facility Test 2 Data (continued).

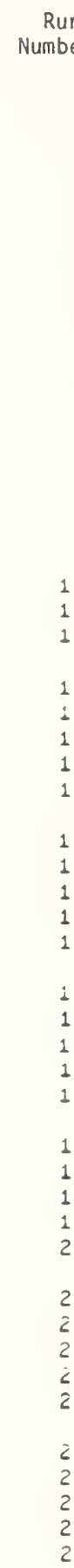

Run Inte-

$\begin{array}{ll}1 & A \\ 2 & A \\ 2 & B \\ 3 & A \\ 3 & B \\ & \\ 4 & A \\ 4 & B \\ 5 & A \\ 5 & B \\ 6 & A\end{array}$

$B$
$A$
$A$
$B$
$A$
$B$
$B$
$A$
$B$
$A$

$B$
$A$
$B$
$A$
$A$

3 B $B$ $A$
$B$
$A$
$A$
$A$
$B$
$B$
$B$
$B$
$B$
$A$

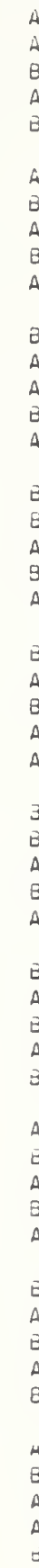
grator
Composition, $\operatorname{mol} \%$

\begin{tabular}{|c|c|c|c|c|c|c|c|}
\hline $\mathrm{C}_{3} \mathrm{H}_{8}$ & $i_{4}{ }_{4}{ }_{10}$ & $\mathrm{nC}_{4} \mathrm{H}_{10}$ & $i \mathrm{C}_{5} \mathrm{H}_{12}$ & $\mathrm{nC}_{5} \mathrm{H}_{12}$ & $c_{6}+$ & $\begin{array}{l}\text { Value } \\
\mathrm{MJ} / \mathrm{m}^{3}\end{array}$ & Gravity \\
\hline $\begin{array}{l}2.414 \\
2.424\end{array}$ & $\begin{array}{l}.223 \\
.225\end{array}$ & $\begin{array}{l}.138 \\
.100\end{array}$ & $\begin{array}{l}.237 \\
.0338\end{array}$ & $\begin{array}{l}. ن 48 \\
.047\end{array}$ & $\begin{array}{l}.083 \\
.086\end{array}$ & $\begin{array}{l}43.147 \\
43.205\end{array}$ & $\begin{array}{l}.0+7 \\
.0488\end{array}$ \\
\hline 2.431 & .220 & $: 100$ & .135 & : & .092 & 43.207 & $\begin{array}{l}.048 \\
.048\end{array}$ \\
\hline $2.3+7$ & .221 & .186 & .037 & .040 & .083 & 43.018 & .645 \\
\hline 2.344 & .210 & .135 & .030 & $.0+\varepsilon$ & .072 & 42.974 & .644 \\
\hline$\angle .7 し 1$ & .252 & .211 & .346 & . J52 & . 090 & +3.788 & .553 \\
\hline $2 \cdot 433$ & .223 & .191 & .034 & $.0+9$ & .077 & +3.179 & .048 \\
\hline $2 .+3 i$ & .233 & . 19E & $.03 E$ & .049 & .084 & 43.306 & .650 \\
\hline 2.483 & .227 & . 295 & .035 & • レ5ち & .093 & 43.305 & .053 \\
\hline 2.383 & .220 & .187 & .037 & . -447 & .082 & 43.123 & .647 \\
\hline 2.397 & .221 & .188 & .031 & .047 & .091 & 43.129 & .647 \\
\hline $2.48 Z$ & .217 & .136 & .034 & .044 & .076 & 43.255 & .649 \\
\hline 2.473 & .218 & .235 & .033 & .044 & $.07 \epsilon$ & 43.244 & $.6+3$ \\
\hline 2.481 & .211 & .185 & .032 & .045 & .079 & 43.241 & .049 \\
\hline 2.514 & .236 & .196 & .039 & 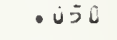 & .687 & 43.389 & .651 \\
\hline $2 .+7 i$ & .215 & .136 & .036 & .045 & .065 & 43.211 & .648 \\
\hline 2.500 & .231 & .199 & .034 & $.05 i$ & $.08 \mathrm{u}$ & 43.366 & .551 \\
\hline 2.539 & .246 & .205 & .641 & $.05 i$ & .089 & 43.596 & .655 \\
\hline 2.608 & .241 & .206 & .032 & .054 & .094 & 43.595 & .655 \\
\hline 2.379 & .217 & .284 & $.03 \varepsilon$ & .044 & .070 & 42.194 & .048 \\
\hline 2.450 & $.22 i$ & .193 & .033 & . & j & 43.265 & .049 \\
\hline 2.425 & .227 & .109 & .039 & .048 & .083 & 43.132 & .643 \\
\hline 2.422 & .221 & .192 & .031 & .056 & .087 & 43.174 & .047 \\
\hline 2.469 & .223 & .190 & $.03 E$ & $.0+7$ & .081 & 43.253 & .649 \\
\hline 2.470 & .224 & .191 & .037 & .046 &.$c 8 c$ & 43.256 & .649 \\
\hline 2.475 & .222 & .192 & .032 & .044 & .075 & 43.233 & .0648 \\
\hline 2.474 & .222 & .192 & .031 & .047 & .090 & 43.262 & .649 \\
\hline 2.427 & .227 & .139 & .037 & $\cdot 047$ & .082 & 43.193 & .649 \\
\hline 2.419 & .224 & .191 & .034 & $.6+5$ & .076 & 43.159 & .047 \\
\hline 2.428 & .235 & .135 & .035 & .049 & .086 & 43.155 & .047 \\
\hline $2.43 i$ & .230 & .194 & . ن37 & .049 & .698 & 43.166 & .647 \\
\hline 2.464 & .231 & .193 & .038 & .049 & .084 & 43.277 & .049 \\
\hline 2.458 & .220 & .192 & .033 & .047 & .094 & 43.269 & $.0+9$ \\
\hline 2.537 & .225 & $.19 a$ & .036 & .045 & .078 & 43.295 & .650 \\
\hline 2.532 & .222 & .193 & .031 & .046 & .075 & 43.275 & .0649 \\
\hline 2.575 & .241 & .504 & .057 & .052 & .091 & $43.55 y$ & .654 \\
\hline 2.582 & .240 & .234 & .037 & .023 & .079 & 43.508 & .053 \\
\hline 2.573 & .230 & $.20 i$ & .056 & .050 & .087 & 43.538 & .654 \\
\hline 2.562 & .230 & .232 & .037 & .042 & .075 & 43.473 & .653 \\
\hline 2.597 & .245 & .204 & $.05 E$ & .052 & .090 & 43.534 & .654 \\
\hline 2.580 & .236 & .206 & .036 & .047 & .080 & 43.537 & .654 \\
\hline 2.410 & .224 & .287 & .055 & .036 & .062 & 43.375 & .651 \\
\hline $2 \cdot 4 \cup 2$ & .217 & .186 & .034 & .042 & .075 & 43.360 & .651 \\
\hline 2.536 & .240 & .205 & .058 & .053 & .092 & 43.571 & .054 \\
\hline $2.58 \bar{c}$ & .239 & .204 & .035 & .047 & .080 & 43.500 & .653 \\
\hline 2.569 & .242 & .203 & .059 & • טラ人 & .090 & 43.558 & .654 \\
\hline 2.566 & .238 & .205 & .637 & .046 & .081 & 43.508 & .653 \\
\hline 2.374 & $.2+0$ & .202 & .057 & .05: & $.08 y$ & 43.571 & .654 \\
\hline 2.589 & .238 & .202 & .057 & .452 & .090 & 43.592 & .654 \\
\hline 2.574 & & $.20 \bar{z}$ & .335 & .044 & .072 & 43.506 & .053 \\
\hline
\end{tabular}

Heating value

$$
\text { Composition, mol }
$$

\begin{tabular}{|c|c|c|c|c|}
\hline $\mathrm{N}_{2}$ & $\mathrm{CH}_{4}$ & $\mathrm{C}_{2} \mathrm{H}_{6}$ & $\mathrm{C}_{3} \mathrm{H}_{8}$ & ${ }^{i C_{4}} \mathrm{H}_{10}$ \\
\hline J. C.CC & 05.017 & 11.991 & 2.414 & .223 \\
\hline U.LU & 04.027 & 12.109 & 2.424 & .225 \\
\hline แレட9 & 04.839 & 12.139 & $2 \cdot 431$ & .220 \\
\hline J. Uu & 85.399 & $11.07 y$ & $2.3+7$ & .221 \\
\hline J. CCU & $85.40 \mathrm{C}$ & 11.647 & 2.344 & .210 \\
\hline 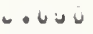 & 03.220 & 13.424 & C. TL 1 & .252 \\
\hline$\dot{U} \cdot 10 \bar{U}$ & $84.9 j 4$ & $12 \cdot 490$ & $2 \cdot+33$ & .223 \\
\hline U. Ou & $d_{4} .575$ & $12 \cdot 3+0$ & $2.43 i$ & .233 \\
\hline J. UCG & $84.56 \mathrm{u}$ & 12.307 & 2.483 & .227 \\
\hline む.ルง & $35.67 c$ & 11.968 & 2.303 & $.220^{\circ}$ \\
\hline - 166 & 85.1065 & 11.954 & 2.397 & .221 \\
\hline$j \cdot i j i$ & $d 4 \cdot t+3$ & 12.319 & $2.48 \overline{2}$ & . 217 \\
\hline$\dot{u} \cdot v i c$ & 84.672 & 12.299 & 2.473 & .218 \\
\hline u ivu & $34 . t 86$ & 12.202 & 2.481 & .211 \\
\hline U U.. & $8+.346$ & $12.53 i$ & 2.514 & .236 \\
\hline ¿. $60 u$ & $d+.726$ & 12.263 & $2.47 i$ & .215 \\
\hline$\dot{0} .0 \cup 0$ & 84.375 & 12.522 & 2.50 & .231 \\
\hline$\checkmark \bullet u \cup C$ & 03.763 & 13.018 & 2.599 & .246 \\
\hline j. i i & 83.775 & 12.907 & 2.608 & .241 \\
\hline U. Cui & 84.759 & 12.365 & 2.379 & .217 \\
\hline $\bar{u} \cdot 00 \hat{v}$ & $0 \rightarrow .680$ & 12.278 & 2.450 & $.22 i$ \\
\hline - Uuo & $c 4.911$ & 12.073 & 2.425 & .227 \\
\hline し・记 & 84.943 & $12 \cdot 454$ & 2.422 & .221 \\
\hline $3.00 \mathrm{~J}$ & 84.695 & 12.200 & 2.409 & .223 \\
\hline u. $\bar{u} u$ & 84.684 & 12.268 & 2.470 & .224 \\
\hline$\checkmark$ Uレt & 04.728 & 12.232 & 2.475 & .222 \\
\hline u.ví & 84.697 & 16.247 & 2.474 & .222 \\
\hline U. Uं & 84.911 & 12.386 & $2 \cdot+27$ & .227 \\
\hline U.u U U & 84.955 & 12.054 & 2.419 & .224 \\
\hline $0 . C 0 \tilde{u}$ & 85.065 & 11.903 & 2.428 & .235 \\
\hline ン・レし & $85 . i 06$ & 11.096 & $2.43 i$ & .230 \\
\hline ن ju & $\Delta 4 . E 56$ & 12.285 & 2.464 & .231 \\
\hline$\triangle . \cup \cup 0$ & 84.085 & 12.266 & 2.458 & .220 \\
\hline$u$ u & 34.606 & $12 .<02$ & 2.537 & .225 \\
\hline$\checkmark . u i c$ & $84 \cdot t+2$ & 12.259 & $2.53 i$ & .222 \\
\hline u. Ou & 33.916 & 12.804 & 2.575 & .241 \\
\hline$\checkmark \cdot v \cup C$ & 83.960 & 12.855 & 2.582 & .240 \\
\hline$\triangle . u$ u & 03.946 & 12.850 & 2.573 & .230 \\
\hline - しし 7 & 83.938 & 12.848 & 2.562 & .230 \\
\hline O.uu & $63.8+9$ & 12.908 & 2.597 & .245 \\
\hline $0.0 \mathrm{j}$ & 83.946 & 12.895 & 2.586 & .236 \\
\hline U. U 6. & 84.148 & 12.877 & 2.410 & .224 \\
\hline Uレu & 84.196 & 16.855 & $2 \cdot+42$ & .217 \\
\hline$\checkmark . \angle 0 i$ & 83.914 & 12.038 & 2.535 & .240 \\
\hline .004 & 83.970 & 12.839 & $2.58 \bar{c}$ & .239 \\
\hline vن vن & $c 3.949$ & 12.878 & 2.569 & .242 \\
\hline$\bullet \Sigma E$ & 03.946 & 12.077 & 2.566 & .238 \\
\hline u. u U u & 83.055 & 12.932 & 2.374 & $.2+0$ \\
\hline - Uúb & 83.822 & 12.947 & 2.589 & .238 \\
\hline$\bullet \sim 5$ & 03.595 & 12.739 & 2.574 & .234 \\
\hline
\end{tabular}
A

.$$
\text { . }
$$ 
Table 7.4.2. LNG Flow Facility Test 2 Data (continued). Composition, mol $\%$

Run InteNumber grator

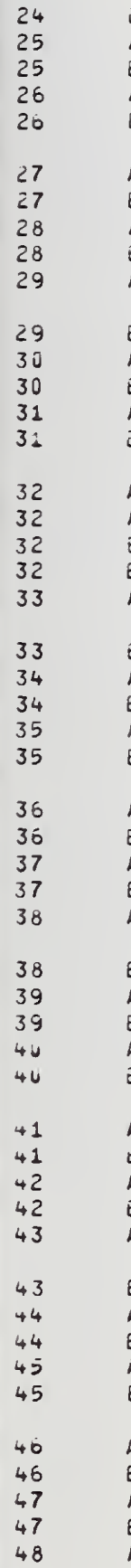

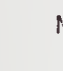

2.966

2. 958

1.978

$80.059 \quad 14.684$

2. 931

1.627

$79.784 \quad 14.591$

1. 275

1.643

$8 \hat{0} .086$

60.325

14.633

14.771

2.952

2.921

2.939

1. 240

83. 366

1. 596

80.103

1.91479 .523

1.581

79.818

14.712

2. 961

14.642

2. 961

2.973

2.988

2.973

$1.506 \quad 80.116 \quad 14.729$

2.961

$1.902 \quad 79.803 \quad 14.645$

$1.570 \quad 80.107 \quad 14.679$

2.935

$1.159 \quad 80.222 \quad 14.912$

$\begin{array}{lll}1.488 & 79.967 & 14.858\end{array}$

2. 951

2. 972

$2.98 \mathrm{j}$

2.940

\section{.233}

.240

.236

.243

.240

.245

.240

.243

.240

.245

.236

.240

.237

.245

.239

.257

.254

.250

.252

.246

.237

.245

.240

.246

.242

.245

.239

.243

.240

.243

.241

.243

.238

.276

.274

.279

.276

.276

- 270

.282

.274

.282

.277

.282

.274

.280

.276

.285

.279

.281

$\begin{array}{ll}.201 & .036 \\ .201 & .055 \\ .203 & .036 \\ .203 & .058 \\ .204 & .037 \\ .205 & .058 \\ .207 & .037 \\ .204 & .059 \\ .206 & .035 \\ .235 & .057\end{array}$

.203

.202

.204

. 234

.235

.216

.216

.216

.216

.205

.207

.207

.205

.206

.208

.234

.205

.205

.205

.205

.207

.203

.204

.234

.234

.233

.235

.231

. 230

.234

.034

.057

.034

. 260

.036

.061

.062

.045

.035

.059

.035

.056

.032

.059

.035

.059

.037

.057

.033

.057

.036

.057

.037

.044

.040

.044

. 044

. 044

$.04 \mathrm{C}$

.045

.235

. 234

.042

. 044

.044

.044

.043

.232

.235

.237

.235

.235

$\mathrm{nC}_{5} \mathrm{H}_{12}$

.046

- $35 \mathrm{i}$

- $v 44$

- 353

. 347

.053

. 045

.052

. 046

.052

. 046

.051

.042

. 052

.046

.055

.056

.050

.049

.053

.045

. 052

.043

.053

.046

.052

- 047

.052

.047

.052

.044

.051

.042 
Table 7.4.2. LNG Flow Facility Test 2 Data (continued).

$\begin{array}{cl}\text { Run } & \text { Inte- } \\ \text { Number } & \text { grator }\end{array}$

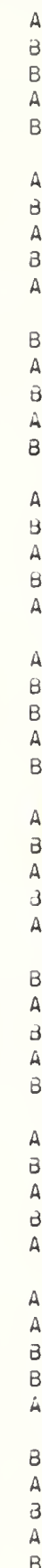

$\begin{array}{lll}1.202 & 50.307 & 14.798 \\ 1.544 & 00.079 & 14.723 \\ 1.547 & 80.071 & 14.727 \\ 1.170 & 00.278 & 14.842 \\ 1.511 & 00.052 & 14.785 \\ 1.515 & 80.291 & 14.80 J \\ 1.573 & 80.034 & 14.733 \\ 1.128 & 60.521 & 14.719 \\ 1.458 & 80.278 & 14.604 \\ 1.191 & 00.231 & 14.842\end{array}$

$1.53+80.022 \quad 14.777$

$.819 \quad 7 y .584 \quad 15.717$

$1.456 \quad 73.436 \quad \$ 5.668$

- Sít 8j.445 14.947

$1.18180 .245 \quad 14.858$

$\begin{array}{lll}.884 & 800.742 & 14.805\end{array}$

$1.157 \quad 53.557 \quad 14.762$

$.94779 .931 \quad 15.344$

$\begin{array}{rrr}1.933 & 79.608 & 14.737 \\ .857 & 79.880 & 15.482\end{array}$

$.861 \quad 79.920 \quad 15.462$

2. $173 \quad 79.399 \quad 14.831$

L. $618 \quad 79.598 \quad 14.848$

$\begin{array}{lll}.935 & 79.998 & 15.200\end{array}$

$\begin{array}{lll}1.417 & 79.798 & 15.202\end{array}$

$4.114 \quad 74.164 \quad 17.153$

$4.069 \quad 74.2+7 \quad 17.150$

$4.132 \quad 74.144 \quad 17.160$

$5.573 \quad 73.621 \quad 16.478$

$4.123 \quad 74.140 \quad \$ 7.181$

$4.571 \quad 74.707 \quad 10.405$

$4.118 \quad 74.165 \quad 17.152$

4.08. 74.238 17.158

$4.159 \quad 7.0 .116 \quad: 7.156$

$4.854 \quad 74.355 \quad 10.449$

$4.053 \quad 74.242 \quad 17.150$

$4.48 \varepsilon \quad 7 . .6 .8 \quad 16.536$

$\begin{array}{lll}4.083 & 74.271 & 17.097\end{array}$

$4.037 \quad 74.352 \quad 17.090$

$4.125 \quad 74.012 \quad 17.269$

4.106 $74.143 \quad 17.10 \mathrm{~J}$

$4.112 \quad 74.169 \quad 17.155$

4. $549 \quad 74.256 \quad 17.156$

4. U63 74.236 17.169

4. $065 \quad 74$. CJ3 17.195

4. UE8 74.274 17.183

$4.132 \quad 74.121 \quad 17.182$

$4.692 \quad 74.194 \quad 17.187$

$4.634 \quad 74.214 \quad 17.191$

$4.00274 .530 \quad 17.248$
Composition, mol \%

\begin{tabular}{|c|c|c|c|c|c|c|c|}
\hline $\mathrm{C}_{3} \mathrm{H}_{3}$ & $i_{4} \mathrm{H}_{10}$ & $\mathrm{nC}_{4} \mathrm{H}_{10}$ & ${ }^{i C_{5}} \mathrm{H}_{12}$ & $\mathrm{nC}_{5} \mathrm{H}_{12}$ & $c_{6}+$ & $\mathrm{Mu} / \mathrm{m}^{3}$ & Gravi \\
\hline $\begin{array}{l}2.975 \\
2.956 \\
2.962 \\
2.975 \\
2.963\end{array}$ & $\begin{array}{r}.278 \\
.276 \\
.275 \\
.283 \\
.270\end{array}$ & $\begin{array}{l}.234 \\
.235 \\
.233 \\
.235 \\
.235\end{array}$ & $\begin{array}{l}.045 \\
.042 \\
.044 \\
.046 \\
.041\end{array}$ & $\begin{array}{l}.059 \\
.052 \\
.054 \\
.061 \\
.056\end{array}$ & $\begin{array}{l}.102 \\
.092 \\
.087 \\
.106 \\
.087\end{array}$ & $\begin{array}{l}43.953 \\
43.764 \\
43.700 \\
43.988 \\
43.790\end{array}$ & $\begin{array}{l}.674 \\
.674 \\
.074 \\
.674 \\
.674\end{array}$ \\
\hline $\begin{array}{l}2.973 \\
2.958 \\
2.923 \\
2.922 \\
2.949\end{array}$ & $\begin{array}{l}.282 \\
.274 \\
.277 \\
.271 \\
.284\end{array}$ & $\begin{array}{l}.234 \\
.235 \\
.230 \\
.236 \\
.236\end{array}$ & $\begin{array}{l}.044 \\
.039 \\
.044 \\
.04 i \\
.044\end{array}$ & $\begin{array}{l}.059 \\
.052 \\
.058 \\
.054 \\
.060\end{array}$ & $\begin{array}{l}.102 \\
.083 \\
.103 \\
.085 \\
.103\end{array}$ & $\begin{array}{l}43.949 \\
43.730 \\
43.919 \\
43.737 \\
43.963\end{array}$ & $\begin{array}{l}.674 \\
.674 \\
.072 \\
.673 \\
.674\end{array}$ \\
\hline $\begin{array}{l}2.967 \\
3.124 \\
3.113 \\
3.000 \\
3.040\end{array}$ & $\begin{array}{l}.273 \\
.290 \\
.288 \\
.287 \\
.278\end{array}$ & $\begin{array}{l}.238 \\
.246 \\
.244 \\
.239 \\
.238\end{array}$ & $\begin{array}{l}.044 \\
.046 \\
.044 \\
.045 \\
.043\end{array}$ & $\begin{array}{l}.053 \\
.061 \\
.056 \\
.000 \\
.052\end{array}$ & $\begin{array}{l}.088 \\
.106 \\
.095 \\
.104 \\
.099\end{array}$ & $\begin{array}{l}43.739 \\
44.492 \\
44.336 \\
44.131 \\
43.994\end{array}$ & $\begin{array}{l}.674 \\
.679 \\
.679 \\
.673 \\
.674\end{array}$ \\
\hline $\begin{array}{l}2.874 \\
2.003 \\
3.095 \\
2.971 \\
3.044\end{array}$ & $\begin{array}{l}.272 \\
.265 \\
.295 \\
.277 \\
.288\end{array}$ & $\begin{array}{r}.225 \\
.227 \\
.245 \\
.235 \\
.239\end{array}$ & $\begin{array}{l}.043 \\
.038 \\
.046 \\
.040 \\
.045\end{array}$ & $\begin{array}{r}.057 \\
.048 \\
.061 \\
.053 \\
.060\end{array}$ & $\begin{array}{l}.095 \\
.080 \\
.106 \\
.086 \\
.105\end{array}$ & $\begin{array}{l}43.994 \\
43.626 \\
44.322 \\
43.619 \\
44.337\end{array}$ & $\begin{array}{l}.671 \\
.671 \\
.677 \\
.076 \\
.076\end{array}$ \\
\hline $\begin{array}{l}3.027 \\
2.915 \\
2.939 \\
3.058 \\
3.058\end{array}$ & $\begin{array}{l}.283 \\
.270 \\
.209 \\
.292 \\
.286\end{array}$ & $\begin{array}{l}.239 \\
.229 \\
.229 \\
.242 \\
.242\end{array}$ & $\begin{array}{l}.044 \\
.043 \\
.039 \\
.047 \\
.044\end{array}$ & $\begin{array}{l}.060 \\
.052 \\
.052 \\
.061 \\
.053\end{array}$ & $\begin{array}{l}.103 \\
.090 \\
.086 \\
.105 \\
.101\end{array}$ & $\begin{array}{l}44.312 \\
43.518 \\
43.555 \\
44.259 \\
44.112\end{array}$ & $\begin{array}{l}.676 \\
.676 \\
.675 \\
.676 \\
.676\end{array}$ \\
\hline $\begin{array}{l}3.670 \\
3.6 E 5 \\
3.664 \\
3.520 \\
3.654\end{array}$ & $\begin{array}{r}.343 \\
.340 \\
.348 \\
.329 \\
.348\end{array}$ & $\begin{array}{l}.291 \\
.292 \\
.291 \\
.280 \\
.291\end{array}$ & $\begin{array}{l}.054 \\
.056 \\
.054 \\
.048 \\
.055\end{array}$ & $\begin{array}{l}. j 78 \\
.006 \\
.076 \\
.065 \\
.076\end{array}$ & $\begin{array}{r}.134 \\
.121 \\
.132 \\
.106 \\
.132\end{array}$ & $\begin{array}{l}44.102 \\
44.076 \\
44.093 \\
43.185 \\
44.099\end{array}$ & $\begin{array}{l}.707 \\
.706 \\
.707 \\
.737 \\
.707\end{array}$ \\
\hline $\begin{array}{l}3.506 \\
3.660 \\
3.661 \\
3.663 \\
3.515\end{array}$ & $\begin{array}{r}.328 \\
.345 \\
.343 \\
.348 \\
.328\end{array}$ & $\begin{array}{l}.276 \\
.292 \\
.293 \\
.291 \\
.280\end{array}$ & $\begin{array}{l}.047 \\
.055 \\
.048 \\
.055 \\
.049\end{array}$ & $\begin{array}{r}.063 \\
.077 \\
.004 \\
.078 \\
.065\end{array}$ & $\begin{array}{r}.097 \\
.134 \\
.116 \\
.134 \\
.104\end{array}$ & $\begin{array}{l}43.514 \\
44.100 \\
44.162 \\
44.087 \\
43.443\end{array}$ & $\begin{array}{l}.702 \\
.707 \\
.706 \\
.707 \\
.704\end{array}$ \\
\hline $\begin{array}{l}3.655 \\
3.531 \\
3.648 \\
3.646 \\
3.686\end{array}$ & $\begin{array}{r}.349 \\
.329 \\
.346 \\
.343 \\
.349\end{array}$ & $\begin{array}{l}.292 \\
.281 \\
.291 \\
.291 \\
.293\end{array}$ & $\begin{array}{l}.055 \\
.053 \\
.055 \\
.055 \\
.054\end{array}$ & $\begin{array}{r}.077 \\
.065 \\
.077 \\
.064 \\
.078\end{array}$ & $\begin{array}{r}.133 \\
.116 \\
.133 \\
.116 \\
.134\end{array}$ & $\begin{array}{l}44.117 \\
43.642 \\
44.086 \\
44.059 \\
44.148\end{array}$ & $\begin{array}{l}.707 \\
.703 \\
.706 \\
.705 \\
.708\end{array}$ \\
\hline $\begin{array}{l}3.689 \\
3.666 \\
3.666 \\
3.667 \\
3.634\end{array}$ & $\begin{array}{r}.348 \\
.343 \\
.343 \\
.344 \\
.347\end{array}$ & $\begin{array}{l}.291 \\
.291 \\
.289 \\
.291 \\
.291\end{array}$ & $\begin{array}{l}.054 \\
.055 \\
.049 \\
.053 \\
.054\end{array}$ & $\begin{array}{r}.077 \\
.077 \\
.065 \\
.066 \\
.077\end{array}$ & $\begin{array}{r}.133 \\
.133 \\
.127 \\
.112 \\
.134\end{array}$ & $\begin{array}{l}44.119 \\
44.099 \\
44.092 \\
44.076 \\
44.115\end{array}$ & $\begin{array}{l}.707 \\
.707 \\
.706 \\
.706 \\
.707\end{array}$ \\
\hline $\begin{array}{l}3.668 \\
3.658 \\
3.672 \\
3.655 \\
3.685\end{array}$ & $\begin{array}{l}.343 \\
.350 \\
.343 \\
.349 \\
.035\end{array}$ & $\begin{array}{l}.292 \\
.292 \\
.290 \\
.292 \\
.290\end{array}$ & $\begin{array}{l}.053 \\
.055 \\
.051 \\
.054 \\
.051\end{array}$ & $\begin{array}{r}.069 \\
.077 \\
.066 \\
.077 \\
.070\end{array}$ & $\begin{array}{r}.111 \\
.134 \\
.115 \\
.134 \\
.121\end{array}$ & $\begin{array}{l}44.104 \\
44.103 \\
44.074 \\
44.139 \\
43.860\end{array}$ & $\begin{array}{l}.706 \\
.707 \\
.706 \\
.707 \\
.702\end{array}$ \\
\hline
\end{tabular}

Heating

value

.674

674

.674

.074

.072

.674

674

.079

.674

671

.677

.076

676

.076

675
.676

ó76

.707

.707

707

.706

.707

707

.703

.708

.707

.707

737

.706

.702 
Table 7.4.2. LNG Flow Facility Test 2 Data (continued).

$\begin{array}{cc}\begin{array}{c}\text { Run } \\ \text { Number }\end{array} & \text { Inte- } \\ \text { grator } \\ 71 & A \\ 71 & B \\ 72 & A \\ 72 & A \\ 72 & B \\ 72 & B \\ 73 & A \\ 73 & B \\ 74 & A \\ 74 & B \\ 75 & A \\ 75 & B \\ 76 & A \\ 76 & B \\ 77 & A \\ 77 & B\end{array}$

Composition, mol $\%$

\begin{tabular}{|c|c|c|c|c|c|c|c|c|}
\hline $\mathrm{N}_{2}$ & $\mathrm{CH}_{4}$ & $\mathrm{C}_{2} \mathrm{H}_{6}$ & $\mathrm{C}_{3} \mathrm{H}_{8}$ & iC $_{4} \mathrm{H}_{10}$ & $\mathrm{nC}_{4} \mathrm{H}_{10}$ & $i_{5} \mathrm{H}_{12}$ & $\mathrm{nC}_{5} \mathrm{H}_{12}$ & $c_{6}{ }^{+}$ \\
\hline $\begin{array}{l}4.635 \\
3.985 \\
3.562 \\
3.550 \\
3.528\end{array}$ & $\begin{array}{l}74.196 \\
74.289 \\
74.420 \\
74.411 \\
74.400\end{array}$ & $\begin{array}{l}17.294 \\
17.189 \\
17.384 \\
17.399 \\
17.406\end{array}$ & $\begin{array}{l}3.669 \\
3.670 \\
3.713 \\
3.720 \\
3.713\end{array}$ & $\begin{array}{l}.349 \\
.340 \\
.356 \\
.348 \\
.347\end{array}$ & $\begin{array}{r}.292 \\
.292 \\
.297 \\
.296 \\
.296\end{array}$ & $\begin{array}{l}.055 \\
.049 \\
.056 \\
.055 \\
.053\end{array}$ & $\begin{array}{l}.077 \\
.006 \\
.078 \\
.078 \\
.068\end{array}$ & $\begin{array}{r}.134 \\
.121 \\
.135 \\
.136 \\
.109\end{array}$ \\
\hline $\begin{array}{l}3.517 \\
3.991 \\
3.955 \\
3.226 \\
3.187\end{array}$ & $\begin{array}{l}74.479 \\
74.209 \\
74.284 \\
74.547 \\
74.716\end{array}$ & $\begin{array}{l}17.407 \\
17.227 \\
17.217 \\
17.493 \\
17.486\end{array}$ & $\begin{array}{l}3.720 \\
3.665 \\
3.650 \\
3.712 \\
3.729\end{array}$ & $\begin{array}{l}.349 \\
.349 \\
.3+4 \\
.355 \\
.349\end{array}$ & $\begin{array}{r}.297 \\
.292 \\
.292 \\
.296 \\
.296\end{array}$ & $\begin{array}{l}.050 \\
.055 \\
.052 \\
.055 \\
.053\end{array}$ & $\begin{array}{r}.069 \\
.078 \\
.067 \\
.079 \\
.068\end{array}$ & $\begin{array}{r}.113 \\
.135 \\
.109 \\
.136 \\
.117\end{array}$ \\
\hline $\begin{array}{l}2.878 \\
3.384 \\
3.259 \\
3.228 \\
3.980\end{array}$ & $\begin{array}{l}74.726 \\
75.315 \\
74.596 \\
74.673 \\
74.310\end{array}$ & $\begin{array}{l}17.712 \\
16.849 \\
17.481 \\
17.402 \\
17.178\end{array}$ & $\begin{array}{l}3.749 \\
3.614 \\
3.742 \\
3.733 \\
3.627\end{array}$ & $\begin{array}{r}.360 \\
.335 \\
.355 \\
.349 \\
.347\end{array}$ & $\begin{array}{r}.302 \\
.285 \\
.296 \\
.297 \\
.292\end{array}$ & $\begin{array}{l}.056 \\
.055 \\
.057 \\
.056 \\
.054\end{array}$ & $\begin{array}{l}.080 \\
.005 \\
.077 \\
.009 \\
.077\end{array}$ & $\begin{array}{r}.130 \\
.108 \\
.134 \\
.122 \\
.134\end{array}$ \\
\hline 661 & 74.609 & 10.365 & 3.493 & .326 & 28 & .047 & . v61 & .100 \\
\hline
\end{tabular}

$\begin{array}{ll}\begin{array}{c}\text { Heating } \\ \text { Value }\end{array} & \begin{array}{c}\text { Specific } \\ \text { Gravity }\end{array} \\ \begin{array}{l}\text { Mu. } \\ 44.149\end{array} & .707 \\ 44.121 & .706 \\ 44.423 & .707 \\ 44.425 & .707 \\ 44.378 & .706 \\ 44.392 & .706 \\ 44.175 & .707 \\ 44.136 & .706 \\ 44.582 & .706 \\ 44.553 & .705 \\ 44.310 & .736 \\ 44.187 & .701 \\ 44.580 & .706 \\ 44.554 & .705 \\ 44.139 & .706 \\ 43.464 & .702\end{array}$




\section{ACKNOWLEDGMENTS}

The authors thank the following companies for their financial and technical support: El Paso Marine Company, Columbia LNG Company, Consolidated System LNG Company and Southern Energy Company. Messers I. W. Schmidt and R. D. Kinley of El Paso Marine arranged for the tests aboard the LNG tanker. Also, Mr. Kinley reviewed the final manuscript of this report.

Within the Cryogenics Division D. B. Mann, J. A. Brennan and J. Hord provided technical advice. C. F. Sindt helped in the initial design and construction of the laboratory apparatus. J. A. Brennan and C. H. Kneebone put in many long hours during the NBS flow facility tests. J. D. Siegwarth made many of the tests involving gas chromatograph performance. Finally, special thanks goes to Mrs. S. L. Erickson who had the patience to do an excellent job preparing the manuscript. 
NBS.114A (REV. 7.73)

\begin{tabular}{|c|c|c|}
\hline \begin{tabular}{c|c}
$\begin{array}{l}\text { U.S. DEPT. OF COMM. } \\
\text { BIBLIOGRAPHIC DATA }\end{array}$ & 1. PUIBLICATION OR REPORT NO. \\
SHEET & NBSIR $78-887$
\end{tabular} & $\begin{array}{l}\text { 2. Gov't Accession } \\
\text { No. }\end{array}$ & 3. Recipient's Accession No. \\
\hline \multicolumn{2}{|c|}{ DEVELOPMENT AND EVALUATION OF AN LNG SAMPLING } & $\begin{array}{l}\text { 5. Publication Date } \\
\text { July } 1978\end{array}$ \\
\hline \multicolumn{2}{|l|}{ MEASUREMENT SYSTEM } & $\begin{array}{l}\text { 6. Performing Organization Code } \\
736\end{array}$ \\
\hline \multicolumn{3}{|c|}{$\begin{array}{l}\text { 7. AUTHOR(S) } \\
\text { W. R. Parrish, J. M. Arvidson and J. F. LaBrecque }\end{array}$} \\
\hline \multirow{2}{*}{\multicolumn{2}{|c|}{$\begin{array}{l}\text { 9. PERFORMING ORGANIZATION NAME AND ADDRESS } \\
\text { NATIONAL BUREAU OF STANDARDS } \\
\text { DEPARTMENT OF COMMERCE } \\
\text { WASHINGTON, D.C. } 20234\end{array}$}} & $\begin{array}{l}\text { 10. Project/Task/Work Unit No. } \\
7360575\end{array}$ \\
\hline & & 11. Contract/Grant No. \\
\hline \multirow{3}{*}{\multicolumn{2}{|c|}{$\begin{array}{l}\text { 12. Sponsoring Organization Name and Complete Address (Street, City, St } \\
\text { LNG Sampling Measurement Supervisory Committee }\end{array}$}} & $\begin{array}{l}\text { 13. Type of Report \& Period } \\
\text { Covered }\end{array}$ \\
\hline & & \\
\hline & & 14. Sponsoring Agency Code \\
\hline
\end{tabular}

15. SUPPLEMENTARY NOTES

16. ABSTRACT (A 200-word or less factual summary of most significant information. If document includes a significant bibliography or literature survey, mention it here.)

This report describes the development and evaluation of procedures and components for sampling and analyzing LNG from flowing streams. Laboratory and field test results showed the total uncertainty in the computed heating value of samples taken with the recommended sampling system could be routinely within \pm 0.3 percent; this included the +0.1 percent uncertainty in analysis by gas chromatography. Three samp $\bar{l}$ probes and two vaporizer designs were considered. Of the ten operating variables considered, six were found to be important in sampling. Test results were used to establish recommended design and operating criteria.

17. KEY WORDS (six to twelve entries; alphabetical order; capitalize only the first letter of the first key word unless a proper name; separated by semicolons)

Custody transfer; density; gas analysis; gas chromatography; heating value; hydrocargon; liquefied natural gas; phase equilibrium; pipelines; sampling.

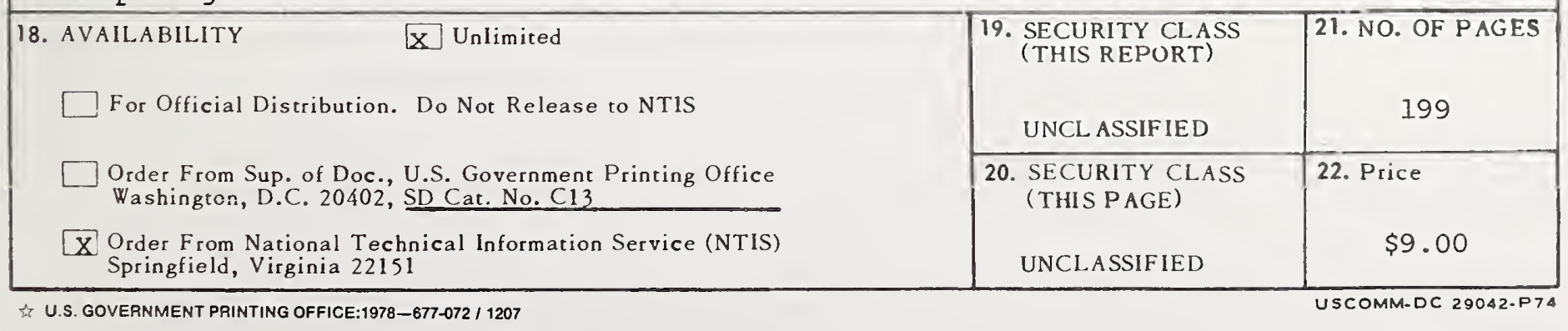






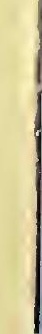

